\title{
AVALIAÇÃO DA TOXICIDADE DO ALUMÍNIO EM GENÓTIPOS DE AVEIA
}

\author{
ELMAR LUIZ FLOSS \\ Engenheiro Agrônomo e Licenciado em Ciências
}

Orientador: Prof. Dr. Antonio Roque Dechen

Tose apresenteda à Escola Superior de Agricultura "Luiz do Queiroz", da Universidade de São Paulo, para obtenção do título de Doutor em Agronomia, área de concentração: Solos e Nutriçāo de Plantas. 
Ficha cataiogrtica preparada peía Secao de Livros da

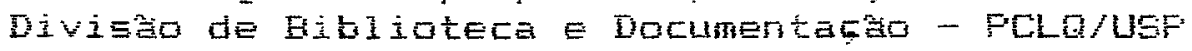

\section{Floss, Elmar Luiz}

F64la Avaliação da toxicidade do alumínio em genótipos de aveia. Piracicaba, 1992. $296 \mathrm{p}$.

Tese - ESALQ

Bibliografia.

1. Alumínio em aveia - Toxicidade 2. Aveia - Crescimento 3. Aveia - Genótipo - Seleção 4. Aveia - Nutriçăo 5. Aveia Redutase do nitrato I. Escola Superior de Agricultura Luiz de Queiroz, Piracicaba 


\section{AVALIAÇÃO DA TOXICIDADE DO ALUMÍNIO \\ EM GENÓTIPOS DE AVEIA}

ELMAR LUIZ FLOSS

Aprovada em: 18 de março de 1993

Comissão julgadora:

Prof. Dr. ANTONIO ROQUE DECHEN

ESALQ/USP

Dr. AUGUSTO CARLOS BAIER

CNPT/EMBRAPA

Prof. Dr. FRANCISCO ANTONIO MONTEIRO

ESALQ/USP

Dr. PEDRO ROBERTO FURLANI

IAC

Prof. Dr. QUIRINO AUGUSTO DE CAMARGO CARMELLO

ESALQ/USP
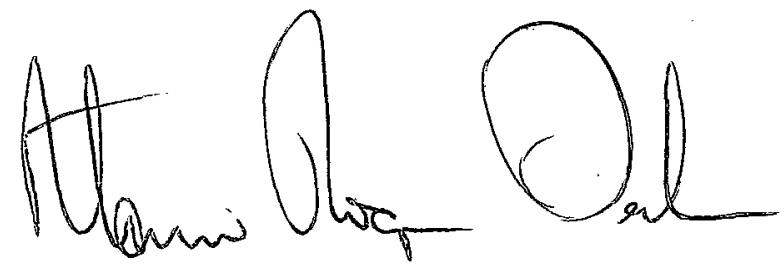

Prof. Dr. ANTONIO ROQUE DECHEN orientador 
OFEREÇO

Aos meus pais Joăo Edwino e Olyra;

$e$ aos meus irmãos sérgio Carlos,

Paulo, Neusa Maria, Nilve Bernadete,

Sônia Terezinha, Wilson Antônio, Ieda

Cecilia, Elton José e Airton Inácio.

DEDICO，

$\grave{A}$ minha esposa Sandra Maria; aos meus filhos Luiz Gustavo, Paulo Marcelo e Márcio Felipe. 


\section{AGRADECIMENTOS}

Ao Prof. Dr. Antonio Roque Dechen, pela valiosa orientação e a grande amizade dedicada.

Aos Professores do Setor de Nutriçăo Mineral de Plantas do Departamento de Química da ESALQ, Dr. Henrique Paulo Haag("in memorian"), Dr. Quirino Augusto de Camargo Carmello e Dr. Francisco Antônio Monteiro, pelas sugestões e apoio na conduçăo dos experimentos.

Ao Dr. Pedro Roberto Furlani, Pesquisador científico do Instituto Agronômico, pelas sugestões e colaboração na execuçăo deste trabalho.

À Prof". Dra. Maria Cristina Stolf Nogueira, do Departamento de Matemática e Estatística da ESALQ e à colega Sônia Maria de stefano piedade pelo auxílio nas análises estatísticas.

Ao Dr. Joaquim Albenisio G. da Silveira, exprofessor do Departamento de Química, por permitir a utilização do Laboratório de Bioquímica do CENA para a realizaçăo das análises de atividade da redutase do nitrato. Aos ex-professores da Faculdade de Agronomia da Universidade de Passo Fundo, Dr. Romeo Ernesto Riegel e Dr. Paulo Fragomeni, pelo incentivo e confiança inicial, possibilitando à introduçăo na carreira docente.

Ao Dr. Augusto Carlos Baier, Pesquisador do Centro Nacional de Pesquisa de Trigo/EMBRAPA, pelo permanente incentivo, colaboração e amizade.

Aos professores Dr. H.L. Shands, Dr. M.A. Brinkman e Dr. B. Forsberg da Universidade de Wisconsin e Dr. M.E. McDaniel da Universidade do Texas A \& $M$ (EUA) pelo apoio científico e fornecimento de germoplasma de aveia. 
Aos funcionários do Setor de Nutriçăo Mineral de Plantas da ESALQ, Lúcia Helena S. Pavan Forti, Lourdes Aparecida Dario de Gonzalez, Fernando Eder Ré, Mirtes Ventura Sesso, Edinéia Cristina Scervino Mondoni, Nivanda Maria de Moura, Sueli Maria Amaral Campos Bovi, Ricardo de Souza Oliveira e Rubens César Pereira pelo auxílio em várias etapas do trabalho.

Às bibliotecárias Eliana Maria Garcia Sabino e Katia Maria de Andrade Ferraz, pela grande ajuda durante o curso e na elaboraçăo das referências bibliográficas.

À acadêmica de agronomia da ESALQ Patricia da Silva Favoretto e à bióloga Vania Ceccatto pelo auxílio na execuça dos experimentos.

Às técnicas especializadas do Laboratorio de Sementes da ESALQ, Ana Dionisia Luz Novembre e Helena Maria Pescarin Chamma, pela colaboraçăo no armazenamento e realização da germinaçăo das sementes de aveia.

Aos professores e funcionários da ESALQ pela indispensável colaboraçăo, amizade e coleguismo, durante o período de realização do curso.

$\grave{A}$ Universidade de Passo Fundo, por ter possibilitado a realizaço do curso através do PICD/UPF.

À CAPES pela bolsa de estudos.

Ao Curso de Pós-Graduaçăo em Solos e Nutriçăo de Plantas da ESALQ/USP, pelo treinamento.

À FAPESP pelo auxílio financeiro para execuçăo da fase experimental. 
" Se considero as obras dos Mestres, vejo o que eles fizeram. Se reparo em minhas quinquilharias, vejo o que deveria ter feito."

\section{GOETHE}




\section{SUMÁRIO}

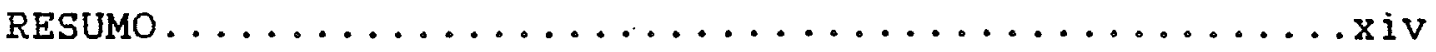
SUMMARY..............................

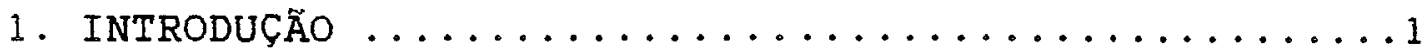

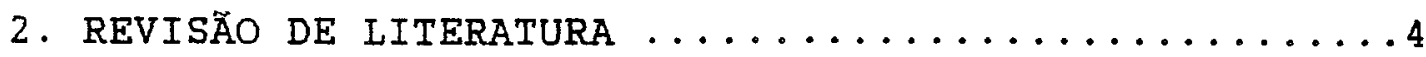

2.1. Química do alumínio no solo $\ldots \ldots \ldots \ldots \ldots \ldots$

2.2. Reaçăo da aveia ao alumínio $\ldots \ldots \ldots \ldots \ldots \ldots$

2.3. Toxicidade do alumínio em plantas..........10

2.3.1. Efeitos sobre as raízes .........11

2.3.2. Efeitos sobre o metabolismo dos nutrien-

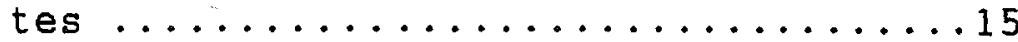

2.3.2.1. Fósforo ............16

2.3.2.2. Nitrogênio.............17

2.3.2.3. Cálcio ...............19

2.3.2.4. Magnésio ............20

2.3.2.5. Potássio ............21

2.3.2.6. Micronutrientes.........21

2.3.3. Efeitos sobre o crescimento e o desenvolvimento..................23

2.3.4. Efeitos sobre outros aspectos metabólicos de plantas................24 
2.4. Toleráncia de plantas ao alumínio.........25 2.4.1. Mecanismos de exclusăo............26 2.4.2. Alteraçăo do pH na rizosfera........28 2.4.3. Nutriçăo das plantas.............28 2.4.4. Formação de complexos orgânicos......29 2.5. Efeito do alumínio sobre a atividade da enzi-

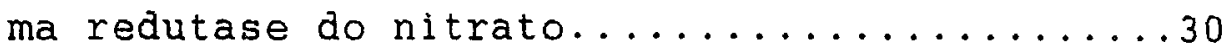

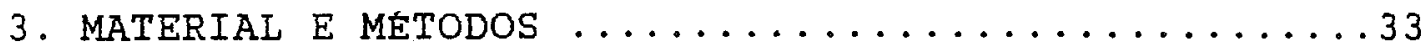

3.1. Determinaçăo da concentração de alumínio na solução nutritiva para classiłicação de genótipos de aveia branca.............33

3.2. Efeito do alumínio na soluçăo nutritiva sobre alguns parâmetros de crescimento da aveia....38

3.3. Seleçăo de genótipos de aveia branca tolerantes ao alumínio, em solução nutritiva.......40 3.3.1. Seleção no nível de $7,5 \mathrm{mg}$ Al/litro de

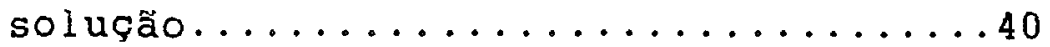

3.3.2. Seleçăo no nivel de $15 \mathrm{mg}$ Al/litro de

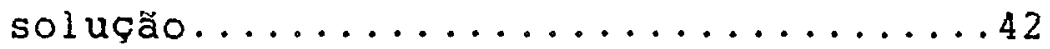

3.4. Avaliação da tolerância de genótipos de aveias pretas ao alumínio, em solução nutri-

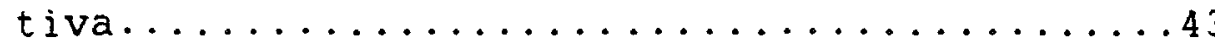


3.5. Efeito do alumínio sobre alguns parâmetros de crescimento e a nutriçăo de aveia, em cultivo hidropônico.....................44

3.6. Efeito do alumínio sobre a atividade da enzima redutase do nitrato em aveia..........48

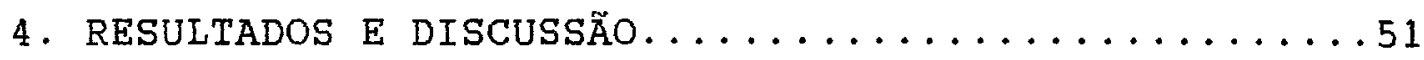

4.1. Determinaçăo da concentraçăo de alumínio na soluçăo nutritiva, para classificação de genótipos de aveia branca............. 51

4.1.1. Comprimento inicial da raíz seminal (CIRS) ...............

4.1.2. Comprimento final da raiz seminal (CRFS) ...............

4.1.3. Comprimento final relativo da raíz seminal (CFRRS)..............

4.1.4. Crescimento da raiz seminal (CRS) ....58 4.1.5. Crescimento relativo da raiz seminal (CRRS) ..............62 4.1.6. Correlações entre os parâmetros de crescimento da raiz...........83 
Página

4.2. Efeito do alumínio na soluçăo nutritiva sobre alguns parâmetros de crescimento da aveía

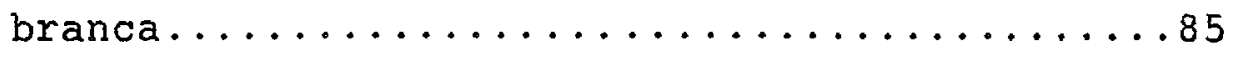

4.2.1. Efeito sobre o crescimento das raízes..85

4.2.2. Efeito sobre o rendimento de matéria $\operatorname{seca} \ldots \ldots \ldots \ldots \ldots \ldots \ldots . \ldots \ldots$

4.2.3. Correlação entre o crescimento da raíz e o rendimento de matéria seca...92

4.3. Seleção de genótipos de aveia branca tolerantes ao alumínio, em soluçăo nutritiva.......95 4.3.1. Seleção ao nível de $7,5 \mathrm{mg} \mathrm{Al/litro} \mathrm{de}$

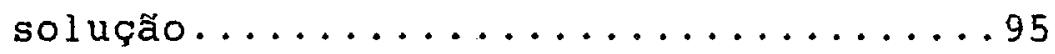

4.3.1.1. Crescimento inicial da raiz seminal (CIRS) .........95

4.3.1.2. Crescimento da raíz seminal $(\mathrm{CRS}) \ldots \ldots \ldots . \ldots 96$

4.3.1.3. Comparação entre as tes temunhas..............109

4.3.1.4. Classificaçăo dos genótipos de aveìa quanto à seleção ao nivel 7,5 mg Al/litro de soluçăo................113 
4.3.2. Seleçăo ao nível $15 \mathrm{mg} A l / 1$ itro de

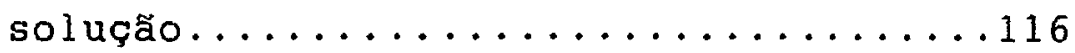

4.4. Tolerância e responsividade de genótipos de aveia branca submetidos aos niveis de 0 e $15 \mathrm{mg} A 1 / 1$ itro de soluçăo...........121

4.5. Avaliação da tolerância de genótipos de aveia preta ao alumínio, em soluçăo nutritiva.....125 4.5.1. Comprimento inicial da raíz

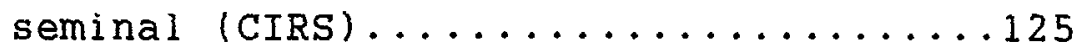

4.5.2. Crescimento da raiz seminal (CRS)....128

4.5.3. Crescimento relativo da raíz seminal (CRRS)........................

4.6. Efeito do alumínio sobre alguns parâmetros de crescimento de aveía em cultivo

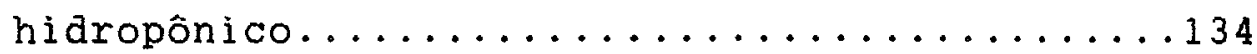

4.6.1. Número de afilhos/vaso (NAF) ........134 4.6.2. Numero relativo de afilhos (NRAF) ....137 4.6.3. Comprimento da maior raíz (CMR)......141 4.6.4. Comprimento relativo da maior

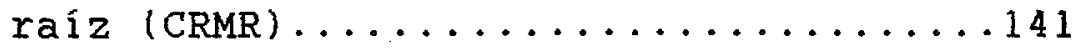

4.6.5. Rendimento de matéria seca de

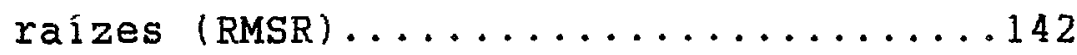


4.6.6. Rendimento relativo de matéria seca de raízes $(\operatorname{RRMSR}) \ldots \ldots \ldots \ldots \ldots \ldots \ldots$

4.6.7. Rendimento de matéria seca de colmos e bainhas $(R M S C B) \ldots \ldots \ldots \ldots \ldots \ldots \ldots$

4.6.8. Rendimento relativo de matéria seca de colmos + bainhas (RRMSCB) ........144

4.6.9. Rendimento de matéria seca das folhas $(\mathrm{RMSF}) \ldots \ldots \ldots \ldots \ldots \ldots \ldots \ldots$

4.6.10. Rendimento relativo de matéria seca das folhas (RRMSF) .................. 145

4.6.11. Rendimento de matéria seca da parte aérea $(\mathrm{RMSPA}) \ldots \ldots \ldots \ldots \ldots \ldots \ldots$

4.6.12. Rendimento relativo da matéria seca da parte aérea (RMSPA) .............. 44

4.6.13. Rendimento da matéria seca da planta $(\operatorname{RMSP}) \ldots \ldots \ldots \ldots \ldots \ldots \ldots$

4.6.14. Rendimento relativo de matéria seca da planta (RRMSPA) .................

4.6.15. Relaçăo de peso foliar (RPF) ........148

4.6.16. Relaçăo de peso de raiz/parte aérea $(R R P A) \ldots \ldots \ldots \ldots \ldots \ldots \ldots \ldots$ 
4.7. Efeito de níveis de alumínio na soluçăo nutritiva. sobre o teor e a extraçăo de alumínio e alguns macronutrientes pela aveia........153

4.7.1. Rendimento de matéria seca..........153

4.7 .2$. Alumínio .................... 156

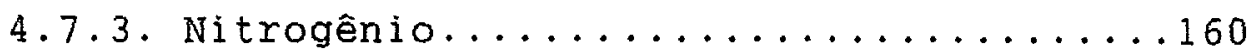

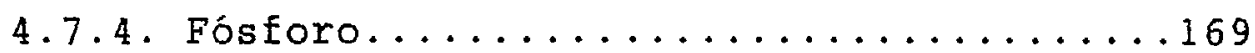

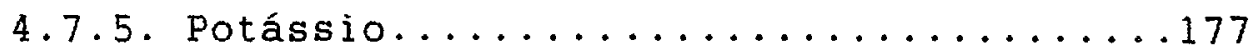

4.7 .6$. Cálcio....................... 182

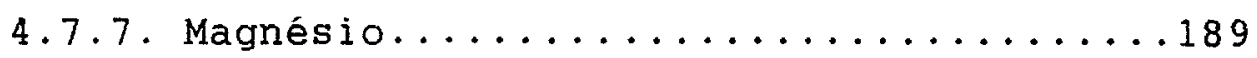

4.7.8. Correlações entre o teor de alumínio, o rendimento de matéria seca e os teores de alguns macronutrientes.........196

4.8. Efeito dos niveis de alumínio na solução nutritiva sobre o teor e a extraçăo de alguns micronutrientes pela aveia.............201

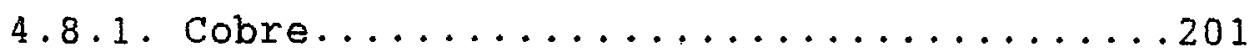

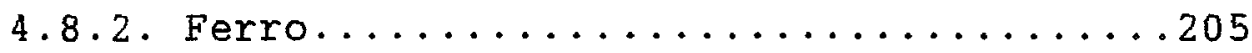

4.8.3. Manganês......................212

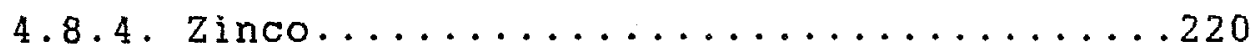

4.8.5. Correlaçóes entre o teor de alumínio, o rendimento de matéría seca e os teores de alguns micronutrientes.........224 
4.9. Efeito dos niveis de alumínio sobre o pH na soluçăo nutritiva, no cultivo de aveia.....226 4.10. Efeito de níveis de alumínio sobre a atividade "in vitro" da redutase do nitrato em aveia...231

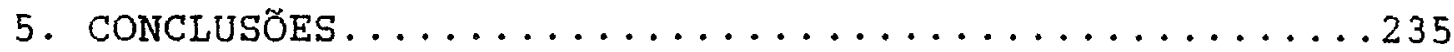

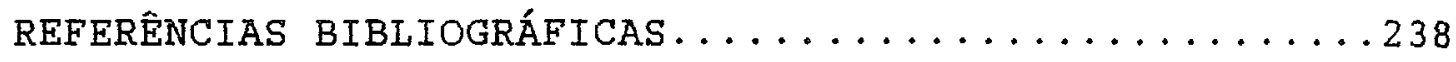

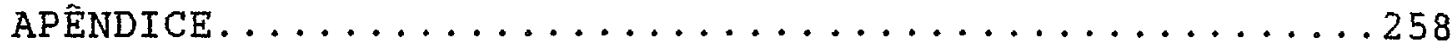




\title{
AVALIAÇÃO DA TOXICIDADE DO ALUMíNIO
}

EM GENÓTIPOS DE AVEIA

\author{
Autor: EIMAR LUIZ FLOSS
}

Orientador: Prof.Dr. ANTONIO ROQUE DECHEN

\section{RESUMO}

O trabalho foi realizado na ESALQ/USP e teve por objetivos estudar o comportamento de genótipos de aveia branca (Avena sativa L.) e aveia preta (Avena strigosa Schreb), quando submetidos a níveis de alumínio (Al) em solução nutritiva, visando a seleção de genótipos tolerantes, bem como tentar identificar as possiveis causas da toxicidade quanto aos aspectos nutricionais e fisiológicos.

Determinou-se a concentração de Al na solução nutritiva, para a classificação de genótipos de aveia e realizou-se a caracterização quanto à tolerância de 156 genótipos de aveia branca e de 14 genótipos de aveia preta. o principal parâmetro de avaliação da tolerância foi o crescimento da raiz seminal (CRS), que foi correlacionado com outros parâmetros de crescimento da raiz e o rendimento de 
matéria seca (MS).

A concentração de $7,5 \mathrm{mg}$ Al/litro na solução nutritiva promoveu uma redução do CRS superior a 50\%, nos genótipos mais sensiveis. O comprimento inicial da raiz seminal (CIRS) não apresentou correlação com os parâmetros CRS, crescimento relativo (CRRS), e comprimento final relativo da raiz seminal (CFRRS), e algumas vezes correlacão entre CIRS e CFRS. Já o CRS apresentou correlação altamente significativa com CRRS, CFRS e CFRRS. Em relação ao rendimento de MS, o CRS apresentou melhor correlação com o rendimento relativo de MS da planta e da parte aérea do que o rendimento de MS das raízes.

Nessa concentração, os genótipos de aveia branca UPF82079, UPF86A1198-5-4b, UPF 3, UFRGS 6 , UPF86A1068, UFRGS 1, UFRGS 4, UPF 15, UPF86120, UPF84297, UPF87070, UPF84321, UPF87128, CTC 1, UPF79302, CTC841412-3e UPF79159-6b, mostraram-se tolerantes (CRS)/responsivos (CRRS). No nível $15 \mathrm{mg} \mathrm{Al/litro,} \mathrm{os} \mathrm{genótipos:} \mathrm{UPF82079,}$ UPF77394-1, UFRGS6, UPF86006, UPF81360, UPF86160, UPF86112, UPF81359 E UPF2, revelaram-se tolerantes pelo indice de tolerância relativa (ITRAI). Em relação às aveias pretas, , os genótipos UPF77434, UPF84AP01, UPF77066, UPF77436, Preta Argentina, UPF77352 e UPF85AP01, mostraram-se tolerantes/responsivos no nível de $30 \mathrm{mg} \mathrm{Al/litro.}$ 
Observou-se que o número de afilhos por vaso, o número relativo de afilhos por vaso e o comprimento da maior raiz foram superiores no genótipo tolerante (UPF86Al169-2b) em relação ao senśível (UPF 7). Quanto à nutrição da aveia, verificou-se correlação positiva entre o teor de Al nas raízes com o teor de $\mathrm{P}$ e negativa com Mg, Mn e Zn no genótipo sensível, enquanto no genótipo tolerante a correlação foi positiva com os teores de $N$ e $P$ e negativa com Mg, Mn e Fe. Na parte aérea do genótipo sensível, o teor de Al correlacionou-se de forma negativa, com os teores de $P, K$, $\mathrm{Ca}, \mathrm{Mg}, \mathrm{Cu}, \mathrm{Mn}$ e $\mathrm{Zn}$, e no tolerante a correlação foi negativa para os teores de $\mathrm{N}$, Ca e Mg. O teor de Al correlacionou-se de forma negativa com o rendimento de MS das raízes e da parte aérea dos dois genótipos. No genótipo sensivel o rendimento de" MS das raízes correlacionou-se de forma positiva com os teores de $\mathrm{P}$, $\mathrm{Mg}$, Mn e $\mathrm{Zn}$ e no tolerante com $\mathrm{N}, \mathrm{P}, \mathrm{Mg}, \mathrm{Fe}$ e Mn. Na parte aérea do genótipo sensivel o rendimento de MS correlacionou-se de forma positiva com os teores de N, P e Mg e no tolerante com N, P, Mg e Fe. O Mg foi dos nutrientes estudados o mais afetado pela toxicidade do Al nas plantas, enquanto o teor de $\mathrm{P}$ aumentou e a extração diminuiu com o aumento da concentração de Al na solução.

o genótipo tolerante e o sensível não diferiram quanto ao teor e a extraça de Al pelas plantas, 
xvi i

mas nas raizes, o teor de Al no genótipo tolerante foi superior ao do sensivel.

O pH médio na solução de cultivo e a média de atividade da redutase do nitrato foram superiores no genótipo tolerante em relação ao sensível.

Concluiu-se que, apesar das aveias brancas apresentarem grande variabilidade, elas são menos tolerantes ao Al do que as aveias pretas. Dentre aquelas, os genótipos UPF82079 e UFRGS 6 mostraram maior tolerância e responsividade ao Al, nos níveis de Al utilizados, podendo ser utilizados em cruzamentos, visando o melhoramento genético para este caráter. As aveias tolerantes e as sensiveis diferem quanto ao efeito do Al sobre o afilhamento e comprimento da maior raiz, teores de alguns nutrientes e atividade "in vitro" da redutase do nitrato. 


\title{
OAT GENOTYPES EVALUATION TO ALUMINUM TOXICITY
}

\author{
Author: ELMAR LUIZ FLOSS
}

Adviser: Prof. Dr. ANTONTO ROQUE DECHEN

SUMMARY

The main goal of this work, carried out at ESALQ/USP, was to study the responses of white (Avena sativa L.) and black oats ( $A$. strigosa Schreb.) genotypes to levels of aluminum in nutrient solution. This study was undertaken to select tolerant genotypes, as well as to study the possible causes of nutritional and physiological effects of the aluminum toxicity.

It was determined the level of Al for selection of oat genotypes, and 156 white oat genotype and 14 black oat were screened for tolerance. The main parameter evaluated was the seminal root growth (SRG) whore values were correlated with other parameters of root growth and dry matter (DM) yield.

The concentration threshold of Al in nutrient 
solution was $7,5 \mathrm{mg} / \mathrm{liter}$. This level promoted a reduction of $50 \%$ in the SRG in the most sensitive genotypes. Initial seminal root lenght (ISRL) did not correlate significantly with SRG, relative growth (RSRG), and final relative length of seminal root (FRLSR) and sometime the ISRL correlated with the final lenght (FLSR). SRG showed a highly significant correlation with RSRG, FLSR and FRLSR. The SRG showed better correlation with DM relative yield for the whole plant and shoots and low correlation with DM root yield.

At the $7,5 \mathrm{mg}$ Al/liter, the white oat genotypes UPF82079, UPF86A1198-5-4b, UPF3, UFRGS 6 , UPF86A1068, UFRGS 1, UFRGS 4, UPF 15, UPF86120, UPF84297, UPF84125, UPF87070, UPF84321, UPF87128, CTC 1, UPF79302, CTC84412-3 and UPF79159, showed tolerance (SRG) and responsiveness (RSRG). The genotypes UPF82079, UPF77394-1, UFRGS6, UPF86006, UPF81360, UPF86160, UPF86112, UPF81359 and UPF2, showed tolerance by the relative tolerance index (RAITI) at the level of $30 \mathrm{mg} \mathrm{Al} / \mathrm{i}$ iter.

The black oat genotypes UPF77434, UPF84AP01, UPF77066, UPF77436, Preta Argentina, UPF77352, and UPF85AP01, were tolerant/responsive at the concentration of $30 \mathrm{mg} \mathrm{Al/1}$.

It was observed that the number of tillers per pot, the relative number of tillers per pot and the length of the most extensive root were higher in the tolerant genotype 
(UPF86A1169-2b) than in the sensitive genotype (UPFT). In relation on oat plant nutrition, it was observed a significant and positive correlation between Al concentration in the roots and the levels of $\mathrm{P}$ and a negative correlation with Mg, Mn and $\mathrm{Zn}$ for the sensitive cultivar. On the other hand for the tolerant genotype the correlation was significant and positive between the concentration of Al and the concentration of $\mathrm{N}$ and $\mathrm{P}$ and negative with $\mathrm{Mg}, \mathrm{Mn}$ and $\mathrm{Fe}$. In the shoots of the sensitive genotype the concentration of Al correlate negatively with the levels of $\mathrm{P}, \mathrm{K}, \mathrm{Ca}, \mathrm{Mg}, \mathrm{Cu}$; Mn and $\mathrm{Zn}$ and the tolerant genotype correlate significant and negatively with the levels concentration of $\mathrm{N}, \mathrm{Ca}$ and $\mathrm{Mg}$.

The correlation between Al concentration and DM yield was significant and negative for the roots and shoots for both genotypes.

In the sensitive genotype the DM root yield correlate positively with the levels of P, Mg, Mn and Zn. The tolerant genotype correlate with $N, P, M g$ and $M$. In the shoots of sensitive genotype the DM yield correlate positively with the levels of $N, P$ and $M$ and in the tolerant with N, P, Mg and Fe. The Mg was most effected of the nutrients on the Al toxicity in plants while the level of $P$ increased and the accumulation decreased with more Al - concentration in the solution. 
The tolerant and sensitive genotypes did not differ for Al concetration and amount extracted from plant althrough in the roots, the level of Al in the tolerant genotype was higher than in the sensitive.

The solution $\mathrm{pH}$ and the nitrate reductase activity were higher for at the tolerant genotype than for the sensitive.

It was concluded that the white oat showed a high variability and were less tolerant than the black oat. The white oat genotypes UPF82079 and UFRGS6 showed the best tolerance and responsiveness considering the Al levels used and might be used for breeding purposes. The tolerant and sensitive genotypes were different tillering and in the length of the most extensive root, concentrations of some nutrients and in the nitrate reductase activity. 


\section{INTRODUÇÃO}

A aveia é um cereal de clima temperado, originário da Ásia, que hoje está adaptado a diferentes regiós do mundo, sendo destinado à produção de grãos e/ou forragem, e à cobertura do solo.

As principais espécies cultivadas no Brasil são a aveia branca (Avena sativa L.) e a amarela (Avena byzantina C. Koch), destinadas à produção de grãos e/ou forragem, além da aveia preta (Avena strigosa Schreb), utilizada como forrageira e cobertura do solo.

A área cultivada com aveia destinada à produção de grãos no Brasil, na safra de 1990, foi de 198.140 hectares, com uma produçăo de 174.226 toneladas e um rendimento de $922 \mathrm{~kg} / \mathrm{ha}$ (ANUÁRIO..., 1991 ).

Na safra de 1989 o principal Estado produtor de aveia foi o Rio Grande do Sul, que teve uma participaça de 65\% na produção nacional, seguido pelo Paraná (24\%) e Santa Catarina (6\%) (ANUÁRIO..., 1990). No Brasil Central, pequenas áreas estão sendo cultivadas com este cereal, como uma alternativa de cultivo para o período de inverno, visando 
principalmente, a produção de forragem verde e de cobertura do solo, além da produção de grãos em menor escala.

o cultivo de aveia, independente do propósito, é realizado geralmente em áreas marginais, utilizando solos com baixa disponibilidade de nutrientes, ácidos e com teores tóxicos de alumínio. No Estado do Rio Grande do Sul, a principal região produtora de aveia, são os Campos de Cima da Serra, que se caracterizam por apresentar solos ácidos e com teores elevados de alumínio.

A correção da acidez do solo através da calagem, é a prática mais recomendada para que as plantas possam aproveitar eficientemente os nutrientes e a água, e expressar suas potencialidades. Esta prática, porém, não é eficiente na correção da acidez em profundidade do solo.

Devido aos elevados custos do calcário e dos fertilizantes, torna-se indispensável, o desenvolvimento, através do melhoramento genético, de genótipos que além de apresentarem altos rendimentos sob condiçסes de solo fértil, sejam capazes de tolerar as adversidades, tais como baixos teores de nutrientes e a presença de elementos tóxicos como o alumínio (MARTINI et al, 1977).

Os genótipos tolerantes selecionados, podem ser utilizados diretamente pelos agricultores e sua característica de tolerância transferida, através de hibridações, aos cultivares comerciais.

o desenvolvimento de cultivares tolerântes ao alumínio, que apresentam sistema radicular mais desenvolvido, permite a exploraça de camadas mais profundas do solo, onde a correção da acidez através da calagem é difícil. Sistemas radiculares mais abundantes representam também um importante mecanismo de tolerância das plantas aos deficits hídricos temporários.

A disponibilidade de cultivares de aveia 
tolerantes ao alumínio, possibilitaria a utilizaça deste cereal em sistemas de rotaça de culturas nos solos ácidos, inclusive com culturas que toleram baixo $\mathrm{pH}$ na camada superficial do solo, como a batata (Solanum tuberosum L.).

A seleção de cultivares tolerantes pode ser realizada no campo ou em solução nutritiva, sob condições ambientais controladas. Inúmeros são os pesquisadores que tem utilizado e aprimorado as técnicas hidropônicas, para a seleção de plantas quanto à sua tolerância ao aluminio, utilizando como principal parâmetro, o crescimento da raíz seminal de plântulas.

Este trabalho teve como objetivos, avaliar o comportamento de genótipos de aveia quando submetidos à niveis de alumínio, em soluçðes nutritivas, visando a seleção de genótipos tolerantes, bem como o estudo das possíveis causas quanto aos aspectos nutricional e fisiológico, dos efeitos da toxicidade do alumínio. 


\section{REVISÃo DE LITERATURA}

2.1 Química do alumínio no solo

O pH baixo dos solos, possibilita o aumento na solubilidade de certos metais, tais como o aluminio, manganês, ferro, zinco e cobre.

Em diferentes regiơes do mundo a presença de alumínio trocável $\left(\mathrm{Al}^{3+}\right)$ em níveis tóxicos para as plantas cultivadas, é uma característica dos solos ácidos. No Brasil, cerca de 1,8 milhőes de $\mathrm{km}^{2}$ de cerrado, ou seja $20 \%$ do território brasileiro, apresentam solos ácidos e sujeitos à toxicidade do alumínio. (EMPRESA..., 1978).

A toxicidade do alumínio é um importante fator limitante do crescimento dos cereais, nos cerrados do Brasil (FAGERIA \& ZIMMERMAN, 1979) e também em regioes de clima frio (KAMPRATH, 1984). As principais regioes produtoras de aveía no sul do Brasil apresentam pH ácido e elevados níveis de Al. A toxicidade é particularmente severa em solos com pH abaixo de 5,0, mas pode ocorrer em solos de valor de $\mathrm{pH}$ até 5,5 (FOY, 1992). O pH critico, no qual o alumínio torna-se solúvel ou trocável, atingindo concentraçoes tóxicas para uma cultura depende de muitos fatores do solo, tais como 
os minerais de argila predominantes, o nível de matéria orgânica e a concentração de outros cátions, ânions e sais totais (RAGLAND \& COLEMAN, 1960; PAVAN, s.d ${ }^{1}$.).

A 1 iberação do $\mathrm{Al}^{3+}$ ocorre devido à ação de prótons $H^{+}$, que penetram na camada octaedral da argila substituindo $\mathrm{O} \mathrm{Al}^{3+}$, e algumas vezes o $\mathrm{Mg}^{2+}$, presentes nas arestas do cristal, os quais ao serem liberados, seráo adsorvidos preferencialmente na nuvem de contra-ions do mineral de argila, dando rapidamente origem a um sistema H-Al-argi la (CAMARGO \& FURLANI, 1989).

O ion $\mathrm{Al}^{3+}$ sofre hidrólise, que pode ser representada esquematicamente por:
$\mathrm{Al}\left(\mathrm{H}_{2} \mathrm{O}\right)_{\mathrm{g}}{ }^{3+}+\mathrm{H}_{2} \mathrm{O}$
< $=$
$\mathrm{Al}(\mathrm{OH})\left(\mathrm{H}_{2} \mathrm{O}\right)_{5}{ }^{2+}+\mathrm{H}_{3} \mathrm{O}^{+}$
$\mathrm{Al}(\mathrm{OH})\left(\mathrm{H}_{2} \mathrm{O}\right)_{5}{ }^{2+}+\mathrm{H}_{2} \mathrm{O}$
$<=$
$\mathrm{Al}(\mathrm{OH})_{2}\left(\mathrm{H}_{2} \mathrm{O}\right)_{4}^{+}+\mathrm{H}_{3} \mathrm{O}^{+}$
$\mathrm{Al}(\mathrm{OH})_{2}\left(\mathrm{H}_{2} \mathrm{O}\right)_{4}{ }^{+}+\mathrm{H}_{2} \mathrm{O}$.
<
$\mathrm{Al}(\mathrm{OH})_{3}\left(\mathrm{H}_{2} \mathrm{O}\right)_{3}+\mathrm{H}_{3} \mathrm{O}^{+}$
$\mathrm{Al}(\mathrm{OH})_{3}\left(\mathrm{H}_{2} \mathrm{O}\right)_{3}+\mathrm{H}_{2} \mathrm{O}$
< $=$
$\mathrm{Al}(\mathrm{OH})_{1}\left(\mathrm{H}_{2} \mathrm{O}\right)_{2}^{-}+\mathrm{H}_{3} \mathrm{O}^{+}$

O efeito da presença de argila sobre o grau de hidrólise do aluminio é contraditório. RAGLAND \& COLEMAN (1960), observaram aumentos no grau de hidrólise, enquanto FRINK \& PEECH (1963), estudando a seletividade da adsorção de $\mathrm{Al}^{3+}, \mathrm{Al}(\mathrm{OH})^{2+}$ e $\mathrm{H}^{+}$, e da relação $\mathrm{H}^{+} / \mathrm{Al}^{3+}$ da suspensão de argila, verificaram uma redução no grau de hidrólise devido à presença desse mineral.

Já o aumento no teor de matéria orgânica do solo, promove um aumento da taxa de hidrólise, devido à reação de seus produtos com os grupos carboxilitcos, (THOMAS \& HARGROVE, 1984).

PAVAN, M.A. Apl icação de alguns conceitos básicos de química na disponibilidade de ions $\mathrm{Al}^{3+}$ para as plantas. s.d. $34 \mathrm{p}$. (IAPAR - Londrina). 
Os íns considerados como responsáveis pela toxicidade em plantas, são os monômeros $\mathrm{Al}^{3+}$ e Al $(\mathrm{OH})^{2+}$ (PAVAN \& BINGHAN, 1982), que estao presentes na faixa de pH 4,0 a 5,0 .

Na planta, o aluminio tem pequena mobilidade (ANDREW et al., 1973), concentrando-se mais nas raizes do que na parte aérea, sendo que os polímeros Hidrogênio-Al podem ser mais tóxicos às plantas do que os íons de monômeros-Al (WAGATSUMA \& EZOE, 1985).

Em trigo, CAMARGO (1983) verificou que os sintomas de toxicidade foram obtidos tanto devido a um aumento da concentração de alumínio, mantendo-se constante a temperatura das soluçōes, quanto devido ao aumento da temperatura, mantendo-se constante determinada concentração de Al nas soluções.

\subsection{Reação da aveia ao alumínio}

A literatura é escassa em informações sobre a tolerância da aveia à acidez do solo e os teores tóxicos de alumínio (REID, 1976). Os primeiros estudos registrados na literatura sobre a tolerância da aveia ao alumínio, foram realizados por McLEAN \& GILBERT (1927), que concluiram, que a toxicidade do Al se manifesta através do encurtamento e pelas injúrias. causadas às raizes. Através do teste da hematoxilina, verificaram que o Al absorvido pelas plantas, acumula-se na camada cortical da raiz, principalmente no protoplasma, concentrando-se no núcleo.

MCLEAN \& GILBERT ( 1927 ), observaram também, que a concentração tóxica de alumínio na solução nutritiva, foi de 7 ppm para aveia branca, centeio e sorgo, enquanto que para a cevada foi de $2,0 \mathrm{ppm} e$ para o milho de 14 ppm. 
THOMPSON (1957) não encontrou diferenças quanto ao rendimento, em aveia cultivada em $\mathrm{pH} 5,7,6,8$ e 7,5 , sendo que para o $\mathrm{pH} 4,7$, a produtividade foi $23 \%$ menor. Para TANAKA et al. (1984), a aveia é tolerante ao pH baixo, mais provavelmente ao Al. Segundo FLOSS et al. (1990), a aveia preta (Avena strigosa Schreb) apresenta maior tolerância ao alumínio tóxico, do que as brancas e amarelas.

Já LONG et al. (1973) citam, que enquanto um cultivar de milheto (Pennisetum glaucum L.) não foi afetado por um nível de alumínio equivalentes a $16 \mathrm{ppm}$, o cultivar Suregrain de aveia branca foi sériamente afetado, por um nivel de somente 1 ppm de alumínio na solução nutritiva. Porém, quando em um solo com pH baixo e elevado teor de Al, a calagem apresentou pequenos efeitos sobre o cultivar.

Em avaliações realizadas a nível de campo em Passo Fundo, RS, utilizando um solo com 3,7 a $3,9 \mathrm{meq}$ Al/100 $\mathrm{cm}^{3}$ de terra, FLOSS et al. (1990), encontraram plantas tolerantes entre as aveias brancas, indicando a possibilidade de obtenção de resultados positivos no melhoramento deste cereal objetivando este caráter.

A aveia é adaptada à uma ampla variação de condições de solo, sendo considerada menos sensível à acidez do solo, quando comparada com o trigo e a cevada (DELORIT et al., 1984; METCALFE \& ELKINS, 1987), sendo porém mais sensivel que o centeio (METCALFE \& ELKINS, 1987).

LOCKHART \& WISEMAN (1975) consideraram que o pH mais adequado para o crescimento da aveia é 5,0 , enquanto MALAVOLTA (1985) recomenda a faixa de 5,5 a 7,0. Segundo MOHR (1960) e KAMPRATH (1970), o nível critico da porcentagem de saturação por bases para a aveia branca é de $15 \%$, enquanto para o trigo e a cevada é de $30 \%$.

Para o Rio Grande do Sul e Santa Catarina, a 
recomendação de calagem para a cultura da aveia, visa atingir o pH 6.0 (SIQUEIRA, 1987). Entretanto, THOMPSON (1957), estudando diversos cereais, concluiu que, a aveia e o centeio apresentavam baixa resposta à aplicação de calcário. Resultados semelhantes foram encontrados para a aveia, por LONG et a l. (1973).

Baseados na média de valores encontrados para diversas espécies em diferentes experimentos, OTSUKA (1968) e BILSKI \& FOY (1987) concluiram que a ordem de tolerância ao alumínio mais comumente encontrada em cereais de inverno é centeiosaveiastrigoscevada. Parece ser importante definir claramente, o comportamento diferencial das diferentes espécies de aveia. Dentre as aveias nativas, a Avena fatua L. mostrou-se tolerante ao alumínio (BILSKI \& FOY, 1988). Este resultado indica ser possivel a utilização dessa espécie nativa, muito comum no Rio Grande do Sul, como fonte de tolerância, através de cruzamentos interespecificos, pois a exemplo das aveias brancas e amarelas, ela também é hexaplóide.

A seleção de genótipos quanto à tolerância ao aluminio pode ser realizada no campo, em solos ácidos, submetidos à doses de calcário, para a obtenção de diferentes niveis de saturação por alumínio. A desvantagem da utilização dos solos é a impossibilidade de se isolar e controlar quantitativamente os fatores de acidez, sendo os resultados frequentemente afetados, pela variabilidade do solo e pela resistência diferente dos cultivares às doenças e pragas (FAGERIA, 1982). HOWELLER \& CADAVID (1976), ressaltaram que as seleçனes no campo são trabalhosas, necessitando de 4 a 5 meses até a avaliação completa, podendo seus resultados serem afetados pelo acamamento e pelos danos provocados por pássaros. 
Para superar essas dificuldades, utilizam-se. métodos de seleção rápida, em casa de vegetação ou câmaras de crescimento com solução nutritiva, onde um grande número de genótipos podem ser avaliados sob condiçres controladas (HOWELLER \& CADAVID, 1976 e MOORE et a 1., 1976).

A concentração ótima de alumínio na solução, para se obter respostas diferenciais no crescimento de raízes, precisa ser determinada para cada espécie vegetal (HOWELLER \& CADAVID, 1976). Outro aspecto relevante, está relacionado com os parâmetros de avaliação na solução nutritiva e sua correlação com as condições de campo. LAFEVER et al. (1977), estudando a resposta diferencial de cultivares de trigo a altos níveis de aluminio no solo, encontraram correlação com os resultados obtidos em solução nutritiva durante três anos, lconcluindo que o comprimento da raiz após 10 dias, é um bom indicador da resposta varietal à condição ácida do solo. Resultados semelhantes foram obtidos por SARTAIN \& KAMPRATH (1978) em soja, por HOWELLER \& CADAVID (1976) em arroz e por CAMPBEL \& LAFEVER (1976) em trigo. Genótipos de trevo vermelho, cultivadas em solução nutritiva, mostraram correlaça baixa mas significativa, entre o comprimento da raiz e o peso seco das raízes $\left(r=0,52^{*}\right)$ e correlação não significativa, entre o comprimento das raizes e o peso seco da parte aérea ( $r=0,40 n s)$, conforme NUERNBERG et a l., (1990).

A principal vantagem da seleção de genótipos tolerantes ao alumínio, através do comprimento da raiz seminal é o fato de que este método não é destruitivo, possibilitando que a plântula selecionada possa ser transplantada e conduzida até a colheita de sementes. $O$ método é facilmente utilizado em cultivos hidropônicos, sendo difícil o seu uso em condições de campo. 
MOORE et al. (1976), indicam como método de seleção, o baseado na injúria às plântulas pela alta concentração de Al e a avaliação da recuperação das plantas, após 72 horas de crescimento em solução nutritiva com ausência de Al.

Com relação às aveias cultivadas, para aveia branca foram identificados alguns genótipos tolerantes. KLIMOV et al. (1985) verificaram, que o cultivar de aveia Yunon foi o mais tolerante em solos com altas concentraços de Al. BILSKI \& FOY (1987), indicaram os cultivares poloneses Solidor e Diaden como tolerantes, com base no crescimento

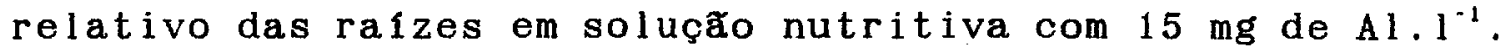
FOY et al. (1987) encontraram diferenças significativas entre cultivares de aveia, quanto à tolerância ao aluminio, destacando como os mais tolerantes Coker83-23, Glen, Victory, ND78406, Pierce e Otona.

Em trabalho de (FURLANI \& CASTRO, 1990) na avaliação de 21 genótipos de aveia sob níveis de alumínio, em condições de casa de vegetação mediante a técnica de hidroponia verificou-se serem tolerantes a aveia preta e os genótipos de aveia branca IAC1, IAC2, IAC6, IORN 130/83, IORN $98 / 84$, IORN $161 / 84$ e IORN $108 / 85$.

FLOSS et al. (1991), avaliando 43 genótipos de aveia, a nível de campo, em um solo com teores de alumínio entre 3,7 e 4,2 meq $/ 100 \mathrm{~cm}^{3}$ de solo, consideraram como tolerantes a aveia preta (CI9020) e as aveias brancas: UPF86011, UPF86112, UPF86136, UPF86083, UPF86113, UPF87101, UPF87070, UPF86A1169-2b, UPF86A1198 e UPF86A1264.

2.3 Toxicidade do aluminio em plantas

o estado atual de conhecimentos sobre a 
toxicidade do aluminio em plantas foi revisada por FOY et a 1., (1978); FAGERIA et a l., (1988); ROY et al., (1988); CAMBRAIA, (1989); FURLANI, (1989) e FOY, (1992).

A toxicidade do alumínio é mais claramente demonstrada em experimentos curtos, no estádio de plântula, através de um menor crescimento, coloração verde-pálido nas folhas e a redução no comprimento de raizes, com engrossamento secundário (VOSE, 1990).

Quando presente em quantidades elevadas no solo, o alumínio trocável atua essencialmente, sobre o sistema radicular das plantas, modificando sua anatomia, interferindo nas reações enzimáticas e na absorção e transporte de água e de nutrientes (FOY, 1966 e 1992), e regula a deposição de pol issacaridios nas paredes celulares (FOY, 1971). Segundo ROY et al. (1988), a elongaçá das raízes fica impedida, devido à redução da atividade mitótica, provocada pelo aluminio, com subsequente aumento da suscetibilidade das plantas à seca.

\subsubsection{Efeitos sobre as raizes}

Os efeitos mais drásticos e típicos da fitotoxicidade do Al ocorrem nas rafzes, que são as partes mais afetadas pelo excesso desse elemento no meio de crescimento (RHUE, 1979, FURLANI, 1989). O Al inibe a elongação das células do eixo principal, tornando as raízes engrossadas, inchadas, com coloração marrom, menor número de ramificaçōes, quebradiças e ocasionalmente, com manchas necróticas (FOY, 1992).

Segundo CLARKSON (1966, 1969), as células das raizes de plantas estressadas por Al, sofrem alteraçoses citológicas, ocasionando paralização do crescimento, devido 
a interferência do Al no processo metabólico associado à divisão celular e à replicação do DNA, durante a interfase do processo de divisão celular.

Para ROY et al. (1988) o alumínio liga-se ao DNA, sendo entretanto, baixa a sua penetraça no DNA mitoticamente ativo. A replicação do DNA é reduzida devido ao aumento da rigidez da dupla hélice (FOY, 1992). Devido ao acúmulo nas raízes, a inibição da atividade mitótica inicial, deve-se, possívelmente, ao seu efeito sobre o controle funcional integrado do meristema radicular (ROY et al., 1988).

o alumínio nas raízes também afeta estruturalmente a membrana plasmática, modificando sua permeabil idade (CAMBRATA, 1989). O crescimento das raizes é limitado, restringindo a absorção de nutrientes e água, o que pode afetar consideravelmente o rendimento das culturas nos solos secos e com baixa fertilidade.

Segundo WAGATSUMA et al. (1987), os efeitos tóxicos do Al sobre as plantas, tem inicialmente lugar nas rafizes, sendo que pequenas quantidades de Al podem inibir a elongação da raíz em poucos dias. A inibição inicia pela raíz principal, depois pela secundária e finalmente as raízes assumem uma forma coralóide. Na maioria dos cereais, os sintomas de injúria provocados pelo alumínio são observados inicialmente nas raízes, que se elongam pouco e apresentam pequena ramificaça, com posterior engrossamento, desintegração apical e aparecimento da coloração marrom (MINELLA, 1989).

Em aveia, a primeira evidência da toxicidade do alumínio, manifesta-se através do encurtamento e da injúria nas raizes (McLEAN \& GILBERT, 1927), diminuição das ramificações laterais (OTSUKA, 1968), ocorrẽncia de pequenas 
depressões nas raizes (ROY et al., 1988), que afetam principalmente o ápice e a região de elongação (WAGATSUMA et al., 1987).

ALAM \& ADAMS (1979b), observaram que a toxicidade do alumínio em aveia afeta o crescimento, como consequência de um desenvolvimento radicular anormal, com pequenas ramificações e afetando a utilização dos diversos nutrientes à planta.

Em plantas de aveia e arroz, o Al induz várias mudanças morfológicas na superfície radicular, com a ocorrência de um grande número de pequenas depressões no ápice e na região de elongação (WAGATSUMA et al., 1987). Segundo os autores, do Al absorvido no ápice das raízes, grande parte se liga ao núcleo das células, ao fósforo e ao DNA, resultando numa diminuição da divisão celular, e finalmente na inibição dessa divisão. O teste de coloração vital na região de elongação das raizes de aveia, mostrou células danificadas somente na epiderme das raízes de plantas tolerantes ao Al, após elas serem tratadas com Al.

BILSKI (1987), verificou que o aumento da concentração de Al na solução de 0 para $7 \mathrm{ppm}$, reduziu em $30 \%$ o peso de raízes de aveia, enquanto que para trigo e cevada, a redução foi de 65 e 85\%, respectivamente. Em aveia, trigo, cevada, ervilha, milho e girassol, o alumínio apresentou toxicidade maior, quando relacionado às doses de manganês, correspondente a 0,5 e 10 ppm (BILSKI, 1988).

O efeito tóxico do Al sobre as raízes de aveia (Avena sativa L. cV. Kassandra) foi maior no $\mathrm{pH} 4,2$ que no meio de cultura neutro (KARATAGLIS, 1987). Este autor verificou que baixas concentraços de Al estimularam 0 crescimento das plantas e a atividade da esterase enquanto altas concentrações de Al (32 e $40 \mathrm{ppm}$ ) provocaram inibição 
completa do crescimento radicular e da atividade dessa enzima.

KLIMOV (1985) verificou, que a supressão do crescimento radicular foi acompanhada pela desidrataçao das plantas de aveia, cevada, centeio e trigo, quando submetidas a solução nutritiva com níveis de alumínio.

Estudos realizados em genótipos de aveia, arroz, milho, ervilha e cevada, que diferem quanto à tolerância ao alumínio, sugerem que uma menor negatividade da superfície da plasmalema das células radiculares, pode determinar uma menor ligação com o alumínio, e em consequência, a tolerância ao metal. (WAGATSUMA \& AKIBA, 1989). As plantas sensiveis, tem as cargas da superfície da plasmalema fortemente ligadas ao aluminio, podendo a membrana eventualmente ser destruida. A negatividade das raízes de plantas jovens é maior do que em plantas adultas (WAGATSUMA et al., 1988). Para FOY (1971), cultivares adaptados a solos ácidos tem capacidade de troca de cátions (CTC) na raiz relativamente menor. A maior CTC das raizes é responsável por maiores conteúdos de Al e $\mathrm{P}$ nesse órgão e menores conteúdos de cálcio na parte aérea em cultivares sensiveis de trigo e cevada (FOY et al., 1967).

MUGWIRA \& ELGAWHARY (1979), concluiram que cultivares de trigo com CTC maior promovem um decréscimo do pH do meio na presença de Al e, uma maior quantidade de Al foi acumulada nas raízes, resultando na suscetibilidade a este elemento tóxico.

A maior parte do Al na raiz está ligado às substâncias pécticas da parede celular, enquanto uma parte do Al penetra no protoplasma $e$ se combina com os ácidos nuclêicos e ácidos solúveis de fosfato (WAGATSUMA, 1983a).

A força de exclusão do alumínio pela plasmalema das células radiculares de plantas de espécies tolerantes, é 
mais forte do que nas plantas de espécies sensiveis ao alumínio (WAGATSUMA \& EZOE, 1985). A exclusão de maior quantidade de alumínio no lado externo da plasmalema, feita pelas células radiculares de plantas tolerantes, possibilita que uma maior quantidade de polímeros H-Al seja polimerizada, precipitando nesse local.

Em aveia, o tratamento com polímeros de Al promoveu o aparecimento de raizes com sintomas coralóides, coloraça marrom e com o crescimento radicular marcadamente inibido (WAGATSUMA \& KANEKO, 1987).

2.3.2. Efeitos sobre o metabolismo dos nutrientes.

Em geral, o alumínio reduz os teores de quase todos os nutrientes das plantas (FOY et al., 1978; MUGWIRA, 1980; CALBO \& CAMBRAIA, 1980) e interfere na absorção, transporte e uso de vários nutrientes, tais como cálcio, fósforo e magnésio (FOY, 1974), podendo também determinar uma maior ou menor absorção de outros nutrientes tais como cobre, zinco, manganês e ferro (ROY et al., 1988). Em plantas de aveia, O Al interfere na redução do $\mathrm{Fe}^{3+}$ para $\mathrm{Fe}^{2+}$, um processo essencial para o metabolismo normal do ferro (ROY et al., 1988).

CAMARGo et al. (1984), observaram uma diminuição nas concentrações de potássio, cálcio e magnésio no tecido foliar de plantas de arroz devido ao aumento do teor de alumínio no substrato nutritivo.

BILSKI (1987) observou um aumento no teor de Ca, Mg e $\mathrm{P}$ nas raízes de aveia e trigo, em concentraçós de até 1-3 ppm de Al, mas decréscimo em concentraçбes maiores.

No entanto, FOY et al. (1987) relataram que, tanto os cultivares de aveia tolerantes aos solos ácidos, 
16.

quanto os sensiveis, não diferiram quanto à concentração de cálcio e magnésio na parte aérea, quando cultivados em solos com $\mathrm{pH} 4,3$ e sem calagem. Entretanto, houve uma tendência. dos cultivares sensiveis em apresentarem maiores concentrações de P, Al e Fe e menores concentraçóes de K e Mn.

Segundo FOY et al. (1967), a tolerância relativa ao alumínio não está relacionada com o teor de Al e $\mathrm{P}$ na fol ha.

\subsubsection{Fósforo}

Os sintomas de dếiciencia de fósforo observados na parte aérea das plantas, é uma das principais evidências da fitotoxidez do Al. Por esta razão, muitos pesquisadores relacionam, os efeitos da fitotoxicidade do Al diretamente com deficiência de fósforo induzida pelo alumínio (FOY, 1988 , 1992), sendo dificil distinguir-se os efeitos depressivos devidos ao alto teor de Al e ao baixo teor de $\mathrm{P}$ dos solos ácidos (FOY, 1971). VIDOR (1972) e BEN \& ROSA (1986) observaram aumentos significativos na eficiência da adubação fosfatada em plantas de trigo e soja, promovidas pela calagem em solos ácidos, pela eliminação da toxicidade do Al.

Para CAMBRAIA (1989), a deficiência de fósforo está relacionada, inicialmente, com a precipitação desse nutriente, na forma de fosfato de alumínio, no espaço livre aparente (ELA), ocasionando uma redução na sua absorção. No interior das células, a interação do fósforo e do alumínio, interfere na fosforilação dos açúcares (CLARKSON, 1966), nucleotideos e ácidos nuclêicos (MATSUMOTo et al., 1976).

O alumínio forma complexos com o ATP e inibe as ATPases (CALBO \& CAMBRAIA, 1980) e outras fosfatases da 
membrana plasmática, dificultando ou impedindo a utilização da energia pelas células (CAMBRAIA, 1989).

Em aveia, ALAM \& ADAMS (1979b) encontraram maiores concentrações de $P$ nas raízes de plantas estressadas pelo alumínio, em relação ao tratamento sem Al, enquanto na parte aérea, ocorreu o contrário. Resultados semelhantes foram obtidos por OTSUKA (1968), com aveia, trigo e cevada, e por MUGWIRA et al., (1981), com triticale e trigo.

Segundo CAMBRAIA (1989), a tolerância ao alumínio está relacionada com a capacidade de absorção e metabolismo do fósforo. Plantas tolerantes ao Al tem maior atividade da fosfatase ácida (CLARK \& BROWN, 1974). Para FOY et al. (1978), o metabolismo do fósforo está relacionado com a capacidade de prevenir a absorção em excesso ou promover a desintoxicação do Al absorvido.

Segundo CLARKSON (1966), os distúrbios no metabolismo do fósforo provocados pelo Al -.. refletem-se num decréscimo na taxa de fosforilação dos açúcares, provavelmente, devido à inibição da enzima hexoquinase.

\section{3 .2 .2 Nitrogênio}

Estudos recentes, mostraram que as plantas tolerantes ao aluminio são capazes de absorver o nitrato, mais rapidamente que o amônio, com reflexos na modificação do $\mathrm{pH}$. Quando o nitrogênio é fornecido na forma de amônio $\left(\mathrm{NH}_{4}{ }^{+}\right)$, as plantas tendem a acidificar o meio, enquanto que a forma de nitrato $\left(\mathrm{NO}_{3}{ }^{-}\right)$, resulta em um aumento no $\mathrm{pH}$.

FOY et al. (1965) foram os primeiros a demonstrar que as variações de $\mathrm{pH}$ do meio de cultivo, produzidos por duas variedades de trigo, estavam relacionadas com suas diferentes capacidades de tolerar o aluminio. Na 
cultura da aveia, McLEAN \& GILBERT (1927) verificaram, que o $\mathrm{pH}$ da solução com alumínio apresentou um aumento de 4,5 para 6,5 , em três dias e meio. No entanto, a variação do pH não foi correlacionada com a sensibilidade da cultura ao alumínio.

PIERRE et al. (1970), observaram para aveia branca, uma acidificação menor que a do pousio ou a do trigo sarraceno, (Fagopirum esculentum) devido à aplicação de $\mathrm{NH}_{4} \mathrm{NO}_{3}$, em um ensaio conduzido em casa de vegetação. Este resultado sugere uma maior absorção de nitrato do que amônio pela aveia. FOY \& FLEMING (1978) concluiram que a tolerância do trigo ao alumínio se deve à capacidade das plantas em utilizarem mais eficientemente o $\mathrm{NO}_{3}^{-}$em presença de $\mathrm{NH}_{4}{ }^{+} \mathrm{e}$ assim aumentarem o $\mathrm{pH}$ do meio.

Estudos de cinética de absorção do nitrato mostram que o Al reduz drasticamente a Vmáx e aumenta o Km da reação (CAMBRAIA, 1989). Cultivares tolerantes parecem apresentar a enzima redutase do nitrato menos sensível ao Al (FOY \& FLEMING, 1982; CAMBRAIA, 1989), aumentando consequentemente a assimilação de nitrogênio (ROY et al., 1988).

Segundo CAMBRAIA (1989) o Al interfere também com várias enzimas relacionadas com a assimilação do nitrogênio e, provavelmente, com o catabolismo de aminoácidos, proteinas e outros compostos nitrogenados. Mas PIMENTA et al. (1987) verificaram que na cultura do sorgo, o alumínio parece não afetar diretamente as atividades das enzimas sintetase da glutamina (GS), sintetase de glutamato (GOGAT) e da glutamato-oxaloacetato-transaminase (GOT).

FOY \& FLEMING (1982) demonstraram que o genótipo de trigo NRUC44-111, tolerante à níveis tóxicos de Al, promoveu um aumento maior no $\mathrm{pH}$ das soluçơes nutritivas e apresentou maior atividade da redutase do nitrato que o 
genótipo ANZA, sensível ao Al. Relataram os autores que o cultivar por ser mais eficiente na absorção de $\mathrm{NO}_{3}$ devido à sua alta atividade da redutase do nitrato, seja capaz de manter um pH mais elevado na regiao próxima ao sistema radicular e, assim, manifestar maior tolerância ao alumínio. MESDAG et al. (1970) verificaram uma ligação entre os gens que controlam a tolerância a Al e o conteúdo de proteína no grão do cultivar de trigo Atlas 66.

Em aveia, a tolerância parece estar associada ao maior teor de proteína no grão e a uma maior eficiência no metabolismo do nitrogênio (BILSKI \& FOY, 1987). A seleção dos genótipos tolerantes, aos solos ácidos e à presença de alumínio, também aumenta a eficiência de utilização do nitrogênio em aveia. (BILSKI \& FOY, 1987) podendo indiretamente resultar em um maior teor de proteína no grão (MESDAG et al., 1970).

\subsubsection{Cálcio}

Niveis tóxicos de alumínio interferem no metabolismo do cálcio, provavelmente inibindo a absorção desse nutriente (FOY, 1971). A similaridade existente entre os sintomas de toxicidade do Al com os da deficiência de $\mathrm{Ca}$ em raizes de plantas estressadas por $A l$, indica que os processos de absorção e transporte de Ca são partes importantes da sindrome de fitotoxidez do Al (FURLANI, 1989).

A ação tóxica do alumínio se manifesta também, sobre a enzima calmodulina (Cam), um polipetídio monomérico com quatro sitios de ligação para o cálcio (CAMBRAIA, 1989). A substituição do Ca pelo Al, cuja afinidade é cerca de 2,5 a 10 vezes maior que a do cálcio, promove mudanças na conformação da proteína, alterando sua interação com certas 
enzimas e proteinas tais como as fosfolipases, cinase do NAD, adenil ciclase e $\mathrm{Ca}^{2+}$-ATPase.

No entanto, LARKIN (1987), trabalhando com cultivares de trigo de diferentes tolerâncias ao Al, não detectou diferenças significativas nos níveis de calmodulina, quando as plantas foram submetidas à níveis tóxicos de Al. f n aveia, OTSUKA (1968) e ALAM \& ADAMS (1979b), encontraram menor teor de cálcio na parte aérea, com o aumento da concentração de Al na solução. Em trigo e cevada resultados semelhantes foram encontrados. (OTSUKA, 1968).

Já, FOY et al. (1987) verificaram, que cultivares de aveia tolerantes e sensiveis à solos ácidos, não diferiram quanto as concentraçðes de $\mathrm{Ca}$ e $\mathrm{Mg}$ da parte aérea, quando cultivados em solos com pH 4,31 sem calagem. Entretanto, a adição de cálcio reduziu os efeitos tóxicos do Al em aveia, cevada e trigo (BILSKI, 1987). Para WAGATSUMA (1983a) a supressão da toxicidade do Al somente ocorre quando a concentração de cálcio é consideravelmente maior que o de a lumínio.

HECHT-BUCHHOLZ \& SCHUSTER ( 1987 ) observaram que - aumento da concentração de Ca diminui os danos causados pelo alumínio nas raízes de plantas tolerantes de cevada e não na sensível. Esta diferença foi devido à maior resistência às injúrias do meristema da raiz do cultivar tolerante. Resultados semelhantes foram encontrados em milho (RHUE \& GROGAN, 1977).

\subsubsection{Magnésio}

Segundo GRIMME (1982 e 1983), o Al acarreta inibição especifica da absorção de Mg pelas raízes de aveia, sendo o principal efeito observado devido a toxicidade do Al, 
enquanto ALAM \& ADAMS (1979b), encontraram maiores teores de Mg na parte aérea com o aumento da concentração de Al no substrato.

KYLIN \& KAHR (1973), estudando frações microssomais das raízes de aveia e trigo, verificaram que no trigo uma alta proporção de $\mathrm{Ca}^{2+}$ estimulava a ATPase, com menor efeito devido ao $\mathrm{Mg}^{2+}$, mas em aveia, o $\mathrm{Mg}^{2+}$ estimulava mais a atividade dessa enzima do que o cálcio. HECHT-BUCHHOLZ \& SCHUSTER (1989) em cevada e RHUE \& GROGAN (1977) em milho verificaram que em baixas concentrações de $\mathrm{Ca}$, o aumento na concentração de $\mathrm{Mg}$ diminui os danos provocados pelo Al nas raizes, tanto em cultivares tolerantes quanto sensiveis ao alumínio.

A partir dessas informaçoes, pode-se supor que, por extensão, a deficiência de magnésio na cultura de aveia, causada pela alta concentração de Al, afeta as atividades da ATPase.

\subsubsection{Potássio}

O aumento nos teores do alumínio no substrato, promoveu a diminuição das concentraçôs de potássio na parte aérea das plantas de aveia (ALAM \& ADAMS, 1979b) e também nas raízes (WAGATSUMA \& EZOE, 1985). Em plantas de arroz, o alumínio compete com o $K$ pelos sitios de absorça na raiz, diminuindo a absorção do nutriente, com a consequente redução no teor de $K$ das raízes e da parte aérea das plantas (ALAM, $1983)$.

2.3.2.6. Micronutrientes

Em aveia, foram observados decréscimos 
significativos nos conteúdos dos micronutrientes Fe, Mn, Zn e Cu nas raizes na parte aérea, com o aumento da concentraçăo de alumínio, em solução nutritiva, de 0 a $0,6 \mathrm{mM}$ (ALAM, 1985).

ALAM \& ADAMS ( $1979 b)$, verificaram que, o teor de ferro da parte aérea de aveia era afetado pelo aumento da concentraça de Al no substrato, enquanto que nas raizes foi observada uma concentração maior.

O arroz acumula Fe nas raízes, com o aumento da concentração de Al acima de 10 ppm (ALAM, 1983). Em sorgo, observou-se clorose por deficiência de $F e$, devido à toxicidade de Al (FURLANI \& CLARK, 1981).

CALBO \& CAMBRAIA (1980), verificaram o aparecimento de uma clorose internerval caracteristica da deficiencia de ferro, devido ao efeito do alumínio em dois cultivares de sorgo com diferentes sensibilidades ao aluminio. Resultados semelhantes foram obtidos por OTSUKA (1970), com cultivares de trigo e cevada, com redução do teor de ferro nas plantas submetidas ao aluminio.

LEMOS FILHO (1981) verificou que a presença de a lumínio causou reduções nos teores de manganês e cobre da parte aérea e raízes do sorgo, sem diferenças entre o cultivar sensivel e o tolerante ao Al, exceto para os teores de cobre no sistema radicular, que foram significativamente menores no cultivar sensivel.

A adição de Al aumentou a toxidez de manganês em aveia, cevada, trigo, ervilha, milho e girassol (BILSKI, 1988). OTSUKA (1968) verificou que o Al induziu a uma clorose por deficiência de $\mathrm{Fe}$, nos cultivares de trigo e cevada sensíveis à acidez do solo.

A redução na absorção do cobre, devido ao alumínio, se deve à competição entre os dois nutrientes pelos 
mesmos sitios na superficie da raiz, mas nao do carregador (FOY, 1971). Nas raízes e na parte aérea de sorgo, observou-se que a toxicidade do alumínio causou uma redução no teor de cobre (CAMBRAIA et al., 1983b).

Segundo ALAM (1981), o Al promove um decréscimo na concentração de Mn de todas as partes da planta de cevada, com exceção dos colmos, onde foram encontrados maiores teores de Mn. Já para arroz, as concentraçoes de Mn decresceram na parte aérea e aumentaram nas raízes, devido ao aumento do Al, sugerindo que o Mn pode competir efetivamente com o Al pelos sitios ativos de absorção (ALAM, 1983). Em sorgo, 8 ppm de Al reduziram o teor de Mn nas raízes e parte aérea (CAMBRAIA et al., 1983b).

2.3.3. Efeitos sobre o crescimento e o desenvolvimento

o crescimento celular parece ser afetado pelo aluminio, provavelmente devido à diminuição na taxa de síntese da parede celular, pois o Al inibe a função secretória do aparelho de Golgi (Huck ${ }^{2}$, citado por FURLANI, 1989).

Aparentemente, o alumínio não interfere com a germinação das sementes, mas pode prejudicar o desenvolvimento de novas raízes e o estabelecimento da plântula (FOY, 1992). Segundo esse autor, as plântulas são mais suscetíveis ao Al do que as plantas velhas.

${ }^{2}$ HUCK, M.G. Impriment of sucrose utilization for cell wal formation in the roots of aluminium damaged cotton seedlings. Plant Cell Physiology. 13:7-14, 1972. 
OTSUKA (1968), verificou que a tolerância de cultivares de trigo aos solos ácidos, foi indicada pelas diferenças no número de afilhos. Reduça no crescimento da parte aérea foi observada, após o tratamento com Al em arroz (FAGERIA, 1982), em café (PAVAN \& BINGHAN, 1982), em cevada (ALAM, 1981) e em aveia (KARATAGLIS, 1987; ALAM, 1985).

As folhas jovens de plantas injuriadas pelo alumínio ficam pequenas, encrespadas ao longo das margens e cloróticas, enquanto as folhas velhas mostram clorose marginal, que progride para o centro (PAVAN \& BINGHAN, 1982). WAGATSUMA \& KANEKO (1987) verificaram que as duas folhas inferiores da aveia amareleceram e finalmente ficaram marrom - avermelhadas, progredindo o sintoma do ápice para a base da folha. No entanto, esta redução da atividade mitótica poderia não estar relacionada com a diminuição na respiração das plantas (CLARKSON, 1969).

\subsubsection{Efeitos sobre outros aspectos metabólicos de plantas}

O alumínio também afeta processos fisiológicos das plantas como a fotossintese, devido ao abaixamento no conteúdo de clorofila e à redução no fluxo de elétrons (ROY et al., 1988).

A atividade respiratória das plantas pode ser inibida (CLARKSON, 1969; FOY, 1992), devido à diminuição do requerimento de energia metabólica, enquanto a síntese de proteínas é reduzida, provavelmente devido ao efeito sobre a distribuição dos ribossomas no reticulo endoplasmático (ROY et al., 1988).

As deficiências de nutrientes causadas pelo alumínio, podem causar modificações no aparelho 
fotossintético e, portanto, na taxa de fotossintese (PIRSON, 1955; BARKER, 1979).

Segundo BARKER (1979), o alumínio pode afetar diretamente a taxa de fotossintese ou, mais provavelmente, de forma indireta, a sintese de enzimas, pigmentos e cofatores essenciais ao processo. Pode provocar diminuição no teor de clorofila, com um decréscimo marcante da fotossintese bruta e liquida em arroz (Sarkunan \& Viddappa ${ }^{3}$, citado por ROY et a 1., 1988).

Em arroz, a intensidade respiratória diminui com o aumento no suprimento de alumínio, seguido pela diminuiça no teor de glicidios solúveis, inclusive açúcares redutores (Sarkunan \& Viddappa ${ }^{3}$, citado por ROY et al.,1988). O alumínio parece não ter efeito direto sobre a mitocôndria, sendo que - declinio na respiraça parece refletir um declínio no requerimento de energia ( $R O Y$ et al., 1988).

\subsection{Tolerância de plantas ao alumínio}

A fisiologia da tolerância de plantas ao aluminio foi revisada por FOY, (1971); FOY et al., (1978); TAYLOR, (1988); ROY et a l., (1988); FURLANI, (1989). Ainda não são muito claras as modificaçбes bioquímicas e fisiológicas associadas ao mecanismo de tolerância das plantas ao alumínio, que se relacionam com o comportamento diferencial entre cultivares. Os mecanismos fisiológicos permanecem desconhecidos, provavelmente devido aos efeitos variados do Al nas plantas. As plantas tolerantes devem ter

\footnotetext{
'SARKUNAN, V. \& VIDDAPPA, C.C. Effect of aluminium on the growth yield and chemical composition of rice. Oryza, Cuttack, 19(3-4):188-90, 1982 .
} 
a capacidade de reduzir a absorção do Al pelas raízes ou de desintoxicá-lo após sua absorção (FOY \& FLEMING, 1978).

A partir dos diversos trabalhos relatados, considera-se que os mecanismos de tolerância das plantas ao alumínio podem ser resumidos em: a) resistência à deficiência de nutrientes, tais como P (WRIGHT, 1943), Ca (FOY et al., 1969) ou $\mathrm{Fe}$ (TANAKA \& NAVASERO, 1966); b) absorção preferencial de $\mathrm{NO}_{3}{ }^{-}$, quando comparada com $\mathrm{NH}_{4}{ }^{+}$, ou ânions comparados com cátions, que resulta num grande aumento de $\mathrm{pH}$ do meio (FOY \& FLEMING, 1978: FOY et a $1 ., 1978$; MUGWIRA et a 1., 1976; TAYLOR \& FOY, 1985); c) tolerância à altas concentrações de Al na parte aérea e raízes das plantas (QUELLETTE \& DESSUREAUX, 1958; MATSUMOTO et a 1., 1976);

d) alta concentração de ácidos orgânicos nas raízes ou maior secreção de ácidos orgânicos no meio(CLARKSON, 1966; FOY et al., 1987; OJIMA \& OHIRA, 1988); e) alto poder de exclusão da plasmalema de células radiculares(WAGATSUMA, 1983b);

f) menores cargas negativas na superficie da plasmalema das células radiculares (WAGATSUMA \& AKIBA, 1989).

A tolerância pode ser diferente para diferentes espécies e cultivares, e parece ser controlada por mais do que um gen (FOY et al., 1978).

\subsubsection{Mecanismos de exclusão}

A taxa de imobilização do alumínio na parede celular, pode representar uma redução na penetração no simplasto (TAYLOR, 1988), sendo que a tolerância está associada com a baixa capacidade de troca de cátions das raízes (MUGWIRA \& ELGAWHARY, 1979). Embora as informaçres disponíveis sejam limitadas, a membrana plasmática, devido à sua seletividade, se constitui numa barreira para a absorção 
de Al pelas plantas, sendo sua eficiência reduzida, em condições não metabólicas (TAYLOR, 1988).

Em aveia, o mecanismo de tolerância pode ser devido à exclusão dos ions alumínio pela plasmalema das células radiculares (Wagatsuma et al.", citado por RoY et al., 1988). Em alguns cultivares de trigo, cevada, soja e triticale, a tolerância ao Al aparentemente envolve os mecanismos de exclusão (FOY, 1974; MUGWIRA et al., 1981). No entanto, outros grupos de plantas apresentaram menores teores de Al na parte aérea, que nas raízes tais como arroz, triticale, centeio, trigo e cevada (FOY et al., 1978). Há ainda um terceiro grupo, no qual a tolerância está diretamente associada à acumulação na parte aérea, apresentando alta tolerância interna (ROY et al., 1988).

Segundo WAGATSUMA \& YAMASAKU (1985), os cultivares tolerantes de cevada excluem ativamente o Al do lado externo da plasmalema das células de raiz, podendo então ser polimerizado ou até reagir com o $P$ ou pectatos. Consequentemente, nestes cultivares, o conteúdo de Al pode ser baixo nos protoplastos da raiz, alto em tecidos inteiros da raíz e o teor de $\mathrm{Ca}$ ou outros nutrientes pode ser alto nas raízes.

WAGATSUMA \& AKIBA (1989), estudando arroz, aveia, milho, ervilha e cevada, que diferem quanto à tolerância ao alumínio, concluiram que as plantas sensiveis apresentaram cargas negativas fortes na superficie da plasmalema, onde se ligaram quantidades maiores dos íons alumínio, podendo eventualmente, a plasmalema ser destruída pelo íon.

\footnotetext{
'WAGATSUMA, T.; KYUUDA, T.; SARKURABA. A luminum accumulation characteristics of aluminum-tolerant plants. Yamagata Daigaku Kiyo, Nogaku, 10(2):355-9, 1987 .
} 
28.

\subsubsection{Alteração do $\mathrm{pH}$ na rizosfera}

Alguns cultivares tolerantes de trigo, cevada, arroz, ervilha e milho não híbrido, promovem o aumento do $\mathrm{pH}$ da solução nutritiva e assim diminuem a solubilidade e a toxicidade do Al por precipitação (FOY et al., 1978). Este fato, poderia ser atribuido à maior absorça de nitratos, em detrimento do amônio (FOY \& FLEMING, 1978).

\subsubsection{Nutriçå das plantas}

Segundo FOY et al. (1978), em muitas plantas, a tolerância ao Al parece estar relacionada com a eficiência da utilização de fósforo, da mesma forma que na tolerância à niveis mais baixos de $P$ pelo milho ou na absorcão de mais $P$ por unidade de comprimento da rafz de soja (Sartain, ${ }^{5}$, citado por ROY et al., 1988).

Em raízes de ervilha, o Al provocou aumento na atividade da ATPase e da fosfatase ácida, sendo a tolerância diferencial de dois cultivares, atribuidas aos efeitos diferenciais do Al sobre a atividade de ATPase, sendo a atividade maior no cultivar tolerante (FOY et al., 1978).

Cultivares tolerantes de milho (Fleming ${ }^{6}$, citado por FOY et al., 1978) e linhagens de milho (CLARK, 1975) apresentaram maiores atividades de fosfatases nas raizes do que os genótipos sensiveis da mesma espécie. No entanto, BRAUNER (1979), verificou que o grau de tolerância

${ }^{5}$ SARTAIN, J.B. Differential effects of aluminium on top and root growth, nutrient accumulation and nodulation of several soybean varieties. Raleigh, 1974 (Ph:D. -North Caroline State University). 
ao alumínio dos cultivares de trigo não está relacionado com as concentraçōes de $\mathrm{P}, \mathrm{Ca} e \mathrm{Mg}$ na parte aérea.

A tolerância maior ao Al, de algumas espécies, pode estar relacionada com sua habilidade em usar o nitrato $\left(\mathrm{NO}_{3}{ }^{-}\right)$na presença de amônio $\left(\mathrm{NH}_{1}{ }^{+}\right)$, promovendo o aumento do $\mathrm{pH}$ do meio de crescimento ou rizosfera (FOY \& FLEMING, 1978) ou o aumento da atividade da redutase do nitrato (FOY \& FLEMING, 1982). Em cultivares tolerantes de trigo (MESDAG et al., 1970) e aveia (BILSKI \& FOY,1987) foram encontrados altos teores de proteina nos grãos.

Segundo FOY et al. (1978), a tolerância ao aluminio de alguns cultivares de trigo, cevada, soja e feijão está associada à habilidade em resistir à deficiência de cálcio, induzida pelo alumínio.

Cultivares tolerantes de cevada, apresentam menor inibição na absorção de Ca e outros cátions, com consequente aumento em seus teores nas plantas (WAGATSUMA \& YAMASAKU, 1985). Em cultivares de batata e milho não híbrido, a tolerância ao alumínio tem sido associada à uma maior absorção de Mg (FOY, 1984). Cultivares de batata tolerantes a Al, também apresentaram maior absorção de potássio (FOY, 1984).

\subsubsection{Formação de complexos orgânicos}

A formação de complexos solúveis de ácidos orgânicos com alumínio, pode eliminar sua toxicidade em plantas (FOY et al., 1978). Estes ácidos produzidos pelas plantas tolerantes, funcionam como quelantes do alumínio, formando um sistema de desintoxicação ou proteção (CLARKSON,

${ }^{6}$ FLEMING, A. L. 1975. Characterization of acid phosphatase activity in wheat varieties differing in $P$ efficiency. ASA Abstr. Ann. Meet., Madison, p.70. 
1966). FOY et al., (1987) verificaram, a presença de ácidos orgânicos nas raízes de cultivares tolerantes e sensiveis de cevada. Observaram uma diminuição significativa dos ácidos levulínico, cítrico e succínico no cultivar sensível, com o aumento da concentraça de alumínio, tendo-se mantido estável seu conteúdo no cultivar tolerante. FOY \& LEE (1987), também observaram que o estresse de alumínio reduziu significativamente a concentração dos ácidos cítrico, succínico e ácidos orgânicos totais nas raizes do cultivar de cevada sensível ao aluminio e não no cultivar tolerante. 0 aluminio diminuiu mais a concentração de ácido levulínico do que o citrico no cultivar sensivel em relaça ao tolerante.

Em cultivares tolerantes de sorgo, foram encontradas concentraçōes substancialmente mais elevadas de ácido cítrico e uma acumulação de ácidos orgânicos $55 \%$ maior do que nos sensíveis. (CAMBRAIA et al., 1983a).

2.5. Efeito do alumínio sobre a atividade da enzima redutase do nitrato.

O efeito de Al no metabolismo do nitrogênio, foi observado em diversas culturas. A enzima redutase do nitrato-RN ( EC 1.6.6.1) é a primeira enzima envolvida no. processo de redução do nitrato, forma de nitrogênio, absorvida predominantemente pelas plantas superiores. A atividade dessa enzima é um fator limitante na taxa de redução do nitrato à amônio em plantas (BEEVERS \& HAGEMAN, 1969).

A atividade da enzima permite estimar o estado nutricional da planta quanto ao nitrogénio e este é frequentemente correlacionado com o crescimento e a produtividade. Em aveia, a quantidade de nitrato absorvido 
parece estar relacionada com o teor de proteína (SCHRADER, 1978), aumentando significativamente a atividade da redutase do nitrato (GOODMAN et al., 1974).

Segundo BEEVERS \& HAGEMAN (1969), na maioria das espécies de plantas, a redução do nitrato é maior na parte aérea do que nas raízes. A atividade da enzima na raíz tende a aumentar proporcionalmente em relação à parte aérea com a diminuição da disponibilidade de nitrato (MARSCHNER, 1986). A atividade da redutase do nitrato parece variar conforme a espécie. LILLO \& HENDRIKSEN (1984) observaram que a atividade da RN em folhas de trigo foi superior à da aveia e da cevada.

O efeito do alumínio sobre a atividade da RN, foi estudado na cultura do trigo (FOY \& FLEMING, 1982), verificando-se uma maior atividade da enzima em genótipos tolerantes, quando relacionada à dos sensiveis, tanto na presença quanto na ausência de Al. Já em sorgo, a atividade da RN diminuiu na parte aérea com o aumento do teor de Al, possivelmente devido ao aumento da absorção de $\mathrm{NH}_{i}^{+}$(KELTJENS, 1988). Como em aveia, os genótipos tolerantes ao alumínio, tem maior teor de proteina nos graos (BILSKI \& FOY, 1987), isto demonstra uma maior eficiência na utilização do nitrogênio.

De outro lado, a maior atividade de redução do nitrato na parte aérea, estimula a absorção de nitrato pelas raízes (BEN ZIONI et al., 1971). Nessas condições, com a maior absorção desse ânion, poderia ser esperado um aumento do $\mathrm{pH}$ na solução.

Quanto à influência do estádio de desenvolvimento da aveia sobre a atividade da redutase do nitrato, SAUVESTY \& GENDRON (1987) observaram, em três cultivares, que a atividade da enzima é alta na fase de 
32.

plântula, máxima na fase de perfilhamento, decaindo após a emissão da panicula. Esta atividade poderia estar relacionada com a taxa de absorção de nitrato pelas plantas de aveia, que decresce aproximadamente aos 50 dias após a emergência (SCHRADER, 1978). 


\section{MATERIAL E METODOS}

3.1. Determinação da concentração de alumínio na solução nutritiva para classificação de genótipos de aveia branca.

o experimento foi conduzido em câmara de crescimento, submetendo-se 16 genótipos de aveia branca a cinco niveis de alumínio na solução nutritiva.

A câmara de crescimento foi instalada no Setor de Nutrição Mineral de Plantas do Departamento de Química da Escola Superior de Agricultura "Luiz de Queiroz", em Piracicaba, SP. A câmara tinha as dimensoes de $3 \mathrm{~m} x 5,40 \mathrm{~m}$, sendo que a parte iluminada correspondia a uma área de $2,40 \mathrm{~m}$ $x 3,0 \mathrm{~m}$. A i luminação da câmara constava da combinaçã́o de 72 lâmpadas fluorescentes de 50 W e 28 lâmpadas de vapor de mercúrio de $250 \mathrm{~W}$. A intensidade luminosa média, tomando por base nove diferentes pontos ao nível de altura das plantas, foi de 208 micro einsteins, 1,13 milivolts, $0,170969 \mathrm{cal} / \mathrm{cm}^{2} / \mathrm{m}$ inuto e $4979 \mathrm{lux}$.

O ciclo de iluminação utilizado foi o de 16 horas luz e 8 horas de escuro, controlado através de um timer. O controle da temperatura foi realizado através de dois condicionadores de ar, frio e quente, com capacidade 
para 17000 e 18000 BTUs. Um dos condicionadores permanecia ligado constantemente, enquanto o outro acompanhava o ciclo de iluminação. A umidificação do ambiente era feita através de constante umedecimento do chão da câmara.

Antes da instalaça deste experimento, executou-se um ensaio prévio, com o objetivo de avaliar-se a metodologia e as condiçôes de funcionamento da câmara de crescimento, especialmente, em relação à idade da plântula na implantação, controle de temperatura e umidade relativa, variação do pH da solução e avaliaçơes na colheita.

ós genótipos de aveia estudados são provenientes do programa de melhoramento genético de aveia desenvolvido pela Universidade de Passo Fundo (Passo Fundo, RS). Com base em uma avaliação preliminar realizada no campo (FLOSS et al., 1990), utilizando solos ácidos que apresentavam altos teores de Al trocável (3,7 e 4,2 meq/100 $\mathrm{cm}^{3}$ de solo), foram incluidos no ensaio os genótipos: UPF 5, UPF 7, UPF791174-3, UPF84057, UPF86011, UPF86018, UPF86045, UPF86066, UPF86112, UPF86113, UPF86136, UPF86A1169-2b, UPF86A1 198-5-1b, UPF86Al264-1b, UPF87071 e UPF87107.A genealogia dos genótipos estudados é apresentada no Apêndice A ( Tabela A1).

As sementes de aveia, após prévia seleção quanto ao tamanho, foram desinfectadas através de tratamento com uma solução de hipoclorito de sódio a $10 \%$ (produto comercial), durante 15 minutos. Seguiu-se uma lavagem com água de torneira e após com água destilada. As sementes foram colocadas para germinar em papel de germinação, umedecido previamente com água destilada, na proporção de $2 \mathrm{~m} l$ de água por grama de papel. Durante o período de germinaça, a temperatura no germinador foi mantida em $20^{\circ}$ Celsius. 
4 dias após a semeadura, as plântulas foram selecionadas quanto a uniformidade de tamanho, medindo-se o comprimento inicial $(\mathrm{cm})$ da raíz seminal primária(CIRS). A seguir foram transferidas para uma solução nutritiva completa. Os níveis de aluminio foram aplicados 24 horas após.

Para sustentação das plântulas sobre a solução nutritiva, elas foram colocadas nos orificios de chapas de PVC opaco, medindo $50 \mathrm{x} 22 \mathrm{~cm}$, com $0,4 \mathrm{~mm}$ de espessura, instaladas sobre as bandejas de polietileno. A capacidade das bandejas era de 15 litros de solução nutritiva. As chapas de sustentação tinham 128 orificios, permitindo a avaliação de 16 genótipos por bandeja, usando-se 8 plântulas por sub-parcela, sendo 6 úteis na avaliação e 2 como bordadura. As bandejas foram previamente pintadas externamente, com tinta aluminizada, para evitar a penetração da luz e a consequente inibição do crescimento radicular.

A composição da solução nutritiva utilizada foi baseada em FURLANI \& HANNA (1984), para a cultura do arroz, sendo modificada, pelo aumento em cinco vezes na concentração dos macronutrientes mantendo-se a mesma concentração de micronutrientes (Tabela 1). Esta maior concentração foi usada, por que em um experimento prévio apareceram sintomas de deficiência de fósforo, mesmo no tratamento com ausência de alumínio. Na solução utilizada, o teor de fósforo foi de 1 mg/litro de solução. Esta concentração de P é menor do que a indicada por FoY (1976), 2 a 4 ppm. Por outro lado, a concentração de Ca de $150 \mathrm{mg} / 1$ utilizada neste trabalho é tres vezes superior àquela indicada por FOY (1976).

o estresse de alumínio foi obtido mediante adições de volumes conhecidos de uma solução contendo 3.000 mğ de Al/litro de solução estoque, preparada a partir de 
AlK $\left(\mathrm{SO}_{4}\right)_{2} .12 \mathrm{H}_{2} \mathrm{O}$, utilizando-se $52,77 \mathrm{~g}$ do sal por litro de solução estoque. As concentraçôes de aluminio utilizadas

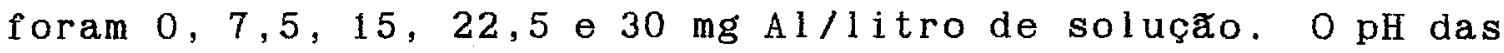
diferentes soluções não foi corrigido, sendo acompanhada a variação, mediante leitura diária. As soluções foram contínuamente arejadas, utilizando-se um compressor.

Tabela 1: Composição da solução estoque e da solução nutritiva utilizadas para estudo da tolerância de plantas de aveia ao aluminio (Modificada a partir de FURLANI \& HANNA, 1984).

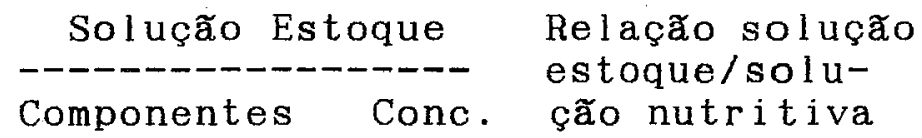

Concentração final da solução nutritiva

\begin{tabular}{|c|c|c|c|c|}
\hline & $---g / 1--$ & $--\mathrm{ml}^{\prime} / \mathrm{l}--$ & nutrientes & $\mathrm{mg} / \mathrm{l}$ \\
\hline $\mathrm{Mg}\left(\mathrm{NO}_{3}\right)_{2} \cdot 6 \mathrm{H}_{2} \mathrm{O}$ & 142,4 & 1,4 & $\mathrm{Ca}$ & 150 \\
\hline $\mathrm{KH}_{2} \mathrm{PO}_{4}$ & 17,6 & 0,25 & $\mathrm{~K}$ & 90 \\
\hline $\begin{array}{l}\mathrm{Ca}\left(\mathrm{NO}_{3}\right)_{2} \cdot 4 \mathrm{H}_{2} \mathrm{O} \\
\mathrm{NH}_{4} \mathrm{NO}_{3}\end{array}$ & $\begin{array}{r}270,0 \\
3,8\end{array}$ & 3,3 & $\begin{array}{l}\mathrm{Mg} \\
\mathrm{N}-\mathrm{NO}_{3}\end{array}$ & $\begin{array}{r}19 \\
150\end{array}$ \\
\hline $\begin{array}{l}\mathrm{FeSO}_{4} \cdot 7 \mathrm{H}_{2} \mathrm{O} \\
\mathrm{Na}_{2} \mathrm{EDTA}^{-}\end{array}$ & $\begin{array}{l}24.9 \\
29.6\end{array}$ & 0,33 & $\begin{array}{l}\mathrm{N}-\mathrm{NH}_{4} \\
\mathrm{P}\end{array}$ & $\begin{array}{r}20 \\
1\end{array}$ \\
\hline $\begin{array}{l}\mathrm{KCl} \\
\mathrm{KNO}_{3} \\
\mathrm{~K}_{2} \mathrm{SO}_{4}\end{array}$ & $\begin{array}{l}18,6 \\
24,6 \\
44,0\end{array}$ & 2,3 & $\begin{array}{l}\mathrm{B} \\
\mathrm{Fe} \\
\mathrm{Mn}\end{array}$ & $\begin{array}{l}0,05 \\
0,5 \\
0,1\end{array}$ \\
\hline $\begin{array}{l}\mathrm{MnCl}_{2} \cdot 4 \mathrm{H}_{2} \mathrm{O} \\
\mathrm{H}_{3} \mathrm{BO}_{3} \\
\mathrm{CuSO}_{4} \cdot 5 \mathrm{H}_{2} \mathrm{O} \\
\mathrm{ZnSO}_{4} \cdot 7 \mathrm{H}_{2} \mathrm{O} \\
\mathrm{MOO}_{3}\end{array}$ & $\begin{array}{l}2,34 \\
2,04 \\
0,3127 \\
1,6587 \\
0,1573\end{array}$ & 0,33 & $\begin{array}{l}\text { Mo } \\
\mathrm{Zn} \\
\mathrm{Cu}\end{array}$ & $\begin{array}{l}0,02 \\
0,03 \\
0,01\end{array}$ \\
\hline
\end{tabular}


As plantas foram mantidas em câmara de crescimento, com uma umidade relativa media de $73 \%$ (Tabela B1), com iluminaça artificial durante todo o período experimental, à uma intensidade de 224 micro-einstein. A temperatura média na câmara foi ajustada para $25^{\circ} \mathrm{C} \pm 4^{\circ} \mathrm{C}$ (Tabela B1).

A avaliação final foi realizada após 10 dias de permanência das plantas nas soluções com níveis de alumínio.

o efeito do aluminio foi avaliado pelo parâmetro crescimento da raíz seminal (CRS) que parece apresentar melhor correlação com o grau de tolerância ao alumínio (FOY et al., 1967; REID et al., 1971; MOORE et a 1., 1976). O crescimento relativo da raíz seminal (CRRS), foi determinado pela relação CRS-A1/CRS $x, 100$, onde CRS-Al, representa a média do comprimento da raíz de plantas cultivadas em solução de cada nível de Al e CRS, representa a média do comprimento da raiz seminal de plantas cultivadas na ausência de alumínio. Também foram avaliados o comprimento final da raiz seminal (CFRS) e o comprimento final relativo da raiz seminal (CFRRS), utilizando o mesmo critério de CRRS.

o delineamento experimental utilizado foi o de blocos casualizados, obedecendo ao esquema de parcelas subdivididas, sendo que as parcelas foram constituidas pelos 5 níveis de alumínio e as sub-parcelas pelos 16 genótipos de aveia. Cada bandeja constituia uma parcela, contendo 16 sub-parcelas, utilizando-se 3 repetições por parcela.

A análise estatística dos resultados foi realizada segundo GOMES (1972), aplicando-se o teste F, segundo o seguinte quadro de análise de variância: 


\begin{tabular}{lc}
\hline Causas de variação & G.L. \\
\hline Blocos & 2 \\
Níveis de Alumínio & 4 \\
Residuo (A) & 8 \\
Genótipos & 15 \\
Genótipos x níveis de alumínio & 60 \\
Residua (B) & 150 \\
\hline
\end{tabular}

Tota 1

239

Para cada causa de variação em que o efeito revelou-se significativo pelo teste $F$, efetuou-se o desdobramento dessa causa para os regressơes polinomiais linear e quadrática. Considerou-se como representativa a regressão de maior grau significativa pelo teste $F$ e o maior coeficiente de determinação $\left(R^{2}\right)$. A comparação entre médias dos genótipos para cada nível de Al foi realizada pelo teste de Tukey, até o nível de $5 \%$ de significancia.

3.2. Efeito do alumínio na solução nutritiva sobre alguns parâmetros de crescimento da aveia.

Este experimento também foi conduzido em câmara de crescimento, av́aliando-se 16 genótipos de aveia branca, nas bandejas, sob dois niveis de aluminio: 0 e $7,5 \mathrm{mg}$ Al/litro de solução.

O delineamento experimental foi igual ao do experimento anterior. As variáveis avaliadas foram os parâmetros de crescimento de raízes CIRS, CFRS, CFRRS, CRS e CRRS, além do rendimento de matéria seca da raiz (RMSR), rendimento relativo de matéria seca da raiz (RRMSR), rendimento de matéria seca da parte aérea (RMSPA), rendimento relativo de matéria seca da parte aérea (RRMSPA), rendimento de matéria seca da planta (RMSP), rendimento relativo de 
matéria seca da planta (RRMSP) e relação entre RMSR e RMSPA (RRPA).

As plantas foram colhidas após 11 dias de crescimento, depois de serem submetidas aos níveis de Al durante 10 dias, medindo-se o comprimento da maior raiz e separando-se o sistema radicular da parte aérea. As partes foram secas em estufa, com temperatura entre. $70-75^{\circ} \mathrm{C}$, por 72 horas. Foi realizada então a pesagem, para a determinação do rendimento de matéria seca das seis plantas/genótipo. 0 rendimento relativo foi calculado, pela relação RMS 7,5 Al/RMS O Al, multiplicado por 100 .

A análise estatística foi realizada segundo o seguinte quadro de análise de variância:

\begin{tabular}{lc}
\hline Causas de variação & G.L. \\
\hline Blocos & 2 \\
Niveis de Aluminio & 1 \\
Residuo (A) & 2 \\
Genótipos & 15 \\
Genótipos X Níveis de Alumínio & 60 \\
Residuo (B) & 95
\end{tabular}

A comparação entre médias foi realizada através do teste de Tukey. Para as variáveis onde o teste $F$ revelou-se significativo para a interação genótipo $x$ níveis de alumínio, esta causa de variação foi desdobrada, fazendose a comparação entre as médias, pelo teste de Tukey, ao nivel de $5 \%$ de significância. 
40 .

3.3. Seleção de genótipos de aveia branca tolerantes ao alumínio, em solução nutritiva

3.3.1. Seleção no nível de $7,5 \mathrm{mg} \mathrm{Al/litro} \mathrm{de}$ sol ução.

Neste experimento foram avaliados 156 genótipos de aveia branca (Tabela A1), visando a seleção de materiais tolerantes ao alumínio. A metodologia utilizada foi a mesma dos experimentos anteriores, com algumas modificações.

Para a obtenção do estresse do alumínio, os genótipos foram submetidos aos tratamentos sem e com aluminio na solução nutritiva. A concentração de aluminio foi a de $7,5 \mathrm{mg}$ Al/l determinada no primeiro experimento, como sendo adequada para separar-se genótipos tolerantes de sensiveis e considerando que McLEAN \& GILBERT (1927) também consideraram 7 ppm como o nível crítico para aveia.

Devido à capacidade da câmara de crescimento, este trabalho foi subdividido em onze experimentos, identificados como experimento 1 (item 3.1), experimento 2 (item 3.2) e experimento 3A, 3B, 3C, 3D, 3E, 3F, 3G, 3H e 31 . Em cada ensaio foram avaliados 14 genótipos 
(subparcelas), incluindo-se duas testemunhas, uma sensível ao alumínio (UPF 7) e outra tolerante (UPF86A1169-2b), de acordo com o resultado da avaliação do primeiro experimento. Os genótipos foram submetidos a 2 niveis de alumínio 0 e 7,5 mg/l (parcelas), com três repetiçôes, totalizando 6 bandejas por ensaio.

Decorridos 10 dias, depois das plântulas serem submetidas aos tratamentos com e sem aluminio, foi feita a avaliação do comprimento da maior raíz seminal de cada planta (CFRS=cm/plântula). O efeito do Al foi avaliado pelo crescimento da raíz seminal(CRS = CFRS - CIRS) e o efeito responsivo através do crescimento relativo (CRRS).

A análise estatistica dos onze experimentos foi realizada, obedecendo ao mesmo quadro de análise de variância do segundo experimento. O comportamento dos genótipos testemunhas também foi analisado estatisticamente quanto ao crescimento da raíz seminal, nos onze experimentos de seleção, com três repetiçôs utilizando o seguinte quadro de análise de variância:

Causas de variação G.L.

Blocos

Genót ipos

Ensaios Genótipos $x$ Ensaios Resíduo

2


42 .

3.3.2. Seleção no nivel de $15 \mathrm{mg}$ Allititro de solução.

Neste ensaio, avaliou-se o efeito do nível de $15 \mathrm{mg}$ Al/litro de solução, sobre 84 genótipos de aveia, considerados tolerantes (CRS > média) ou responsivo (CRRS) média) na seleção efetuada ao nível de $7,5 \mathrm{mg} A l / 1$. Como testemunhas, foram utilizados os genótipos UPF86Al169-2b(tolerante) e UPF7(sensível). Em cada bandeja foram avaliados 14 genótipos, além das duas testemunhas, usando-se um total de 6 bandejas por repetição.

O del ineamento experimental utilizado foi o de blocos casualizados, com três repetiçðes. As condições de condução de experimento foram as mesmas da seleção anterior e os parâmetros avaliados foram CIRS, CFRS, CRS e o indice de tolerância ao Al (ITRAl). O ITRAl foi calculado segundo a fórmula, modificada a partir de FURLANI \& CASTRO (1990):

$$
\text { ITRAl }=\frac{(\text { CRSx }- \text { CRSs })}{(\text { CRSt }- \text { CRSs })} \times 8,0+1,0
$$

onde: CRSx, CRSs e CRSt representam os valores do crescimento da raiz seminal dos genótipos em estudo ( $x$ ) e contrôles 
sensivel (s) e tolerante ( $t$ ).

A análise estatística dos resultados foi efetuada segundo o seguinte quadro de análise de variância:

\begin{tabular}{lr}
\hline Causas de variação & G.L. \\
\hline Genótipos & 85 \\
Blocos & 2 \\
Resíduo & 170 \\
\hline Total & 257
\end{tabular}

Com o propósito de comparar o efeito relativo, foi conduzida uma bandeja, com 16 genótipos com três repetições em solução nutritiva com ausência de alumínio. O nível de tolerância foi avaliado pelo CRS e o efeito responsivo através do CRRS. A análise estatística foi realizada, utilizando o mesmo quadro de análise de variância do segundo experimento (item 3.2).

3.4. Avaliação da tolerância de genótipos de aveias pretas ao alumínio, em solução nutritiva

Neste experimento foram avaliados 14 genótipos de aveia preta, tendo como testemunhas os genótipos de aveia branca UPF 7 (sensível) e UPF86A1169-2b (tolerante). As plantas foram obtidas conforme foi descrito no primeiro experimento ( 3.1 ), bem como a metodologia de condução. A 
44 .

genealogia dos genótipos de aveia preta avaliados está no Apêndice A (Tabela A2).

Foram utilizados quatro níveis de alumínio na solução nutritiva: $0,7,5,15$ e $30 \mathrm{mg}$ Al/ litro de solução. Após 10 dias de cultivo nas diferentes soluçôes, os genótipos foram avaliados, quanto ao crescimento da raiz seminal (CRS), crescimento relativo da raiz seminal (CRRS) e comprimento inicial da raíz seminal (CIRS).

A análise de variância dos resultados deste experimento, foi realizada utilizando-se o seguinte quadro de análise de variância:

Causas de variação

G.L.

Blocos

Níveis de Alumínio 3

Resíduo (A)

Genót ipos

Genótipos $x$ Níveis de Alumínio

Resíduo (B)

Tota 1

191

3.5. Efeito do alumínio sobre alguns parâmetros de crescimento e a nutrição de aveia, em cultivo hidropônico

Neste experimento foi avaliado o efeito do 
alumínio sobre alguns parâmetros de crescimento, o teor e a extraça de alguns macro e micronutrientes por dois genótipos de aveia. o experimento foi conduzido na casa de vegetação do setor de Nutrição Mineral de Plantas do Departamento de Química, da Escola Superior de Agricultura "Luiz de Queiroz"/USP, em Piracicaba, SP.

Foram utilizados baldes de polietileno brancos, com a capacidade para 3,8 litros. As plântulas foram obtidas conforme a metodologia descrita no primeiro experimento. No nono dia após a semeadura, plântulas norma is e uniformes foram transferidas para as tampas dos vasos de polietileno perfuradas, protegidas por espuma plástica, com orificios de $2 \mathrm{~cm}$ de diâmetro, utilizando-se 7 plantas por vaso.

Os tratamentos constaram de dois genótipos de aveia, sendo um tolerante(UPF86Al169-2b) e um sensivel(UPF7) e cinco níveis de alumínio $(0,10,20,30$ e $40 \mathrm{mg} / 1$ itro de solução). O delineamento experimental foi o de blocos casualizados, distribuindo-se os tratamentos em um esquema fatorial com 2 genótipos $x 5$ níveis de Al x 3 blocos.

Duranté cinco dias após a implantação, as plantas receberam uma solução nutritiva diluida equivalente a um quinto da concentração da solução original mostrado na Tabela 1. Após esse período as plantas receberam a solução nutritiva completa, e foram aplicados os tratamentos respectivos de alumínio. A solução nutritiva foi renovada a cada cinco dias. O pH inicial e final da soluça de cada período e cada vaso, foi determinado através de potenciômetro manual. No $1^{\circ}, 3^{\circ}$ e $5^{\circ}$ período, foram realizados os controles diários do $\mathrm{pH}$, às 7 horas.

Vinte e tres dias após a instalação do experimento, foram retirada uma folha de cada planta, a última 
completamente expandida, para a determinação da atividade "in vitro" da redutase do nitrato ( $R N$ ).

0 experimento foi colhido 25 dias após sua instalação. As plantas colhidas foram lavadas rapidamente e foi medido o comprimento da maior raiz (CMR) e feita a contagem do número de afilhos (NAF). Em seguida, as plantas foram fracionadas em folhas (F), colmo + bainha (CB) e raizes (R). O material foi seco em estufa, com temperatura de 70 $75^{\circ}$ C. Após 72 horas, o material foi pesado, para a determinação do rendimento de matéria seca (MS) das diversas frações. A relação de peso foliar (RPF), foi obtida pelo quociente RMSF/RMSP, multiplicado por 100. A relação raiz/parte aérea (RRPA), foi obtido pelo quociente RMSR/RMSPA, multiplicado por 100 .

A análise estatística nos parâmetros avaliados, aplicando-se o teste F, obedeceu ao seguinte quadro de análise de variância:

Causas de variação

G.L.

Genótipos

Niveis de Aluminio

Genótipos $x$ Níveis de Aluminio

Blocos

Residuo

Total

Quando o teste F revelou-se significativo para a interação, efetuou-se o desdobramento das causas através de regressőes polinomiais até o $3^{\circ}$ grau, utilizando-se o teste $F$ e o coeficiente de determinação $\left(R^{2}\right)$ para escolher aquela que melhor se adaptava à distribuição dos resultados.

A matéria seca das rafizes e da parte aérea, 
após secagem e pesagem, foi moída em moinho do tipo Willey, para posterior determinaça dos teores de $\mathrm{N}, \mathrm{P}, \mathrm{K}, \mathrm{Ca}, \mathrm{Mg}$, Fe, Mn, Zn e Cu, segundo metodologia descrita por SARRUGE \& HAAG (1974). A análise do teor de alumínio foi realizada no Laboratório de Radioquímica do Centro de Energia Nuclear na Agricultura (CENA/USP), em Piracicaba, S.P., através de espectrometria de emissão atômica com plasma induzido de argônio, modelo 975 JERREL ASH.

Como a quantidade de material vegetal das raizes foi muito pequena no nivel de $40 \mathrm{mg}$ de Al/litro, a análise dos teores foi realizada apenas em quatro niveis de A1. A partir dos teores obtidos na análise, foi calculada a extração de nutrientes pelas duas partes (aérea e raizes) e pela planta toda, em cada vaso.

A análise estatistica dos resultados foi feita, aplicando-se o teste $F$, segundo o seguinte quadro de análise de variância:

\begin{tabular}{lc}
\hline Causas de variação & G.L. \\
\hline Partes & 1 \\
Genótipos & 1 \\
Niveis de Alumínio & 3 \\
Partes x Genótipos & 1 \\
Partes x Niveis de aluminio & 3 \\
Genotipos x Niveis de Alumínio & 3 \\
Partes x Genótipos x Niveis de aluminio & 3 \\
Blocos & 2 \\
Residuo & 30 \\
\hline Total & 47
\end{tabular}

Os efeitos de niveis de Al sobre o rendimento de MS e extração de Al e alguns nutrientes na planta toda, foi obtido pela soma do rendimento de MS e extração de nutrientes 
de cada parte. O teor foi calculado pela relaça da quantidade de nutrientes extraidos/rendimento de MS. A análise dos resultados foi realizada obedecendo ao seguinte quadro de análise de variância:

\begin{tabular}{lc}
\hline Causas de variação & G.L. \\
\hline Genótipos & 1 \\
Níveis de Alumínio & 3 \\
Genótipos x Niveis de Alumínio & 3 \\
Residuo & 16 \\
\hline Total & 23
\end{tabular}

3.6. Efeito do alumínio sobre a atividade "in vitro" da enzima redutase do nitrato em aveia

o efeito do alumínio sobre a atividade da redutase do nitrato (EC 1.6.6.1), foi determinado à partir de folhas coletadas no experimento de cultivo hidropônico (3.5.), colhidos com 23 dias.

Previamente foi realizado um experimento para determinar o órgão (folha ou raiz) de maior atividade da RN em aveia e o melhor estádio de desenvolvimento, 14 ou 21 dias após a emergência (DAE). Foram cultivados dois genótipos de aveia (UPF 7 e UPF86A1169-2b), em cultivo hidropônico, utilizando a solução nutritiva da Tabela 1 e na ausência de Al. Aos 14 e 21 DAE foi coletada a última folha completamente expandida e avaliada a atividade da $\mathrm{RN}$, no Laboratório de Bioquímica do CENA/USP.

Foi utilizado o método "in vitro", modificado de HARPER \& HAGEMAN (1972).

o sistema foi formado por $200 \mathrm{mil}$ igramas de 
folhas cortadas, com aproximadamente $1 \mathrm{~cm}$ de comprimento. 0 material foi transferido para um tubo de vácuo contendo 5,0 ml de solução tampão fosfato $0,1 \mathrm{M}, \mathrm{pH} 7,5$, com isopropanol $1 \%$ e $\mathrm{KNO}_{3} 50 \mathrm{mM}$ e, posteriormente, vedadas com tampa de borracha para remoção do ar, através de vácuo por 2 minutos. Os tubos foram incubados em banho-maria, na temperatura de $30^{\circ} \mathrm{C}$, por 30 minutos, ao abrigo da luz.

Após a incubação, foram retiradas allquotas para as diluições (faixa de leitura de 0,2 a 0,5 de absorbância) e em seguida efetuadas reações na proporção de $2 \mathrm{ml}$ de aliquota $+1 \mathrm{ml}$ de sulfanilamida $1 \%(\mathrm{em} \mathrm{HCl} .2 \mathrm{~N})+1$ $\mathrm{ml}$ de NNEDA 0,02\%, esperando-se 15 minutos. O branco foi feito com reativos em ausência de tecido vegetal. As leituras foram feitas em espectrofotômetro no comprimento de onda $540 \mathrm{~nm}$. Os resultados foram expressos em $\mu \mathrm{mol} \mathrm{NO}_{2}^{-} \cdot \mathrm{h}^{-1} \cdot \mathrm{g}^{-1}$ de tecido fresco.

No experimento para determinação da atividade da RN em diferentes órgãos e estádios, foi utilizado o delineamento experimental inteiramente casualizado, distribuindo-se os tratamentos em esquema fatorial com dois genótipos $x$ dois estádios $x$ dois órgãos, em quatro repetições. A análise estatística dos resultados, aplicandose o teste F, foi realizada segundo o seguinte quadro de análise de variância: 
Genót ipos

Estádios

órgãos

Genótipos $\mathrm{x}$ estádios

Genótipos $\mathrm{x}$ órgãos

Estádios $x$ órgãos

Genótipos $x$ estádios $x$ órgãos

Res íduo

Tota 1

$\mathrm{Na}$ avaliação do efeito de níveis de Al sobre a atividade da RN, utilizou-se o delineamento experimental de blocos casualizados com três repetiçôes, em esquema fatorial $(2 \mathrm{x} 5)$ tendo como tratamentos os dois genotipos (UPF7 e UPF86A1169-2b) e cinco níveis de alumínio $(0,10,20,30$ e 40 mg $A(/ 1)$.

A análise estatística dos resultados, aplicando-se o teste $F$, foi realizada segundo o seguinte quadro de análise de variância:

\begin{tabular}{cc}
\hline Causas de variação & G.L. \\
\hline Genótipos & 1 \\
Níveis de Alumínio & 4 \\
Genotipos x Níveis de Alumínio & 4 \\
Blocos & 2 \\
Resíduo & 18 \\
\hline Total & 29
\end{tabular}


4. RESUltados E Discussão

4.1. Determinaça da concentração de alumínio na soluçáo nutritiva, para classificaça de genótipos de aveia branca.

4.1.1. Comprimento inicial da raíz seminal (CIRS)

Pela análise de variância (teste F) não foram detectadas diferenças significativas ( $>>0,05)$ entre os niveis de aluminio, quanto ao comprimento inicial da raiz seminal (CIRS) (Tabela D1). Este resultado indica a uniformidade entre as plântulas no momento da implantação do experimento (Tabela 2). A interação genótipos $x$ niveis de aluminio, não foi significativa pelo teste $F$ ao nivel de $5 \%$ de significância, sendo significativa apenas a diferença na média dos genótipos avaliados quanto ao parâmetro CIRS.

$\mathrm{Na}$ média dos genótipos, verificou-se que os genótipos UPF5, UPF86A1198-5-1b, UPF79I174-3, UPF84057, UPF87107, UPF86Al169-2b e UPF86136, apresentam CIRS significativamente superior $(P<0,05)$ aos demais genótipos avaliados. 
Tabela 2: Comprimento inicial da raiz seminal (CIRS) de genótipos de aveia submetidos a cinco níveis de aluminio na solução nutritiva.

\begin{tabular}{|c|c|c|c|c|c|c|}
\hline \multirow[t]{2}{*}{ Genótipos } & \multicolumn{6}{|c|}{ Teores de aluminio (mg/l) } \\
\hline & 0 & 7,5 & 15,0 & 22,5 & 30,0 & Méd i $a^{\prime}$ \\
\hline \multicolumn{7}{|c|}{$----------\mathrm{cl}$} \\
\hline UPF5 & 6,84 & 7,23 & 6,84 & 6,74 & 6,47 & $6,82 \mathrm{a}$ \\
\hline UPF 86 A $1198-5-1 \mathrm{~b}$ & 6,29 & 7,02 & 6,55 & 6,74 & 5,96 & $6,51 \mathrm{a}$ \\
\hline UPF79I $174-3$ & 5,95 & 6,41 & 6,09 & 5,97 & 6,34 & $6,15 a b$ \\
\hline UPF 84057 & 5,90 & 6,09 & 5,83 & 5,86 & 5,92 & $5,92 a b$ \\
\hline UPF87107 & 6,03 & 5,86 & 5,63 & 5,91 & 5,91 & $5,87 a b$ \\
\hline UPF 86A $1169-2 b$ & 6,35 & 5,80 & 5,84 & 5,65 & 5,48 & $5,82 \mathrm{abc}$ \\
\hline UPF86136 & 5,55 & 6,00 & 5,64 & 5,96 & 5,92 & $5,82 \mathrm{abc}$ \\
\hline UPF 86071 & 5,56 & 6,16 & 5,29 & 5,88 & 4,44 & 5,46 bc \\
\hline UPF 86018 & 5,51 & 5,74 & 5,70 & 5,38 & 4,96 & 5,46 bc \\
\hline UPF 86112 & 5,04 & 5,04 & 5,96 & 5,67 & 5,16 & $5,37 \mathrm{bc}$ \\
\hline UPF 7 & 5,51 & 5,13 & 5,43 & 5,38 & 5,29 & $5,35 \mathrm{bc}$ \\
\hline UPF 86066 & 5,40 & 5,27 & 5,30 & 5,53 & 5,15 & $5,33 \mathrm{bc}$ \\
\hline UPF86011 & 5,37 & 5,57 & 5,34 & 4,92 & 4,87 & $5,22 \mathrm{bc}$ \\
\hline UPF 86045 & 5,31 & 5,17 & 5,16 & 5,07 & 5,19 & $5,18 \mathrm{bc}$ \\
\hline UPF86113 & 4,42 & 4,28 & 4,46 & 7,67 & 4,78 & 5,12 bc \\
\hline UPF $86 A 1264-1 b$ & 5,39 & 4,62 & 4,55 & 4,96 & 4,58 & 4,82 \\
\hline $\begin{array}{l}\text { Média } \\
\text { Tukey }(0,05) \text { Gen } \\
\text { Tukey }(0,05) \text { Niv } \\
\text { C.V. Genótipos } \\
\text { C.V. Niveis de A }\end{array}$ & $\begin{array}{l}5,65 \mathrm{~A} \\
\text { nótipos } \\
\text { veis de } \\
\text { (\%) } \\
\text { Al }(\%)\end{array}$ & $\begin{array}{l}5,71 \mathrm{~A} \\
(\mathrm{~ns}) \\
\text { Alumín }\end{array}$ & $\begin{array}{r}5,60 \mathrm{~A} \\
\mathrm{io}(\mathrm{ns})\end{array}$ & $5,83 \mathrm{~A}$ & $5,40 \mathrm{~A}$ & $\begin{array}{r}5,64 \\
4,03 \\
0,68 \\
4,32 \\
14,41\end{array}$ \\
\hline
\end{tabular}

- Médias seguidas da mesma letra, não diferem pelo teste de Tukey ao nível de $5 \%$ de significância 
A ausência de diferenças significativas no parâmetro CIRS, ao nivel de $5 \%$ de significância, entre niveis de alumínio, confere maior precisão à avaliação do efeito do Al sobre as plantas, através de parämetros relacionados com o crescimento de raizes.

\subsubsection{Comprimento final da raíz seminal (CFRS)}

Os resultados do parâmetro CFRS são apresentados na Tabela 3. A análise de variância mostrou diferenças significativas entre genótipos, níveis de aluminio na solução e para a interação genótipos $x$ níveis de alumínio, ao nível de $5 \%$ de significância. A média geral do experimento foi de $13,49 \mathrm{~cm}$, com um coeficiente de variaça para as parcelas de $6,41 \%$ e para as sub parcelas de $9,78 \%$. (Tabela D1).

Pela Tabela 3, verifica-se que no nível 0 de aluminio, os genótipos UPF86045; UPF86A1169-2b e UPF86112, sem diferir significativamente dos genótipos UPF86136, UPF 84057 e UPF 5 apresentaram CFRS significativamente superior aos demais genótipos. Mas apenas os genótipos UPF86A1169-2b, UPF 86136 e UPF 86045 apresentaram CFRS no grupo estatistico superior, em todos os niveis de aluminio.

Na mesma Tabela 3 , observa-se que no maior nível de Al (30 mg/l), os genótipos UPF86A1169-2b e UPF 86136 apesar de não diferirem dos genótipos UPF86045, UPF86A1 198-5-1b, UPF86011, UPF87107, UPF86112, UPF79I174-3, UPF84057, foram superiores aos demais genótipos avaliados.

A redução do parâmetro CFRS, com o aumento do nível de Al na solução, foi significativa para a maioria dos genótipos avaliados. Apenas os genótipos UPF86A1198-5-1b, UPF79I174-3, UPF86A1264-1b, UPF86113 e UPF86018, não sofreram 
redução significativa do CFRS entre os niveis 0 e 7,5 e apenas os genótipos UPF86A1198-5-1b, UPF86A1264-1b e UPF86018, não diferiram entre os niveis 0 e 15 . O genotipo UPF86Al264-1b, não diferiu quanto ao parâmetro CFRS para os cinco niveis de Al testados (Tabela 3), pelo teste de Tukey, ao nível de $5 \%$ de significância.

Como a interaça genótipo $x$ nivel foi significativa, a análise de variância foi desdobrada, fixando-se o fator genótipos e realizando-se a análise de regressão polinomial. Considerou-se a regressão significativa de maior grau (Tabela 4), ao nível de $1 \%$ de significância.

Para os genótipos UPF79I174-3, UPF86018, UPF86066, UPF86113, UPF86A1264-1b, UPF87107 e UPF7, o parâmetro CFRS decresceu de forma linear, enquanto os demais genotipos, apresentaram efeito conforme a regressão quadrática.

O genótipo UPF86A1198-5-1b foi o unico que apresentou aumento inicial do parâmetro CFRS com o aumento da concentração de alumínio na solução, expresso de forma quadrática, apresentando um valor máximo no nível $13,8 \mathrm{mg}$ Al/litro de solução.

\subsubsection{Comprimento final relativo da raiz seminal (CFRRS)}

A análise de variância desse parâmetro mostrou diferenças significativas entre genótipos, niveis de alumínio e para a interação entre genótipos e níveis de alumínio. A média geral foi de $67,89 \%$, com um coeficiente de variação 
$\frac{0}{0} \frac{0}{0}$

告

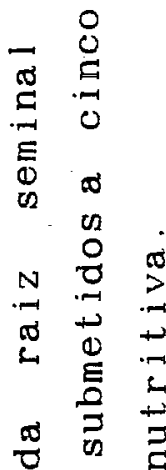

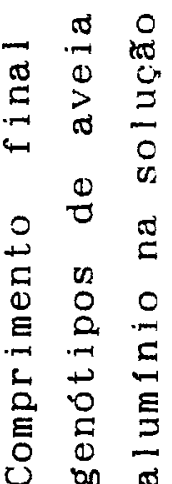

$\dot{2}$

$\frac{\infty}{2}$

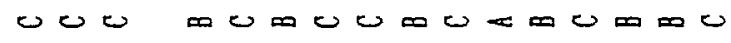

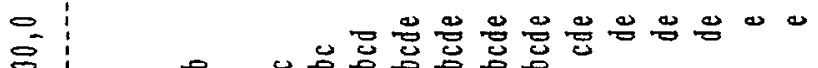

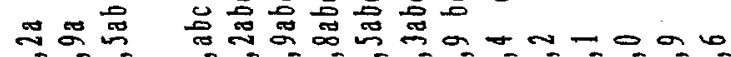

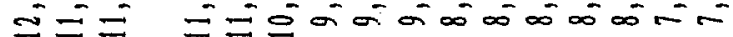

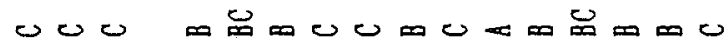

$\approx$

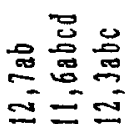

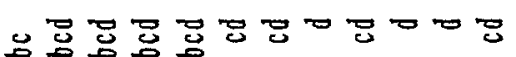

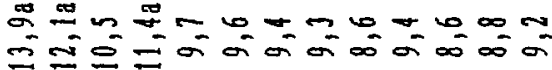

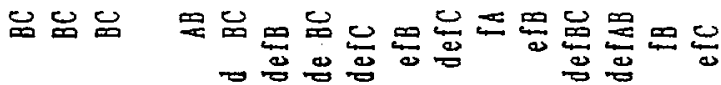
$=$

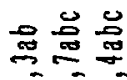
$-5=$ $\approx$ 营 0

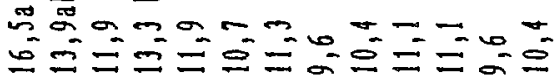

$\infty \infty$

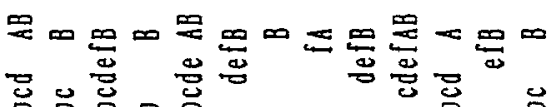

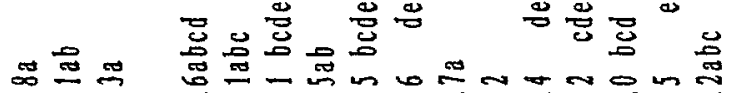

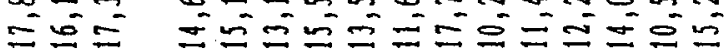
$+\frac{1}{2}$

○

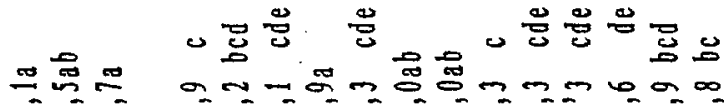

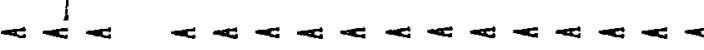

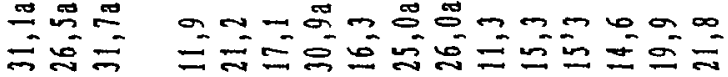

$\underset{1}{2}$

总 $\frac{2}{6} 8$

$\stackrel{5}{\infty}$

की

음

空

要

$\underset{8}{8}$

:

昰

$\underset{2}{2}$

$\approx-$

응 $\pm-$

뚱 8 용

8
9
$=0$

$\stackrel{\square}{\square}$ 量

$\underline{z}$

$\div$ 웅

赵

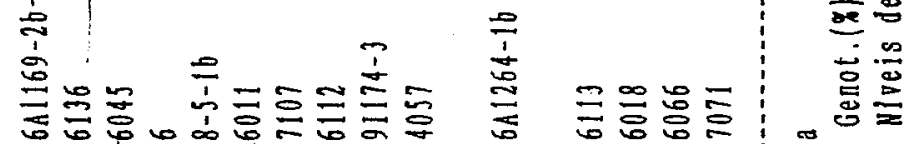

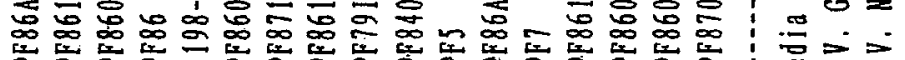

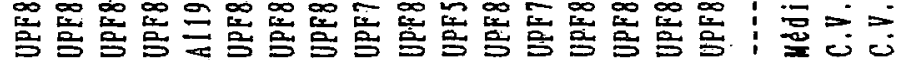


56.

para os genótipos de $6,34 \%$ e para os níveis de Al de $9,34 \%$ (Tabela D1).

Tabela 4: Equaçōes de regressão polinomial, coeficiente de determinação $\left(R^{2}\right)$ e valores máximo ou mínimo, para efeito de niveis de Alumínio ( $X$ ) sobre" o parâmetro CFRS ( $Y$ ) de genótipos de aveia branca.

Genót i pos

Equações

$\mathrm{R}^{2}$

(\%)

Máx./

mín.

\begin{tabular}{llcc}
\hline UPF79I174-3 & $Y=15,66-0,23 \mathrm{X}$ & $94,10 * *$ & - \\
UPF84057 & $\mathrm{Y}=23,67-1,44 \mathrm{X}+0,03 \mathrm{X}^{2}$ & $90,70 * *$ & 24,0 \\
UPF86011 & $\mathrm{Y}=20,72-0,68 \mathrm{X}+0,01 \mathrm{X}^{2}$ & $96,30 * *$ & 34,0 \\
UPF86018 & $\mathrm{Y}=14,93-0,25 \mathrm{X}$ & $94,80 * *$ & - \\
UPF86045 & $\mathrm{Y}=30,56-1,68 \mathrm{X}+0,036 \mathrm{X}^{2}$ & $95,60 * *$ & 23,3 \\
UPF86066 & $\mathrm{Y}=16,45-0,34 \mathrm{X}$ & $69,30 * *$ & - \\
UPF86112 & $\mathrm{Y}=29,42-1,68 \mathrm{X}+0,035 \mathrm{X}^{2}$ & $93,50 * *$ & 24,0 \\
UPF86113 & $\mathrm{Y}=14,63-0,23 \mathrm{X}$ & $96,13 * *$ & - \\
UPF86136 & $\mathrm{Y}=25,68-1,19 \mathrm{X}+0,02 \mathrm{X}^{2}$ & $95,47 * *$ & 29,8 \\
UPF86A1169-2b & $\mathrm{Y}=30,05-1,54 \mathrm{X}+0,032 \mathrm{X}^{2}$ & $95,77 * *$ & 24,1 \\
UPF86A1198-5-1b & $\mathrm{Y}=11,86+0,55 \mathrm{X}-0,02 \mathrm{X}^{2}$ & $93,98 * *$ & 13,8 \\
UPF86A1264-1b & $\mathrm{Y}=11,14-0,09 \mathrm{X}$ & $96,82 * *$ & - \\
IPF87071 & $\mathrm{Y}=21,68-0,98 \mathrm{X}+0,017 \mathrm{X}^{2}$ & $99,31 * *$ & 28,8 \\
UPF87107 & $\mathrm{Y}=15,70-0,20 \mathrm{X}$ & $79,98 * *$ & - \\
UPF5 & $\mathrm{Y}=26,06-1,34 \mathrm{X}+0,03 \mathrm{X}^{2}$ & $99,78 * *$ & 22,3 \\
UPF7 & $\mathrm{Y}=14,22-0,23 \mathrm{X}$ & $89,25 * *$ & - \\
& & &
\end{tabular}

** significativo ao nível de $1 \%$ 
57.

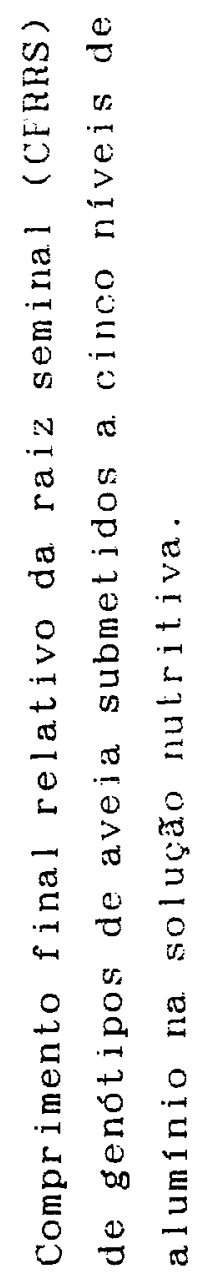

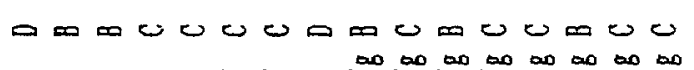

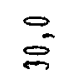

م.

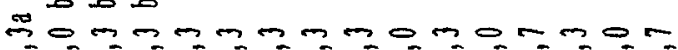

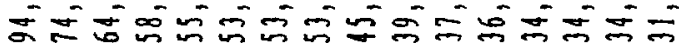

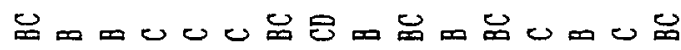

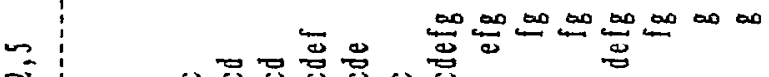

$\approx$

D20-000m-

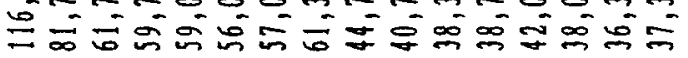

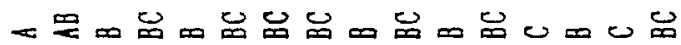

0

J

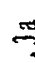

2000-0-0000-1000

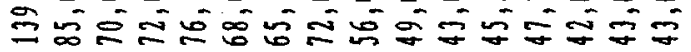

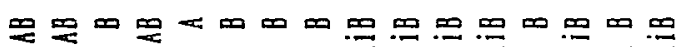

म

$\infty$

Ð

-mmo-000Nmmmomo

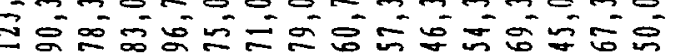

$\approx \approx$

$=\infty$ on $^{\circ}$

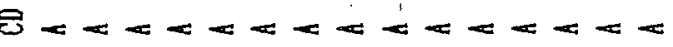

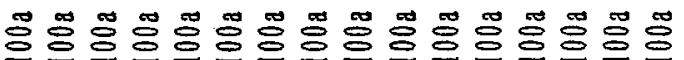

10

$\frac{0}{1}=$

$\frac{\pi}{\infty}$

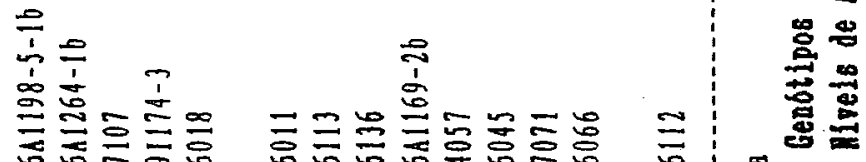

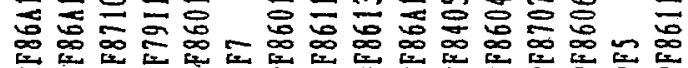


o genótipo UPF86Al198-5-1b apresentou o parâmetro CFRRS superior aos demais genótipos em todos os níveis de aluminio utilizados (Tabela 5).

O efeito da interação genótipos $x$ níveis de alumínio, foi desdobrado através da regressão polinomial, sendo que as equações obtidas para cada genótipo e seu respectivo coeficiente de determinação $\left(R^{2}\right)$, são apresentados nà Tabela 6 .

Considerando-se os genótipos que se destacaram quanto ao parâmetro CFRRS no maior nivel de Al, observa-se que o comportamento foi praticamente o mesmo quando considera-se as regressões do parâmetro CFRS, excetuando-se o genótipo UPF86066, que apresenta efeito quadrático.

o genótipo UPF86Al198-5-1b apresentou acréscimo inicial no parâmetro CFRRS em função do aumento do nível de alumínio, expresso através de uma equaça quadrática, com máximo no nível de $24,1 \mathrm{mg}$ Al/litro da solução.

4.1.4. Crescimento da raíz seminal (CRS)

A análise de variância deste parâmetro mostrou diferenças altamente significativas $(P<0,01)$ pelo teste $F$, entre genstipos, níveis de alumínio e para a interação genótipo $x$ níveis de alumínio (Tabela D1). A média geral foi de $7,93 \mathrm{~cm}$ e o coeficiente de variação para genótipos foi de $10,77 \%$ sendo para níveis de Al de $12,44 \%$.

Como a interação genótipos $x$ niveis de alúmínio foi significativa, realizou-se o desdobramento, fixando os níveis de alumínio, para avaliar melhor o comportamento dos genótipos em cada nível. 
Tabela 6: Equações de regressão polinomial, coeficientes de determinação $\left(R^{2}\right)$ e valores máximo ou mínimo, para o efeito do nível de alumínio ( $X$ ) sobre o parâmetro CFRRS $(Y)$ de genótipos de aveia branca.

\begin{tabular}{llcc}
\hline Genótipos & Equações & $\begin{array}{c}\mathrm{R}^{2} \\
(\%)\end{array}$ & $\begin{array}{c}\text { Máx.' } \\
\mathrm{m} 1 \mathrm{n} .\end{array}$ \\
\hline UPF791174-3 & $\mathrm{Y}=96,00-1,42 \mathrm{X}$ & $94,20 * *$ & - \\
UPF84057 & $\mathrm{Y}=94,52-5,74 \mathrm{X}+0,13 \mathrm{X}^{2}$ & $90,60 * *$ & 22,1 \\
UPF86011 & $\mathrm{Y}=97,60-3,22 \mathrm{X}+0,06 \mathrm{X}^{2}$ & $96,10 * *$ & 26,8 \\
UPF86018 & $\mathrm{Y}=102,93-1,69 \mathrm{X}$ & $94,44 * *$ & - \\
UPF86045 & $\mathrm{Y}=96,22-5,28 \mathrm{X}+0,112 \mathrm{X}^{2}$ & $95,40 * *$ & 23,6 \\
UPF86066 & $\mathrm{Y}=94,06-5,72 \mathrm{X}+0,129 \mathrm{X}^{2}$ & $89,60 * *$ & 22,2 \\
UPF86112 & $\mathrm{Y}=95,12-5,42 \mathrm{X}+0,114 \mathrm{X}^{2}$ & $93,10 * *$ & 23,8 \\
UPF86113 & $\mathrm{Y}=95,40-1,49 \mathrm{X}$ & $95,80 * *$ & - \\
UPF86136 & $\mathrm{Y}=96,88-4,46 \mathrm{X}+0,09 \mathrm{X}^{2}$ & $95,00 * *$ & 24,8 \\
UPF86A1169-2b & $\mathrm{Y}=96,65-4,97 \mathrm{X}+0,104 \mathrm{X}^{2}$ & $96,00 * *$ & 23,9 \\
UPF86A1198-5-1b & $\mathrm{Y}=99,68+7,70 \mathrm{X}-0,16 \mathrm{X}^{2}$ & $94,03 * *$ & 24,1 \\
UPF86A1264-1b & $\mathrm{Y}=98,33-0,81 \mathrm{X}$ & $97,27 *$ & - \\
IPF87071 & $\mathrm{Y}=99,29-4,49 \mathrm{X}+0,08 \mathrm{X}^{2}$ & $99,28 * *$ & 28,1 \\
UPF87107 & $\mathrm{Y}=92,47-1,17 \mathrm{X}$ & $81,30 * *$ & - \\
UPF5 & $\mathrm{Y}=99,92-5,16 \mathrm{X}+0,10 \mathrm{X}^{2}$ & $99,71 * *$ & 25,8 \\
UPF7 & $\mathrm{Y}=92,93-1,50 \mathrm{X}$ & $90,03 * *$ & - \\
\hline
\end{tabular}

* e ** significativos respectivamente, aos niveis de 5 e $1 \%$ Na Tabela 7 observou-se que, no nível 0 de 
alumínio, o parâmetro CRS dos genótipos UPF86045 e UPF86112, sem diferir do genótipo UPF 86Al169-2b foram superiores aos demais genótipos avaliados $(P<0,05)$. Os genótipos UPF 86Al169-2b e UPF86045 mantiveram-se no grupo estatístico superior em todos os níveis de aluminio. Os genótipos UPF86011 e UPF86136, apesar de não apresentarem bom crescimento da raiz seminal na ausência do aluminio, destacam-se na presença do mesmo. Por outro lado, os genótipos UPF86045 e UPF86A1169-2b, mostraram-se não responsivos, pois sofreram uma redução significativa nesse parâmetro com o aumento da concentração de Al de 0 para $7,5 \mathrm{mg} / 1$.

- genotipo UPF86A1198-5-1b apresentou um aumento no CRS, com o aumento da concentração de alumínio na solução nutritiva. O menor crescimento da raiz seminal na ausência de alumínio, poderia ser atribuído ao efeito de toxicidade de algum nutriente da solução, cuja ação seria reduzida com a presença de alumínio, pois esta toxicidade evidenciou-se pelo enrolamento das raizes, observado principalmente no nível 0 de alumínio. Com o aumento de concentração de alumínio, este sintoma diminuiu e não foi observado nos níveis 22,5 e $30 \mathrm{mg}$ Al/litro de solução. Este comportamento também îoi observado por KARATAGLIS (1987), com o cultivar de aveia Kassandra, tolerante ao alumínio. Segundo esse autor, as baixas concentrações de Al estimularam a atividade da esterase, possibilitando uma melhor utilização do $P$, com reflexos positivos no crescimento das plantas.

Na Tabela 8 são apresentadas as equações de regressão polinomial e seus respectivos coeficientes de 


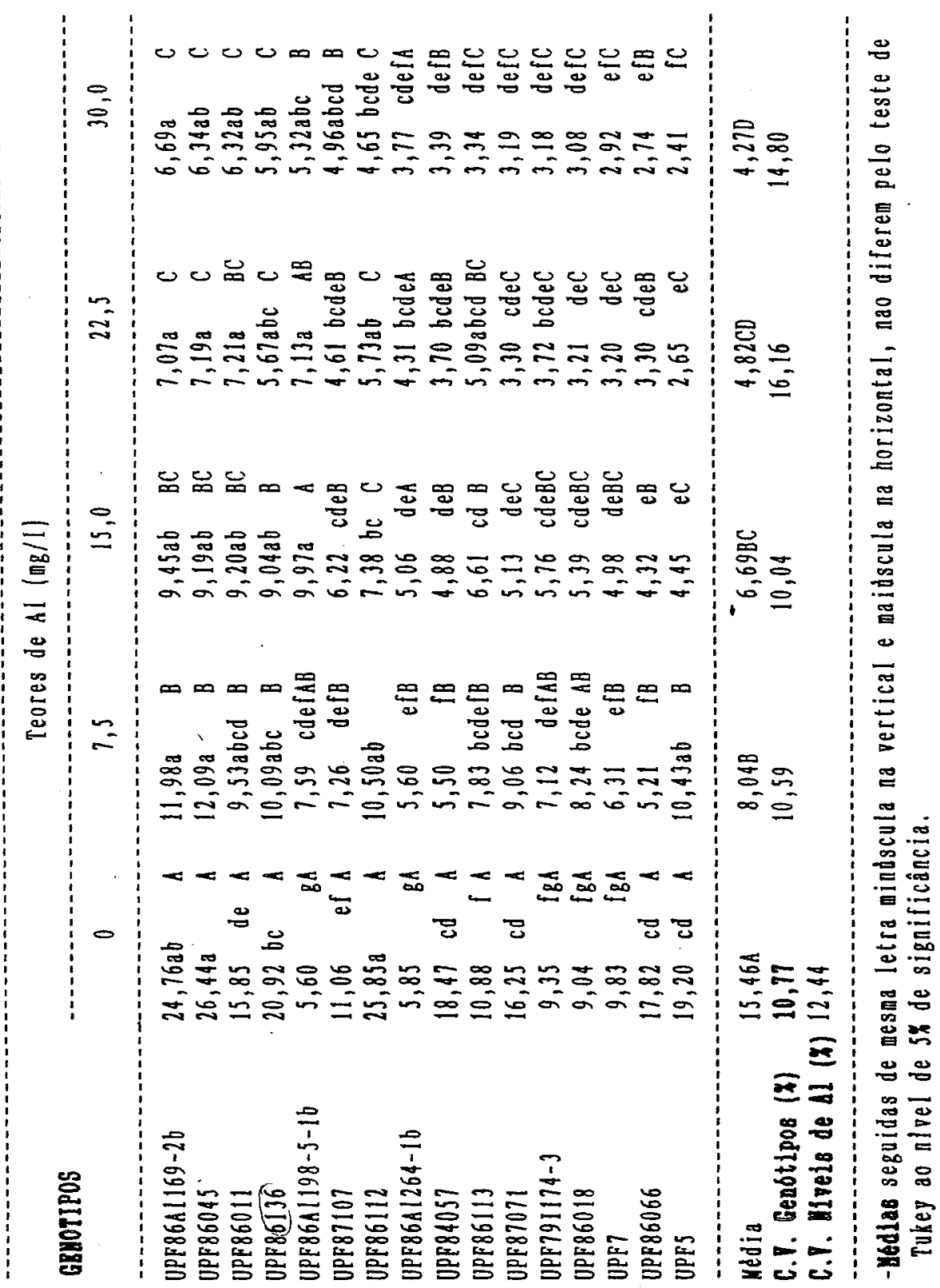


determinação para o desdobramento da interação genotipos $\mathrm{x}$ niveis de alumínio. Observa-se que apenas nos genótipos UPF87107, UPF791174-3, UPF86018, UPF86113, UPF7 e UPF867A1264-1b o crescimento da raíz seminal (CRS) decresceu I inearmente com o aumento da concentração de alumínio na solução. Porém no genótipo UPF86Al264-1b a regressão foi menos significativa, com um coeficiente angular menor.

Nos genótipos mais tolerantes em todos os níveis de aluminio, verifica-se que para UPF86Al169-2b, UPF86011, UPF86045 e UPF86136, o CRS se expressou de forma quadrática, com valores mínimos, respectivamente, de 25,0, $5,3,20,8,20,3$. No genótipo UPF86A1198-5-1b, observou-se uma equação quadrática, com um valor máximo no nível de 11,8 mg Al/litro de solução.

\subsubsection{Crescimento relativo da raíz seminal (CRRS)}

A análise de variância deste parâmetro, mostrou diferenças significativas entre os genótipos, niveis de alumínio e para a interação genótipos $x$ níveis de alumínio (Tabela D1). A média geral foi de $57,98 \%$ e o coeficiente de variaça para genótipos foi de $11,71 \%$ e para os niveis de alumínio de $16,86 \%$.

Em relação ao desempenho dos genótipos em cada nivel de alumínio, verificou-se que o genótipo UPF86Al198-5-1b foi superior $(P<0,05)$ aos demais genótipos avaliados (Tabela 9). Este comportamento é semelhante ao verificado para o parâmetro CFRRS (Tabela 5).

Quanto ao efeito dos níveis de aluminio em cada genótipo, verificou-se que, com exceção dos genótipos UPF86A1264-1b, UPF79I174-3 e UPF86018, houve uma redução significativa do parâmetro CRRS entre os níveis 0 e 7,5 mg Al/l (Tabela 9). 
Tabela 8. Equações de regressão polinomial, coeficientes de determinação $\left(R^{2}\right)$ e valores máximo ou mínimo, para o efeito de niveis de alumínio ( $X$ ) sobre o parâmetro CRS(Y) ou genótipos de aveia branca

\begin{tabular}{llcc}
\hline Genótipos & Equações & $\begin{array}{c}\mathrm{R}^{2} \\
(\%)\end{array}$ & $\begin{array}{c}\text { Máx.' } \\
\mathrm{m} \text { ín. }\end{array}$ \\
\hline UPF791174-3 & $\mathrm{Y}=8,98-0,21 \mathrm{X}$ & $97,00 * *$ & - \\
UPF84057 & $\mathrm{Y}=17,12-1,37 \mathrm{X}+0,03 \mathrm{X}^{2}$ & $90,10 * *$ & 22,8 \\
UPF86011 & $\mathrm{Y}=15,21-0,64 \mathrm{X}+0,06 \mathrm{X}^{2}$ & $92,90 * *$ & 5,3 \\
UPF86018 & $\mathrm{Y}=9,18-0,23 \mathrm{X}$ & $93,50 * *$ & - \\
UPF86045 & $\mathrm{Y}=25,25-1,66 \mathrm{X}+0,04 \mathrm{X}^{2}$ & $95,50 * *$ & 20,8 \\
UPF86066 & $\mathrm{Y}=16,52-1,34 \mathrm{X}+0,03 \mathrm{X}^{2}$ & $90,60 * *$ & 22,3 \\
UPF86112 & $\mathrm{Y}=24,54-1,77 \mathrm{X}+0,04 \mathrm{X}^{2}$ & $95,00 * *$ & 22,1 \\
UPF86113 & $\mathrm{Y}=10,33-0,24 \mathrm{X}$ & $97,50 * *$ & - \\
UPF86136 & $\mathrm{Y}=20,05-1,22 \mathrm{X}+0,03 \mathrm{X}^{2}$ & $94,50 * *$ & 20,3 \\
UPF86A1169-2b & $\mathrm{Y}=23,77-1,50 \mathrm{X}+0,03 \mathrm{X}^{2}$ & $96,00 * *$ & 25,0 \\
UPF86A1198-5-1b & $\mathrm{Y}=5,50+0,47 \mathrm{X}-0,02 \mathrm{X}^{2}$ & $85,20 * *$ & 11,8 \\
UPF86A1264-1b & $\mathrm{Y}=6,06-0,08 \mathrm{X}$ & $98,70 *$ & - \\
IPF87071 & $\mathrm{Y}=16,09-1,04 \mathrm{X}+0,02 \mathrm{X}^{2}$ & $99,80 * *$ & 26,0 \\
UPF87107 & $\mathrm{Y}=9,79-0,20 \mathrm{X}$ & $82,00 * *$ & - \\
UPF5 & $\mathrm{Y}=19,13-1,36 \mathrm{X}+0,03 \mathrm{X}^{2}$ & $99,80 * *$ & 22,7 \\
UPF7 & $\mathrm{Y}=8,83-0,23 \mathrm{X}$ & $90,70 * *$ & -
\end{tabular}

* e ** significativos respectivamente, aos níveis de 5 e $1 \%$

Também em relação a esse parâmetro observou-se que o genótipo: UPF86Al198-5-1b apresentou aumentos significativos com o aumento da concentração de aluminio da solução nos niveis $7,5,15$ e $22,5 \mathrm{mg} / \mathrm{l}$, quando relacionado com o nível 0 , que não diferiu $(P>0,05)$ do nível $30 \mathrm{mg} \mathrm{Al/l}$. 


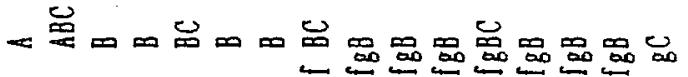

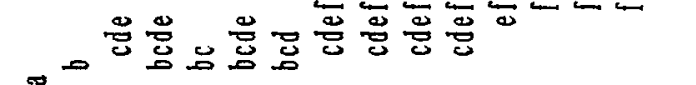
$9=-3=-2=-2=0=3=$

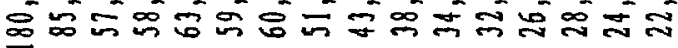

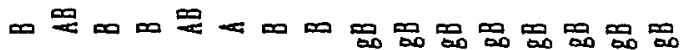

$=$

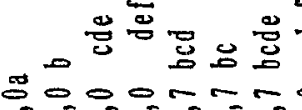
क्ष

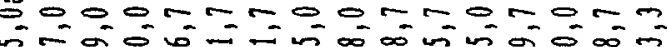

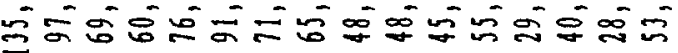


Para os demais genótipos avaliados, houve efeito depressivo significativo do alumínio sobre o crescimento da raiz seminal, inclusive no nivel $7,5 \mathrm{mg} \mathrm{Al/l}$ para as linhagens UPF86A1264-1b (3\%), UPF79I174-3 (23\%), UPF86018 (8,3\%). O genótipo UPF86A1264-1b também não sofreu inibição significativa no nivel de $15 \mathrm{mg} \mathrm{Al/l,} \mathrm{enquanto} \mathrm{nos}$ demais niveis a redução. de crescimento foi significativa ao nivel de $5 \%$ de significância.

No maior nivel de alumínio da solução (30 mg/l), em relação ao nível 0 de Al, a menor redução foi de $5 \%$ para o genótipo UPF86A1198-5-1b e a maior para o genótipo UPF5 (87,7\%). Na média dos genótipos avaliados, a inibição do parâmetro CRRS foi de $36,6 \%$ para o nível $7,5,45,8 \%$ para o $15,61,2 \%$ para o 22,5 e $66,5 \%$ para o nível $30 \mathrm{mg}$ Al/litro de sol ução.

A interação genótipos $x$ niveis de alumínio foi desdobrada através da regressão polinomial (Tabela 10). Observa-se nessa tabela que nos genótipos mais tolerantes, a redução no crescimento da raíz seminal, devido ao alumínio, se manifestou de forma quadrática. Já nos genótipos mais sensíveis, esta depressão foi I inear.

Nas Figuras 1 a 16 são apresentadas as regressões lineares ou quadráticas, obtidas em função do efeito do alumínio sobre os parâmetros CRS, CFRS, CRRS e CFRRS nos dezesseis genótipos avaliados.

Quanto aos sintomas visuais, verificou-se no transcorrer do experimento, nos genótipos mais sensiveis, o aparecimento de sintomas típicos de deficiência de magnésio, que ocorreu a partir do sétimo dia de cultivo nas soluções com aluminio, acentuando-se em função do aumento da concentração. Este sintoma não foi verificado nos genótipos UPF86045, UPF86136 e UPF86A1169-2b nos niveis de 7,5 e $15,0 \mathrm{mg} \mathrm{Al/1}$. Já no nível de $22,5 \mathrm{mg} \mathrm{Al/1,} \mathrm{somente} \mathrm{o}$ 
Tabela 10: Equações de regressão polinomial, coeficientes de determinação $\left(R^{2}\right)$ e valores máximo ou mínimo, para o efeito de níveis de alumínio (X) sobre o parâmetro CRRS(Y) em genótipos de aveia branca.

Genótipos

Equações

$\mathrm{R}^{2}$

Máx./

(\%)

mín.

UPF79I174-3

$\mathrm{Y}=96,40-2,21 \mathrm{X}$

$97,6 * *$

UPF 84057

UPF 86011

$Y=92,66-7,42 X+0,17 X^{2}$

$90,0 * *$

21,8

UPF 86018

$\mathrm{Y}=95,93-4,00 \mathrm{X}+0,07 \mathrm{X}^{2}$

$92,6 * *$

28,6

UPF 86045

$\mathrm{Y}=101,87-2,52 \mathrm{X}$

$93,3 * *$

$\mathrm{Y}=95,54-6,31 \mathrm{X}+0,13 \mathrm{X}^{2}$

$95,5 * *$

24,3

UPF 86066

$Y=92,58-7,55 X+0,17 X^{2}$

$90,4 * *$

22,2

UPF 86112

$\mathrm{Y}=94,75-6,86 \mathrm{X}+0,15 \mathrm{X}^{2}$

$94,7 * *$

22,9

UPF 86113

$\mathrm{Y}=94,67-2,19 \mathrm{X}$

$97,2 * *$

UPF 86136

$\mathrm{Y}=95,75-5,81 \mathrm{X}+0,12 \mathrm{X}^{2}$

$94,3 * *$

24,2

UPF 86A1169-2b

$\mathrm{Y}=96,04-6,02 \mathrm{X}+0,13 \mathrm{X}^{2}$

$96,1 * *$

23,2

UPF86A $1198-5-1 b$

$\mathrm{Y}=97,83+8,62 \mathrm{X}-0,30 \mathrm{X}^{2}$

$83,7 * *$

14,4

UPF 86A $1264-1 \mathrm{~b}$

$\mathrm{Y}=103,27-1,32 \mathrm{X}$

$96,8 *$

IPF 87071

$\mathrm{Y}=98,72-6,40 \mathrm{X}+0,13 \mathrm{X}^{2}$

$99,7 * *$

24,6

UPF 87107

$\mathrm{Y}=90,00-1,80 \mathrm{X}$

$84,9 * *$

$\mathrm{Y}=99,40-7,13 \mathrm{X}+0,14 \mathrm{X}^{2}$

$99,7 * *$

25,5

UPF7

$\mathrm{Y}=90,20-2,30 \mathrm{X}$

$91,0 * *$

* e** significativos respectivamente, aos níveis de 5 e $1 \%$ genótipo UPF86A1 169-2b não apresentou o sintoma, apesar de apresentar uma clorose intensa. No nível máximo de alumínio, todos os genótipos avaliados apresentaram sintomas de crestamento na parte aérea.

Além da redução no comprimento da raíz seminal, verificou-se uma diminuição no número de raízes secundárias com o aumento da concentração de alumínio na solução. 
67 .

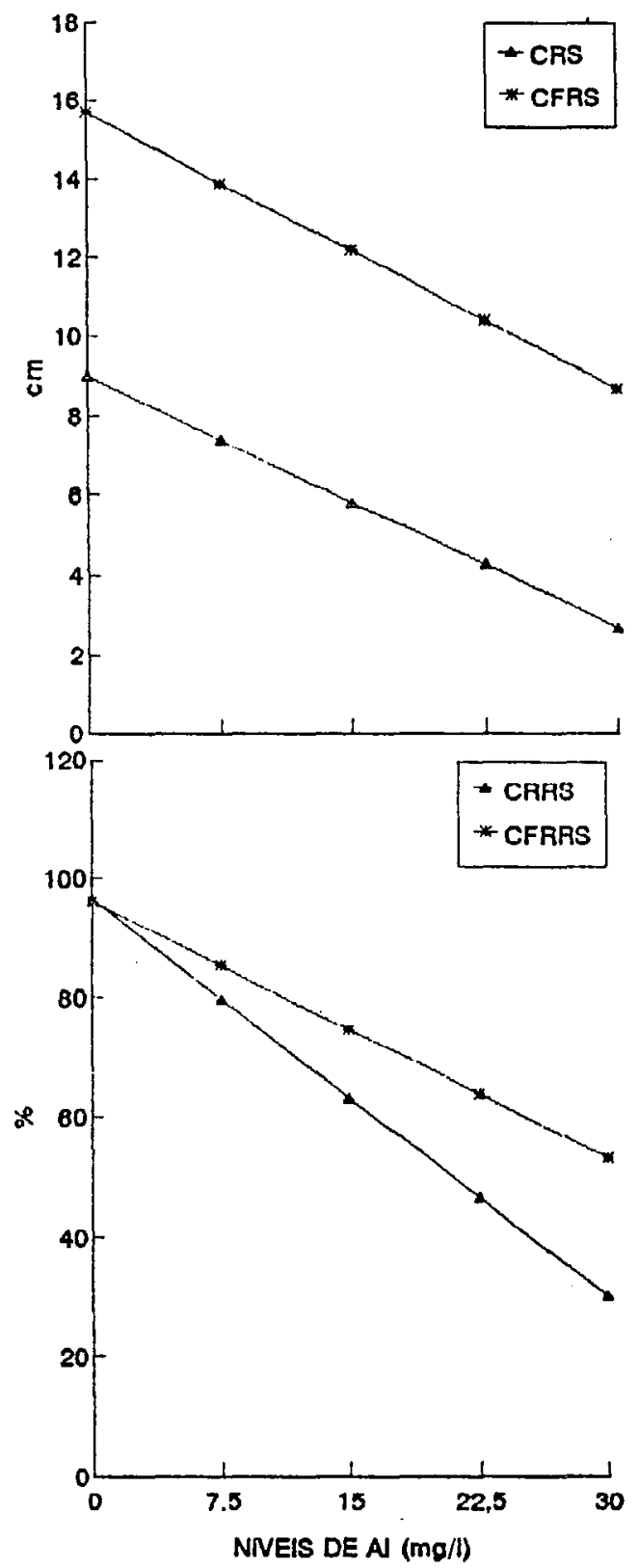

Figura 1. Comportamento dos parâmetros CRS / CFRS e CRRS / CFRRS em função dos niveis de alumínio, para o genótipo UPF79I174-3. 
68.

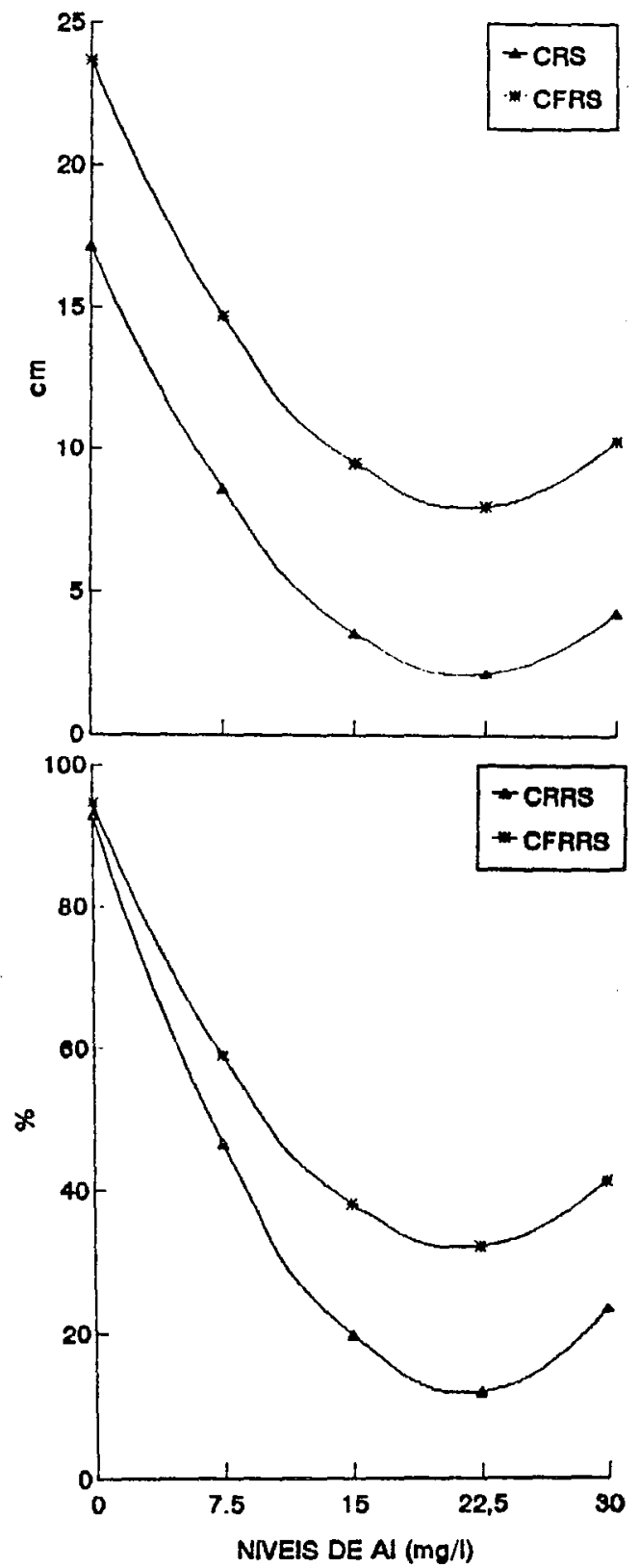

Figura 2: Comportamento dos parâmetros CRS / CFRS e CRRS / CFRRS em função dos níveis de alumínio, para o genót i po UPF84057. 
69.

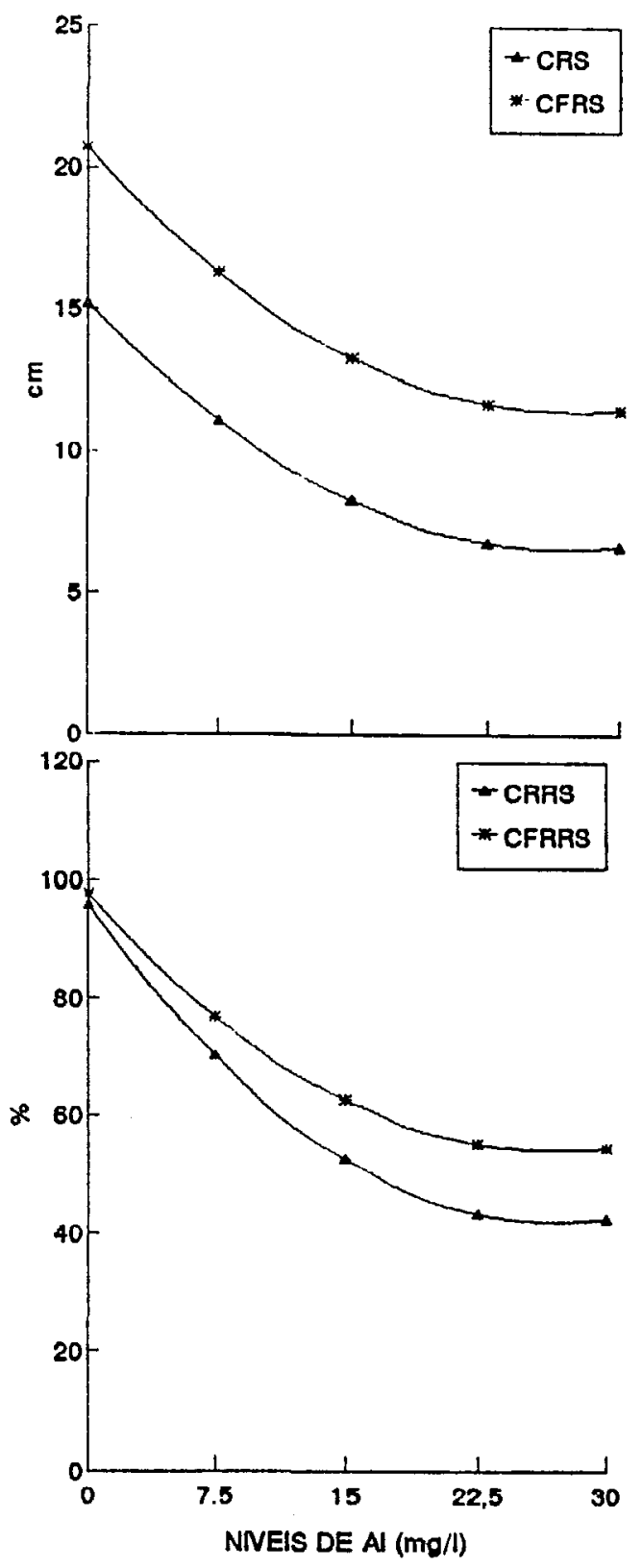

Figura 3. Comportamento dos parâmetros CRS / CFRS e CRRS / CFRRS em função dos níveis de alumínio, para o genót i po UPF86011. 
70 .

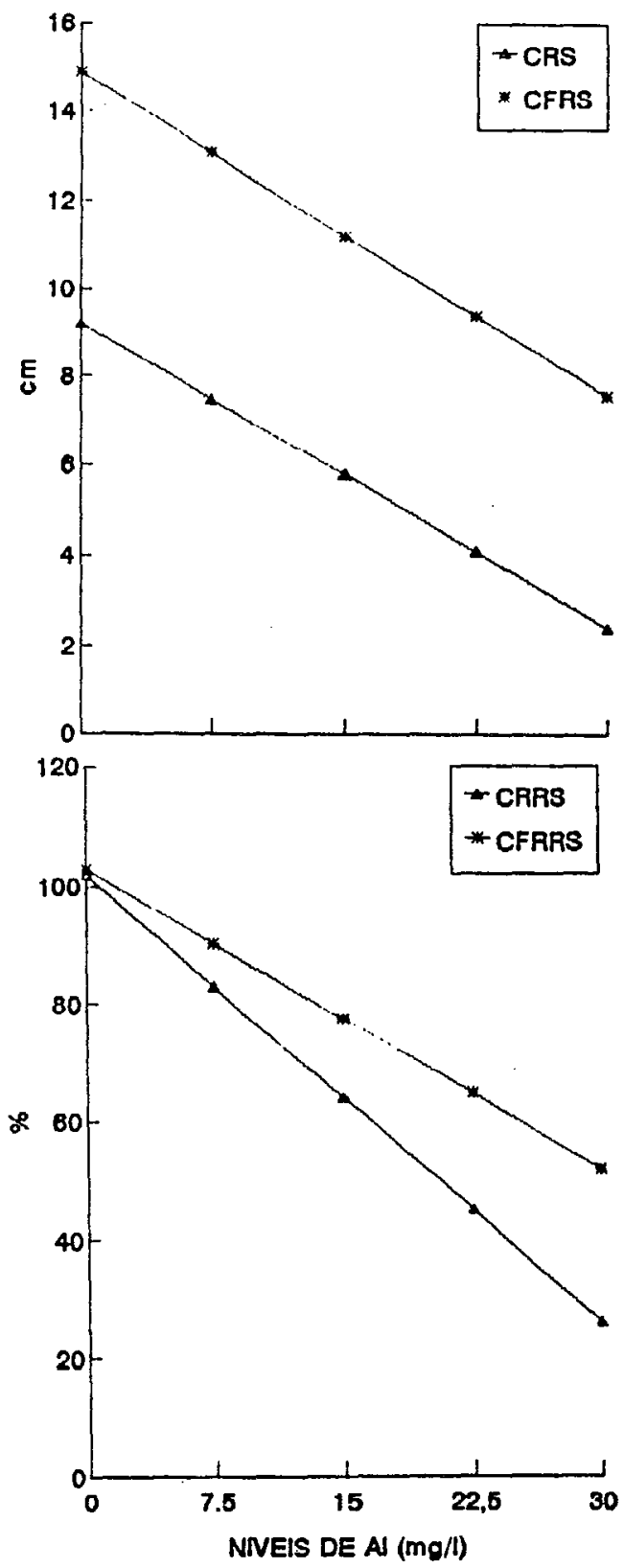

Figura 4. Comportamento dos parâmetros CRS / CFRS e CRRS / CFRRS em função dos níveis de alumínio, para o genót i po UPF86018. 


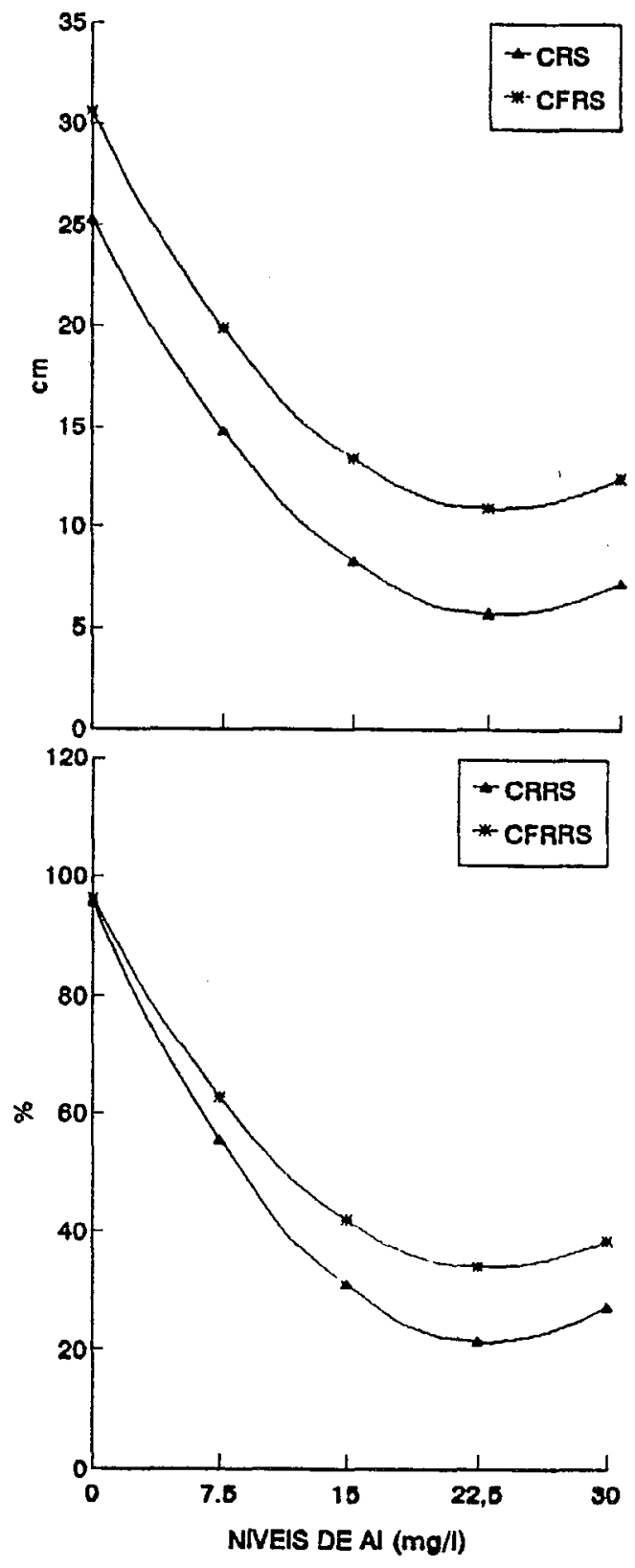

Figura 5. Comportamento dos parâmetros CRS / CFRS e CRRS / . CFRRS em função dos níveis de alumínio, para o genót i po UPF 86045 . 
72 .

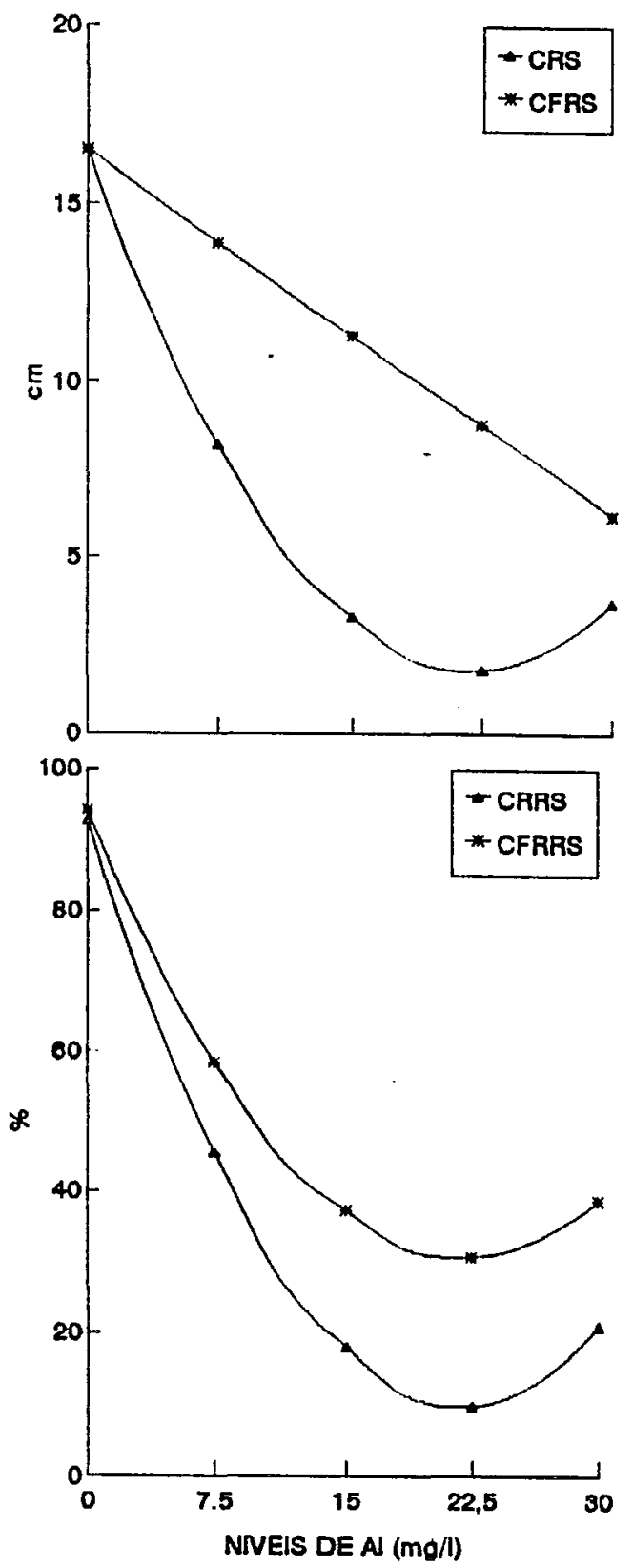

Figura 6. Comportamento dos parâmetros CRS / CFRS e CRRS / CFRRS em função dos níveis de alumínio, para o genót ipo UPF86066. 


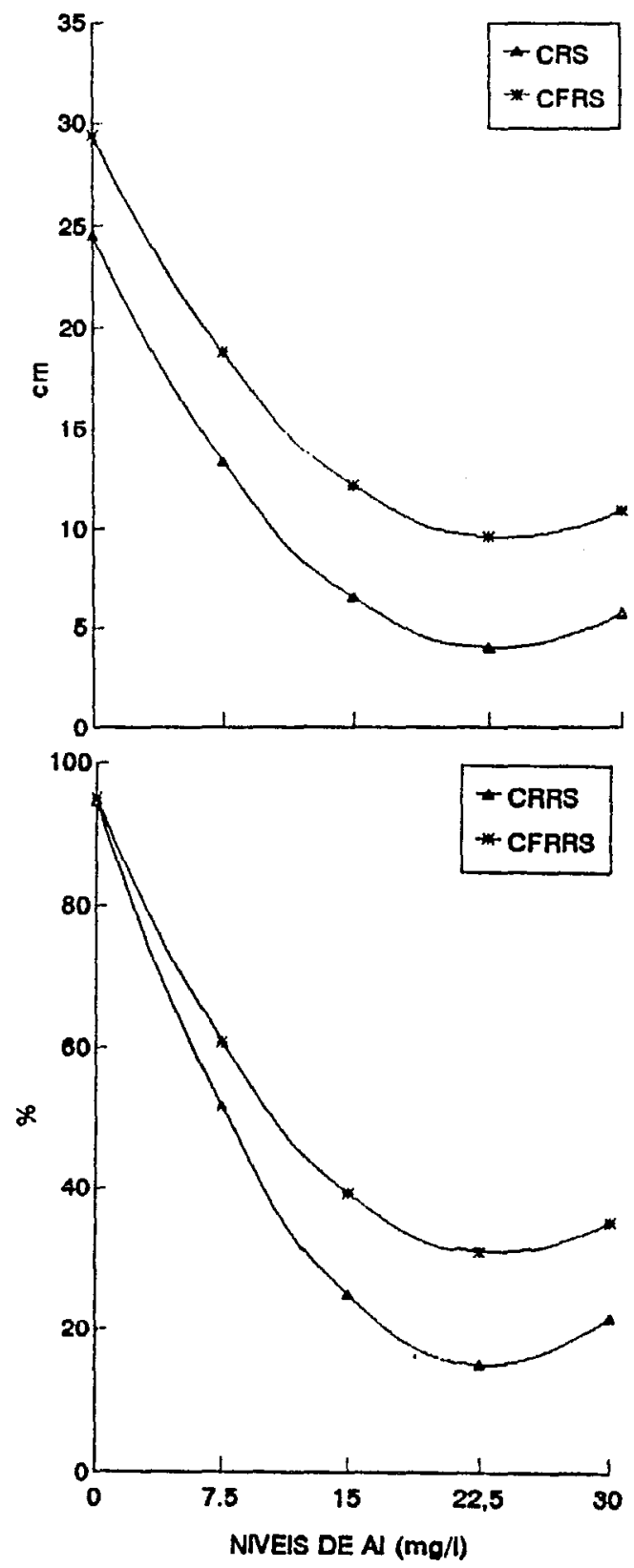

Figura 7. Comportamento dos parâmetros CRS / CFRS e CRRS / CFRRS em função dos níveis de alumínio, para o genót i po UPF86112. 


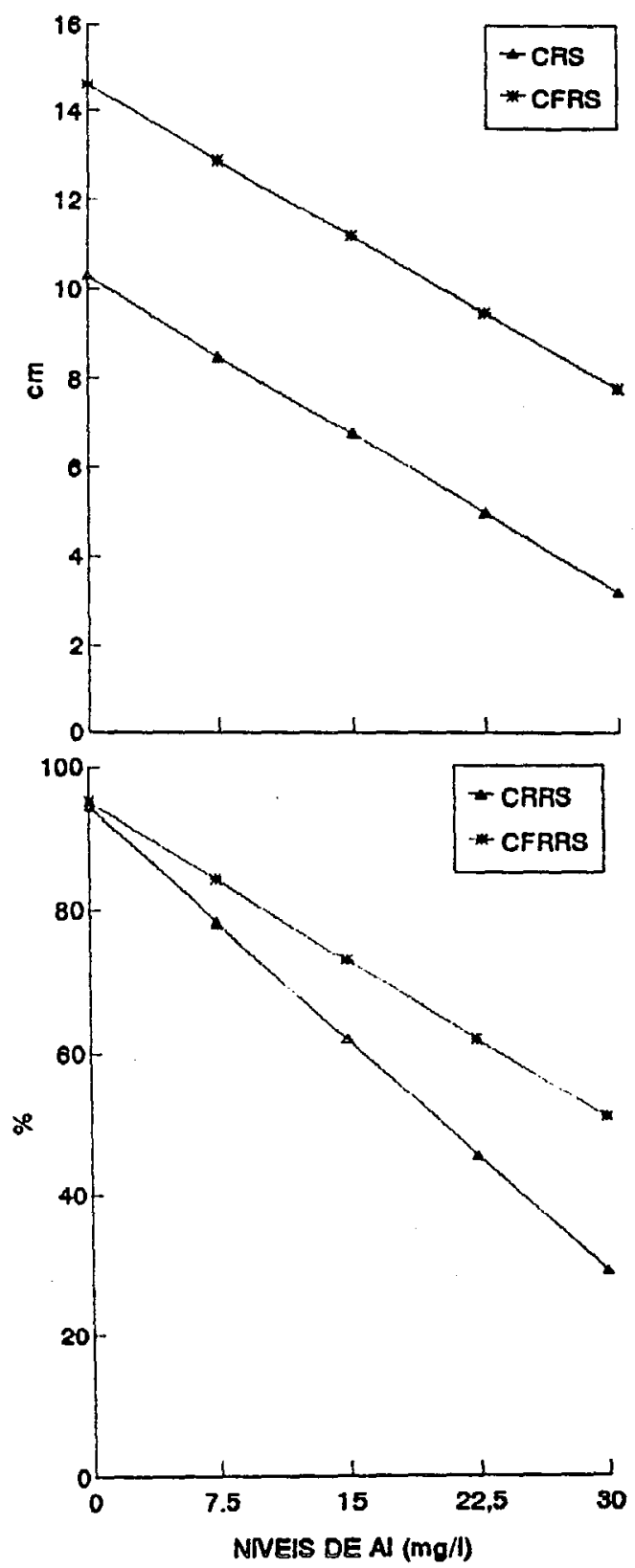

Figura 8. Comportamento dos parâmetros CRS / CFRS e CRRS / CFRRS em funça dos niveis de aluminio, para o genót i po UPF86113. 


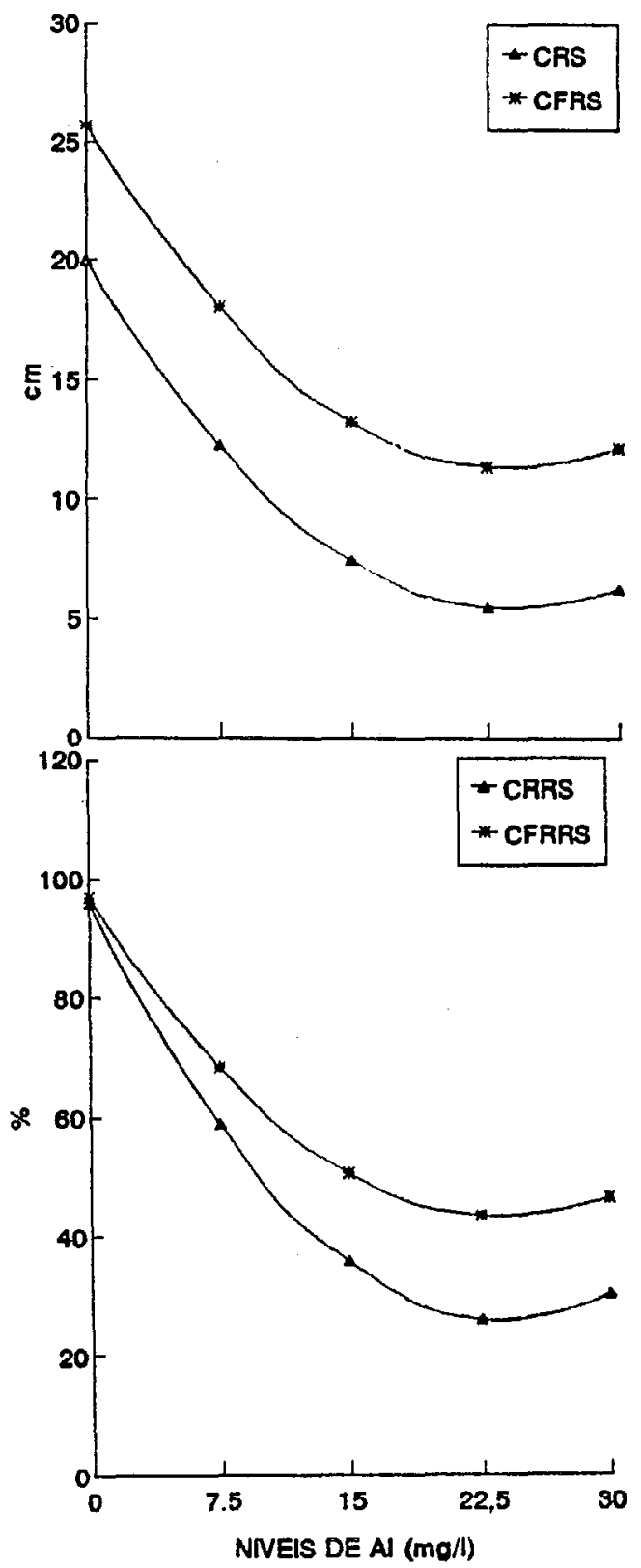

Figura 9. Comportamento dos parâmetros CRS / CFRS e CRRS / CFRRS em função dos niveis de alumínio, para o genótipo UPF86136. 


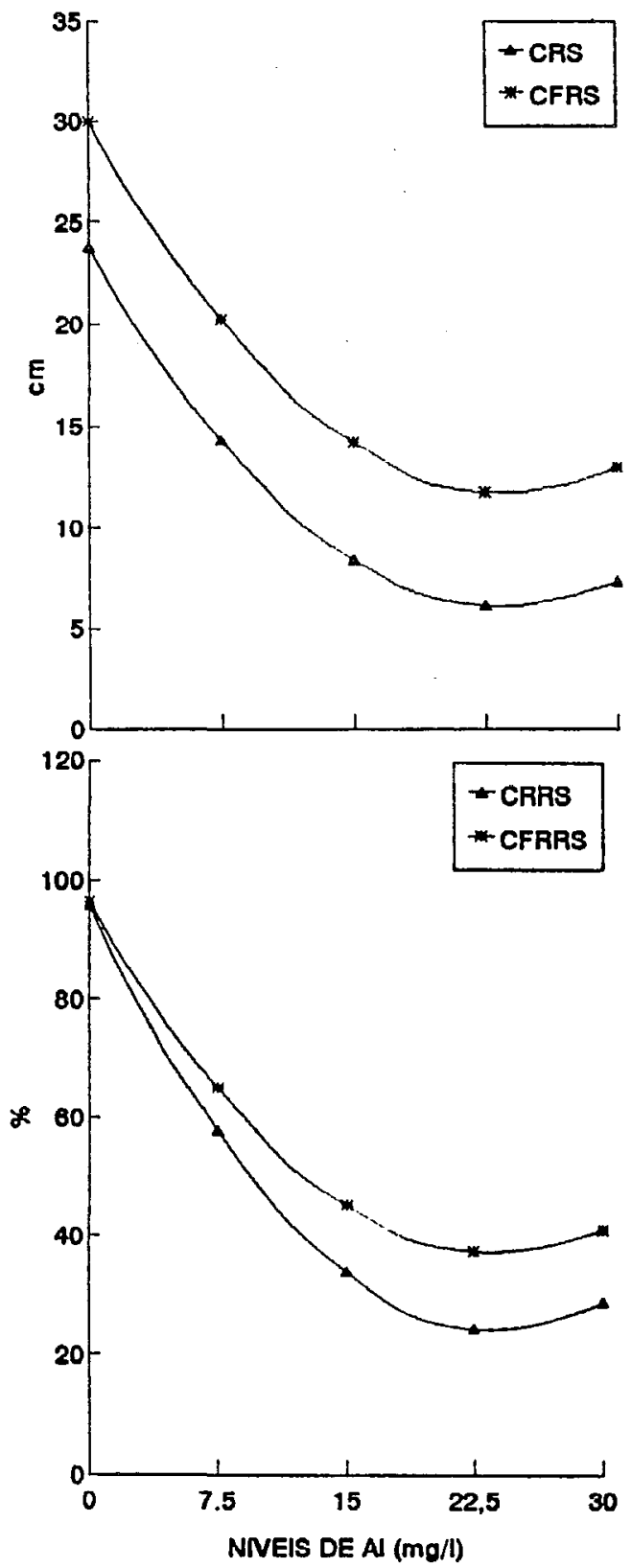

Figura 10. Comportamento dos parâmetros CRS / CFRS e CRRS/ CFRRS em função dos niveis de aluminio, para o genót i po UPF86A1 169-2b. 


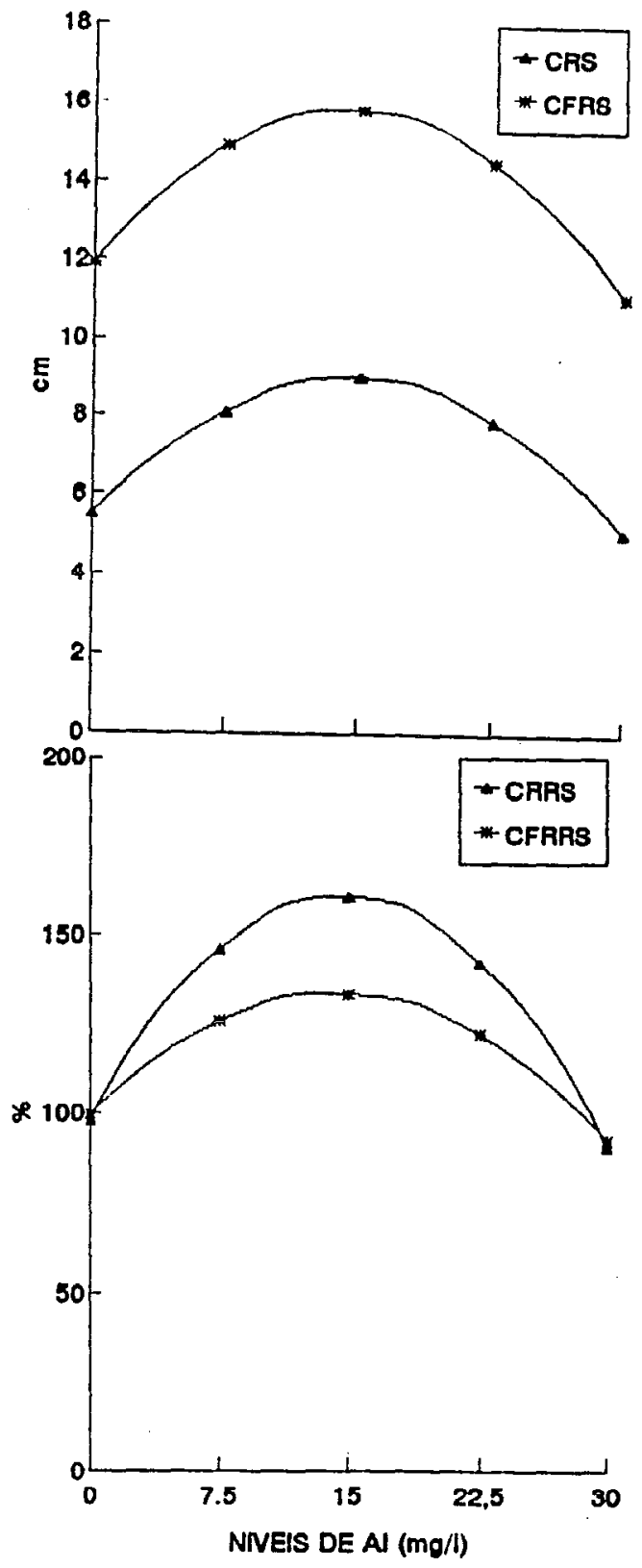

Figura 11. Comportamento dos parâmetros CRS / CFRS e CRRS / CFRRS em funça dos níveis de alumínio, para o genótipo UPF86A1198-5-1b. 
78

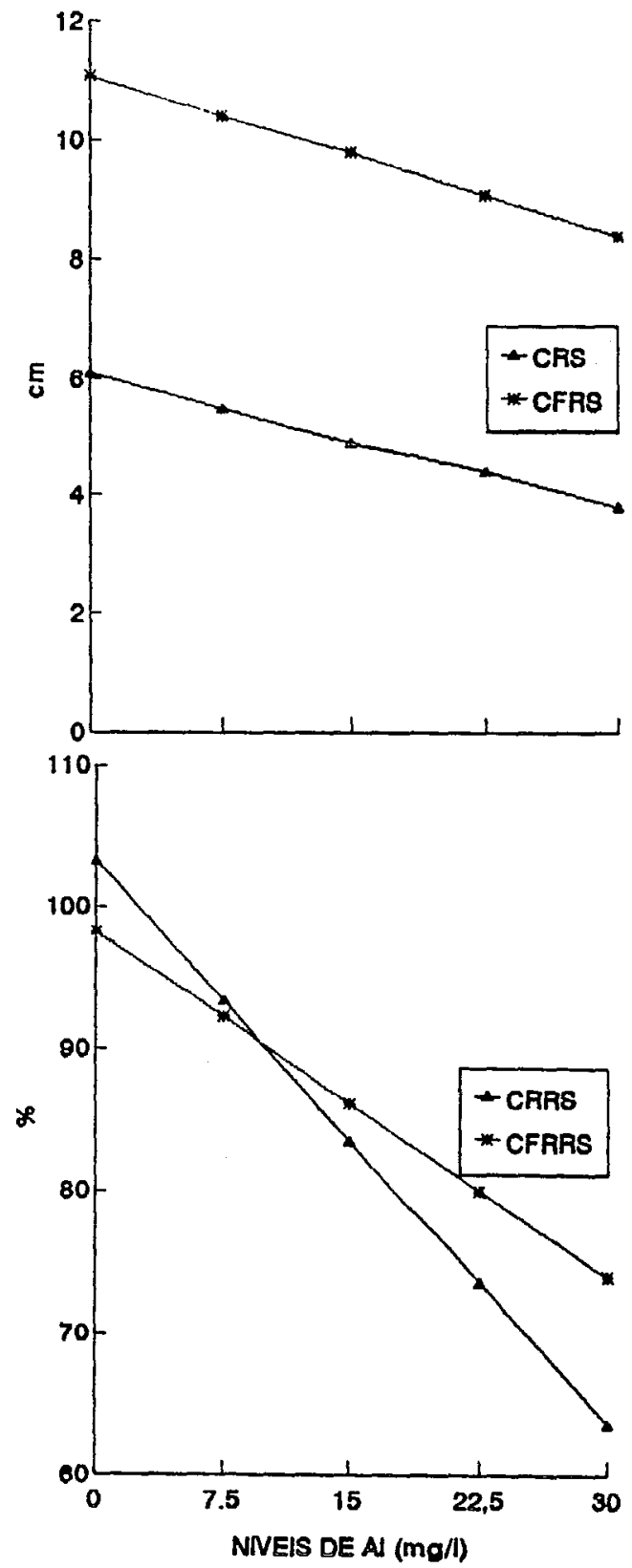

Figura 12. Comportamento dos parâmetros CRS / CFRS e CRRS / CFRRS em função dos niveis de alumínio, para o genót i po UPF86A1264-1b. 


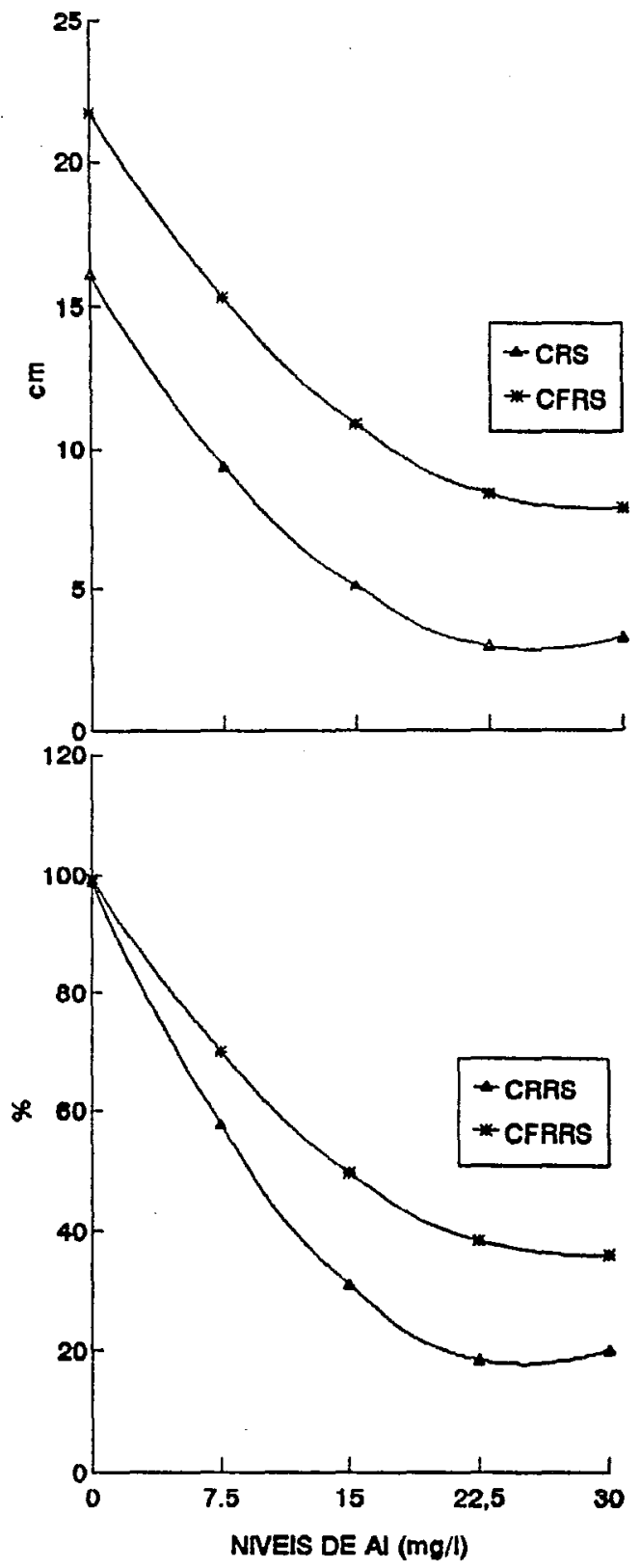

Figura 13. Comportamento dos parâmetros CRS / CFRS e CRRS / CFRRS em função dos níveis de alumínio, para o genótipo UPF87071. 


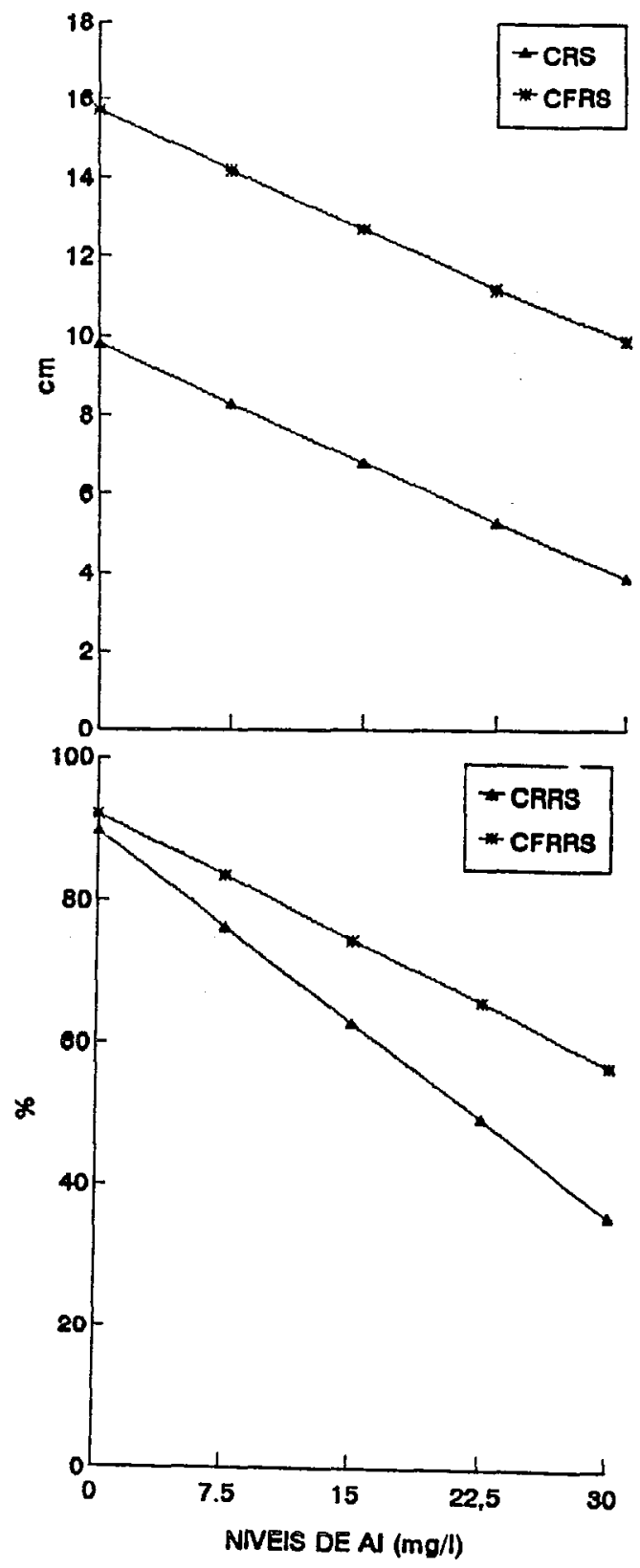

Figura 14. Comportamento dos parâmetros CRS / CFRS e CRRS / CFRRS em função dos níveis de alumínio, para o genót ipo UPF87107. 


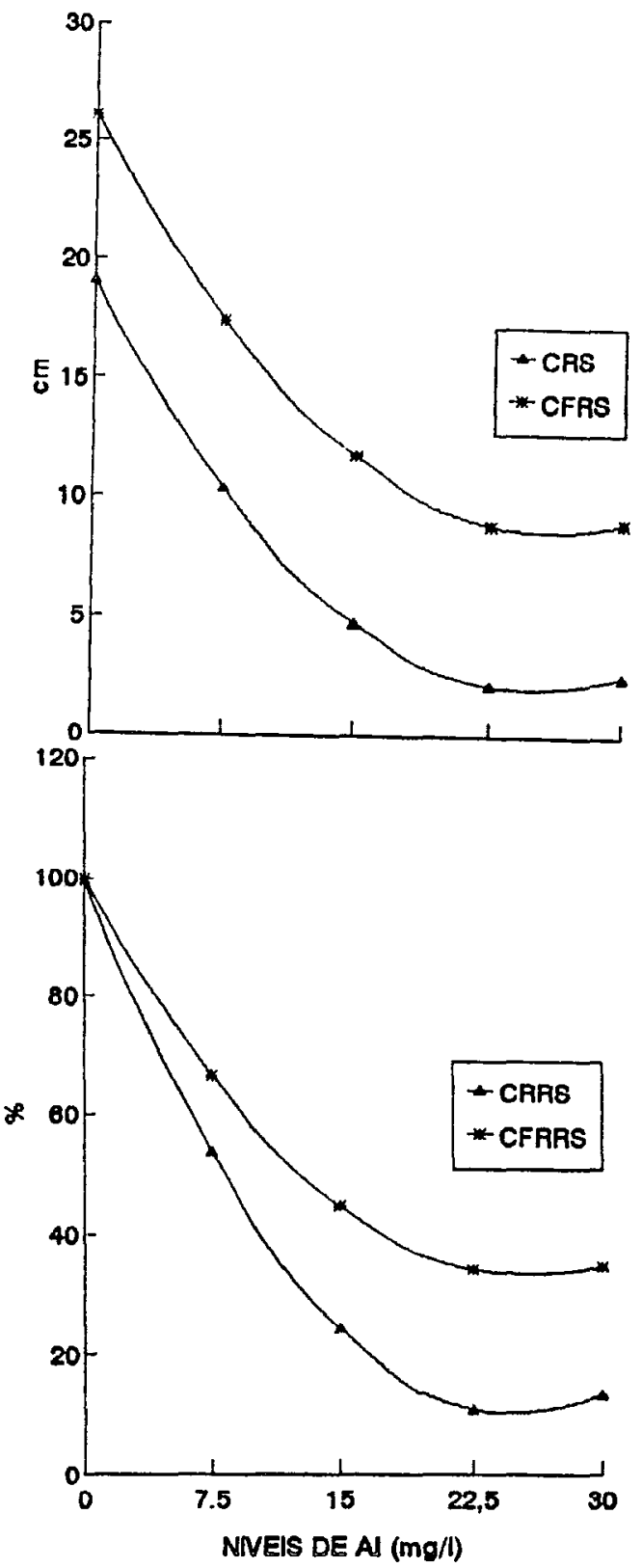

Figura 15. Comportamento dos parâmetros CRS / CFRS e CRRS / CFRRS em função dos níveis de alumínio, para o genótipo UPF5. 


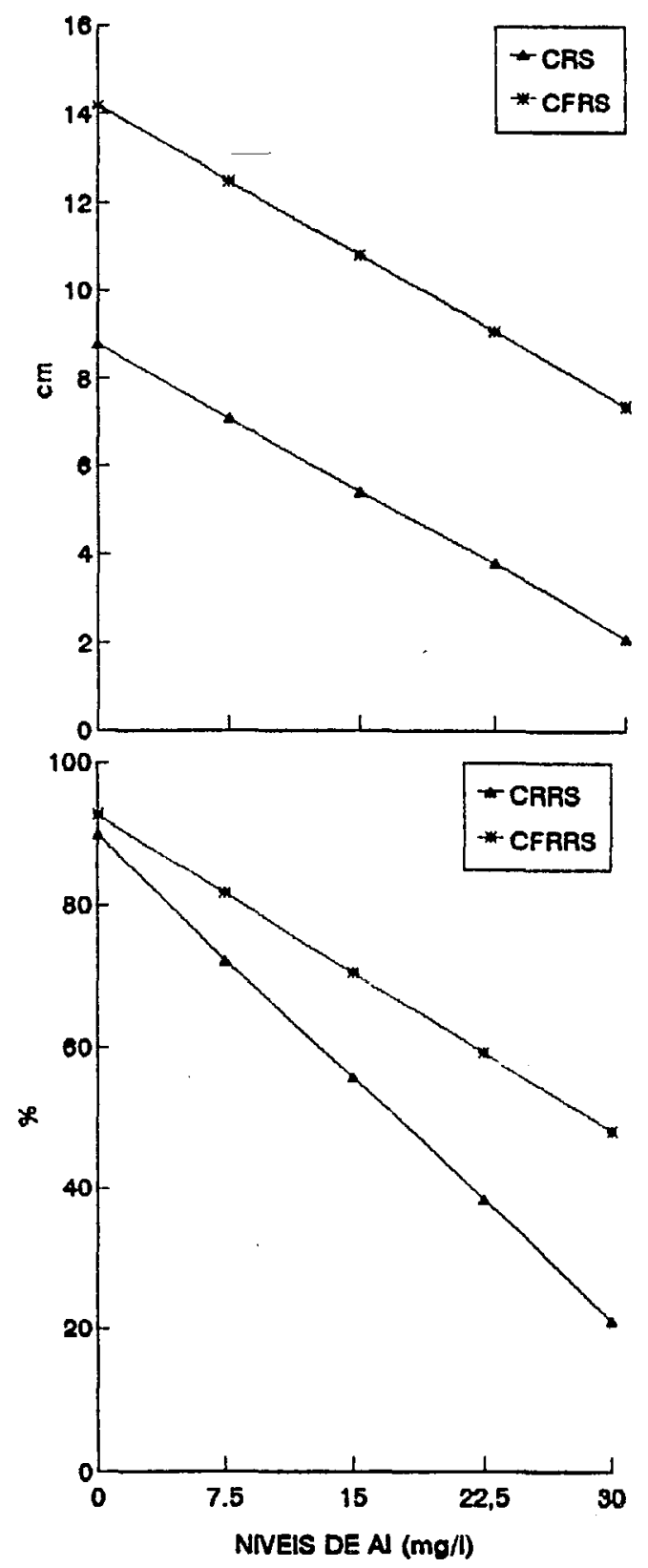

Figura 16. Comportamento dos parâmetros CRS / CFRS e CRRS / CFRRS em função dos niveis de alumínio, para o genót ipo UPF 7 . 
4.1.6. Correlações entre os parâmetros de crescimento da raiz.

Foi realizada a análise de correlação linear simples entre os diversos parâmetros, que foram comparadas pelo teste $t$ (Tabela 11).

Tabela 11. Correlação linear simples entre CRS, CRRS, CFRS, CFRRS e CIRS.

\begin{tabular}{|c|c|c|c|}
\hline \multicolumn{2}{|c|}{ Correlações } & \multirow{2}{*}{ valor $t$} & \multirow{2}{*}{$\frac{r(\%)}{56,3}$} \\
\hline CRS $\mathrm{x}$ & CRRS & & \\
\hline & CFRS & $79,025 * *$ & 98,1 \\
\hline & CFRRS & $10,247 * *$ & 65,3 \\
\hline & CIRS & $0,097 \mathrm{~ns}$ & -- \\
\hline \multirow[t]{3}{*}{ CRRS $\mathrm{x}$} & CFRS & $10,626 * *$ & 56,7 \\
\hline & CFRRS & $73,919 * *$ & 97,9 \\
\hline & CIRS & $1,000 n s$ & -- \\
\hline \multirow[t]{2}{*}{ CFRS $x$} & CFRRS & $10,538 * *$ & 56,4 \\
\hline & CIRS & $1,757 \mathrm{~ns}$ & -- \\
\hline CFRRS $\mathrm{x}$ & CIRS & $1,610 \mathrm{~ns}$ & $-\infty$ \\
\hline
\end{tabular}

* - significativo ao nível de $1 \%$; ns - não significativo

Observa-se que as melhores correlações foram obtidas entre CRS e CFRS $(r=98,1 * *)$, e CRRS e CFRRS $(r=97,9 * *)$.

- A correlação com o comprimento inicial da raíz seminal (CIRS) não foi significativa com qualquer dos outros parâmetros avaliados (CRS, CRRS, CFRS e CFRRS). Isso significa, que o maior comprimento inicial da raíz seminal, e seu possivel vigor, não se refletiram no maior crescimento 
da raíz seminal (CRS), quando submetido níveis de alumínio. Já o parâmetro CFRS, apesar de não ser significativo ao nível de $5 \%$, neste experimento, apresentou efeito. O trabalho comprova que a avaliação do CRS, é o melhor parâmetro para a seleção dos genótipos de aveia tolerantes ao aluminio, confirmando os resultados obtidos por FOY et al, (1967); REID et a l., (1971); MOORE et a.1., (1976).

Dessa forma, o crescimento da raiz seminal (CRS) avaliou o grau de tolerância dos genótipos ao alumínio, enquanto o parâmetro CRRS, avalia o grau de reduçao no crescimento, provocado pelo alumínio, e que foi utilizado como medida do efeito responsivo.

Com base nos parâmetros CRS (tolerância) e CRRS (eficiência responsiva), realizou-se a classificação dos 16 genótipos avaliados, considerando-se o nível de $15 \mathrm{mg}$ de Al/litro de soluça e utilizando como critérios: a) tolerantes - CRS > média e sensíveis - CRS ( média; b) eficientes - CRRS > média e ineficientes - CRRS < média (Tabela 12).

O nivel $15 \mathrm{mg}$ de Al/litro foi escolhido, tendo em vista o fato de que nos niveis maiores a inibição média do crescimento radicular foi maior que 50\%. Verifica-se, pela Tabela 12, que os genótipos UPF86011, UPF86A1198-5-1b e UPF86112 foram classificados como tolerantes e responsivos, enquanto os genótipos UPF86Al169-2b, UPF86045 e UPF86136, foram classificados como tolerantes, mas não responsivos. Cinco genótipos foram classificados como sensíveis e responsivos e cinco genótipos como sensíveis e não responsivos.

O cultivar de aveia UPFT mostrou-se sensivel e não responsivo, enquanto a linhagem UPF86A1169-2b, como tolerante e não responsiva. 
Tabela 12. Classificação dos genótipos quanto à tolerância e ao efeito responsivo, para o nível $15 \mathrm{mg}$ Al/litro de solução.

Tolerantes e Responsivos UPF 86011

UPF 86A $1198-5-1 \mathrm{~b}$

UPF 86112
Tolerantes e não Responsivos UPF 86A $1169-2 \mathrm{~b}$

UPF 86045

UPF 86136
Sensiveis e Responsivos

UPF 87107

UPF86A $1264-1 \mathrm{~b}$

UPF86113

UPF79I174-3

UPF 86018
Sensíveis e não Responsivos UPF 7

UPF 84057

UPF 87071

UPF 86066

UPF 5

4.2. Efeito do alumínio na solução nutritiva.. sobre alguns parâmetros de crescimento da aveia branca.

4.2.1. Efeito sobre o crescimento das raízes.

A análise de variância dos resultados da avaliação do comprimento inicial da raíz seminal (CIRS), aplicando-se o teste $F$, revelou diferenças altamente significativas $(P<0,01)$ entre genótipos, mas sem diferença significativa $(P>0,05)$ em relação aos niveis de alumínio e para a interação genótipos $x$ níveis de alumínio (Tabela D2).

A média geral do experimento foi de $7,2 \mathrm{~cm}$ e - coeficiente de variação para genótipos de $1,84 \%$ e para níveis de Al de $5,73 \%$ (Tabela 13).

Pela comparação entre as médias através do 
teste de Tukey observa-se, que o CIRS do genótipo UPF81350 $(8,3 \mathrm{~cm})$ não diferiu dos genótipos UPF82005 $(8,0 \mathrm{~cm})$ e UPF81251 (7,5 cm) e foram superiores aos demais genótipos avàliados, ao nível de $5 \%$ de significância.

Para as variáveis comprimento final da raiz seminal (CFRS), comprimento final relativo da raíz seminal (CFRRS), crescimento da raíz seminal (CRS) e crescimento relativo da raiz seminal (CRRS), a análise de variância revelou diferenças altamente significativas, através do teste $F$, entre genótipos, níveis de Al e para a interação genótipos $x$ níveis de Al (Tabela D2).

Como a interação genótipos $x$ niveis de alumínio, revelou-se altamente significativa, a análise foi desdobrada, fixando-se o fator níveis de Al, para a comparação entre genótipos, dentro de cada nível de alumínio.

$\mathrm{Na}$ ausência de $\mathrm{Al}$, a média de CFRS foi $20,5 \mathrm{~cm}$ e no nível $7,5 \mathrm{mg}$ Al/litro de solução foi de $14,8 \mathrm{~cm}$ (Tabela 13). O coeficiente de variação para genótipos foi de $2,42 \%$ e para, o fator níveis de Al de 7,01\%. Verifica-se nessa tabela, através da comparação entre médias pelo teste de Tukey, que os genótipos UPF81350 (28,3cm), UPF82005 $(27,0 \mathrm{~cm})$ e UPF86Al169-2b (26,3 cm) sem diferir significativamente entre si, apresentaram maior CFRS quando relacionados com os demais genótipos na ausência de Al. Na presença de Al, o genótipo UPF82079 $(22,7 \mathrm{~cm})$ apresentou CFRS superior aos demais genótipos avaliados, ao nível de $5 \%$ de significância. 


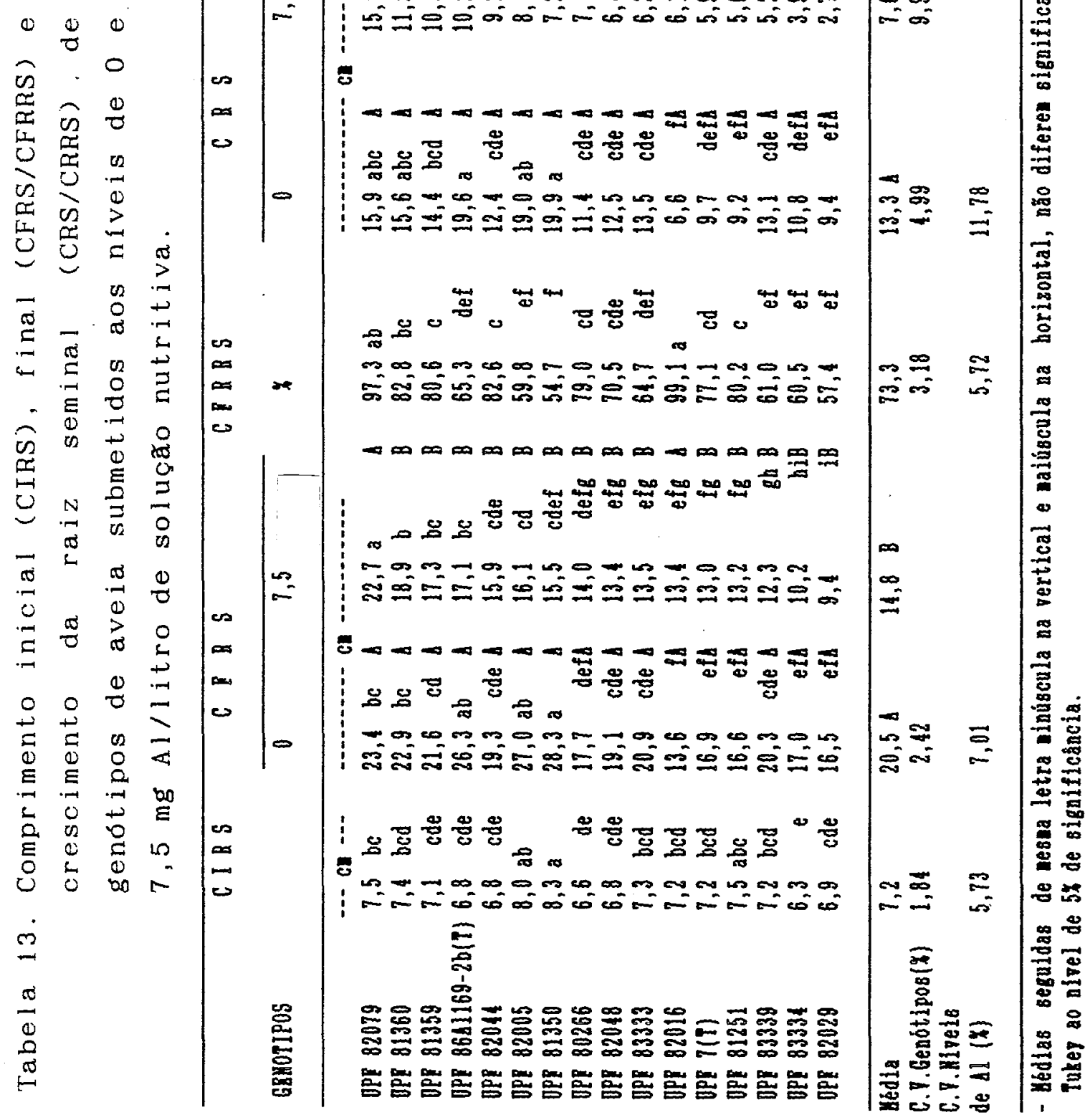


A inibição média sobre o comprimento final da raiz (CFRS) promovida pelo Al(CFRRS), foi de $26,7 \%$, com um coeficiente de variação de $3,18 \%$ para genótípos e $5,72 \%$ para niveis de Al.

Quanto ao CFRRS observa-se, na tabela 13, que a redução não foi significativa apenas nos genótipos UPF82079 $(2,7 \%)$ e UPF82016 (0,9\%). Oprimeiro, destacou-se pelo grande comprimento inicial da raiz e o segundo, pelo pequeno comprimento inicial da raiz. Este comportamento comprova que esta é uma variável inadequada para selecionar os genótipos tolerantes, através da redução relativa, pois quando as plantas apresentam pequeno crescimento radicular, a pequena diferença depressiva não é detectada estatisticamente.

Como deve-se selecionar plantas tolerantes, com grande comprimento de raízes, este critério deve ser priorizado. Dentre os materiais genéticos que se destacarem pelo grande comprimento das raizes, seleciona-se aqueles com menor redução no comprimento, provocado pela ação inibitória do Al.

O crescimento da raíz seminal (CRS) media, na ausência de alumínio, foi de $13,3 \mathrm{~cm}$, enquanto na presença de Al foi de $7,6 \mathrm{~cm}$, com um coeficiente de variação de $4,99 \%$ para genótipos e 11,78\% para os níveis de Al (Tabela 13).

No tratamento com ausência de Al, os genótipos UPF86Al169-2b $(19,6 \mathrm{~cm})$ e UPF81350 $(19,9 \mathrm{~cm})$ que nao diferiram dos genótipos UPF82005 (19,0 cm), UPF82079 (15,9 $\mathrm{cm})$ e UPF81360 (15,6 cm) foram superiores aos demais genótipos avaliados ( $\mathrm{P}<0,05)$. Com presença de Al na solução, o genótipo UPF82079 $(15,2 \mathrm{~cm})$ superou todos os genótipos avaliados, ao nível de $5 \%$ de significância.

A redução média (CRRS) provocada pelo nível de $7,5 \mathrm{mg} A 1 / \mathrm{l}$, no crescimento da raíz seminal dos genótipos de aveia foi de $38 \%$ (Tabela 13). O coeficiente de variação para genotipos foi de $7,17 \%$ e para os niveis de Al, de $8,84 \%$. 
Quanto ao comportamento dos genótipos de aveia, em relação ao Al, os genótipos UPF82079 e UPF82016, apresentaram menor inibição, respectivamente de $3,6 \%$ e $6,6 \%$, significativa ao nível de $5 \%$, pelo teste de Tukey.

O genótipo UPF82079 se destacou como tolerante ao alumínio (CRS), e também por ser responsivo (CRRS). Já o genótipo UPF82016, pode ser considerado responsivo, mas não tolerante ao Al.

4.2.2. Efeito sobre o rendimento de matéria seca

A análise de variância mostrou diferenças altamente significativas $(P<0,01)$ para os genótipos, níveis de Al e para a interaça genótipos $x$ níveis de alumínio, para as variáveis rendimento de matéria seca da raíz (RMSR), rendimento de matéria seca da parte aérea (RMSPA), rendimento relativo de matéria seca da parte aérea (RRMSPA), rendimento de matéria seca da planta (RMSP) e rendimento relativo de matéria seca da planta (RRMSP), e diferenças significativas $(\mathrm{P}<0,05)$ para o rendimento relativo de média seca da raíz (RRMSR), conforme Tabela D2.

O RMSR médio na ausência de alumínio foi de $136,3 \mathrm{mg} e$ na presença de Al, de $61,9 \mathrm{mg}$ (Tabela 14). 0 coeficiente de variação para genótipos foi de $6,26 \%$ e para niveis de Al de $39,86 \%$. 
Pela comparação entre as médias do parâmetro RMSR através do teste de Tukey, observa-se que na ausência de Al, o genótipo UPF82029 (244,7 mg), que não diferiu dos genótipos UPF82016 (143,3mg), UPF82048 (183,3 mg), UPF81251 $(193,3 \mathrm{mg}), \quad$ UPF82044 (136,7 mg), UPF81360 (173,3 mg), UPF80266 (153,3 mg), UPF83333 (183,3 mg) e UPF81350 (220,0 $\mathrm{mg})$, superaram os demais genótipos ao nível de $5 \%$ de significância (Tabela 14). Já na presença de Al, o genótipo UPF82016 ( $156,7 \mathrm{mg} / v a s o)$, foi superior ao cultivar UPF7 e outros oito genótipos avaliados, mas não diferiu significativamente dos genótipos UPF82079, UPF82048, UPF86A1 169-2b, UPF83334, UPF82029 e UPF81251.

A inibição média do aluminio sobre o rendimento de matéria seca da raíz (RRMSR) foi $36,5 \%$. o genótipo UPF82079 $(+161,3 \%)$, apesar de não diferir dos genótipos UPF83334 (+23,3\%), UPF82016 (+14,7\%) e UPF86A1169$2 \mathrm{~b}(+4,7 \%)$, foi significativamente superior aos demais genótipos avaliados. Todos esses genótipos ficaram no grupo estatístico superior quanto ao RMSR, na presença de $7,5 \mathrm{mg} \mathrm{Al}$ na solução.

Em relação ao rendimento de MS da parte aérea (RMSPA), o genótipo UPF83333 (663,3 mg), apesar de não diferir de outros 8 genótipos, foi superior aos demais, na ausência de Al ao nível de 5\% de significância (Tabela 14). $\mathrm{Na}$ presença do Al, destacam-se os genótipos UPF82016 (483,3 $\mathrm{mg})$ e UPF81251 (453,3 $\mathrm{mg})$ que não diferiram significativamente dos genótipos UPF82079, UPF82048, UPF82044, UPF81350, UPF81360, UPF80266, UPF81359 e UPF83333. Na comparação dos genótipos que se destacam pelo RMSPA, na ausência e presença de Al, verifica-se que apresentam-se no grupo estatístico superior as 1 inhagens: UPF82016, UPF82079, UPF 82048, UPF81251, UPF82044, UPF81350 e UPF83333. Já os genótipos UPF81360, UPF80266 e UPF81359, que apresentaram RMSPA menor na ausência de Al, destacaram-se no tratamento 
com presença de Al, mostrando tolerância a esse nível.

A inibição do nível $7,5 \mathrm{mg}$ Al em relação a ausência de Al, sobre rendimento de. MS da parte aérea não foi significativa quando comparam-se os genótipos UPF82016, UPF82079, UPF81360, UPF80266 e UPF81359 (Tabela 14). O RRMSPA médio foi de $65,8 \%$ para os genótipos avaliados e a menor inibição ocorreu na linhagem UPF80266 (8\%), que não diferiu, porém de outros onze genótipos.

Comparando-se os resultados de rendimentos relativos de MS da raíz e parte aérea, verificou-se um efeito de inibição maior do aluminio sobre o sistema radicular, que concorda com os resultados obtidos em aveia por BILSKI $(1987)$.

Quanto ao rendimento de MS da planta inteira (RMSP), o genótipo UPF82029 destacou-se no tratamento com ausência de alumínio, não diferindo porém, de outros sete genótipos avaliados $(P>0,05)$. Na presença de Al, destacouse o genótipo UPF82016 (640,0 $\mathrm{mg})$, que não diferiu significativamente dos genótipos UPF82079, UPF82048, UPF81251 e UPF82044. O genótipo UPF82029 sofreu a maior inibicão pelo Al no rendimento de MS (66\%), enquanto no genótipo UPF82079 essa inibição foi de $5 \%$. O efeito depressivo só não foi significativo para os genótipos UPF82079, UPF82016 e UPF 81359 .

\subsubsection{Correlação entre crescimento da raíz} e rendimento de matéria seca.

Com o objetivo de verificar-se as relações entre os diversos parâmetros avaliados, e usá-las como indicador para o melhoramento genético, foram realizadas correlação linear simples entre o crescimento de raizes e o rendimento de matéria seca da raiz, parte aérea e planta (Tabela 15). 
Tabela 15. Valores de $t$ e coeficiente de correlaça ( $r$ ) entre parâmetros de crescimento de genótipos de aveia submetidos ao niveis de $7,5 \mathrm{mg} \mathrm{Al} / 1$ itro de solução nutritiva.

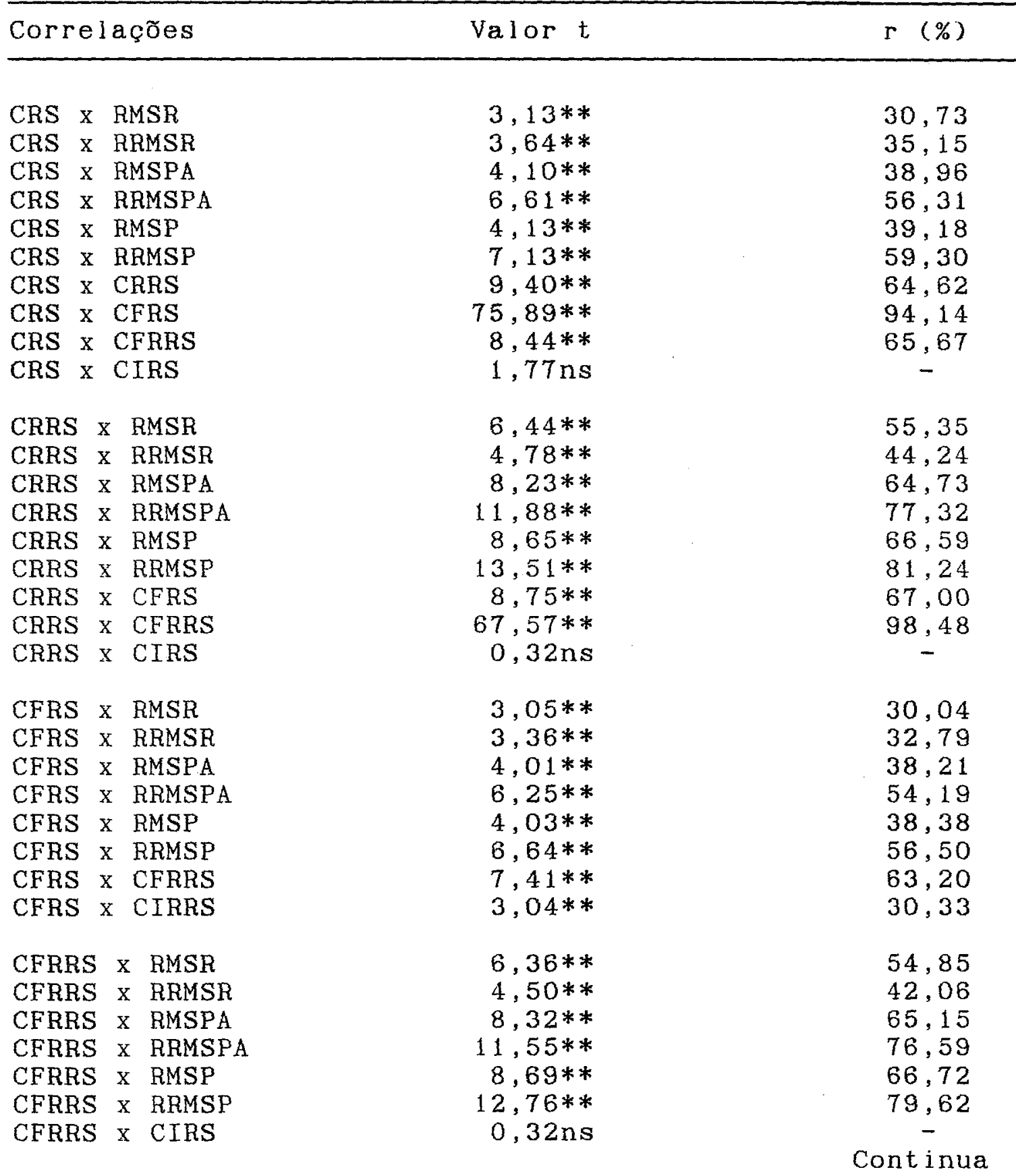


Cont i nua ção.

\section{Correlações}

CIRS $x$ RMSR

CIRS $x$ RRMSR

CIRS $x$ RMSPA

CIRS $x$ RRMSPA

CIRS $x$ RMSP

CIRS $x$ RRMSP
Valor $t$

$0,21 \mathrm{~ns}$

$0,95 \mathrm{~ns}$

$0,35 \mathrm{~ns}$

$0,27 \mathrm{~ns}$

$0,32 \mathrm{~ns}$

$0,71 \mathrm{~ns}$ r (\%)

-
$\overline{-}$
$\overline{-}$

** significativo ao nível de $1 \%$; ns = não significativo ( $P$ $>0,05$ ).

Observa-se nessa tabela, que o CIRS apresentou correlação significativa apenas com CFRS, nåo se correlacionando com os demais parâmetros. Este resultado demonstra que o comprimento inicial da raiz não influiu nos demais parâmetros, quanto ao efeito da toxicidade do alumínio, mas pode influir no comprimento final da raíz seminal.

- CRS apresentou correlação altamente significativa $(P<0,01)$, com as variáveis de crescimento de raízes, CRRS $(r=64,6 \%)$, CFRS $(94,1 \%)$ e CFRRS $(65,7 \%)$ e outros. Em relação aos parâmetros de rendimento de MS, a melhor correlação do CRS foi com o RRMSP $(r=59,3 \%)$, significativa ao nivel de $1 \%$. A correlação do CRS com RMSPA $(r=39,0 \%)$ foi melhor que com o RMSR $(r=30,7 \%)$.

A pequena correlação entre o crescimento da rá́z e o seu rendimento de matéria seca é atribuida ao fato de que, apesar de ocorrer reduça no comprimento da raíz, provocada pelo aluminio, as plantas injuriadas apresentam raízes engrossadas, o que se reflete no rendimento de MS. (NUERNBERG et al., 1990).

Já o CRRS, apresentou correlaçסes melhores com os parâmetros de rendimento de MS, do que o CRS. No entanto, o CFRS e o CFRRS, apresentam menor correlação com os 
parâmetros de rendimento de MS, quando comparados ao CRS e CRRS, respectivamente.

Estes resultados estao de acordo com REID (1976), SARTAIN \& KAMPRATH (1978), HOWELLER \& CADAVID (1976) e LAFEVER et al. (1977), que consideraram o CRS como o melhor parâmetro para avaliar o grau de tolerância das plantas ao Al.

O CRS tem ainda a vantagem de nao ser um método destruitivo, podendo a planta selecionada ser conduzida até o final do ciclo. E sobre o CRRS, apresenta a vantagem de não ser necessária a avaliação da planta na ausência de Al, para a seleção de materiais genéticos tolerantes.

Concluiu-se que os parâmetros CRS e CFRS são mais recomendados para realizar a seleção de materiais (melhoramento genético). Destes, o parâmetro que melhor se correlaciona com o RRMSPA e RRMSP, é o CRS.

4.3. Seleção de genótipos de aveia branca tolerantes ao aluminio, em solução nutritiva.

4.3.1. Seleção ao nivel $7,5 \mathrm{mg} \mathrm{Al/litro} \mathrm{de} \mathrm{soluçăo}$

4.3.1.1. Crescimento inicial da raiz seminal (CIRS)

$\mathrm{Na}$ análise comparativa dos onze experimentos conduzidos, e avaliando um total de 156 genótipos de aveia branca, não mostrou diferenças significativas na análise de variância (teste F), quanto ao comprimento inicial da raiz seminal (CIRS) para os niveis de alumínio e a interaçăo niveis de alumínio $x$ genótipos $(P>0,05)$. Já os genótipos diferiram quanto à esse parâmetro, ao nivel de $1 \%$ de significância, em todos os experimentos (Tabelas D1, D2 e D3). 
Considerando-se que o CRS correlacionou-se melhor com o rendimento de matéria seca (Tabela 15), foi analisado o desdobramento da interação apenas para esse parâmetro, e as médias dos genótipos em cada nivel $(0$ e 7,5 mg Al/1) foi comparada pelo teste de Tukey, ao nível de $5 \%$ de significância.

Os resultados da avaliação do parâmetro CIRS, são apresentados nas Tabelas 16 a 26, apresentando-se a média para os dois níveis, uma vez que a interaça entre niveis de Al $x$ genótipo não foi significativa ao nível de $5 \%$ de significância.

4.3.1.2. Crescimento da raiz seminal (CRS)

O desempenho dos 156 genótipos quanto ao crescimento da raíz seminal (CRS), também aparece nas Tabelas 16 a 26 , apresentando-se a comparação das médias através do teste de Tukey.

Verifica-se, que o genótipo testemunha UPF86A1169-2b, somente foi superado significativamente no experimento 2 , pelo genótipo UPF82079, no tratamento com alumínio (Tabela 24). Nos demais experimentos, quanto ao parâmetro CRS, este genótipo UPF86Al169-2b ficou no grupo estatistico superior, mas não diferiu $(P>0,05)$ dos genótipos UPF86045, UPF86112, UPF5, UPF86136 e UPF86011 (Tabela 16); UPF3 e UPF2 (Tabela 
Tabela 16. Comprimento inicial (CIRS) e crescimento da raiz seminal (CRS/CRRS) de genótipos de aveia submetidos aos níveis 0 e $7,5 \mathrm{mg}$ Al/litro de solução nutritiva (Exp. 1).

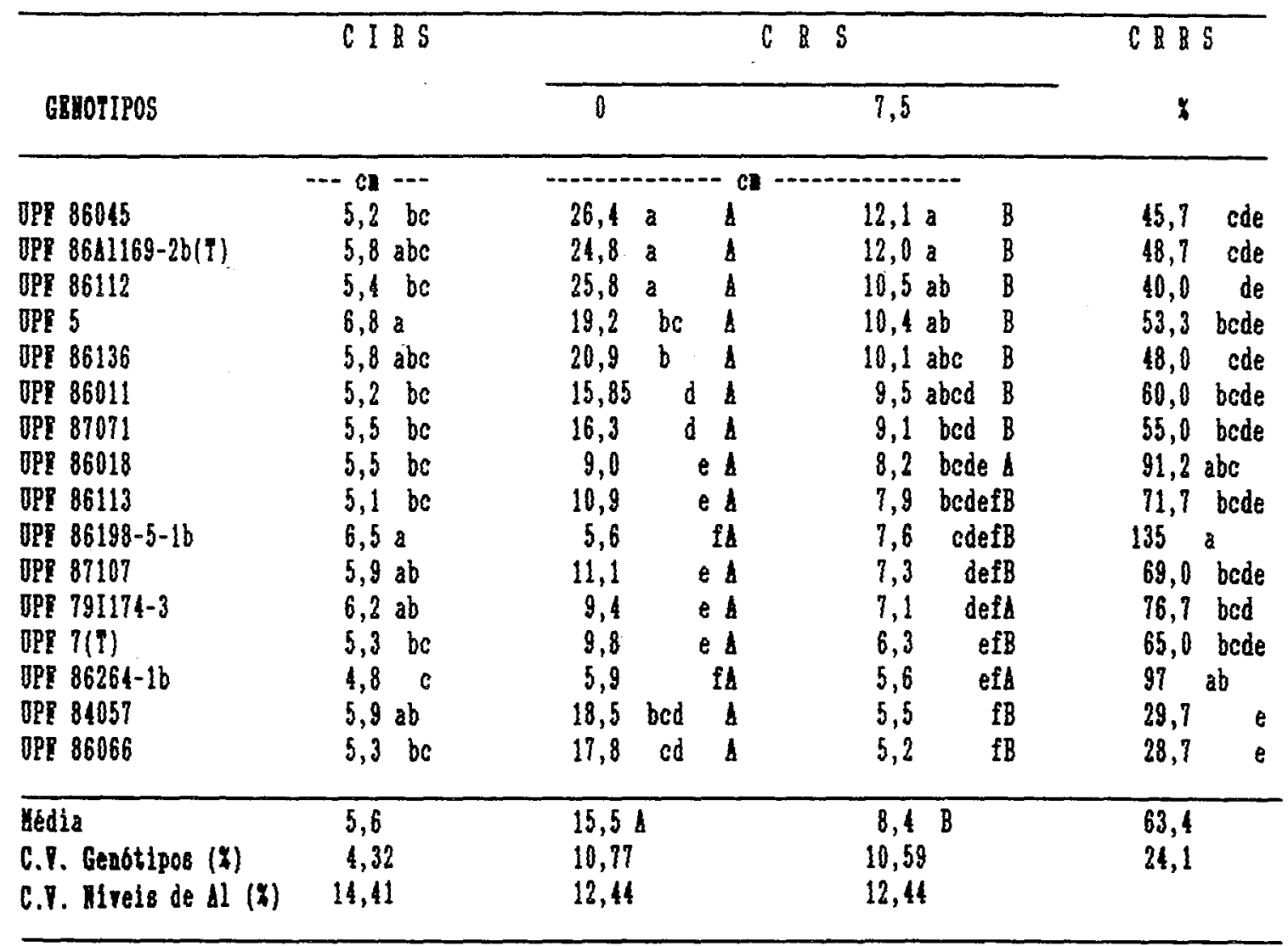

- Médias seguidas de resıa letra ninúscula na vertical e naiúccula na horisontal, aão diferen pelo teste de lukey ao nivel de $5 \%$ de significância. 
Tabela 17. Comprimento inicial (CIRS) e crescimento da raiz seminal (CRS/CRRS) de genótipos de aveia submetidos aos níveis 0 e $7,5 \mathrm{mg}$ Al/litro de solução nutritiva (Exp. 3A).

\begin{tabular}{|c|c|c|c|c|}
\hline \multirow[b]{2}{*}{ GBOTIPOS } & \multirow[b]{2}{*}{$C 1 R S$} & \multicolumn{2}{|c|}{$C 85$} & \multirow{2}{*}{$\begin{array}{r}\text { CRRS } \\
\%\end{array}$} \\
\hline & & 0 & 7,5 & \\
\hline & $---c \leqslant---$ & 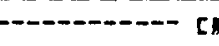 & 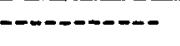 & \\
\hline UPF $86 d 1169-2 b(t)$ & 7,1 bede & 23,9 a $A$ & $9,0 \geq \quad B$ & 34,3 abcde \\
\hline UPF 3 & 6,9 bede & $15,6 \quad c d e A$ & 7,2 ab 8 & 47,3 abcd \\
\hline UPF 2 & $7,7 \mathrm{abc}$ & 21,4 ab $A$ & 6,7 abc $B$ & 31,3 cde \\
\hline UPF 6 & 7,4 abcd & 19,2 abcd $A$ & 6,4 bo $B$ & 33,7 abcde \\
\hline UPF 11 & 6,6 cdef & 22,7 \& $A$ & 6,3 be $B$ & 27,7 cde \\
\hline UPF 8 & 7,0 bcde & $14,6 \quad$ cdefA & 6,2 bcd & 46,0 abcd \\
\hline SAO CARLOS & $5,6 \quad f$ & 18,7 abcd $A$ & 6,2 bcdB & 35,0 abcde \\
\hline UPF 12 & 8,3 a & 19,0 abed $A$ & 6,1 bed & 33,0 abcde \\
\hline COLORADO & 7,3 abcd & 22,2 a $\quad A$ & 5,9 bcds & 27,0 de \\
\hline SUREGRAIN & 6,2 ef & $12,8 \quad$ ef $A$ & 5,9 bcd & 48,3 abc \\
\hline UPF 1 & 6,8 cde & 16,2 bcde $A$ & 4,9 bcd 8 & 31,7 bcde \\
\hline UPF 7 (T) & 7,1 bcde & $9,7 \quad f A$ & $4,8 \quad \operatorname{cd} 8$ & 52,3 ab \\
\hline UPF 9 & 6,8 bcde & 19,6 abc & 4,7 & 24,7 \\
\hline UPF 13 & 6,6 def & 9,5 & 4,7 & 53,3 a \\
\hline UPF 10 & 7,3 abcde & 13,5 & 4,5 & 33,7 abcd \\
\hline UPF 4 & $7,9 \mathrm{ab}$ & 11,6 & 4,0 & 35,0 abcde \\
\hline Media & 7,0 & $16,9 \mathrm{~A}$ & $5,8 \quad 8$ & 37,1 \\
\hline C.Y. Genotipos $(x)$ & 3,0 & 10,97 & 13,39 & 5,15 \\
\hline C.7. Biveis de $d I(7)$ & 7,5 & 17,4 & - & 10,3 \\
\hline
\end{tabular}

- Médias seguidas de nesa letra inúscula na vertical e asiuscula na horizontal, nádo diferea pelo teste de Tukey ao nivel de $5 \%$ significantia. 
Tabela 18. Comprimento inicial (CIRS) e crescimento da raiz seminal (CRS/CRRS) de genótipos de aveia submetidos aos níveis 0 e $7,5 \mathrm{mg}$ Al/litro de solução nutritiva (Exp. 3B).

\begin{tabular}{|c|c|c|c|c|}
\hline \multirow[b]{2}{*}{ GRYOTIPOS } & \multirow[b]{2}{*}{ C I B S } & \multicolumn{2}{|c|}{ C R 5} & \multirow{2}{*}{$\begin{array}{c}\text { CBBS } \\
*\end{array}$} \\
\hline & & 0 & 7,5 & \\
\hline & -- a & ard & (n........ & \\
\hline OPE 8641169-2b(T) & $7,7 \mathrm{ab}$ & 25,0 a & $7,38 \quad B$ & $29,4 \quad \mathrm{fg}$ \\
\hline OPR 89106 & 6,1 cd & 14,2 & 7,1 ab $B$ & 50,0 bed \\
\hline OPF 86A1198-5-4b & $7,2 a b c$ & 8,6 & 5,8 abc B & $67,6 a$ \\
\hline DPP 89085 & $5,9 d$ & 20,5 b & 5,6 be $B$ & 27,3 \\
\hline OPP $8641264-2-7 b$ & $8,2 a$ & 18,8 be & 4,7 cd $B$ & 25,4 \\
\hline DPI 86006 & 6,2 cd & 13,8 e & 4,7 Cd B & 34,1 \\
\hline OPR 861264-7-4b & $6,3 \mathrm{~cd}$ & 8,9 & 4,6 cd $B$ & 52,3 bcd \\
\hline OPR $8643264-7-83$ & 6,7 bod & 7,5 & 4,6 cd $B$ & $61,1 a b$ \\
\hline DPR $8641264-1-4 b$ & $6,3 \mathrm{~cd}$ & 7,8 & 4,4 cdeB & 56,0 abc \\
\hline OPR 8641264-10b & $6,1 d$ & 10,3 & 4,4 cdeB & 42,5 de \\
\hline DPR $8641264-10-2 b$ & 6,4 cd & 9,1 & $\operatorname{cde} B$ & 47,8 \\
\hline GPR $8641264-1-1 b$ & 6,2 cd & 8,7 & 4,3 cdeB & 49,6 bod \\
\hline DPF 89130 & $6,3 \mathrm{~cd}$ & 18,4 bod 1 & 3,7 deB & $20,1 \quad f$ \\
\hline OPP 7 (1) & 6,4 cd & 13,9 e 1 & 3,5 & 25,4 \\
\hline OPR 88109 & 6,1 cd & 15,5 de $\mathrm{A}$ & 3,4 & 21,8 \\
\hline DPP 86015 & $6,3 \mathrm{~cd}$ & 16,6 cde 1 & 2,9 & 17,3 \\
\hline Hedis & 6,5 & $13,6 \AA$ & $4,7 \mathrm{~B}$ & 39,2 \\
\hline C.7. Geabtipos (z) & 1,01 & 4,08 & & 1,24 \\
\hline C.I. Mlvels de dl (7) & 8,20 & 10,78 & & 6,29 \\
\hline
\end{tabular}

- Médiss seguidas de esea letra cinúccula á vertical e saiúscula na horizontal, aão diferel pelo teste de fuker ao nivel de 5 h de significância. 
100

Tabela. 19 Comprimento inicial (CIRS) e crescimento da raiz seminal (CRS/CRRS) de genótipos de aveia submetidos aos níveis 0 e $7,5 \mathrm{mg}$ Al/litro de solução nutritiva (Exp. 3C).

\begin{tabular}{|c|c|c|c|c|c|}
\hline \multirow[b]{2}{*}{ GEOTIPOS } & \multirow[b]{2}{*}{$C I B S$} & \multicolumn{3}{|c|}{$C B i$} & \multirow{2}{*}{$\begin{array}{c}C B R S \\
\%\end{array}$} \\
\hline & & 0 & & 7,5 & \\
\hline & - a -- & - - - & & - - - n-- & \\
\hline OPI 8641169-2b (T) & 8,5 bed & $23,0 \mathrm{ab} \cdot \mathrm{d}$ & $d$ & 8,48 & $37,1 \mathrm{abc}$ \\
\hline JRPGS 6 & $9,1 \mathrm{ab}$ & 25,8 a & d & $8,4 a b \quad B$ & 32,4 abcd \\
\hline JPP 86068 & 7,4 e & 18,8 bcdefg \& & 1 & 7,1 abc $B$ & $37,9 a b c$ \\
\hline ORBGS 1 & 7,8 cde & 17,2 defghd & 1 & 6,7 abed $B$ & $40,8 a$ \\
\hline ORBGS 4 & 7,8 cde & $16,1 \quad \mathrm{fghd}$ & 1 & 6,2 abcde $B$ & $38,1 \mathrm{ab}$ \\
\hline ORRGS 10 & 8,5 bcd & 22,3 abc & $\$$ & 5,6 bedefB & 25,0 cde \\
\hline ORBGS 2 & 7,7 de & 14,9 fghd & 1 & 5,6 bedefB & $38,5 \mathrm{ab}$ \\
\hline OPR 86081 & 8,4 bcde & $14,5 \quad$ gad & $\$$ & 4,8 cdefB & $34,0 \mathrm{abc}$ \\
\hline ORRGS 7 & 8,1 bede & 19,4 bcdef & $\$$ & $\operatorname{cdefB}$ & 25,2 cde \\
\hline ORGBS 12 & 8,0 cde & 17,0 efght & 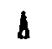 & $\operatorname{cdefB}$ & 27,8 bede \\
\hline DRRGS 5 & 8,7 bc & 21,2 abcd & 1 & $\operatorname{def} B$ & $18,8 \quad \varepsilon$ \\
\hline OPP 7 (I) & 8,6 bcd & 13,1 & $i$ & 3,6 & 29,4 abcde \\
\hline OPR 86238 & 8,4 bode & 21,9 abcd & a & 3,6 & $16,5 \in$ \\
\hline ORBgS 9 & $8,4 a$ & 17,8 cdefgha & $i$ & 3,5 & 19,7 \\
\hline UTRGS II & 8,5 bod & 16,1 fghd & 1 & 3,2 & 20,3 \\
\hline BRPGS 8 & $9,8 \mathrm{a}$ & 15,9 & 1 & 3,2 & 20,8 \\
\hline Yedia & 8,5 & 18,41 & & $5,2 \mathrm{~B}$ & 29,4 \\
\hline C.7. Geabtipos (x) & 1,85 & 8,84 & & 17,5 & 5,87 \\
\hline C.P. Nireis de Al (z) & 5,80 & 13,78 & & 6,85 & \\
\hline
\end{tabular}

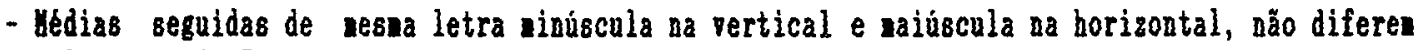
pelo teste de fukey ao nivel de $5 *$ de significância. 
Tabela 20. Comprimento inicial (CIRS) e crescimento da raiz seminal (CRS/CRRS) de genótipos de aveia submetidos aos niveis de 0 e $7,5 \mathrm{mg} \mathrm{Al/litro} \mathrm{de}$ solução nutritiva (Exp. 3D).

\begin{tabular}{|c|c|c|c|c|}
\hline \multirow[b]{2}{*}{ GEROTIPOS } & \multirow[b]{2}{*}{$C I B S$} & \multicolumn{2}{|c|}{$C \& S$} & \multirow{2}{*}{$\begin{array}{c}C R B S \\
*\end{array}$} \\
\hline & & 0 & 7,5 & \\
\hline 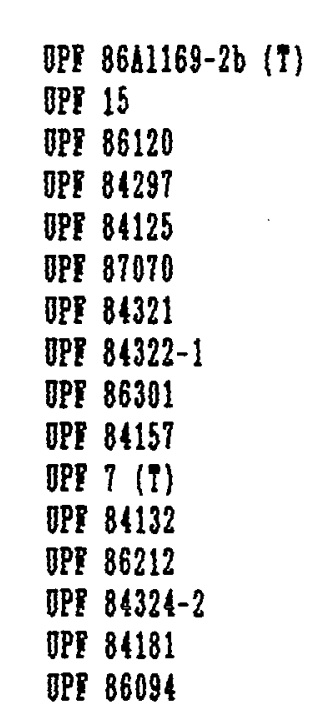 & $\begin{array}{l}--c a \\
7,0 \text { abcd } \\
6,3 \text { de } \\
5,9 \text { e } \\
6,7 \text { bcde } \\
6,3 \text { de } \\
7,8 \text { a } \\
6,5 \text { cde } \\
6,6 \text { bcde } \\
7,0 \text { abcd } \\
6,7 \text { bcde } \\
7,1 \text { abcd } \\
7,4 \text { ab } \\
7,2 \text { abc } \\
7,1 \text { abcd } \\
7,8 \text { a } \\
6,8 \text { bcd }\end{array}$ & $\begin{array}{l}20,9 \text { a } d \\
20,2 \text { ab } b \\
16,1 \text { bcde } d \\
16,2 \text { bcde } d \\
14,9 \text { cdefd } \\
17,6 \text { abcd } \\
17,5 \text { abcd } \\
13,9 \text { defd } \\
20,0 \text { ab d } \\
10,5 \text { id } \\
11,8 \text { efd } \\
14,0 \text { defd } \\
16,4 \text { abcde } d \\
19,9 \text { efd } \\
19,3 \text { abc } \\
10,6 \text { fd }\end{array}$ & $\begin{array}{ll}9,6 \text { a } & B \\
9,3 \text { ab } & B \\
9,1 \text { ab } & B \\
8,6 \text { ab } & B \\
8,4 \text { ab } & B \\
7,3 \text { abc } & B \\
7,3 \text { abc } & B \\
6,8 \text { bcd } & B \\
5,7 & \text { cde } B \\
5,4 & \text { cde } \\
5,2 & \text { cde } B \\
5,0 & \text { cde } B \\
4,7 & \text { cde } B \\
4,6 & \text { de } B \\
3,8 & \text { efB } \\
1,9 & \text { fB }\end{array}$ & $\begin{array}{l}49,9 \text { abc } \\
47,5 \text { abc } \\
58,7 \mathrm{a} \\
52,9 \text { ab } \\
56,5 \text { a } \\
44,1 \text { abcd } \\
42,1 \text { abcd } \\
50,0 \text { abc } \\
28,6 \text { def } \\
50,7 \text { abc } \\
49,1 \text { abc } \\
38,1 \text { bcd } \\
29,2 \text { def } \\
35,8 \text { cde } \\
19,6 \text { ef } \\
18,9 \text { f }\end{array}$ \\
\hline $\begin{array}{l}\text { Gedis } \\
\text { C.P. Genotipos (x) } \\
\text { C.7. Biveis de } A l(x)\end{array}$ & $\begin{array}{l}6,9 \\
2,77 \\
6,48\end{array}$ & $\begin{array}{l}15,8 \\
17,83 \\
13,87\end{array}$ & $\begin{array}{c}6,4 \mathrm{~B} \\
13,36\end{array}$ & $\begin{array}{r}42,0 \\
9,71 \\
8,06\end{array}$ \\
\hline
\end{tabular}

- Hédias seguidas da nesea letra ciníccula na vertical e caíscula na horizontal, ačo diferea teste de lukey ao nivel de 5\% significáncia. 
102 .

Tabela 21. Comprimento inicial (CIRS) e crescimento da raiz seminal (CRS/CRRS) de genótipos de aveia submetidos aos níveis 0 e $7,5 \mathrm{mg}$ Al/litro de solução nutritiva (Exp. $3 E$ ).

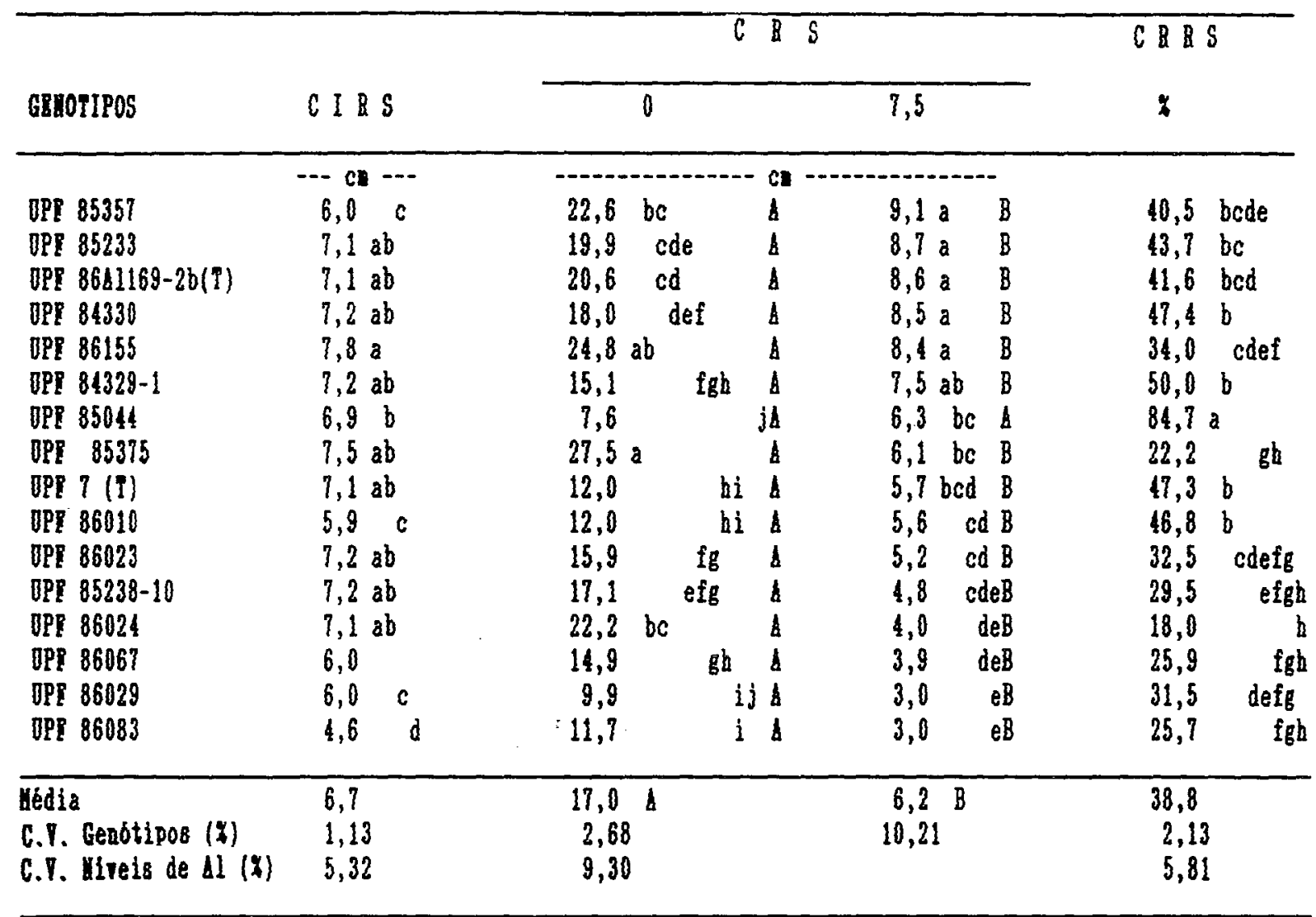

- Lédias seguidas de aesa letra cinúscula aa vertical e aiúscula aa horizontal, aáo diferes pelo teste de fukey ao nirel de $5 \%$ de significancia. 
Tabela 22. Comprimento inicial (CIRS) e crescimento da raiz seminal (CRS/CRRS) de genótipos de aveia submetidos aos níveis 0 e $7,5 \mathrm{mg}$ Al/litro de solução nutritiva (Exp. 3F).

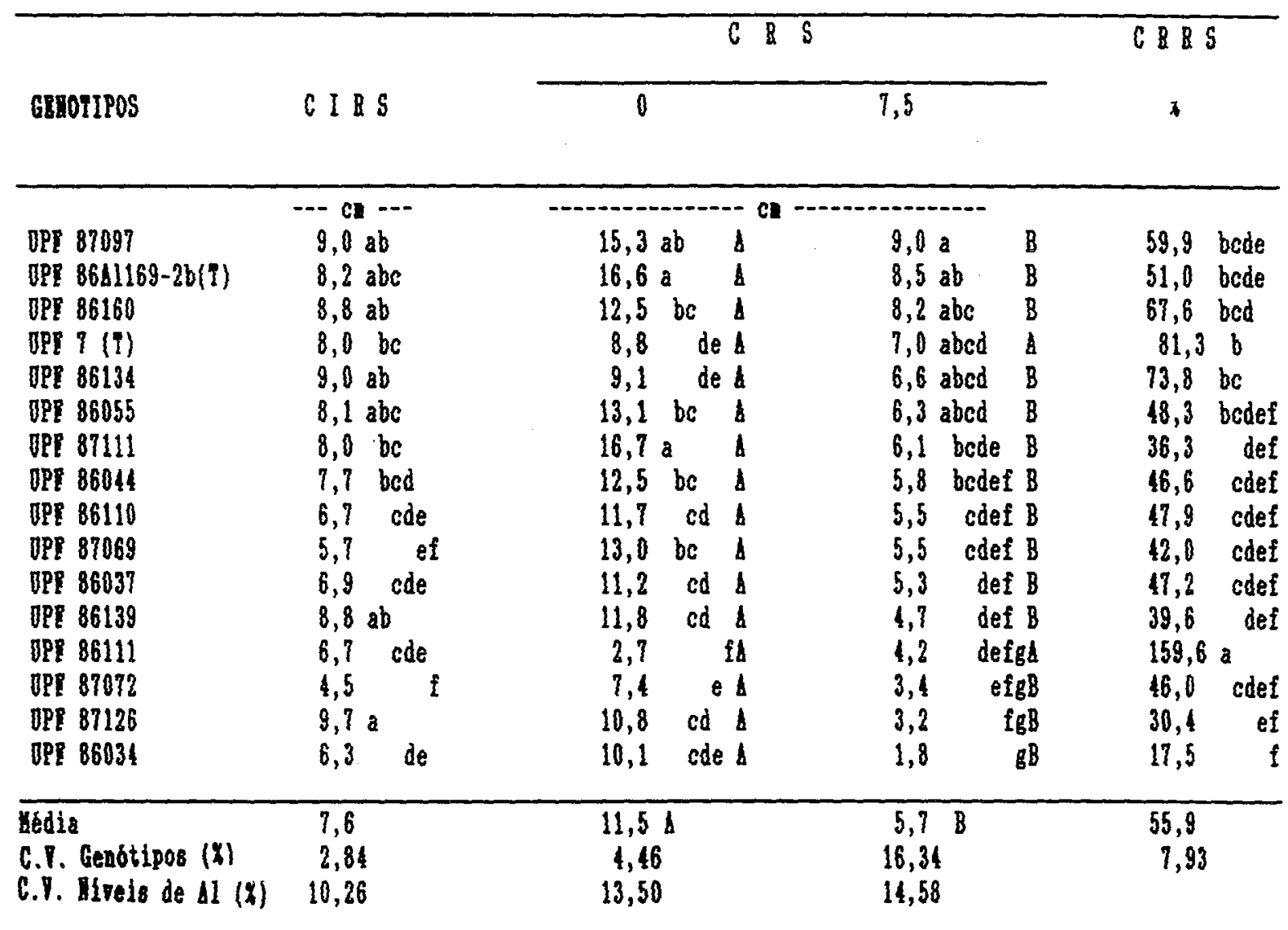

- Védias seguidas de nesıa letra ninúscula na vertical e saińccula a horizontal, năo diferen pelo terte de lukey ao nivel de 57 de significância. 
Tabela 23. Comprimento inicial (CIRS) e crescimento da raiz seminal (CRS/CRRS) de genótipos de aveia submetidos aos níveis 0 e $7,5 \mathrm{mg}$ Al/litro de solução nutritiva (Exp. $3 G$ ).

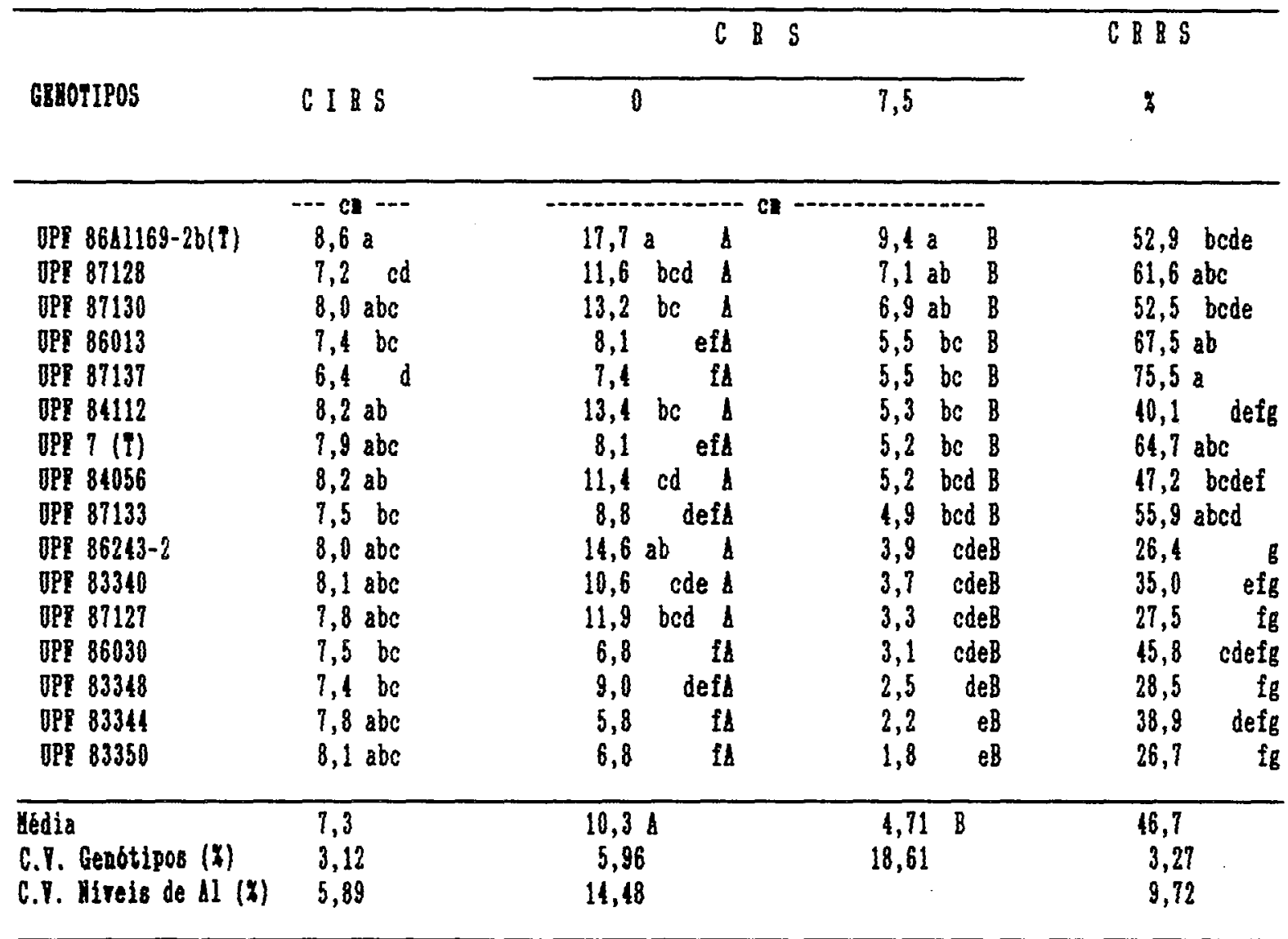

- Védias seguidas de nesa letra ninúscula na vertical e acióscula na borizontal, nấo

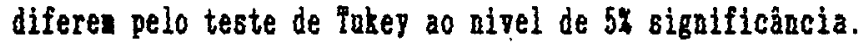


Tabela 24. Comprimento inicial (CIRS) e crescimento da raiz seminal (CRS/CRRS) de genótipos de aveia submetidos aos niveis $0 \in 7,5 \mathrm{mg}$ Al/litro de solução nutritiva (Exp. 2).

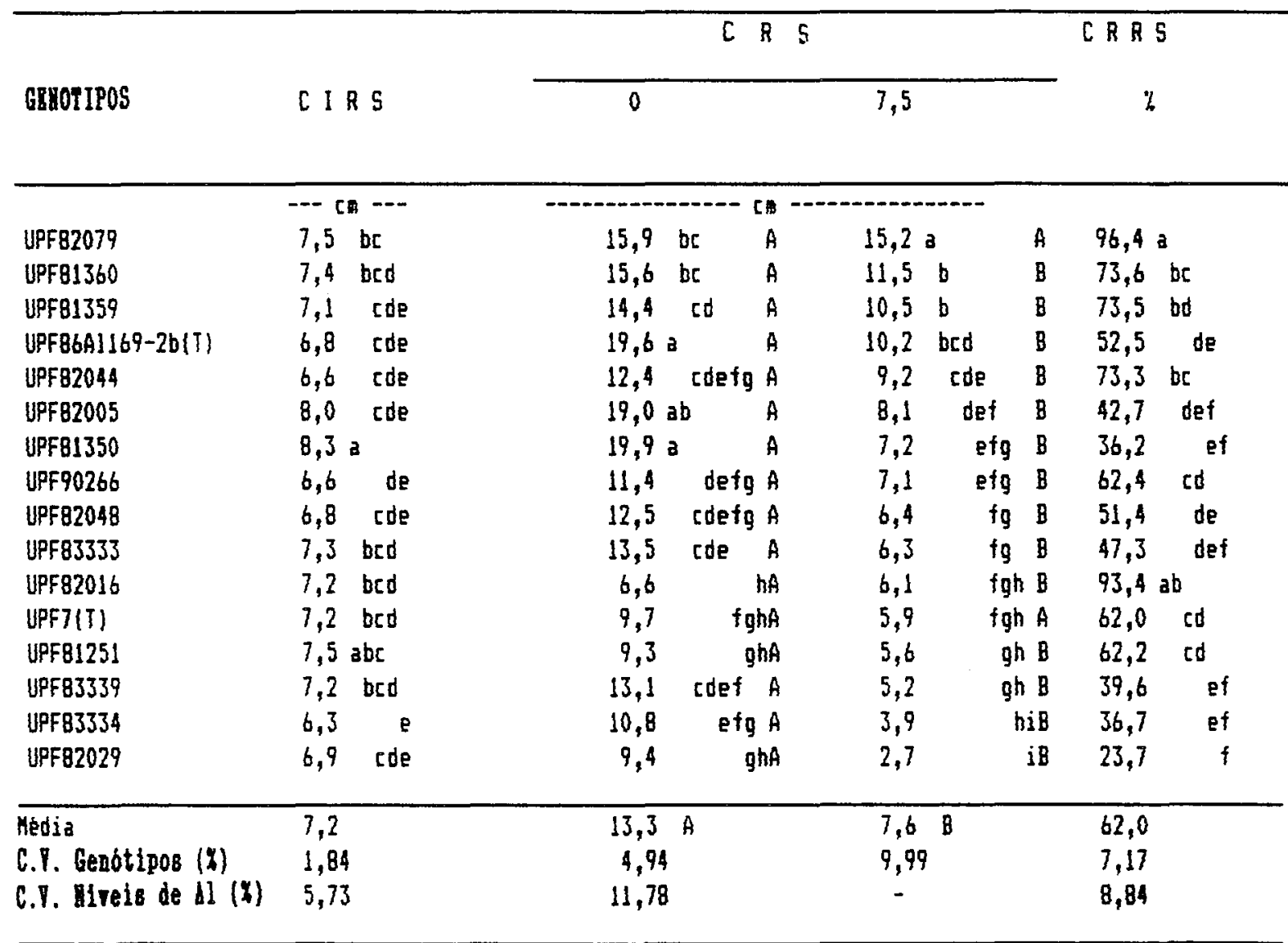

- Medias sequidas de mesa letra cinúscula na vertical a majuscula na horizontal, nto diferea pelo teste de Tukey ao nivel de $5 \%$ significencia. 
106.

Tabela 25. Comprimento inicial (CIRS) e crescimento da raiz seminal (CRS/CRRS) de genótipos de aveia submetidos aos níveis 0 e $7,5 \mathrm{mg}$ Al/litro de solução nutritiva (Exp. 3H).

\begin{tabular}{|c|c|c|c|c|}
\hline \multirow[b]{2}{*}{ GBHOTIPOS } & \multirow[b]{2}{*}{ CIBS } & \multicolumn{2}{|c|}{$C B S$} & \multirow{2}{*}{$\begin{array}{c}C B 85 \\
4\end{array}$} \\
\hline & & 0 & 7,5 & \\
\hline & --- ct --- & - & $-\ldots+\cdots$ & \\
\hline BPE $8641169-2 b(T)$ & 9,3 abc & $16,6 \mathrm{ab}$ & 11,8 a & 72,8 bed \\
\hline OPP 80221 & 8,7 bc & 17,1 a & 11,1 a B & 69,4 bed \\
\hline OPR 79223-2 & 8,7 bc & 14,1 abcd $\mathbb{A}$ & $11,0 \mathrm{ab}$ & 80,4 bc \\
\hline DPE 78B381-1 & $10,2 a$ & 14,2 abcd $d$ & 10,6 abc $B$ & 71,8 bc \\
\hline apt 79302 & $9,9 \mathrm{ab}$ & 7,1 ed & 9,6 abcdt & 134,9 a \\
\hline OPI $79205-1$ & 9,6 abc & 15,0 abc $d$ & 9,0 abcdB & 60,1 ad \\
\hline OPR 80265 & $9,7 \mathrm{abc}$ & 13,9 abcd $d$ & 8,8 abcdB & 85,0 bcd \\
\hline UPI 79229-1 & 9,0 abc & 9,74 cded & 8,4 abcd & 89,6 bc \\
\hline DPP $79 B 388$ & $9,8 \mathrm{ab}$ & 11,6 boded & $7,8 a b c d B$ & 74,7 bc \\
\hline DPR $7(T)$ & $8,5 \quad c$ & 8,2 el & 7,8 abcdd & $94,8 \mathrm{abc}$ \\
\hline OPI $80176-5$ & 9,6 abc & 7,7 el & $6,9 \mathrm{bcdt}$ & $103,3 a b c$ \\
\hline DPR 80197 & 9,5 abc & 9,1 & 6,9 bcds & 81,8 bc \\
\hline GPI 80215 & $9,5 a b c$ & 7,0 ed & 6,7 cds & $106,0 \mathrm{ab}$ \\
\hline UPR 80155 & 9,4 abc & 10,5 cded & 6,2 & $60,0 \mathrm{~cd}$ \\
\hline OPR $79339-2$ & $9,6 a b c$ & 6,9 & 5,8 & 28,8 bc \\
\hline DPP 79239-1 & $9,7 \mathrm{abc}$ & 18,9 a & 5,4 & 27,9 d \\
\hline Média & 9,4 & $11,7 \downarrow$ & 8,11 & 80,3 \\
\hline C.7. Genotipos (y) & 2,10 & 11,16 & 16,52 & 8,87 \\
\hline C.P. Miveis de Al (X) & 6,50 & 18,40 & & 17,07 \\
\hline
\end{tabular}

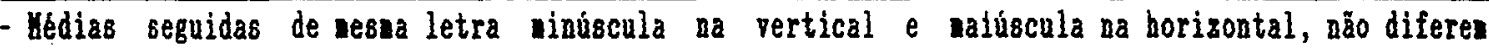
pelo teste de tukey ao aivel de $5 \%$ de significancia. 
Tabela 26. Comprimento inicial (CIRS) e crescimento da raiz seminal (CRS/CRRS) de genótipos de aveia submetidos aos niveis 0 e $7,5 \mathrm{mg}$ Al/litro de solução nutritiva (Exp. $3 I$ ).

\begin{tabular}{|c|c|c|c|c|}
\hline \multirow[b]{2}{*}{ GRORIPOS } & \multirow[b]{2}{*}{$C I \& S$} & \multicolumn{2}{|c|}{$C B S$} & \multirow{2}{*}{$\begin{array}{c}C B B S \\
*\end{array}$} \\
\hline & & 0 & 7,5 & \\
\hline 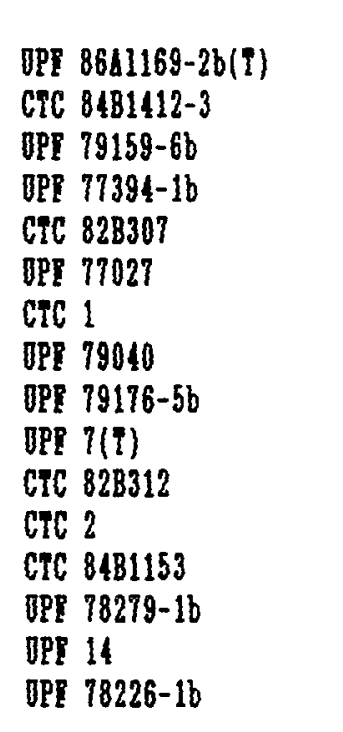 & $\begin{array}{l}7,5 \text { bcd } \\
7,5 \text { abc } \\
6,4 \text { f } \\
5,8 \text { f } \\
7,4 \text { cde } \\
8,3 \text { ab } \\
8 \text { abc } \\
7,3 \text { de } \\
7,5 \text { cd } \\
6,6 \text { ef } \\
7,4 \text { cde } \\
7,9 \text { abcd } \\
7,3 \text { de } \\
7,7 \text { abcd } \\
8,4 \text { a } \\
8,1 \text { abc }\end{array}$ & 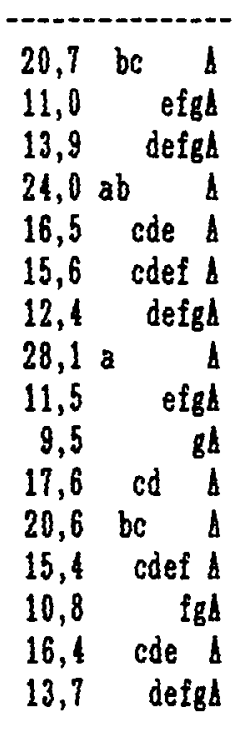 & 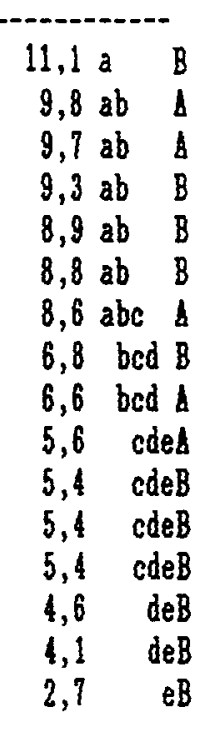 & $\begin{array}{l}53,7 \text { bcde } \\
94,0 \mathrm{a} \\
72,7 \mathrm{ab} \\
39,0 \text { cdef } \\
61,7 \text { bcd } \\
63,0 \text { bc } \\
69,7 \mathrm{ab} \\
24,3 \text { f } \\
59,3 \text { bcd } \\
62,3 \text { bed } \\
31,3 \text { ef } \\
26,3 \text { f } \\
36,0 \text { def } \\
43,0 \text { cdef } \\
24,7 \text { } \\
20,0\end{array}$ \\
\hline Yedis & 7,5 & $16,1 d$ & $7,0 \quad 8$ & 48,8 \\
\hline C.7. Genótipos (x) & 2,99 & 19,41 & 15,02 & 10,67 \\
\hline C.I. Ulirels de Al (X) & 6,14 & 16,34 & & 12,16 \\
\hline
\end{tabular}

- Vedias seguidas de resea letra inúscula aa vertical e adúscula aa horizontal, não diferex sigaificativaneate pelo teste de fukey ao nivel de $5 \%$ de significancia. 
108.

17); UPF89106 e UPF86Al198-5-4b (Tabela 18), UFRGS6, UPF86068, UFRGS1 e UFRGS4 (Tabela 19); UPF15, UPF86120, UPF84297, UPF84125, UPF87070 e UPF84321 (Tabela 20); UPF 85357, UPF85233, UPF84330, UPF86155 e UPF84329-1 (Tabela 21); UPF87097, UPF86160, UPF7, UPF86134 e UPF86055 (Tabela 22); UPF87128 e UPF87130 (Tabela 23); UPF80221, UPF79223-2, UPF78B381-1, UPF79302, UPF79205-1, UPF80265, UPF79229-1, UPF79B388 e UPF7 (Tabela 25); e, CTC84B1412-3, UPF79159-6b, UPF77394-1b, CTC82B307, UPF77027 e CTC 1 (Tabela 26).

Quanto ao efeito inibitório do nível $7,5 \mathrm{mg}$ Al, em relação o nível 0 , sobre o crescimento, observa-se que essa redução não foi significativa para os genótipos UPF86018, UPF79I174-3, UPF86A1264-1b (Tabela 16); UPF84157 (Tabela 20); UPF85044 (Tabela 21), UPF7 e UPF86111 (Tabela 22): UPF82079 e UPF7 (Tabela 24); UPF79223-2, UPF79302, UPF79229-1, UPF7, UPF80176-5, UPF80197, UPF80215 e UPF79339-2 (Tabela 25); e, CTC84B1412-3, UPF79159-6b, CTC1, UPF79176-5b e UPF7 (Tabela 26).

O crescimento relativo da raíz seminal (CRRS), considerando os onze experimentos de seleção, foi de $49,4 \%$ no tratamento com aluminio, em relação ao nivel zero. Destacaram-se os genótipos: UPF86A1198-5-1b (Tabela 16); UPF13 (Tabela 17); UPF86A1198-5-4b (Tabela 18); UFRGS-1 (Tabela 19); UPF86120 e UPF84125 (Tabela 20); UPF85044 (Tabela 21); UPF86111 (Tabela 22); UPF87137 (Tabela 23); UPF82079 (Tabela 24); UPF79302 (Tabela 25); e CTC84B1412-3 (Tabela 26).

Dentre os 156 genótipos de aveia avaliados, pode-se destacar por apresentarem média no grupo estatístico superior, pelo teste Tukey, quanto ao parâmetro CRS na presença de Al, e crescimento relativo (CRRS), não diferindo na média dos tratamentos 0 e $7,5 \mathrm{mg} \mathrm{Al} / \mathrm{litro}$ de solução, os genótipos UPF82079 (Tabela 24), CTC84B1412-3, UPF79159-6b e CTC-1 (Tabela 26). 


\subsubsection{Comparação entre as testemunhas}

A análise de variância conjunta das médias do CIRS, CFRS e CRS dos genótipos testemunhas, UPF86Al169-2b (tolerante) e UPF7 (sensivel), revelou diferencas altamente significativas entre os onze experimentos considerados na seleção e entre genótipos, não sendo significativa a interação genótipos $x$ experimentos (Tabela D4).

o desdobramento da interaça em cada experimento, revelou diferenças significativas entre as testemunhas, quanto ao CIRS, apenas no experimento $3-B$, não sendo significativa nos demais experimentos. Quanto ao crescimento da raíz seminal (CRS) e comprimento final (CFRS), as testemunhas só não diferiram no ensaio 3-F (Tabela D4), ao nível de $5 \%$ de significância.

Em relação ao crescimento inicial da raíz seminal (CIRS), o teste de Tukey ao nivel de $5 \%$ de significância, não revelou diferenças entre as médias gerais das duas testemunhas nos diferentes experimentos (Tabela 27). Observa-se na média dos dois genótipos, que o experimento $3 \mathrm{H}$, apesar de não diferire significativamente $(P>0,05)$ dos experimentos $3 \mathrm{C}$ e $3 \mathrm{~F}$, foi superior aos demais experimento ao nivel de $5 \%$ de significância. Na comparação dos dois genótipos dentro dos experimentos, verifica-se que apenas nos experimentos 1 e $3 B$, o CIRS do genótipo UPF86Al169-2b (tolerante) foi superior ao da testemunha sensivel UPF7, não diferindo nos demais experimentos ao nivel de $5 \%$ de significância. 
Tabela 27. Comprimento inicial da raiz seminal (CIRS) de dois genótipos de aveia submetidos ao nível $7,5 \mathrm{mg}$ Al/litro de solução nutritiva.

Experimentos

UPF86A1 169-2b UPF 7

Média

\begin{tabular}{|c|c|c|c|}
\hline & 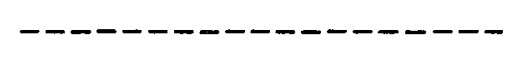 & $\mathrm{cm}----$ & ------- \\
\hline $\operatorname{Exp} \cdot 3 H$ & $9,47 \mathrm{~A}$ & $8,74 \mathrm{~A}$ & $9,10 \mathrm{a}$ \\
\hline Exp. $3 C$ & 8,44 A & $8,84 \mathrm{~A}$ & $8,64 \mathrm{ab}$ \\
\hline $\operatorname{Exp} \cdot 3 F$ & $8,22 \mathrm{~A}$ & $8,18 \mathrm{~A}$ & $8,20 \mathrm{ab}$ \\
\hline Exp. $3 G$ & $8,41 \mathrm{~A}$ & 7,74 A & $8,07 \mathrm{~b}$ \\
\hline $\operatorname{Exp} \cdot 3 E$ & 7,08 A & $7,14 \mathrm{~A}$ & $7,11 \quad \mathrm{c}$ \\
\hline Exp. $3 \mathrm{~A}$ & $7,37 \mathrm{~A}$ & $6,78 \mathrm{~A}$ & $7,07 \quad \mathrm{c}$ \\
\hline Exp. 3D & $6,97 \mathrm{~A}$ & $7,07 \mathrm{~A}$ & 7,02 \\
\hline Exp. 2 & $6,89 \mathrm{~A}$ & $7,15 \mathrm{~A}$ & 7,02 \\
\hline Exp. 3B & $7,56 \mathrm{~A}$ & $6,40 \mathrm{~B}$ & 6,98 \\
\hline Exp. $3 I$ & $7,27 \mathrm{~A}$ & $6.64 \mathrm{~A}$ & 6,96 \\
\hline $\operatorname{Exp} \cdot 1$ & $5.80 \mathrm{~A}$ & $5,13 \mathrm{~B}$ & 5,47 \\
\hline Media & $7.59 \mathrm{~A}$ & $7,25 \mathrm{~B}$ & 7,42 \\
\hline Tukey $(0,05)$ & $\mathrm{ns}$ & $\mathrm{ns}$ & $0,96 *$ \\
\hline C.V. $(\%)$ & 6,61 & & \\
\hline
\end{tabular}

- Médias seguidas da mesma letra minúscula na vertical e maiúscula na horizontal não diferem pelo teste de Tukey ao nível de $5 \%$ de significância.

Quanto ao crescimento final da raíz seminal (CFRS), não houve diferença significativa entre os experimentos para os dois genótipos que também nao diferiram entre si, pelo teste de Tukey, ao nivel de $5 \%$ de significância (Tabela 28). A média dos dois genótipos, no experimento $3 \mathrm{H}(18.84)$. foi significativamente superior aos demais experimentos. 
Tabela 28. Comprimento final da raiz seminal (CFRS) de dois genótipos de aveia submetidos ao nível $7,5 \mathrm{mg}$ Al/litro de solução nutritiva.

Experimentos

$$
\text { UPF 86Al 169-2b UPF } 7
$$

Médi a

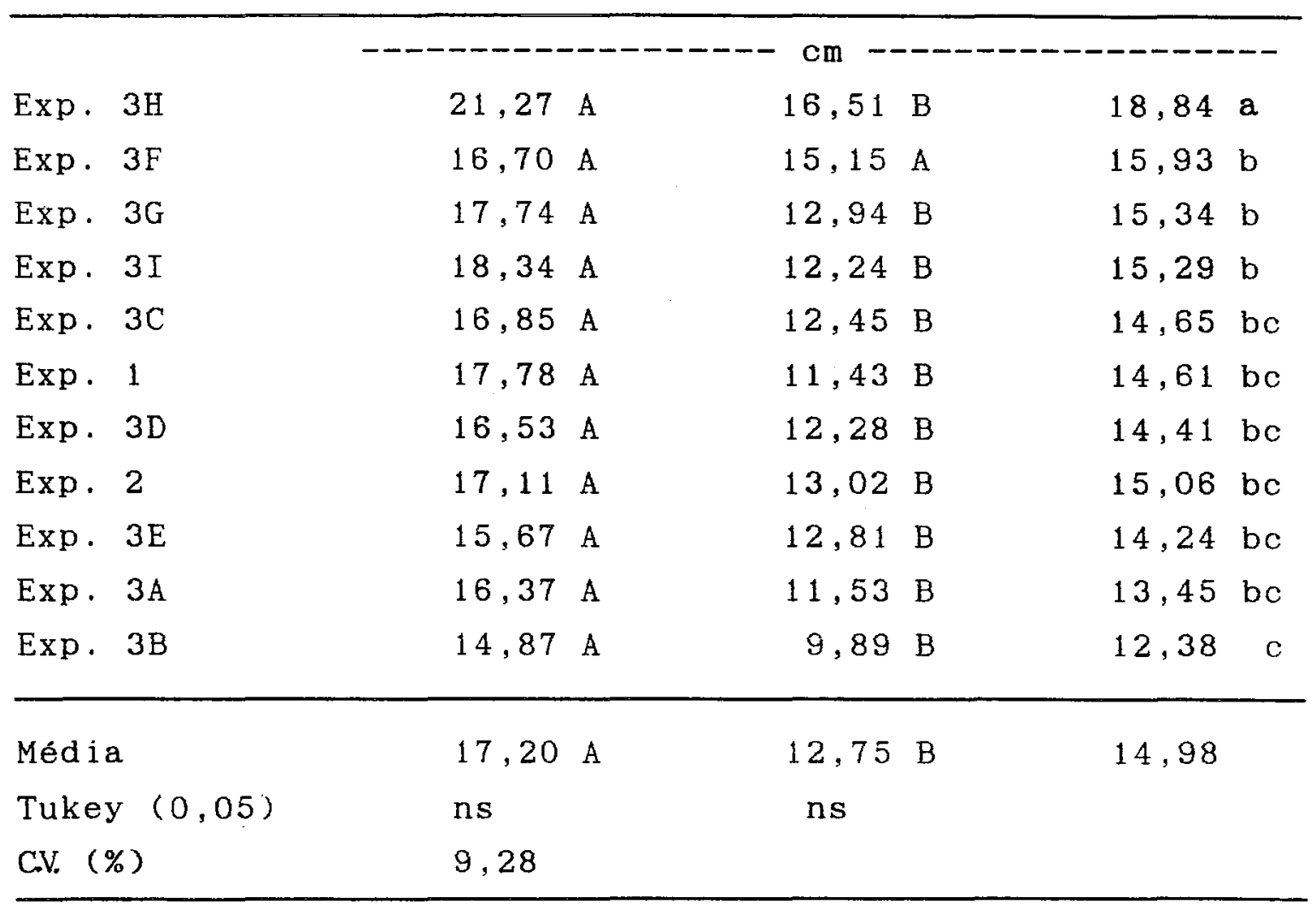

- Médias seguidas de mesma letra minúscula na vertical e maiúscula na horizontal não diferem pelo teste de Tukey ao nível de $5 \%$ de significäncia.

Para a variável CRS, as médias de cada um dos genotipos não diferiram entre experimentos e também não diferiram entre si, no experimento 3F (Tabela 29). Nos demais experimentos. O CRS da testemunha tolerante UPF86A1169-2b foi 
significativamente superior em relaçao a testemunha sensivel UPF7. Na comparação entre médias dos dois genótipos, observase que a média do Exp 3H, apesar de não diferir dos experimentos $1,3 \mathrm{I}, 3 \mathrm{~F}, 3 \mathrm{D}, 3 \mathrm{G}$ e 2 foi significativamente superior às médias dos demais experimentos, ao nível de $5 \%$ de significância.

Tabela 29. Crescimento da raiz seminal (CRS) de dois genótipos de aveia submetidos ao nível $7,5 \mathrm{mg}$ Al/litro de solucão nutritiva.

Experimentos

UPF 86A $1169-2 \mathrm{~b}$

Média

UPF 7

\begin{tabular}{|c|c|c|c|}
\hline & ---------- & $-\mathrm{cm}--$ & --------- \\
\hline Exp. $3 H$ & $11,80 \mathrm{~A}$ & $7,78 \mathrm{~B}$ & $9,79 \mathrm{a}$ \\
\hline $\operatorname{Exp} \cdot 1$ & $11,98 \mathrm{~A}$ & $6,31 \mathrm{~B}$ & $9,14 \mathrm{ab}$ \\
\hline Exp. $3 I$ & $11,07 \mathrm{~A}$ & $5,60 \mathrm{~B}$ & $8,33 a b c$ \\
\hline Exp. 2 & $10,22 \mathrm{~A}$ & $5,87 \mathrm{~B}$ & $8,04 a b c$ \\
\hline Exp. $3 F$ & $8,48 \mathrm{~A}$ & $6,98 \mathrm{~A}$ & $7,73 \mathrm{abcd}$ \\
\hline $\operatorname{Exp} \cdot 3 D$ & $9,56 \mathrm{~A}$ & $5,21 \quad \mathrm{~B}$ & $7,39 a b c d$ \\
\hline Exp. $3 G$ & $9,37 \mathrm{~A}$ & $5,20 \mathrm{~B}$ & $7,29 a b c d$ \\
\hline Exp. $3 E$ & $8,59 \mathrm{~A}$ & $5,67 \mathrm{~B}$ & $7,13 \mathrm{bcd}$ \\
\hline Exp. $3 A$ & $9,00 \mathrm{~A}$ & $4,75 \mathrm{~B}$ & $6,88 \mathrm{bcd}$ \\
\hline Exp. $3 \mathrm{C}$ & $8,42 \mathrm{~A}$ & $3,62 \mathrm{~B}$ & $6,02 \mathrm{~cd}$ \\
\hline Exp. $3 B$ & $7,32 \mathrm{~A}$ & $3,49 \mathrm{~B}$ & 5,41 \\
\hline Média & $9,62 \mathrm{~A}$ & $5,50 \mathrm{~B}$ & 7,56 \\
\hline Tukey $(0,05)$ & $\mathrm{ns}$ & ns & \\
\hline C.V. (\%) & 16,97 & & \\
\hline
\end{tabular}

- Médias seguidas de mesma letra minúscula na vertical e maiúscula na horizontal não diferem pelo teste de Tukey ao nivel de $5 \%$ de significância. 
4.3.1.4. Classificação dos genótipos de aveia quanto a seleção ao nível $7,5 \mathrm{mg}$ Al/litro de solução

A partir dos resultados de crescimento da raiz seminal (CRS) dos 156 genótipos de aveia (Tabela 16 a 26), foi realizada uma classificaça dos mesmos, em tolerantes (grupo estatistico superior pelo teste de Tukey no respectivo experimento), sensíveis (grupo estatístico inferior) e pouco tolerantes (intermediários). Em cada grupo de tolerância, os genótipos foram subdivididos em tres grupos, mediante o resultado do crescimento relativo da raiz seminal (CRRS), no nível $7,5 \mathrm{mg}$ Al/litro de solução, respectivamente em: responsivos (grupo estatístico superior pelo teste de Tukey), não responsivos (grupo estatístico inferior) e pouco responsivos (intermediários), conforme Tabela 30.

Verifica-se na Tabela 30 , que 18 genótipos são tolerantes/responsivos, 18 tolerantes/pouco responsivos, 10 tolerantes/não responsivos, 14 pouco tolerantes/responsivos, 25 pouco tolerantes/pouco responsivos, 18 pouco tolerantes/nao responsivos, 12 sensiveis/responsivos, 9 sensiveis/pouco responsivos e 32 sensiveis/não responsivos. Pelos critérios utilizados, o genótipo UPF86Al169-2b pode ser considerado tolerante/pouco responsivo, considerando-se o CRS médio nos onze experimentos, enquanto o cultivar UPF 7 foi pouco tolerante/responsivo, pelo mesmo critério

Concluiu-se que, ao nivel de $7,5 \mathrm{mg}$ Al/litro de solução nutritiva, os genótipos mais tolerantes e mais responsivos são: UPF79159-6b, UPF79302, UPF82079, UPF84125, UPF84297, UPF84321, UPF86068, UPF86120, UPF86A1198-5-4b, UPF 87070, UPF87128, UPF3, UPF15, UFRSS1, UFRSS4, UFRSS6, CTC84B1412-3 e CTC1. 
Tabela 30. Classificação dos genótipos de aveia quanto à tolerância (CRS) e ao efeito responsivo (CRRS) em relação ao nível $7,5 \mathrm{mg}$ Al/litro de solução.

\begin{tabular}{|c|c|c|}
\hline Responsivos & Pouco responsivos & Näo responsivos \\
\hline \multicolumn{3}{|c|}{ Tolerantes } \\
\hline $\begin{array}{l}\text { UPF82079 } \\
\text { UPF86A } 198-5-4 \mathrm{~b} \\
\text { UPF3 } \\
\text { UFRGS } 6 \\
\text { UPF } 86068 \\
\text { UFRGS } 1 \\
\text { UFRGS } \\
\text { UPF } 15 \\
\text { UPF86120 } \\
\text { UPF84297 } \\
\text { UPF84125 } \\
\text { UPF87070 } \\
\text { UPF84321 } \\
\text { UPF87128 } \\
\text { CTC1 } \\
\text { UPF79302 } \\
\text { CTC84B1412-3 } \\
\text { UPF79159-6b }\end{array}$ & $\begin{array}{l}\text { UPF86A1169-2b } \\
\text { UPF89106 } \\
\text { UPF85357 } \\
\text { UPF85233 } \\
\text { UPF2 } \\
\text { UPF84330 } \\
\text { UPF86155 } \\
\text { UPF84329-1 } \\
\text { UPF87097 } \\
\text { UPF86160 } \\
\text { UPF86134 } \\
\text { UPF87130 } \\
\text { UPF79223-2 } \\
\text { UPF78B381-1 } \\
\text { UPF79229-1 } \\
\text { UPF79B388 } \\
\text { CTC82B307 } \\
\text { UPF77027 }\end{array}$ & $\begin{array}{l}\text { UPF86011 } \\
\text { UPF86112 } \\
\text { UPF5 } \\
\text { UPF86136 } \\
\text { UPF86045 } \\
\text { UPF86055 } \\
\text { UPF80221 } \\
\text { UPF9205-1 } \\
\text { UPF80265 } \\
\text { UPF77394-1 }\end{array}$ \\
\hline \multicolumn{3}{|c|}{ Pouco tolerantes } \\
\hline $\begin{array}{l}\text { UPF7 } \\
\text { UPF80176-5 } \\
\text { UPF80215 } \\
\text { UPF84322-1 } \\
\text { UPF85044 } \\
\text { UPF86A1264-7-8b } \\
\text { UPF 86013 } \\
\text { UPF86018 } \\
\text { UPF86057 } \\
\text { UPF86081 } \\
\text { UPF87133 } \\
\text { UPF87137 } \\
\text { UPF6 } \\
\text { UFRGS } 2\end{array}$ & $\begin{array}{l}\text { UPF } 11 \\
\text { UPF } 86006 \\
\text { UPF86A } 1264-7-4 \mathrm{~b} \\
\text { UFRGS } 10 \\
\text { UFRGS } 7 \\
\text { UFRGS } 12 \\
\text { UFRGS } 5 \\
\text { UPF86238 } \\
\text { UFRGS } 9 \\
\text { UFRGS } 11 \\
\text { UFRGS } 8 \\
\text { UPF84132 } \\
\text { UPF84324-2 } \\
\text { UPF85375 } \\
\text { UPF86010 } \\
\text { UPF 86023 } \\
\text { UPF84056 } \\
\text { UPF81360 }\end{array}$ & $\begin{array}{l}\text { UPF87071 } \\
\text { UPF89085 } \\
\text { UPF86A1264-2- } \\
\text { UPF86212 } \\
\text { UPF87111 } \\
\text { UPF86044 } \\
\text { UPF86110 } \\
\text { UPF87069 } \\
\text { UPF86037 } \\
\text { UPF86139 } \\
\text { UPF84112 } \\
\text { UPF82005 } \\
\text { UPF81350 } \\
\text { UPF83333 } \\
\text { UPF80155 } \\
\text { UPF79239-1 } \\
\text { UPF79040 } \\
\text { UPF86301-1 }\end{array}$ \\
\hline
\end{tabular}


Cont i nuação.

\begin{tabular}{ll}
\hline Responsivos & Pouco responsivos Na responsivos \\
\hline Pouco tolerantes \\
UPF81359 \\
UPF82044 \\
UPF80266 \\
UPF82048 \\
UPF80197 \\
UPF79339-2 \\
UPF79176-5b
\end{tabular}

\section{Sensive is}

UPF 8

São Carlos

UPF 12

Suregrain

UPF 13

UPF 10

UPF 4

UPF 86A 1 198-5-1b

UPF 87 A $1264-1 \mathrm{~b}$

UPF 86 A 1 264-1-4b

UPF 86111

UPF82016
Coronado

UPF 1

UPF9

UPF79 i 174-3

UPF 86A $1264-10 \mathrm{~b}$

UPF 86A1 264-10-2b

UPF 86A $1264-1-1 \mathrm{~b}$

UPF 86029

UPF 81251
UPF86113

UPF 87107

UPF 84057

UPF 86066

UPF 84181

UPF 86094

UPF 85238-10

UPF 86024

UPF 86067

UPF 86083

UPF 87072

UPF87 126

UPF86034

UPF 86243-2

UPF 83340

UPF87 127

UPF 86030

UPF 83348

UPF 83344

UPF 83350

UPF 83359

UPF 83334

UPF 89130

UPF 88109

UPF 89043

UPF 82029

CTC82B3 12

CTC2

CTC84B1 153

UPF 7 8279-1b

UPF 14

UPF 7 8226-1 b 


\subsubsection{Seleção ao nível $15 \mathrm{mg}$ Al/litro de solução}

A análise de variância (teste $F$ ), dos parâmetros CIRS, CFRS e CRS, revelou diferenças altamente significativas $(P<0,01)$ entre os 86 genótipos avaliados ( Tabela D5).

A média do CIRS foi de $6,11 \mathrm{~cm}$, com um coeficiente de variação de $6,83 \%$ e uma diferença mínima significativa, pelo teste de Tukey ao nível de $5 \%$ de significância de 0,15 (Tabela 31). A média do CFRS foi de $15,81 \mathrm{~cm}$, com um coeficiente de variação de $7,8 \%$ e uma diferença minima significativa pelo teste de Tukey de $4,33 \mathrm{~cm}$.

$\mathrm{Na}$ Tabela 31, também é apresentada a comparação entre as médias do crescimento da raíz seminal. A média final deste parâmetro foi de $9,73 \mathrm{~cm}$, com um coeficiente de variação de $11,69 \%$. Verifica-se, que o genótipo UPF82079 $(19,7 \mathrm{~cm})$, apesar de não diferir significativamente $(\mathrm{P}>0,05)$ do genótipo UPF77394-1, apresentou CRS superior aos demais genótipos avaliados. Os genótipos UPF86A1169-2b e UPF7, não diferiram significativamente $(P<0,05)$ quanto aoCRS, quando submetidos ao nivel $15 \mathrm{mg}$ Al/litro de solução nutritiva.

Quanto ao indice de tolerância relativa ao Al (ITRAl), calculado para o parâmetro CRS, observou-se uma média de 3,53. A comparação entre genótipos foi efetuada mediante a determinação do desvio padrão (1,34), conforme Tabela 31. Verifica-se, que o genótipo UPF82079 com média do ITRAL de 9,0, revelou-se altamente tolerante, pois o CRS é igual à média acrescida de 4 desvios padrão. Em seguida aparece o genótipo UPF77394-1, média do ITRAL de 7,8 igual a média acrescida de 3 desvios padrão. Os genótipos UFRGS-6 $(5,9), \operatorname{UPF} 86006(5,8), \operatorname{UPF} 81360(5,7), \operatorname{UPF} 86160(5,3)$, 
UPF86112 (5,1), UPF81359 $(5,0)$ e UPF2 $(4,9)$, apresentam ITRAl superior a média acrescida de um desvio padrão. Destes genótipos que se destacam, os genótipos UPF81360, UPF86006 e UPF81359 foram classificadas como pouco tolerantes/pouco responsivos (Tabela 30 ), no nível $7,5 \mathrm{mg} \mathrm{Al/litro.} \mathrm{Os} \mathrm{demais}$ genótipos foram todos classificados como tolerantes.

Os genótipos UPF86Al169-2b $(4,8)$ e UPF7 $(3,7)$ também não diferiram entre si através da comparação quanto ao ITRA 1 .

Já os genótipos UPF79176-5b, UPF79I174-3, UPF86018, UPF84056, UPF79223-2, UPF86057, UPF82044, UPF87133, Suregrain, UPF86A1264-2-7b, UPF86A1264-10b, UPF84321, UPF80265, São Carlos, UPF80197 e UPF87071 apresentaram ITRAI inferior (média subtraída de um desvio padrão), quando submetidos ao nível $15 \mathrm{mg} \mathrm{Al/litro} \mathrm{de} \mathrm{soluçáo.} \mathrm{Comparando} \mathrm{com}$ a Tabela 30 , observa-se que dos genótipos mais sensiveis ao nivel $15 \mathrm{mg} \mathrm{Al/1}$, apenas UPF79223-2, UPF84321 e UPF80265 se comportaram como tolerantes ao nível $7,5 \mathrm{mg}$ Al/litro de solução.

Tabela 31. Comprimento inicial (CIRS), e final (CFRS), crescimento da raiz seminal (CRS) e indice de tolerância relativa ( ITRAl), de genótipos de aveia branca submetidos ao nivel $15 \mathrm{mg}$ Al/litro de solução nutritiva.

\begin{tabular}{lcccc}
\hline Genótipos & CIRS & CFRS & CRS & ITRAl \\
\hline UPF82079 & $-0-1,0$ & 24,7 & 19,7 & 9,0 SSSS \\
UPF77394-1 & 5,2 & 22,8 & 17,6 & $7,85 S$ \\
UFRGS6 & 7,3 & 21,4 & 14,0 & $5,9 S$ \\
\hline
\end{tabular}


Cont i nuação .

\begin{tabular}{|c|c|c|c|c|}
\hline Genótipos & CIRS & CFRS & CRS & ITRA 1 \\
\hline \multicolumn{5}{|c|}{ 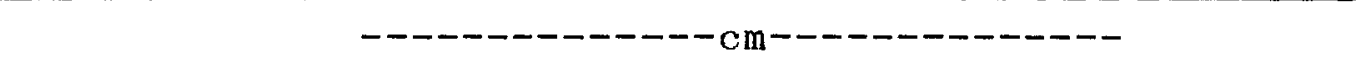 } \\
\hline UPF 86006 & 5,2 & 19,0 & 13,8 & $5,8 \mathrm{~S}$ \\
\hline $\mathrm{UPF} 81360$ & 6,1 & 19,7 & 13,6 & $5,7 \mathrm{~S}$ \\
\hline UPF86160 & 6,6 & 19,5 & 12,6 & $5,3 \mathrm{~S}$ \\
\hline UPF 86112 & 7,2 & 19,6 & 12,5 & $5,1 \mathrm{~S}$ \\
\hline UPF8 1359 & 6,2 & 18,7 & 12,4 & $5,0 S$ \\
\hline UPF2 & 7,5 & 17,4 & 12,2 & $4,9 \mathrm{~S}$ \\
\hline UPF 86045 & 7,3 & 19,4 & 12,1 & 4,8 \\
\hline UPF86A $1198-5-4 b$ & 6,9 & 18,9 & 12,0 & 4,8 \\
\hline UPF86Al 169-2b & 7,1 & 19,1 & 12,0 & 4,8 \\
\hline UPF $79159-6 b$ & 5,2 & 17,1 & 11,9 & 4,7 \\
\hline UPF 87070 & 5,7 & 17,6 & 11,8 & 4,7 \\
\hline UPF86Al198-5-1b & 6,2 & 17,9 & 11,8 & 4,7 \\
\hline UPF79229-1 & 6,0 & 17,6 & 11,7 & 4,6 \\
\hline UPF 5 & 6,6 & 18,2 & 11,6 & 4,6 \\
\hline UPF3 & $6 ; 5$ & 18,1 & 11,6 & 4,6 \\
\hline UPF 86136 & 7,2 & 18,8 & 11,6 & 4,6 \\
\hline UPF86011 & 6,3 & 17,9 & 11,5 & $4 ; 5$ \\
\hline UPF86155 & 7,3 & 18,5 & 11,2 & 4,3 \\
\hline UPF87097 & 5,3 & 16,5 & 11,2 & 4,3 \\
\hline UPF 87128 & 6,2 & 17,4 & 11,2 & 4,3 \\
\hline UPF79176-5b & 6,4 & 17,6 & 11,2 & 4,3 \\
\hline UPF79205-1 & 5,4 & 16,5 & 11,1 & 4,3 \\
\hline UPF86120 & 5,5 & 16,5 & 11,0 & 4,2 \\
\hline UPF 84297 & 5,3 & 16,2 & 10,9 & 4,2 \\
\hline UFRGS-2 & 6,6 & 17,3 & 10,6 & 4,0 \\
\hline UPF78B381-1 & 6,4 & 16,9 & 10,5 & 4,0 \\
\hline UPF80221 & 4,9 & 15,4 & 10,5 & 4,0 \\
\hline UPF87 130 & 6,1 & 16,5 & 10,4 & 3,9 \\
\hline
\end{tabular}


Cont i nuação

\begin{tabular}{lcccc}
\hline Genótipos & CIRS & CFRS & CRS & ITRA \\
\hline UPF15 & 5,6 & 16,0 & 10,4 & 3,9 \\
UFRGS10 & 6,7 & 17,1 & 10,4 & 3,9 \\
UPF86055 & 6,6 & 16,9 & 10,3 & 3,8 \\
UPF86013 & 4,1 & 14,4 & 10,3 & 3,8 \\
UPF-6 & 6,2 & 16,5 & 10,3 & 3,8 \\
CTC82B307 & 5,8 & 16,0 & 10,1 & 3,7 \\
UPF-8 & 7,8 & 17,9 & 10,1 & 3,7 \\
UPF-7(T) & 6,6 & 16,6 & 10,0 & 3,7 \\
UPF84330 & 6,4 & 16,4 & 9,9 & 3,6 \\
UPF85233 & 6,6 & 16,5 & 9,9 & 3,6 \\
UFRGS4 & 6,6 & 16,4 & 9,8 & 3,6 \\
UPF89106 & 5,5 & 15,2 & 9,8 & 3,6 \\
CTC84B1415-3 & 7,2 & 17,0 & 9,8 & 3,6 \\
UPF82005 & 5,6 & 15,3 & 9,7 & 3,5 \\
UPF79339-2 & 6,6 & 16,1 & 9,5 & 3,4 \\
UPF89085 & 5,3 & 14,8 & 9,5 & 3,4 \\
UPF84112 & 5,8 & 15,3 & 9,5 & 3,4 \\
UPF77027 & 7,2 & 16,6 & 9,4 & 3,4 \\
UPF86068 & 6,1 & 15,5 & 9,4 & 3,4 \\
UPF79302 & 6,7 & 16,1 & 9,4 & 3,4 \\
UPF-12 & 7,3 & 16,6 & 9,2 & 3,2 \\
UFRGS1 & 5,2 & 14,4 & 9,2 & 3,2 \\
UPF85375 & 6,2 & 15,4 & 9,2 & 3,2 \\
UPF87073 & 6,8 & 15,9 & 9,1 & 3,2 \\
UPF85357 & 5,7 & 14,7 & 9,0 & 3,1 \\
UPF86113 & 5,3 & 14,2 & 9,0 & 3,1 \\
UPF84329-1 & 6,0 & 14,8 & 8,8 & 3,0 \\
UPF87137 & 5,5 & 14,1 & 8,6 & 2,9 \\
\hline
\end{tabular}


Cont i nuação

\begin{tabular}{|c|c|c|c|c|}
\hline Genótipos & CIRS & CFRS & CRS & ITRA I \\
\hline \multicolumn{5}{|c|}{ 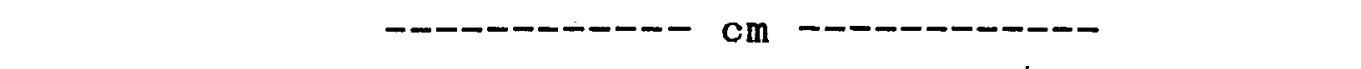 } \\
\hline UPF-11 & 6,7 & 15,0 & 8,6 & 2,9 \\
\hline UPF 84322-1 & 5,2 & 13,6 & 8,4 & 2,8 \\
\hline CORONADO & 7,1 & 15,5 & 8,3 & 2,8 \\
\hline CTC1412-3 & 6,8 & 15,0 & 8,2 & 2,7 \\
\hline UPF86111 & 5,2 & 13,1 & 7,9 & 2,5 \\
\hline UPF 80215 & 5,3 & 13,1 & 7,9 & 2,5 \\
\hline UPF84125 & 4,2 & 12,0 & 7,7 & 2,4 \\
\hline UPF87111 & 5,9 & 13,4 & 7,6 & 2,4 \\
\hline UPF87030 & 5,8 & 13,2 & 7,4 & 2,3 \\
\hline UPF85044 & 7,2 & 14,7 & 7,4 & 2,3 \\
\hline UPF 86Al 264-1b & 6,1 & 13,5 & 7,4 & 2,3 \\
\hline UPF $79176-5 b$ & 6,4 & 13,6 & 7,1 & $2,1 \mathrm{I}$ \\
\hline UPF79I174-3 & 6,3 & 13,3 & 7,0 & $2 ; 0 I$ \\
\hline UPF6018 & 5,6 & 12,5 & 6,8 & $1,9 \mathrm{I}$ \\
\hline UPF84056 & 5,2 & 12,0 & 6,8 & $1,9 I$ \\
\hline UPF79223-2 & 6,9 & 13,6 & 6,7 & $1,9 \mathrm{I}$ \\
\hline UPF 86057 & 5,6 & 12,3 & 6,6 & $1,8 \mathrm{I}$ \\
\hline UPF82044 & 4,4 & 10,9 & 6,6 & $1,8 \mathrm{I}$ \\
\hline UPF87133 & 6,3 & 12,8 & 6,5 & $1,8 \mathrm{I}$ \\
\hline SUREGRA IN & 6,1 & 12,6 & 6,4 & $1,7 \mathrm{I}$ \\
\hline UPF $86 \mathrm{~A} 1264-2-7 \mathrm{~b}$ & 7,5 & 13,9 & 6,4 & $1,7 I$ \\
\hline UPF 86A 1264-10b & 6,6 & 12,9 & 6,3 & $1,7 \mathrm{I}$ \\
\hline UPF84321 & 4,8 & 11,1 & 6,3 & $1,7 \mathrm{I}$ \\
\hline UPF 80265 & 6,5 & 12,6 & 6,0 & $1,5 I$ \\
\hline S̃̃O CARLOS & 5,4 & 11,4 & 6,0 & $1,5 \mathrm{I}$ \\
\hline
\end{tabular}


Cont i nuação

\begin{tabular}{lcccc}
\hline Genótipos & CIRS & CFRS & CRS & ITRA I \\
\hline & $-5,9$ & 11,3 & 5,4 & 1,2 I \\
UPF80197 & 5,3 & 10,4 & 5,1 & 1,01 \\
UPF87071 & & & & \\
\hline Média & 6,11 & 15,81 & 9,73 & 3,53 \\
Tukey (0,05) & 0,15 & 4,33 & 4,00 & $1,34 *$ \\
C.V. (\%) & 6,83 & 7,80 & 11,64 & 38,96
\end{tabular}

* Desvio padrão. SSSS = média acrescida de 4 desvio padrão; SSS = média acrescida de 3 desvio padrão; $S=$ média acrescida de um desvio padrão; $I$ = média subtraída de um desvio padrão.

4.4. Tolerância e responsividade de genótipos de aveia branca submetidos aos niveis 0 e $15 \mathrm{mg} \mathrm{Al/litro} \mathrm{de}$ sol ução

A análise de variância (teste $F$ ) dos resultados da avaliação de 16 genótipos de aveia branca, submetidos aos niveis 0 e $15 \mathrm{mg} A 1 / 1$ itro de solução, revelou diferenças significativas $(P<0,05)$, para os niveis de Al, quanto aos parâmetros CIRS, CRS, CRRS, CFRS e CFRRS (Tabela D6). Nessa mesma tabela, verifica-se que para genótipos, as diferenças foram altamente significativas $(P<0,01)$. Já a interação genótipos $x$ níveis de $A l$, não foi significativa para o parâmetro CIRS e foi altamente significativa para os parâmetros CRS, CRRS, CFRS e CFRRS.

A correlação linear simples entre esses parâmetros (Tabela 32) mostrou que o CIRS não se correlacionou com CRS, CRRS e CFRRS, pelo teste $t(P<0,05)$. Já a correlação entre CIRS e CFRS foi altamente significativa, resultado que comprova a tendência já observada nos itens 4.1 (Tabela 11) e 4.2 (Tabela 18). 
Portanto, apesar da correlaça entre CRS e CFRS ser altamente significativa e o coeficiente de correlaçăo de $98,6 \%$, a comparaçăo entre médias, foi realizada apenas para o crescimento da raíz seminal (CRS), pois este não sofre a interferência do CIRS, na avaliaça do grau de tolerância dos genótipos ao alumínio e o crescimento relativo da raíz seminal (CRRS) na avaliação do grau de responsividade.

O comprimento inicial da raíz seminal (CIRS) médio foi de $5,96 \mathrm{~cm}$, com um coeficiente de variação de $1,26 \%$ para genótipos e 8,91 para níveis de Al (Tabela 33). Verifica-se que o genótipo UPF86045 (7,4 cm), apesar de não diferir ( $>$, 0,05) dos genótipos UPF7, UPF86A1169-2b, UPF79302, UPF86112, UPF86A1198-5-4b, UPF3 e UPF86136, foi

Tabela 32. Valores de $t$ e coeficiente das correlaços ( $r$ ) entre parâmetros de crescimento da raíz seminal de genótipos de aveia submetidos a 0 e $15 \mathrm{mg} \mathrm{Al/1}$ itro de solução.

$\begin{array}{lllrlc}\text { CIRS } & x & \text { CRS } & 0,87 \text { ns } & - \\ & x & \text { CRRS } & 0,57 \text { ns } & - \\ & x & \text { CFRS } & 2,65 * * & - \\ & x & \text { CFRRS } & 0,36 \text { ns } & \\ \text { CRS } & x & \text { CRRS } & 4,71 * * & 43,7 \\ & x & \text { CFRS } & 32,40 * * & 98,4 \\ & x & \text { CFRRS } & 4,58 * * & 42,7 \\ \text { CRRS } & x & \text { CFRS } & 4,41 * * & 41,3 \\ & x & \text { CFRRS } & 56,53 * * & 98,6 \\ \text { CFRS } & x & \text { CFRRS } & 4,35 * * & 40,9\end{array}$


Tabela 33. Efeito de niveis de alumínio sobre os parâmetros CIRS, CRS e CRRS em plantas de aveia submetidos aos níveis 0 e $15 \mathrm{mg}$ Al/litro de solução.

\section{R S}

CRRS

Genótipos

CIRS

15

\begin{tabular}{|c|c|c|c|c|}
\hline & $---\cdots$ & $--c \mathrm{~cm}-\cdots$ & $--\infty-\cdots-\cdots$ & \\
\hline UPF 82079 & $5,2 \mathrm{fg}$ & $20,0 \mathrm{~b} A$ & $19,7 \mathrm{a} \quad \mathrm{A}$ & $97,7 b$ \\
\hline UPF86112 & $6,4 \mathrm{abcde}$ & $27,7 \mathrm{a} A$ & $12,5 b \quad B$ & 44,7 ef \\
\hline UPF86045 & $7,4 a$ & $25,9 \mathrm{aA}$ & $12,1 \mathrm{~b} B$ & $46,3 \mathrm{ef}$ \\
\hline UPF $86 A 1198-5-4 b$ & $6,7 \mathrm{abcd}$ & $8,4 g \quad A$ & $12, \mathrm{Ob} \mathrm{A}$ & $149,0 \mathrm{a}$ \\
\hline$U P F 86 A 1169-2 b(T)$ & $6,4 a b c$ & $26,2 \mathrm{a} \quad \mathrm{A}$ & $12, \mathrm{Ob} B$ & 45,7 ef \\
\hline UPF3 & $6,5 a b c d e$ & $16,1 \mathrm{bcdeA}$ & $11,6 \mathrm{bc} \mathrm{B}$ & 71,7 bcde \\
\hline UPF 86136 & $7,0 a b$ & $20,2 \mathrm{~b} \quad \mathrm{~A}$ & $11,6 \mathrm{bc} A$ & $58,3 \mathrm{cdef}$ \\
\hline UPF87128 & 6, obcdef & $16,4 \mathrm{bcd} A$ & $11,2 \mathrm{bc} A$ & $66,3 \mathrm{cde}$ \\
\hline UPF 84297 & $5,4 e f g$ & 13,7 def $A$ & $10,9 \mathrm{bc} B$ & $79,3 \mathrm{bcd}$ \\
\hline UPF 15 & $5,6 \mathrm{defg}$ & $19,3 \mathrm{bc} \quad \mathrm{A}$ & $10,4 \mathrm{bcd} B$ & $54,7 \mathrm{def}$ \\
\hline UPFT (T) & $6,3 a b c d e$ & $11,8 \mathrm{efg} A$ & $10,0 \mathrm{bcd} A$ & $85,7 \mathrm{bc}$ \\
\hline UPF 86068 & $5,9 \mathrm{cdef}$ & $15,0 \mathrm{cde} A$ & 9,4 bcde $A$ & 64, Ocdef \\
\hline UPF79302 & $6,4 a b c d e$ & $10,0 f g \quad A$ & 9,4 bcde A & $97,0 \mathrm{~b}$ \\
\hline UPF 84322 & $5,1 \mathrm{fg}$ & $12,3 \operatorname{defg} A$ & $8,4 \mathrm{cde} \quad A$ & $68,3 \mathrm{cde}$ \\
\hline UPF 84125 & $3,4 \mathrm{~h}$ & $14,7 \mathrm{de} \mathrm{A}$ & $7,7 \mathrm{de} \mathrm{A}$ & 53, Odef \\
\hline UPF 84321 & $4,6 g \mathrm{~h}$ & $16,4 \mathrm{bcd}$ & $6,3 \mathrm{e} B$ & $38,7 \mathrm{f}$ \\
\hline Média & 5,96 & 17,1 & 10,9 & 70,0 \\
\hline C.V. genótipo(\%) & 1,26 & 8,7 & 10,3 & 5,05 \\
\hline C.V. níveis de Al & 8,91 & - & - & 11,03 \\
\hline
\end{tabular}

* Médias seguidas de mesma letra minúscula na vertical e -maíscula na horizontal não diferem pelo teste de Tukey ao nível de $5 \%$ de significäncia. 
superior aos demais genótipos avaliados ao nivel de $5 \%$ de significância.

Quanto ao crescimento da raíz seminal (CRS), a comparação entre médias pelo teste de Tukey, mostrou que na ausência de alumínio, os genótipos UPF86Al169-2b $(26,2 \mathrm{~cm})$, UPF86045 $(25,9 \mathrm{~cm})$ e UPF86112 $(27,7 \mathrm{~cm}), \quad$ superaram significativamente os demais genótipos avaliados. Este resultado demonstra o alto potencial de crescimento radicular desses genótipos. Já o genótipo UPF86A1198-5-4b, apresentou o menor crescimento da raíz nesse nível de Al, comprovando os resultados discutidos anteriormente (Tabela 18).

$\mathrm{Na}$ presença de $15 \mathrm{mg}$ Al/litro de solução, (Tabela 33) observou-se que o genótipo UPF82079 $(19,7 \mathrm{~cm}$ ) apresentou CRS significativamente superior aos demais genótipos avaliados, confirmando os resultados discutidos nos ítens $4.2,4.3 .1$ e 4.3 .2 (Tabela 16,24 e 31), como sendo dentre os 156 avaliados o genótipo de aveia branca mais tolerante ao alumínio.

Verifica-se na Tabela 33 , que a inibição provocada por $15 \mathrm{mg}$ Al/litro de solução, em relação ao tratamento com ausência do elemento, não foi significativa ao nível de 5\%, para os genótipos UPF82079, UPF7, UPF87128, UPF79302, UPFA1 198-5-4b, UPF84125, UPF84322, UPF86068 e UPF86136.

Quanto ao crescimento relativo de raíz seminal (CRRS), verificou-se que no genóti po UPF86A1 198-5-4b houve um aumento de $49 \%$ quando na presença de alumínio, sendo superior aos demais genótipos avaliados, na comparaça pelo teste de Tukey $(P<0,05)$, conforme Tabela 33 .

Segundo os critérios utilizados no item 4.1, observou-se que os genótipos UPF82079, UPF84297, UPF86A1 1985-4b e UPF3, mostraram-se tolerantes e responsivos quando 
submetidos ao nível de $15 \mathrm{mg}$ Al/litro de soluçao. Os genótipos UPF86A1169-2b, UPF87128, UPF86045, UPF86112 e UPF86136 são tolerantes mas não responsivos. Os genótipos UPF7 e UPF79302, apesar de sensiveis são responsivos, enquanto os genótipos UPF84125, UPF84321, UPF84322, UPF86068 e UPF 15, podem ser considerados sensíveis ao nivel $15 \mathrm{mg}$ Al/litro e não responsivos. Esses resultados confirmam aqueles obtidos na seleção com $15 \mathrm{mg}$ Al/litro, discutido no ítem 4.3 .2 e os resultados apresentados na Tabela 31.

4.5. Avaliação da tolerância de genótipos de aveia preta ao alumínio, em solução nutritiva

A análise de variância dos resultados da avaliação de 14 genótipos de aveia preta e duas testemunhas de aveia branca UPF 7 (sensivel) e. UPF 86Al169-2b (tolerante), aplicando o teste $F$, revelou diferenças altamente significativas $(P<0,01)$ entre os genótipos, para todos os parâmetros (CIRS, CRS, CRRS, CFRS e CFRRS). Para os niveis de alumínio e a interação genótipos $x$ níveis de $A l$ as diferenças não foram significativas $(P>0,05)$ para o parâmetro CIRS e foram altamente significativas $(P<0,01)$ para os demais parâmetros (Tabela DT).

\subsubsection{Comprimento inicial da raíz seminal (CIRS)}

A comparação, entre médias pelo teste de Tukey, é apresentada na Tabela 34 , tendo em vista que a interação não foi significativa. Verifica-se que o CIRS do genótipo UPF86Al169-2b $(6,9 \mathrm{~cm})$, sem diferir do genótipo GR9 $(6,4 \mathrm{~cm})$, foi superior aos demais genótipos avaliados 
126.

Tabela 34. Efeito de quatro níveis de alumínio na soluçao nutritiva sobre o crescimento inicial da raiz seminal (CIRS) de genótipos de aveia preta.

\begin{tabular}{|c|c|c|c|c|c|}
\hline \multirow{2}{*}{ Genótipos } & \multicolumn{4}{|c|}{ Niveis de Al (mg/l) } & \multirow{2}{*}{ Média } \\
\hline & 0 & 7,5 & 15 & 30 & \\
\hline & \multicolumn{5}{|c|}{ 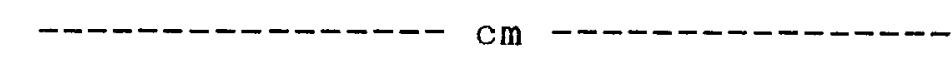 } \\
\hline $\mathrm{UPF}-7$ (T) & 5,97 & 6,27 & 5,94 & 5,69 & $6,0 \mathrm{bc}$ \\
\hline UPF $86 \mathrm{~A} \perp 169-2 \mathrm{~b}(\mathrm{~T})$ & 6,94 & 6,98 & 6,77 & 6,75 & $6,9 \mathrm{a}$ \\
\hline UPF 84APO 1 & 5,87 & 5,85 & 6,05 & 6,20 & $6,0 \mathrm{bc}$ \\
\hline Preta comum & 5,53 & 5,72 & 5,38 & 5,13 & 5,4 \\
\hline UPF 87AP0 1 & 5,71 & 5,59 & 5,58 & 5,98 & 5,7 \\
\hline Preta Argentina & 6,17 & 5,88 & 5,90 & 5,57 & $5,9 \mathrm{bc}$ \\
\hline UPF 87APO2 & 5,87 & 5,57 & 5,80 & 5,47 & 5,7 \\
\hline UPF 85 APO 1 & 5,79 & 5,82 & 5,75 & 5,56 & $5,7 \mathrm{bc}$ \\
\hline UPF771066 & 5,93 & 5,77 & 6,07 & 5,97 & $5,9 \mathrm{bc}$ \\
\hline UPF771352 & 5,68 & 6,14 & 6,03 & 5,59 & $5,9 \mathrm{bc}$ \\
\hline UPF771434 & 5,69 & 5,77 & 6,14 & 6,17 & $5,9 \mathrm{bc}$ \\
\hline UPF7 71436 & 5,93 & 5,86 & 5,80 & 5,97 & $5,9 \mathrm{bc}$ \\
\hline UPF771456 & 5,81 & 4,98 & 5,59 & 5,24 & $5,4 \quad \mathrm{c}$ \\
\hline UPF8 41005 & 6,05 & 6,02 & 6,04 & 5,97 & $6,0 \mathrm{bc}$ \\
\hline UPF781101 & 5,95 & 6,00 & 6,10 & 5,99 & $6,0 \mathrm{bc}$ \\
\hline GR9 & 6,57 & 6,26 & 6,41 & 6,30 & $6,4 a b$ \\
\hline Média & 5,97 & 5,96 & 5,90 & 5,85 & 5,9 \\
\hline C.V. Genótipos (\%) & 2,01 & & & & \\
\hline C.V. Niveis de Al (\%) & 8,47 & & & & \\
\hline
\end{tabular}

* Médias seguidas de mesma letra minúscula na vertical e maiúscula na horizontal não diferem pelo teste de Tukey ao nível de $5 \%$ de significância.

$(P<0,05)$. A média geral foi de $5,9 \mathrm{~cm}$, com um coeficiente de 
variação para genótipos de $2,01 \%$ e de $8,47 \%$ para níveis de A I .

A correlação I inear simples de CIRS, com os demais parâmetros (Tabela 35 ), foi significativa pelo teste $t$, com o CFRS, ao nível de $5 \%$ de significância, com um coeficiente de correlação de $15,1 \%$. Suas correlações com os demais parâmetros, não foram significativas, ao nível de $5 \%$ de significância.

Em função dos resultados das correlações, os efeitos do aluminio sobre os genótipos de aveia preta são discutidos, apenas em relação ao crescimento da raíz seminal (CRS) e ao crescimento relativo (CRRS).

Tabela 35. Valores de $t$ e coeficiente de correlação ( $r$ ) das correlações entre os parâmetros de crescimento da raíz seminal, em genótipos de aveia preta submetidas a quatro níveis de Al em solução nutritiva.

$\begin{array}{rll}\text { CIRS } & \mathrm{x} & \text { CRS } \\ \mathrm{x} & \text { CRRS } \\ \mathrm{x} & \text { CFRS } \\ \mathrm{x} & \text { CFRRS }\end{array}$

CRS $\mathrm{x}$ CRRS

$\mathrm{x}$ CFRS

$\mathrm{x}$ CFRRS

CRRS $x$ CFRS

$x$ CFRRS

CFRS $x$ CFRRS

$$
\begin{aligned}
& 0,20 \mathrm{~ns} \\
& 0,96 \mathrm{~ns} \\
& 2,11 \text { * } \\
& 0,12 \mathrm{~ns}
\end{aligned}
$$

$13,61 * *$

$60,06 * *$

$12,78 * *$

$12,67 * *$

$92,96 * *$

$12,26 * *$

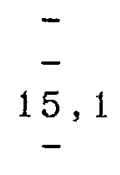

70,3

97,5

68,0

67,7

98,9

66,5 níveis de 5 e $1 \%$ de significância; ns = não significativo. 


\subsubsection{Crescimento da raiz seminal (CRS)}

Na Tabela 36 são apresentadas as comparações entre as médias, através do teste de Tukey, quanto ao parâmetro CRS. No nível 0 de alumínio, o genótipo UPF77434 $(24,8 \mathrm{~cm})$, que sem diferir $(P>0,05)$ dos genótipos UPF78101 $(22,4 \mathrm{~cm})$ e UPF87AP01 $(21,9 \mathrm{~cm})$, apresentou crescimento da raiz seminal superior em relação aos demais genótipos $(P<0,05)$. Para 7,5 mg Al/litro de solução, o genótipo UPF77436 $(17,7 \mathrm{~cm})$, que sem diferir $(P>0,05)$ de UPF84005, UPF84AP01, UPF77434, UPF77066, UPF77352 e Preta Comum, foi superior aos demais genótipos $(P<0,05)$.

No nível $15 \mathrm{mg} A l / l$ de solução, o genótipo UPF84AP01 $(17,3 \mathrm{~cm})$, que sem diferir de UPF77434, UPF77436, UPF77066, UPF84005, GR9 e Preta Argentina, superou significativamente os demais genótipos avaliados. Quando submetidos ao nível máximo de Al (30 $\mathrm{mg} / \mathrm{l})$ o genótipo UPF77434 $(17,6 \mathrm{~cm})$, sem diferir significativamente de UPF84AP01, UPF77066 e UPF77436, apresentou CRS superior aos demais genótipos (Tabela 36).

Na comparação de desempenho das aveias pretas em relação às duas testemunhas de aveia branca, verificou-se que em nenhum dos níveis de Al, apresentaram CRS no grupo estatístico superior. Nos níveis 0 e 7,5 , a testemunha UPF86A1169-2b foi superior em relação à UPF7. Nos níveis 15 e $30 \mathrm{mg} A \mathrm{l} / 1$, as duas testemunhas apresentaram médias de CRS inferiores a todos os genótipos de aveia preta, ao nivel de $5 \%$ de significância, sem diferirem entre si.

Quanto ao efeito do aumento da concentração de Al na solução, verificou-se que, além das testemunhas, apenas os genótipos UPF77434, UPF87AP02, Preta Comum e UPF87AP01, apresentaram redução significativa entre os niveis 0 e $7,5 \mathrm{mg}$ 
Al/l (Tabela 36).

Tabela 36. Efeito de quatro níveis de alumínio nasolucão nutritiva sobre o crescimento da raíz seminal (CRS) de genótipos de aveia preta.

\begin{tabular}{|c|c|c|c|c|}
\hline \multirow{2}{*}{ Genót ipos } & \multicolumn{4}{|c|}{ Niveis de Al (mg/l) } \\
\hline & 0 & 7,5 & 15 & 30 \\
\hline \multicolumn{5}{|c|}{$---------------\quad \mathrm{cm}---------------$} \\
\hline UPF77434 & $24,8 \mathrm{aA}$ & $14,8 \mathrm{abcB}$ & $15,8 \mathrm{abB}$ & $17,6 \mathrm{aB}$ \\
\hline UPF $84 A P O 1$ & $18,8 \mathrm{bcdA}$ & $14,8 \mathrm{abcA}$ & $17.3 \mathrm{aA}$ & $15,3 \mathrm{abA}$ \\
\hline UPF77066 & $16,5 \mathrm{bcdA}$ & $14,2 \mathrm{abcA}$ & $15,0 a b c A$ & $13,4 \mathrm{abcA}$ \\
\hline UPF77436 & $16,6 \mathrm{cdeA}$ & $17,7 \mathrm{aAB}$ & $15,3 \mathrm{abcAB}$ & $13,3 \mathrm{abcB}$ \\
\hline Preta Argentina & $14,7 \mathrm{deA}$ & $12,9 \mathrm{bcA}$ & $12,5 \mathrm{acA}$ & $12,4 \mathrm{bcA}$ \\
\hline UPF87AP02 & $18,2 \mathrm{bcdA}$ & $11,1 \mathrm{cdB}$ & $12,9 \mathrm{bcdB}$ & $11,6 \mathrm{bcB}$ \\
\hline UPF7 7352 & $14,3 \mathrm{deA}$ & $13,9 \mathrm{abcA}$ & $13,7 \mathrm{bcdA}$ & $11,6 \mathrm{bcA}$ \\
\hline UPF85AP01 & $15,5 \mathrm{cdeA}$ & $11,7 \mathrm{bcdA}$ & $12,2 \mathrm{cdA}$ & $11,3 \mathrm{bcA}$ \\
\hline GR9 & $16,5 \mathrm{cdeA}$ & $12,9 \mathrm{bcAB}$ & $14,2 \mathrm{abcdAB}$ & $11,2 \mathrm{bcB}$ \\
\hline Preta Comum & $18,9 \mathrm{bcdA}$ & $13,8 \mathrm{abcB}$ & $13,0 \mathrm{bcdB}$ & $11,2 \mathrm{bcB}$ \\
\hline UPF84005 & $16,1 \mathrm{cdeA}$ & $16,1 \mathrm{abA}$ & $14,6 \mathrm{abcAB}$ & $11, \mathrm{ObcB}$ \\
\hline UPF 87APO 1 & $21,9 a b A$ & $11.8 \mathrm{bcdB}$ & $11,2 \mathrm{~dB}$ & $10,8 \mathrm{bcB}$ \\
\hline UPF77456 & $11,9 \mathrm{eA}$ & $12,2 \mathrm{bcdA}$ & $13,8 \mathrm{bcdA}$ & $10,6 \mathrm{cA}$ \\
\hline UPF78101 & $22,4 \mathrm{abA}$ & $12,6 \mathrm{bcA}$ & $13,9 \mathrm{bcd} B$ & $10,0 \mathrm{cB}$ \\
\hline UPF86A1 169-2b(T) & $19,6 \mathrm{bcA}$ & $12,7 \mathrm{bcB}$ & $7,8 \mathrm{eC}$ & $4,5 \mathrm{dC}$ \\
\hline UPF $7(T)$ & $12,3 \mathrm{eA}$ & $7,7 \mathrm{~dB}$ & $4,8 \mathrm{eB}$ & $4,1 \mathrm{~dB}$ \\
\hline Média & $17,5 \mathrm{~A}$ & $13,2 \mathrm{~B}$ & $12,44 \mathrm{~B}$ & $11,3 \mathrm{~B}$ \\
\hline C.V. Genótipos (\%) & 9,31 & 11,67 & & \\
\hline C.V. Niveis de Al (\%) & 10,73 & & & \\
\hline
\end{tabular}

* Médias seguidas da mesma letra minúscula na vertical e maiúscula na horizontal, não diferem pelo teste de Tukey ao nível de $5 \%$ de significância. 
superiores quanto ao parâmetro CRS no nível máximo de Al, não apresentaram reduça significativa para o aumento da concentração de Al na soluçào (Tabela 36). Este mesmo resultado foi observado para os genótipos menos tolerantes no nivel máximo, como a Preta Argentina, UPF77352 e UPF77456.

Quanto ao CRS, o comportamento dos genótipos nos niveis de Al é melhor observado, através da análise de regressão polinomial, cujas equaçós e coefi-cientes de determinação $\left(R^{2}\right)$ são apresentados na Tabela 37.

O CRS das testemunhas decresceu de forma quadrática, com um $R^{2}$ de $100 \%$, significativo ao nivel de $1 \%$. A reação dos genótipos Preta Argentina, UPF85AP01, UPF77352 e UPF77456 ao Al, não se expressa significativamente pela regressão linear, quadrática ou cúbica, ao nível de $5 \%$ de significância. Resultado semelhante foi obtido em relação ao genótipo UPF84AP01, que apresentou entretanto, significância para a regressão cúbica.

Os genótipos UPF77434 e UPF84AP01, que se destacaram no nível máximo de alumínio, apresentaram decréscimo no CRS, expresso de forma quadrática, enquanto para genótipos UPF77066 e UPF77436, o decréscimo do CRS se expressa de forma linear (Tabela 37 ).

\subsubsection{Crescimento relativo da raiz seminal} (CRRS)

A comparação entre as médias do crescimento relativo da raiz seminal, através do teste de Tukey, são apresentados na Tabela 38. Observa-se, em termos percentuais, que a redução de crescimento devido ao aumento na concentração de Al não foi significativa, ao nível de $5 \%$ de significância, para os genótipos Preta Argentina, UPF84AP01, UPF77352, UPF77066 e UPF85AP01. 
Tabela 37. Equaçoes de regressão polinomial, coeficientes de determinação $\left(R^{2}\right)$ e valores máximos ou mínimos, para o efeito de quatro niveis de Al (Y), sobre o CRS (X) de genótipos de aveia preta.

\begin{tabular}{|c|c|c|c|}
\hline Genotipos & Equações & $\mathrm{R}^{2}(\%)$ & $\begin{array}{c}\text { Máx. } \\
\text { mín. }\end{array}$ \\
\hline UPF 7 (T) & $Y=12,28-0,73 X+0,015 X^{2}$ & 100,0 & 24,3 \\
\hline UPF86A1169-2b(T) & $Y=19,63-1,07 X+0,019 X^{2}$ & 100,0 & 28,2 \\
\hline UPF84AP0 1 & $Y=18,76-1,26 X+0,117 X^{2}-0,003 X^{3}$ & 100,0 & - \\
\hline Preta Comum & $Y=17,22-0,229 \mathrm{X}$ & 78,5 & - \\
\hline UPF87AP0 1 & $Y=21,15-1,193 X+0,029 X^{2}$ & 92,1 & 20,6 \\
\hline UPF 87AP02 & $Y=17,29-0,64 X+0,015 \mathrm{X}^{2}$ & 70,8 & 21,3 \\
\hline UPF77066 & $Y=16,49-0,113 \mathrm{X}$ & 67,7 & - \\
\hline UPF77434 & $Y=23,43-1,127 X+0,031 X^{2}$ & 83,5 & 18,2 \\
\hline UPF77436 & $Y=17,42-0,130 X$ & 78,5 & - \\
\hline UPF 84005 & $Y=16,79-0,17 X$ & 92,5 & - \\
\hline UPF78101 & $Y=19,22-0,342 X$ & 67,8 & - \\
\hline GR 9 & $Y=15,66-0,149 x$ & 73,4 & - \\
\hline
\end{tabular}

No maior nível de Al utilizado ( $30 \mathrm{mg} / \mathrm{l}$ ), o maior CRRS foi o do genótipo UPF77456 (90,7\%), que não diferiu de outros oito genotipos $(P>0,05)$. Nesse nivel de $A 1$, as testemunhas UPF86Al169-2b (23,3\%) e UPF7 (34,0\%), apresentaram CRRS significativamente inferior, no nível de $5 \%$ de significância em relação a 11 genótipos de aveia preta (Tabela 38), como também foi, em relação ao parâmetro CRS (Tabela 36). 
Tabela 38. Efeitos de quatro níveis de Aluminio na soluça nutritiva sobre o crescimento relativo da raiz seminal (CRRS) de genótipos de aveia preta.

\begin{tabular}{|c|c|c|c|c|}
\hline \multirow{2}{*}{ Genótipos } & \multicolumn{4}{|c|}{ Niveis de Al (mg/l) } \\
\hline & 0 & 7,5 & 15 & 30 \\
\hline & \multicolumn{4}{|c|}{ 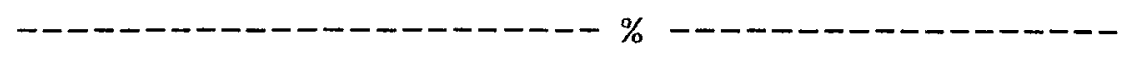 } \\
\hline UPF77456 & $100 \mathrm{aA}$ & $105,7 \mathrm{abAB}$ & $116,7 \mathrm{aAB}$ & $90,7 \mathrm{aB}$ \\
\hline Preta Argentina & $100 \mathrm{aA}$ & $89,0 a b c d e A$ & $86,7 \mathrm{bcdA}$ & $85,0 a b A$ \\
\hline UPF $84 \mathrm{APO} 1$ & $100 \mathrm{aA}$ & 79,7 bcdef gA & $92,7 \mathrm{abcA}$ & $82,0 \mathrm{abcA}$ \\
\hline UPF77436 & $100 \mathrm{aA}$ & $107,7 \mathrm{aAB}$ & $92,3 \mathrm{abcAB}$ & $81,0 \mathrm{abcB}$ \\
\hline UPF7 7352 & $100 \mathrm{aA}$ & $99,0 \mathrm{abcdA}$ & $97,0 \mathrm{abA}$ & $81,0 \mathrm{abcA}$ \\
\hline UPF77066 & $100 \mathrm{aA}$ & $81,3 \mathrm{bcdef} A$ & $86, O$ bcdA & $76,7 \mathrm{abcA}$ \\
\hline UPF 85AP01 & $100 \mathrm{aA}$ & 77,3 cdefgA & $81,7 \mathrm{bcdA}$ & $75,3 a b c d A$ \\
\hline UPF 7 7434 & $100 \mathrm{aA}$ & $59,3 f g B$ & 63,3 def $B$ & $70,7 \mathrm{abcde} B$ \\
\hline UPF 84005 & $100 \mathrm{aA}$ & $100,0 \mathrm{abcA}$ & $90,7 \mathrm{abcAB}$ & $68,7 \mathrm{abcde} B$ \\
\hline GR 9 & $100 a A$ & $79,3 \mathrm{cdef} g \mathrm{AB}$ & $87,3 \mathrm{bcdAB}$ & $68,3 \mathrm{bcde} B$ \\
\hline UPF 87AP02 & $100 a \mathrm{~A}$ & $61,3 \mathrm{fgB}$ & 71, ObcdeB & 64,0 bcdeB \\
\hline Preta comum & $100 \mathrm{aA}$ & 73,3 def $g B$ & $69,7 \mathrm{cdeB}$ & $58,3 \mathrm{cdef} B$ \\
\hline UPF87AP01 & $100 \mathrm{aA}$ & $55,0 g B$ & 51,7 ef $\mathrm{B}$ & 50, Odef $B$ \\
\hline UPF78101 & $100 \mathrm{aA}$ & $57,3 \mathrm{fgB}$ & $63,7 \mathrm{def} B$ & 46,0 efgB. \\
\hline UPF $7(\mathrm{~T})$ & $100 a A$ & 63,0 efgB & 39,3 ef $B C$ & $34,0 \mathrm{fgC}$ \\
\hline UPF85AI 169-2b(T) & $100 \mathrm{aA}$ & 65,3 efgB & $40,7 \mathrm{fBC}$ & $23,3 \mathrm{gC}$ \\
\hline Média & $100 \mathrm{~A}$ & $78,4 \mathrm{~B}$ & $76, \mathrm{OB}$ & $65,9 \mathrm{~B}$ \\
\hline C.V. Genótipos (\%) & 8,93 & & & \\
\hline C.V. Niveis de Al(\%) & 11,56 & & & \\
\hline
\end{tabular}

Médias seguidas da mesma letra minúscula na vertical e maiúscula na horizontal, não diferem pelo teste de Tukey ao nível de $5 \%$ de significância. 
Utilizando os critérios: tolerante para CRS > média e sensível para CRS < média e responsivo para CRRS > média e não responsivo para CRRS < média, e considerando-se o maior nivel de alumínio utilizado, as aveias pretas avaliadas podem ser classificadas em: a) Tolerantes/responsivos: UPF77434, UPF84AP01, UPF77066, UPF77436, Preta Argentina, UPF77352 e UPF85AP01: b) Tolerantes/não responsivas: UPF87AP02; c) Sensiveis/responsivas: GR9, UPF84005, UPF77456; d) Sensiveis/não responsivas: Preta Comum, UPF78101 e UPF87AP01.

No nivel de $30 \mathrm{mg} / \mathrm{l} \mathrm{Al}$, as testemunhas são classificadas como sensiveis e não responsivas.

O genótipo UPF77456, apesar de apresentar uma inibição de apenas $9,3 \%$ no nivel de $30 \mathrm{mg} A 1 / 1$, em relação ao tratamento com ausência de Al, apresentou um pequeno CRS, caracterizando-se como sensivel mas altamente responsivo. Por outro lado, os quatro genótipos que se destacaram quanto ao CRS, UPF77434, UPF84AP01, UPF77066 e UPF77436, apresentaram também pequena redução no crescimento, respectivamente de $29,3 \%, 18,8 \%$, $23,3 \%$ e $19,0 \%$, podendo ser considerados como muito tolerantes e muito responsivos.

Considerando que apenas um genótipo de aveia preta (UPF78101) apresentou inibição do crescimento da raíz seminal superior a $50 \%$, pode-se concluir que a concentração para a separação de genótipos de aveia preta tolerantes e sensíveis é superior a $30 \mathrm{mg} \mathrm{Al/l}$ de solução.

Já a concentração de Al para separar-se o nível de tolerância entre aveias pretas e brancas tolerantes, considerando a testemunha utilizada, foi de $15 \mathrm{mg} \mathrm{Al/l}$, pois neste nível o CRRS foi inferior a $50 \%$ (Tabela 38 ). 
4.6. Efeito do alumínio sobre alguns parâmetros de crescimento de aveia em cultivo hidropônico.

A influência dos níveis de alumínio sobre o crescimento de dois cultivares de aveia branca foi avaliado através do número de afilhos (NAF), comprimento da maior raíz (CMR), relação de peso foliar (RPF), rendimento de matéria seca das raizes (RMSR), folhas (RMSF), colmos e bainha (RMSCB), parte aérea (RMSPA) e da planta total (MST), e, através da relação raíz/parte aérea (RRPA).

\subsubsection{Número de afilhos/vaso (NAF)}

A análise de variância dos resultados do número de afilhos (NAF), pelo teste $F$, detectou diferenças significativas ( $P$ ( 0,05) apenas para os niveis de alumínio, e para a interaça genótipo $x$ níveis de alumínio (Tabela $D 8$ ). Não foram observadas diferenças significativos entre genotipos, sendo o coeficiente de variaçao de $13,2 \%$.

Pela comparação entre médias, através do teste de Tukey (Tabela 39), verificou-se que na ausência de alumínio, o número de afilhos (NAF) foi significativamente superior no genótipo UPF7 (sensivel) em relação a UPF86A1169-2b (tolerante) ao nivel de $5 \%$ de significância. No nível $10 \mathrm{mg} \mathrm{Al} / \mathrm{litro}$, esta posição se inverteu, demonstrando a interferência do Al, inibindo a emissão de afilhos em materiais genéticos mais sensiveis. Na comparação entre os níveis 0 e $10 \mathrm{mg} \mathrm{Al/1}$, observou-se que a redução do número de afilhos foi significativa no cultivar UPF7 e não significativa para UPF86A1169-2b. Estes resultados confirmam os relatados por OTSUKA (1968), que observou ser a tolerância de cultivares de trigo aos solos àcidos, indicada pela diferença no número de afilhos. 
Tabela 39. Efeito dos niveis de aluminio sobre alguns parâmetros de crescimento da aveia branca, em cultivo hidropônico.

\begin{tabular}{lccccc}
\hline \multirow{3}{*}{ Genótipos } & \multicolumn{1}{c}{ Niveis de Al } & $(\mathrm{mg} / \mathrm{l})$ \\
& 0 & 10 & 20 & 30 & 40 \\
\hline
\end{tabular}

Número de af ilhos (NAF)

$\begin{array}{lllllll}\text { UPF86A1169-2b } & 17,3 \mathrm{bA} & 17,0 \mathrm{aA} & 11,7 \mathrm{aB} & 11,3 \mathrm{aB} & 7,7 \mathrm{aB} & 13,0 \mathrm{a} \\ \text { UPF-7 } & 22,7 \mathrm{aA} & 12,0 \mathrm{bB} & 11,3 \mathrm{aBC} & 10,7 \mathrm{aBC} & 7,7 \mathrm{aC} & 12,9 \mathrm{a} \\ \text { Média } & 20,2 \mathrm{~A} & 14,5 \mathrm{~B} & 11,5 \mathrm{C} & 11,0 \mathrm{C} & 7,7 \mathrm{D} & 12,9 \\ \text { C.V. (\%) } & 13,20 & & & & & \end{array}$

Comprimento da maior raíz (CMR)

- cm -

$\begin{array}{lllllll}\text { UPF86Al 169-2b } & 49,3 \mathrm{aA} & 44,7 \mathrm{aA} & 33,7 \mathrm{aB} & 30,7 \mathrm{aB} & 27,0 \mathrm{aB} & 37,1 \mathrm{a}\end{array}$

UPF-7

Média $36,0 \mathrm{bA} \quad 33,7 \mathrm{bAB} \quad 30,3 \mathrm{aAB} \quad 29,7 \mathrm{aAB} \quad 25,0 \mathrm{aB} \quad 30,9 \mathrm{~b}$

C.V. (\%) $42,7 \mathrm{~A} \quad 39,2 \mathrm{~A} \quad 32,0 \mathrm{~B} \quad 30,2 \mathrm{~B} \quad 26,0 \mathrm{~B} \quad 34,0$

11,32

Rendimento de matéria seca de raizes (RMSR) - g/vaso -

$\begin{array}{lllllll}\text { UPF86A1169-2b } & 1,25 & 0,50 & 0,38 & 0,32 & 0,25 & 0,54 \mathrm{a} \\ \text { UPF-7 } & 1,21 & 0,46 & 0,33 & 0,23 & 0,21 & 0,49 \mathrm{~b} \\ \text { Média } & 1,23 \mathrm{~A} & 0,48 \mathrm{~B} & 0,36 \mathrm{C} & 0,27 \mathrm{D} & 0,23 \mathrm{D} & 0,51 \\ \text { C.V.(\%) } & 8,81 & & & & & \end{array}$

Rendimento de matéria seca de colmos e bainhas (RMSCB)

\begin{tabular}{lllllll} 
& \multicolumn{5}{c}{- g/vaso -} \\
UPF86A1 169-2b & 0,90 & 0,52 & 0,51 & 0,48 & 0,50 & $0,58 \mathrm{a}$ \\
UPF-7 & 0,76 & 0,54 & 0,49 & 0,50 & 0,49 & $0,55 \mathrm{a}$ \\
Média & $0,83 \mathrm{~A}$ & $0,52 \mathrm{~B}$ & $0,50 \mathrm{~B}$ & $0,49 \mathrm{~B}$ & $0,49 \mathrm{~B}$ & 0,57 \\
C.V.(\%) & $\mathbf{8 , 5 3}$ & & & & &
\end{tabular}




\begin{tabular}{|c|c|c|c|c|c|c|}
\hline \multirow{2}{*}{ Genótipos } & \multicolumn{4}{|c|}{ Niveis de Al (mg/l) } & & \multirow{2}{*}{ Média } \\
\hline & 0 & 10 & 20 & 30 & 40 & \\
\hline
\end{tabular}

Rendimento de materia seca das folhas (RMSF) - g/vaso -

$\begin{array}{lllllll}\text { UPF86A1 169-2b } & 2,41 & 1,41 & 1,00 & 0,81 & 0,85 & 1,30 \mathrm{a} \\ \text { UPF-7 } & 2,29 & 1,16 & 0,77 & 0,76 & 0,70 & 1,14 \mathrm{~b} \\ \text { Média } & 2,35 \mathrm{~A} & 1,29 \mathrm{~B} & 0,88 \mathrm{C} & 0,79 \mathrm{C} & 0,77 \mathrm{C} & 1,22 \\ \text { C.V.(\%) } & 8,50 & & & & & \end{array}$

Rendimento de matéria seca da parte aérea (RMSPA)

- g/vaso -

$\begin{array}{lllllll}\text { UPF86A1 169-2b } & 3,31 & 1,93 & 1,51 & 1,29 & 1,34 & 1,87 \mathrm{a} \\ \text { UPF-7 } & 3,06 & 1,70 & 1,25 & 1,26 & 1,19 & 1,69 \mathrm{~b} \\ \text { Média } & 3,18 \mathrm{~A} & 1,82 \mathrm{~B} & 1,38 \mathrm{C} & 1,28 \mathrm{C} & 1,27 \mathrm{C} & 1,78 \\ \text { C.V.(\%) } & 6,55 & & & & & \end{array}$

Rendimento de matéria seca da planta (PMSP) - g/vaso -

\begin{tabular}{|c|c|c|c|c|c|c|}
\hline UPF86Al 169-2b & 4,56 & 2,44 & 1,88 & 1,61 & 1,60 & $2,42 a$ \\
\hline UPF-7 & 4,27 & 2,16 & 1,59 & 1,49 & 1,39 & $2,17 \mathrm{~b}$ \\
\hline Média & $4,41 \mathrm{~A}$ & $2,30 \mathrm{~B}$ & $1,76 \mathrm{C}$ & $1,55 \mathrm{C}$ & $1,50 \mathrm{C}$ & 2,30 \\
\hline C.V. (\%) & 6,31 & & & & & \\
\hline \multicolumn{7}{|c|}{$\begin{array}{c}\text { Relaçå de peso foliar (RPF) } \\
-\%-\end{array}$} \\
\hline UPF86Al 169-2b & 74,7 & 72,7 & 65,7 & 62,7 & 63,3 & $67,8 \mathrm{a}$ \\
\hline UPF-7 & 75,3 & 68,3 & 60,7 & 61,0 & 59,0 & $64,9 b$ \\
\hline Média & $75,0 A$ & $70,5 \mathrm{~A}$ & $63,2 \mathrm{~B}$ & $61,8 \mathrm{~B}$ & $61,2 \mathrm{~B}$ & 66,3 \\
\hline C.V. (\%) & 5,03 & & & & & \\
\hline
\end{tabular}




\begin{tabular}{|c|c|c|c|c|c|c|}
\hline \multirow{2}{*}{ Genót ipos } & \multicolumn{4}{|c|}{ Níveis de Al (mg/l) } & & \multirow{2}{*}{ Média } \\
\hline & 0 & 10 & 20 & 30 & 40 & \\
\hline
\end{tabular}

Relação raiz/parte aérea (RRPA) $-\%-$

$\begin{array}{lclllll}\text { UPF86Al169-2b } & 38,0 \mathrm{aA} & 26,0 \mathrm{aB} & 25,0 \mathrm{aB} & 24,7 \mathrm{aB} & 19,0 \mathrm{aC} & 26,5 \mathrm{a} \\ \text { UPF-7 } & 39,7 \mathrm{aA} & 27,0 \mathrm{aB} & 26,7 \mathrm{aB} & 18,0 \mathrm{bC} & 17,3 \mathrm{aC} & 25,7 \mathrm{a} \\ \text { Média } & 38,8 \mathrm{~A} & 26,5 \mathrm{~B} & 25,8 \mathrm{~B} & 21,3 \mathrm{C} & 18,2 \mathrm{C} & 26,1 \\ \text { C.V.(\%) } & 8,68 & & & & & \end{array}$

* Médias seguidas da mesma letra minúscula na vertical e maiúscula na horizontal, não diferem pelo teste de Tukey ao nível de $5 \%$ de signi ficância.

Nos níveis maiores de Al na solução, não foram verificadas diferenças significativas entre os genotipos.

Através da análise de regressão (figura 17), observa-se que no genótipo tolerante, a diminuição do número de afilhos se manifestou de forma linear $\left(R^{2}=92,2 * *\right)$ e no sensível de forma quadrática $\left(\mathrm{R}^{2}=87,8 * *\right)$.

\subsubsection{Número relativo de afilhos (NRAF)}

Quanto ao número relativo de afilhos nos diferentes níveis de Al, verificou-se através da análise de variância (teste F), diferenças altamente significativas $P<0,01$ para os genótipos, níveis de Al e para a interação genótipo $x$ níveis de Al (Tabela D8), com um coeficiente de variação de $11,54 \%$.

Pela comparação entre as médias (Tabela 40), observa-se que o no relativo de afilhos (NRAF) no genótipo tolerante foi superior ao sensível, nos níveis 10,20 e $30 \mathrm{mg}$ Al/l, não diferindo no nível maior ( $40 \mathrm{mg} \mathrm{Al} / \mathrm{l}$ ), ao nível de 


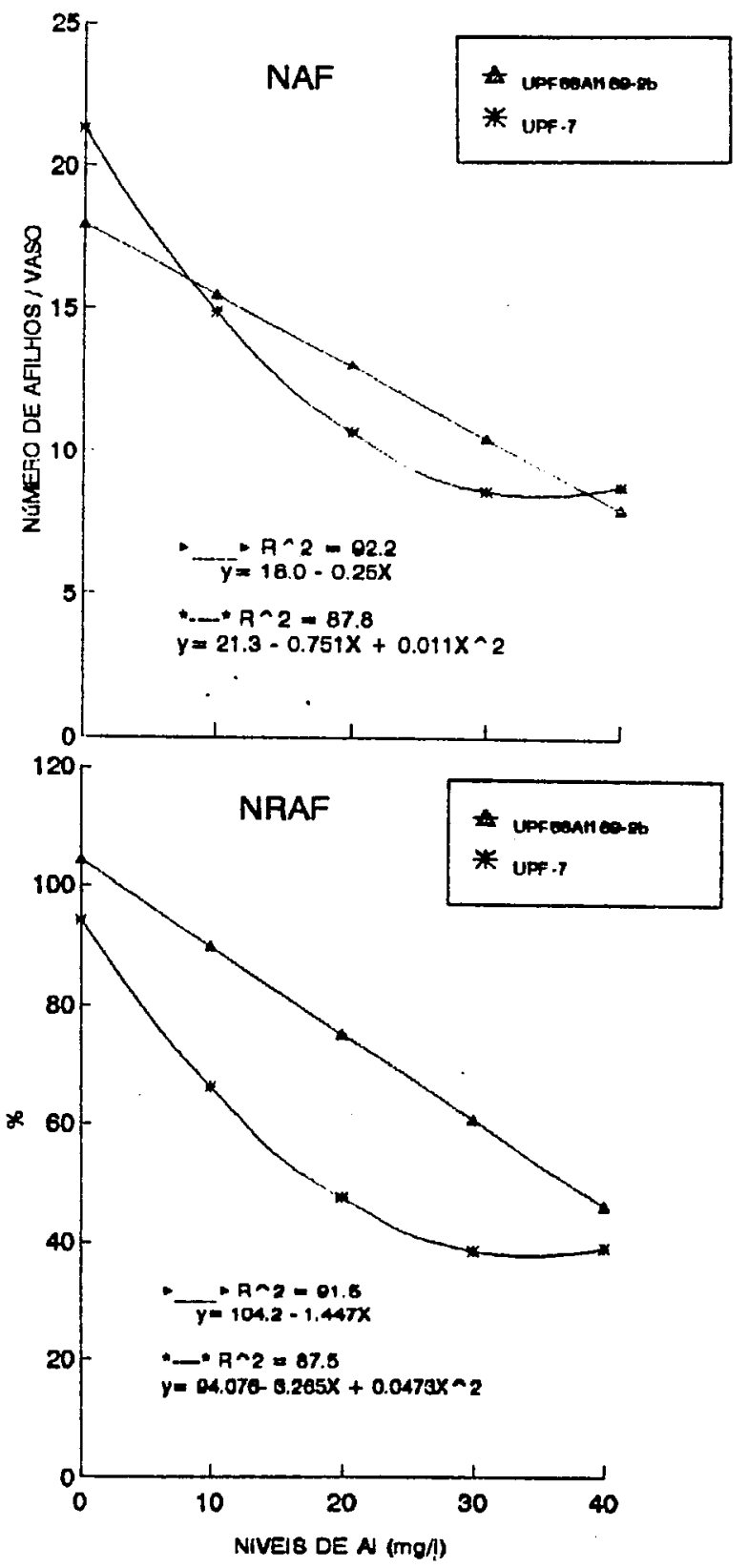

Figura 17. Efeito de niveis de aluminio sobre o número de afilhos (NAF) e sobre o seu número relativo (NRAF), em dois genótipos de aveia. 
Tabela 40. Efeito relativo dos niveis de aluminio sobre alguns parâmetros do crescimento da aveia branca em cultivo hidropônico.

\begin{tabular}{|c|c|c|c|c|c|}
\hline \multirow{3}{*}{ Genótipos } & \multicolumn{4}{|c|}{ Niveis de Al (mg/l) } & \multirow[b]{2}{*}{ Média } \\
\hline & -- & --- & --- & -ー-ー-ー-ー- & \\
\hline & 0 & 10 & 20 & 30 & 40 \\
\hline
\end{tabular}

Número relativo de afilhos (NRAF)

$\begin{array}{lclllll}\text { UPF86Al169-2b } & 100,0 \mathrm{aA} & 99,0 \mathrm{aA} & 67,3 \mathrm{aB} & 65,7 \mathrm{aB} & 44,3 \mathrm{aC} & 75,3 \mathrm{a} \\ \text { UPF-7 } & 100,0 \mathrm{aA} & 53,3 \mathrm{bB} & 50,7 \mathrm{bBC} & 47,7 \mathrm{bBC} & 34,3 \mathrm{aC} & 57,2 \mathrm{~b} \\ \text { Média } & 100,0 \mathrm{~A} & 76,2 \mathrm{~B} & 59,0 \mathrm{C} & 56,7 \mathrm{C} & 39,3 \mathrm{D} & 66,2 \\ \text { C.V.(\%) } & 11,54 & & & & & \end{array}$

Comprimento relativo da maior raíz (CRMR)

$\begin{array}{lclllll}\text { UPF86Al 169-2b } & 100,0 & 90,7 & 68,7 & 62,3 & 54,7 & 75,3 \mathrm{~b} \\ \text { UPF-7 } & 100,0 & 94,0 & 85,0 & 83,3 & 70,3 & 86,5 \mathrm{a} \\ \text { Média } & 100,0 \mathrm{~A} & 92,3 \mathrm{AB} & 76,8 \mathrm{BC} & 72,8 \mathrm{C} & 62, \mathrm{C} & 80,9 \\ \text { C.V.(\%) } & 11,17 & & & & & \end{array}$

Rendimento relativo de matéria seca de raízes (RRMSR)

$\begin{array}{lrlllll}\text { UPF86Al 169-2b } & 100,0 & 40,3 & 30,3 & 25,3 & 20,3 & 43,3 \mathrm{a} \\ \text { UPF-7 } & 100,0 & 38,3 & 27,3 & 18,7 & 17,0 & 40,3 \mathrm{~b} \\ \text { Média } & 100,0 \mathrm{~A} & 39,3 \mathrm{~B} & 28,8 \mathrm{C} & 22,0 \mathrm{D} & 18,7 \mathrm{D} & 41,8 \\ \text { C.V.(\%) } & 6,33 & & & & & \end{array}$

Rendimento relativo de matéria seca de colmos + bainhas (RRMSCB)

$\begin{array}{lrlllll}\text { UPF86Al169-2b } & 100,0 & 58,3 & 58,0 & 53,3 & 56,0 & 65,1 \mathrm{~b} \\ \text { UPF-7 } & 100,0 & 70,3 & 63,7 & 65,7 & 64,0 & 72,7 \mathrm{a} \\ \text { Média } & 100,0 \mathrm{~A} & 64,3 \mathrm{~B} & 60,8 \mathrm{~B} & 60,0 \mathrm{~B} & 59,5 \mathrm{~B} & 68,9 \\ \text { C.V.(\%) } & 7,48 & & & & & \end{array}$


Niveis de Al (mg/l)

Genótipos

\begin{tabular}{llllll}
0 & 10 & 20 & 30 & 40 & Média \\
\hline
\end{tabular}

Rendimento relativo de matéria seca de folhas (RRMSF)

$\begin{array}{lrlllll}\text { UPF86Al169-2b } & 100,0 & 58,7 & 41,3 & 33,7 & 35,3 & 53,8 \mathrm{a} \\ \text { UPF-7 } & 100,0 & 51,0 & 33,3 & 33,3 & 30,3 & 49,6 \mathrm{~b} \\ \text { Média } & 100,0 \mathrm{~A} & 54,8 \mathrm{~B} & 37,3 \mathrm{C} & 33,5 \mathrm{C} & 32,8 \mathrm{C} & 51,7 \\ \text { C.V.(\%) } & 7,98 & & & & & \end{array}$

Rendimento relativo de matéria seca da parte aérea (RPMSPA)

$\begin{array}{lrlllll}\text { UPF86Al169-2b } & 100,0 & 58,7 & 45,7 & 39,0 & 40,7 & 56,8 \mathrm{a} \\ \text { UPF-7 } & 100,0 & 55,3 & 41,0 & 41,3 & 39,0 & 55,3 \mathrm{a} \\ \text { Média } & 100,0 \mathrm{~A} & 57,0 \mathrm{~B} & 43,4 \mathrm{C} & 40,2 \mathrm{C} & 39,8 \mathrm{C} & 56,1 \\ \text { C.V.(\%) } & 5,28 & & & & & \end{array}$

Rendimento relativo de matéria seca da planta (RRMSP)

$\begin{array}{lrrllll}\text { UPF86Al 169-2b } & 100,0 & 53,7 & 41,3 & 35,3 & 35,0 & 53,1 \mathrm{a} \\ \text { UPF-7 } & 100,0 & 50,7 & 37,3 & 35,0 & 32,7 & 51,1 \mathrm{~b} \\ \text { Média } & 100,0 \mathrm{~A} & 52,2 \mathrm{~B} & 39,3 \mathrm{C} & 35,2 \mathrm{D} & 33,8 \mathrm{D} & 52,1 \\ \text { C.V.(\%) } & 4,40 & & & & & \end{array}$

* Médias seguidas de mesma letra minúscula na vertical e maiúscula na horizontal, não diferem pelo teste de Tukey ao nível de $5 \%$ de significância.

5\% de significância. Quanto ao efeito dos niveis do Al, no genótipo tolerante, não houve diferença significativa entre o nível 0 e 10 , sendo que no sensível, esta diferença foi significativa. Quanto aos niveis de Al, esta inibição foi significativa para os dois genótipos.

A inibição pelo alumínio do NRAF, se expressou na forma de uma regressão linear (Figura 17) para o genótipo UPF 86Al169-2b $\left(R^{2}=91,5 * *\right)$ e de forma quadrática para o cultivar UPF7 $\left(R^{2}=87,5 * *\right)$. 
A inibição do afilhamento pelo alumínio também foi verificada em cereais de inverno por MESDAG \& BALKEMA BOOMSTRA (1984).

\subsubsection{Comprimento da maior raiz (CMR)}

A análise de variância dos resultados da avaliação do comprimento da maior raíz (CMR), revelou diferenças altamente significativas $(P<0,01$ ) entre genótipos e niveis de Al (Tabela D8). A interação genótipos $x$ níveis de alumínio foi significativa ao nível de 5\% de significância. O coeficiente de variação desta variável foi de $11,32 \%$.

Na comparação entre as médias dos dois genótipos nos niveis de Al (teste de Tukey), observam-se a Tabela 39, que o CMR do genótipo tolerante foi superior ao do sensivel nos niveis 0 e $10 \mathrm{mg} A l / l(P<0,05)$, não diferindo nos demais níveis. Para UPF86Al169-2b, a redução no CMR não foi significativa ( $P$ )

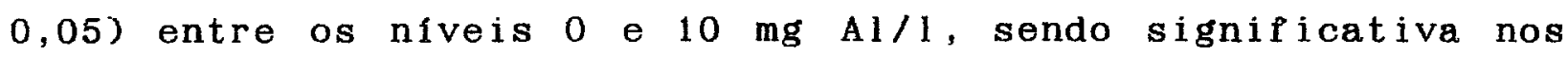
demais níveis em relação aos mais baixos. Já no genótipo sensível, a redução não foi significativa entre os niveis $0,10,20$ e $30 \mathrm{mg} A l / l$, dife-rindo apenas no maior nível de aluminio, ao nivel de $5 \%$ de significância.

Através da análise de regressão (Figura 18) verifica-se que nos dois genótipos avaliados, a redução do CMR se manifestou de forma linear, sendo o coeficiente angu- lar, maior para o genótipo UPFAl169-2b.

4.6.4. Comprimento relativo da maior raiz (CRMR)

A análise de variância dos resultados da avaliação do comprimento relativo da maior raíz (CRMR), detectou diferenças altamente significativas $(P<0,01)$ para os genótipos e os níveis de alumínio (Tabela D8). Mas, a interação genótipos $x$ níveis de alumínio não foi significativa $(P>0,05)$, sendo o coeficiente de variação de $11,17 \%$. 
Da comparação entre as médias dos dois genótipos, dentro de cada nível de Al verifica-se que a reduça relativa no CMR , foi menor para o cultivar UPF7, em relação ao genótipo UPF 86Al169-2b ( $P<0,05$ ). No nível $40 \mathrm{mg} \mathrm{Al/l}$, a reduçao no CRMR foi de $24,7 \%$ para UPF86A1169-2b e de 13,5\% para o cultivar UPF7. A redução média no CRMR não foi significativa $(P>0,05)$ entre os niveis 0 e $10 \mathrm{mg} A / / 1$, diferindo significativamente nos demais níveis, (tabela 40 ).

\subsubsection{Rendimento de matéria seca de raf́es (RMSR)}

Não foram observadas diferenças significa- tivas entre os genótipos e nem efeitos significativos para a interaça genótipos $x$ níveis de $A 1$, na análise de variancia dos resultados do rendimento de matéria seca de raízes (RMSR), pelo teste $F$ ao nivel de $5 \%$ de significância (Tabela D8). Entretanto, para os valores médios dos genótipos, foi detectada diferença significativa. O coeficiente de variação deste parâmetro foi de $8,81 \%$.

Na comparação entre as médias para os genótipos, pelo teste de Tukey, observa-se que o RMSR médio do genótipo tolerante (UPF86A1169-2b) foi significativamente superior ao sensível (UPF7), ao nivel de 5\% (Tabela 39). Quanto ao efeito do Al sobre o RMSR médio dos dois genótipos, verifica-se uma redução significativa entre os níveis 0 e $10 \mathrm{mg} \mathrm{Al/l,} 10$ e $20 \mathrm{mg} \mathrm{Al/l}$ e 20 e $30 \mathrm{mg} \mathrm{Al/l}$, não diferindo entre os niveis 30 e $40 \mathrm{mg} \mathrm{Al/l}$.

Estes resultados demonstram que o maior comprimento das raízes, para o genótipo tolerante em relação ao sensível, não se evidenciou em termos de rendimento de matéria seca. Resultados semelhantes, foram relatados por diversos autores (SARTAIN \& KAMPRATH, 1978 e HOWELLER \& CADAVID, 1976). Atribui-se esse fato ao engrossamento, nas raízes de plantas sensiveis provocado pelo aluminio, não diferindo entretanto em peso, com as raízes de plantas não afetadas. 


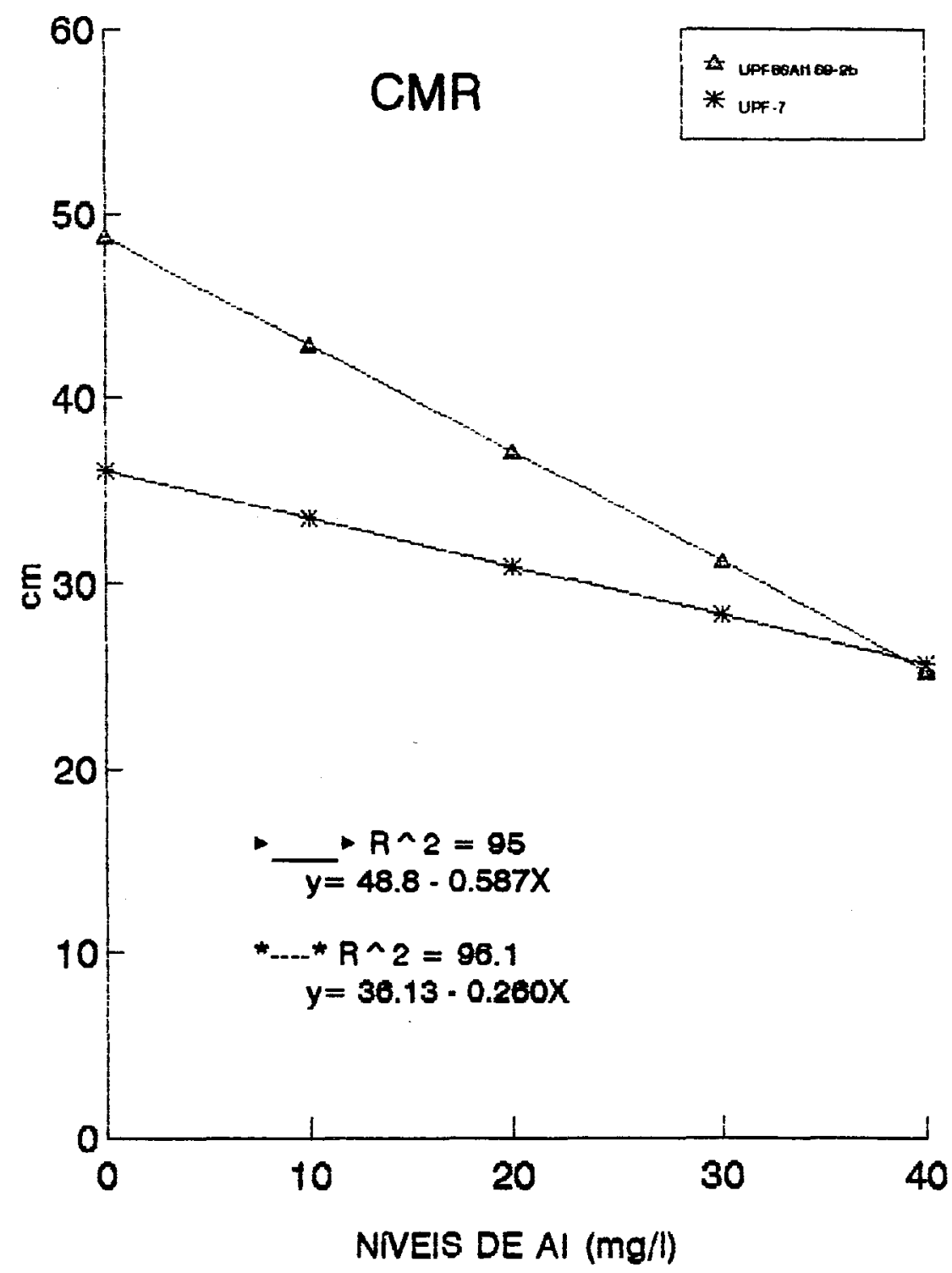

Figura 18. Efeito dos níveis de aluminio sobre o comprimento da maior raíz (CMR), em dois genótipos de aveia. 
4.6.6. Rendimento relativo de materia seca de raizes (RRMSR)

A análise de variância dos resultados da avaliação do RRMSR revelou diferenças altamente significativas $(P<0,01)$ para genótipos e níveis de aluminio, mas para a interação ela não foi significativa $(P>0,05)$ (Tabela D8). O coeficiente de variação obtido para este parâmetro foi de $6,33 \%$.

A comparaça entre as médias dos genótipos, pelo teste de Tukey (Tabela 40), mostrou que o RRMSR foi significativamente maior no genot ipo tolerante (UPF86Al169-2b) que no sensível, ao nível de $5 \%$ de significância. Verifica-se, na mesma tabela, que a inibição do Al sobre a média dos genótipos, foi significativa entre os niveis 0 e 10,10 e 20 e 20 e $30 \mathrm{mg}$ Al/1, não diferindo significativamente entre os niveis 30 e $40 \mathrm{mg}$ Al/1.

4.6.7. Rendimento de matéria seca de colmos e bainhas ( RMSCB)

A análise de variância do RMSCB revelou diferenças significativas entre os niveis de Al, e diferenças não significativas entre os genótipos e para a interação genótipos $\mathrm{x}$ niveis de Al, conforme a Tabela D8. O coeficiente de variaça para os resultados deste parâmetro foi de $8,54 \%$.

Na média dos níveis de Al, a comparaça pelo teste de Tukey, mostrou que o RMSCB foi significativamente inferior no nivel de $10 \mathrm{mg} \mathrm{Al/l}$ em relaçăo ao tratamento com ausência de $\mathrm{Al}$, não diferindo nos demais níveis de Al, ao nível de $5 \%$ de significância (Tabela 39).

4.6.8. Rendimento relativo de matéria seca de colmos + bainhas (RRMSCB) 
A análise de variância dos resultados da avaliaça do RRMSCB revelou diferenças altamente significativas ( $P<0,01)$ entre os genótipos $e$ os niveis de aluminio, não sendo significativa a interação entre eles. O coeficiente de variação obtido para este parâmetro foi de $7,48 \%$ (TabelaD8).

$\mathrm{Na}$ média dos níveis de Al, o genótipo sensivel UPF7, apresentou RRMSCB médio superior ao genótipo tolerante, pelo teste de Tukey, ao nível de $5 \%$ de significância (Tabela 40). No entanto, a média dos dois genótipos sofreu redução significativa do RRMSCB do nível 0 para o nível com $10 \mathrm{mg} A l / 1$, sem que este tenha diferido significativamente dos demais níveis mais elevados de Al.

4.6.9. Rendimento de matéria seca das folhas (RMSF)

A anál ise de variância dos resultados do rendimento de matéria seca das folhas (RMSF) revelou diferenças significativas entre os genótipos e niveis de $A l(P<0,05)$. A interação genótipos $\mathrm{x}$ niveis de Al não foi significativa, ao nível de 5\% (Tabela D8). O coeficiente de variação para este parâmetro foi de $8,5 \%$.

Pela comparaça entre as médias dos genótipos, (teste de Tukey), verificou-se que o RMSF do genótipo tolerante foi, superior ao do sensivel $(P<0,05)$, conforme Tabela 39. 0 nivel $10 \mathrm{mg} \mathrm{Al/l}$, causou uma redução significativa no RMSF, em relação ao tratamento com 0 de Al. Também foi significativa a

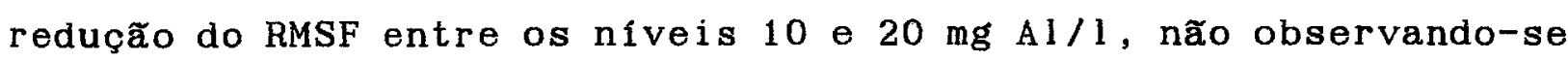
diferenças significativas entre o nivel 20 e os mais elevados de Al.

\subsubsection{Rendimento relativo de materia seca das fol has (RRMSF)}

A análise de variância dos resultados da avaliação do RRMSF revelou diferenças significativas entre genótipos ( $P$ < 
$0,05)$ e altamente significativas $(P<0,01)$ entre os niveis de Al. A interação genótipos $x$ níveis de $A l$ não foi significativa, e o coếiciente de variação obtido para este parâmetro foi de 7,98\% (Tabela D8).

Pela comparação entre as médias, pelo teste de Tukey, observou-se que o genótipo UPF86Al169-2b (tolerante), apresentou RRMSF na média dos níveis de Al superior ao do genótipo sensivel (UPF7), ao nível de $5 \%$ de significância (Tabela 40). Quanto à média dos dois genótipos em cada nível de Al, verificouse que o RRMSF sofreu uma redução significativa, entre os niveis

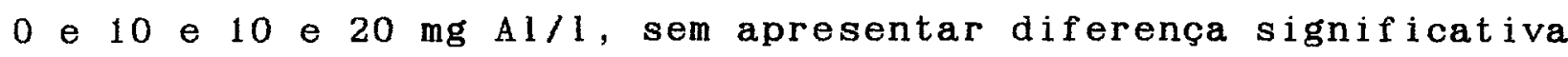
entre os demais niveis de Alumínio.

Estes resultados demonstram que o crescimento da folha é um dos parãmetros mais afetados pela toxicidade do alumínio. Este fato pode ser atribuido à menor absorção de nutrientes, especialmente nitrogênio, e de água pelas plantas, fatores que influenciam diretamente a expansåo foliar. Resultados semel hantes foram relatados por PAVAN \& BINGHAN (1982) e WAGATSUMA \& KANEKO (1987).

4.6.11. Rendimento de matéria seca da parte aérea (RMSPA)

A análise de variância dos resultados do RMSPA mostram diferenças altamente significativas $(P<0,01)$ entre os genótipos e os níveis de $A 1$, enquanto a interação genótipos $x$ níveis de Al não foi significativa ao nível de $5 \%$ de significância (Tabela D8). O coeficiente de variação deste parâmetro foi de $6,55 \%$.

Através da comparação da média dos genótipos, verificou-se que o RMSPA do genótipo tolerante foi superior ao sensível, pelo teste de Tukey, ao nível de $5 \%$ de significância (Tabela 39).

Quanto à comparação entre os niveis de $\mathrm{Al}$, observase que a redução no RMSPA foi significativa $(P<0,05)$ entre os 
niveis 0 e 10 e 10 e $20 \mathrm{mg} A 1 / \mathrm{l}$, nao diferindo nos demais niveis de Al $(P>0,05)$.

\subsubsection{Rendimento relativo da matéria seca da parte aérea (RRMSPA)}

A análise de variância dos resultados da avaliação do RRMSPA não revelou diferenças significativas entre os genótipos e nem significância para a interaçao genótipos $x$ níveis $d e$ alumínio $(P>0,05)$. Os níveis de alumínio diferiram ao nível de 1\% de significância (Tabela D8). O coeficiente de variação deste parâmetro foi de $5,28 \%$.

Na comparação entre médias dos niveis de alumínio, através do teste de Tukey, observou-se uma redução significativa no RRMSPA entre os niveis 0 e 10 e 10 e $20 \mathrm{mg} \mathrm{Al/l,} \mathrm{sem} \mathrm{diferenças}$ significativas entre os demais niveis de aluminio (Tabela 39).

4.6.13. Rendimento de matéria seca da planta (RMSP)

A análise de variância dos resultados da avaliaçao do RMSP revelou diferenças altamente significa-tivas $(P<0,01)$ para os genótipos e os níveis de Al. A interaça genótipos $x$ niveis de alumínio não foi significativa $(P>0,05)$. O coeficiente de variação para este parâmetro foi de 6,31\% (Tabela D8).

o genotipo tolerante UPF 86Al169-2b, pelo teste de Tukey, apresentou na média dos níveis, RMSP superior ao do cultivar sensível UPF7, ao nível de $5 \%$ de significância (Tabela 39). Na comparação da média dos dois genótipos, em cada nível de Al, observou-se que a redução foi significativa entre os niveis 0 e $10 \mathrm{mg} \mathrm{Al/l}, 10$ e $20 \mathrm{mg} \mathrm{Al/l}(\mathrm{P}<0,05)$, não diferindo nos demais níveis de aluminio. 
4.6.14. Rendimento relativo de matéria seca da planta (RRMSP)

A análise de variância dos resultados de avaliação do RRMSP, revelou diferenças significativas $(P<0,05)$ entre os genótipos e altamente significativas $(P<0,01)$ entre os niveis de Al. A interação genótipos $x$ níveis de Al não foi significativa, ao nivel de $5 \%$ de significância. O coeficiente de variação para este parâmetro foi de $4,4 \%$ (Tabela D8).

A média dos niveis de Al para o RRMSP do genótipo tolerante UPF86A1169-2b foi superior ao do genótipo sensível UPF7, pelo teste de Tukey, ao nível de $5 \%$ de significância (Tabela 40). Quanto à comparação entre as médias dos níveis de Al, verifica-se que a redução no RRMSP foi significativa entre os níveis 0 e $10 \mathrm{mg}$ e 10 e $20 \mathrm{mg} \mathrm{Al/1}$, sem diferirem entre os niveis 20 , 30 e $40 \mathrm{gm}$ Al/litro.

4.6.15. Relação de peso foliar (RPF)

A análise de variância dos resultados dos RPF revelou diferenças significativas $(P<0,05)$ entre os genótipos e altamente significativas $(P<0,01)$ para os niveis de aluminio. A interação genótipos $x$ niveis de aluminio não foi significativa ao nível de $5 \%$ de significância (Tabela D8). O coeficiente de variação deste parâmetro foi de 5,03\%.

Pela comparação entre as médias dos genótipos, através do teste de Tukey, observa-se que o RPF no genótipo tolerante foi significativamente superior ao RPF do cultivar sensível (UPF7), conforme Tabela 39. Em relação à comparação das médias dos dois níveis de Al, verifica-se que a diferença não foi significativa entre os níveis 0 e $10 \mathrm{mg} \mathrm{Al/1}$. Entre os níveis 0 e $10 \mathrm{mg} A l / l$ e os demais, a redução no RPF foi significativa, ao nivel de $5 \%$ de significância. 
4.6.16. Relaçao do peso de raíz/parte aérea (RRPA)

A análise de variância dos resultados da RRPA, não revelou diferença significativa $(P>0,05)$ entre os genótipos $e$ uma diferença altamente significativa $(P<0,01)$ entre os niveis de Al. A interação genótipos $x$ niveis de aluminio foi significativa ao nível de $5 \%$ de significância. O coeficiente de variaça obtido para este parâmetro foi de $8,68 \%$ (Tabela D8).

Quanto à comparação entre as médias, pelo teste de Tukey, verifica-se na Tabela 39 que para o nível $30 \mathrm{mg} \mathrm{Al/1}$, o genótipo tolerante apresentou RRPA superior ao do cultivar sensivel ( $P<0,05)$, sem diferirem, dentro dos demais niveis ( $P$ ) 0,05). Em relação à média dos níveis de Al, observou-se uma redução significativa entre os níveis 0 e $10 \mathrm{mg} A l / l$ que por sua vez não diferiu do nível $20 \mathrm{mg} \mathrm{Al/1}(P<0,05)$. Os níveis de Al 20 e 30 diferiram entre si ao nível de $5 \%$ de significância, não sendo detectada diferença significativa entre os niveis 30 e $40 \mathrm{mg}$ Al/litro.

A regressão do efeito dos níveis de Al sobre o RRPA dos genótipos, expressou-se na forma linear, com coeficientes de determinação $\left(R^{2}\right)$ de $88,1 \%$ e $79,6 \%$, respectivamente, para UPF7 e UPF86A1 169-2b (Figura 19).

Este resultado confirma os relatados por BILSKI (1987), mostrando que a raíz de aveia é mais afetada pela toxicidade do alumínio que a parte aérea.

A partir da análise dos resultados das diversas variáveis apresentadas, verificou-se que apenas para os parâmetros comprimento da maior raíz (CMR), número de afilhos/vaso (NAF), número relativo de afillhos/vaso (NRAF) e relação raíz/parte aérea (ARPA), foi observada a interação genótipo e níveis de alumínio. Este fato reforça as posiçres de FOY et al., (1967); REID et al., (1971) e MOORE et al., (1976), que consideraram o crescimento da raíz, como o melhor indicador da reação das plantas à toxicidade do alumínio. 
150.

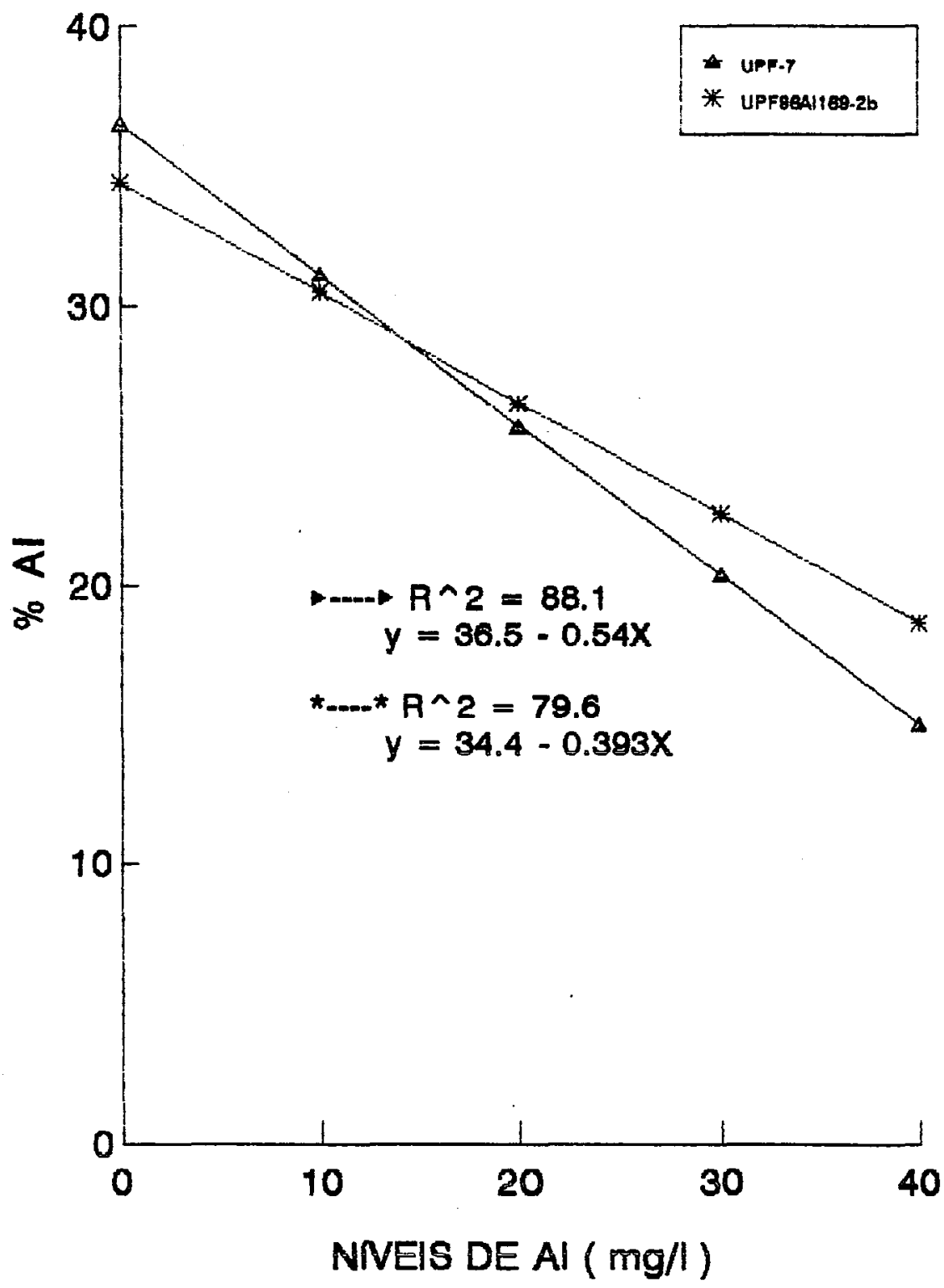

Figura 19. Efeito dos niveis de alumínio sobre a relação de peso da raiz / parte aérea (RRPA), em dois genótipos de aveia. 
Para as correlaçós linear simples, realizadas entre o comprimento da maior raíz (CMR) e os parâmetros de rendimento da matéria seca e suas relações (RPF e RRPA), apresentados na Tabela 41 , observou-se que todos foram altamente significativos ( $P$ < $0,01)$ pelo teste $t$.

Tabela 41. Valores de $t$ e coeficientes de correlaça ( $r$ ) entre os parâmetros de crescimento e os rendi- mento de dois genótipos de aveia, submetidos a cinco níveis de alumínio, em cultivo hidropônico.

\begin{tabular}{|c|c|c|c|c|c|}
\hline \multicolumn{3}{|c|}{ Correlações } & Valor & $t$ & $\Gamma(\%)$ \\
\hline CMR $\mathrm{x}$ & $\begin{array}{l}\text { RMS } \\
\text { RMS } \\
\text { RMS } \\
\text { RMS } \\
\text { RMS } \\
\text { RPE } \\
\text { CRP } \\
\text { RRI } \\
\text { RRI } \\
\text { RRP } \\
\text { RRY } \\
\text { RRF }\end{array}$ & $\begin{array}{l}\text { R } \\
\mathrm{CB} \\
\mathrm{F} \\
\mathrm{PA} \\
\mathrm{P} \\
\mathrm{R} \\
\mathrm{SR} \\
\mathrm{SF} \\
\mathrm{SPA} \\
\mathrm{SP} \\
\mathrm{A}\end{array}$ & $\begin{array}{l}4,43 \\
4,78 \\
5,64 \\
5,64 \\
5,42 \\
5,36 \\
4,74 \\
4,79 \\
5,33 \\
5,01 \\
4,98 \\
4,38\end{array}$ & $\begin{array}{l}* * \\
* * \\
* * \\
* * \\
* * \\
* * \\
* * \\
* * \\
* * \\
* * \\
* * \\
* *\end{array}$ & $\begin{array}{l}68,2 \\
67,1 \\
73,0 \\
72,9 \\
71,6 \\
71,2 \\
66,7 \\
67,1 \\
71,0 \\
68,6 \\
68,5 \\
63,8\end{array}$ \\
\hline RMSR & $\mathrm{x}$ & $\begin{array}{l}\text { RMSCB } \\
\text { RMSF } \\
\text { RMSPA } \\
\text { RMSP } \\
\text { RPF } \\
\text { CMRR } \\
\text { RRMSR } \\
\text { RRMSF } \\
\text { RRMSPA } \\
\text { RRMSP } \\
\text { RRPA }\end{array}$ & $\begin{array}{r}13,98 \\
25,07 \\
29,68 \\
44,82 \\
6,94 \\
4,39 \\
66,28 \\
25,15 \\
30,42 \\
41,87 \\
13,14\end{array}$ & $\begin{array}{l}* * \\
* * \\
* * \\
* * \\
* * \\
* * \\
* * \\
* * \\
* * \\
* * \\
* *\end{array}$ & $\begin{array}{l}93,5 \\
97,8 \\
98,4 \\
94,3 \\
79,5 \\
63,8 \\
94,7 \\
97,9 \\
98,5 \\
99,2 \\
92,8\end{array}$ \\
\hline RRMSF & & $\begin{array}{l}\text { RMSPA } \\
\text { RMSP } \\
\text { RPF }\end{array}$ & $\begin{array}{r}65,44 \\
48,35 \\
9,74\end{array}$ & $\begin{array}{l}* * \\
* * \\
* *\end{array}$ & $\begin{array}{l}99,7 \\
99,4 \\
87,4\end{array}$ \\
\hline
\end{tabular}


Cont i nuação

\begin{tabular}{|c|c|c|c|c|c|}
\hline \multicolumn{3}{|c|}{ Correlações } & $\frac{\text { Valor }}{4,31}$ & $\frac{\mathrm{t}}{* *}$ & $\frac{r(\%)}{63,2}$ \\
\hline & & $\begin{array}{l}\text { CMRR } \\
\text { RRMSR } \\
\text { RRMSF } \\
\text { RRMSPA } \\
\text { RRMSP } \\
\text { RRPA }\end{array}$ & $\begin{array}{r}4,31 \\
22,7 \\
57,5 \\
35,17 \\
32,47 \\
9,08\end{array}$ & $\begin{array}{l}* * \\
* * \\
* * \\
* * \\
* * \\
* *\end{array}$ & $\begin{array}{l}63,2 \\
97,4 \\
99,6 \\
98,9 \\
98,7 \\
86,4\end{array}$ \\
\hline RRMSPA & $x$ & $\begin{array}{l}\text { RMSP } \\
\text { RPF } \\
\text { CMRR } \\
\text { RRMSR } \\
\text { RRMSF } \\
\text { RRMSPA } \\
\text { RRMSP } \\
\text { RRPA }\end{array}$ & $\begin{array}{r}89,72 \\
8,37 \\
4,27 \\
25,23 \\
38,73 \\
35,45 \\
34,86 \\
9,14\end{array}$ & $\begin{array}{l}* * \\
* * \\
* * \\
* * \\
* * \\
* * \\
* * \\
* *\end{array}$ & $\begin{array}{l}99,8 \\
84,5 \\
62,8 \\
97,8 \\
99,1 \\
98,9 \\
98,9 \\
86,5\end{array}$ \\
\hline RMSP $\quad x$ & $\mathrm{x}$ & $\begin{array}{l}\text { RPF } \\
\text { CMRR } \\
\text { RRMSR } \\
\text { RRMSF } \\
\text { RRMSPA } \\
\text { RRMSP } \\
\text { RRPA }\end{array}$ & $\begin{array}{r}7,42 \\
4,33 \\
34,11 \\
37,39 \\
39,60 \\
45,34 \\
10,30\end{array}$ & $\begin{array}{l}* * \\
* * \\
* * \\
* * \\
* * \\
* * \\
* *\end{array}$ & $\begin{array}{l}83,1 \\
63,4 \\
98,8 \\
99,0 \\
99,1 \\
99,3 \\
88,9\end{array}$ \\
\hline $\mathrm{RPF}$ & $\mathrm{x}$ & $\begin{array}{l}\text { CMRR } \\
\text { RRMSR } \\
\text { RRMSF } \\
\text { RRMSPA } \\
\text { RRMSP } \\
\text { RRPA }\end{array}$ & $\begin{array}{l}3,67 \\
6,76 \\
9,57 \\
7,99 \\
7,59 \\
5,32\end{array}$ & $\begin{array}{l}* * \\
* * \\
* * \\
* * \\
* * \\
* *\end{array}$ & $\begin{array}{l}57,0 \\
78,7 \\
87,5 \\
83,4 \\
82,0 \\
70,1\end{array}$ \\
\hline CMRR & $\mathrm{x}$ & $\begin{array}{l}\text { RRMSR } \\
\text { RRMSF } \\
\text { RRMSPA } \\
\text { RRMSP } \\
\text { RRPA }\end{array}$ & $\begin{array}{l}4,45 \\
4,52 \\
4,73 \\
4,64 \\
4,59\end{array}$ & $\begin{array}{l}* * \\
* * \\
* * \\
* * \\
* *\end{array}$ & $\begin{array}{l}64,4 \\
65,0 \\
66,7 \\
65,4 \\
65,5\end{array}$ \\
\hline RRMSR & $\mathrm{x}$ & $\begin{array}{l}\text { RRMSF } \\
\text { RRMSPA } \\
\text { RRMSP } \\
\text { RRPA }\end{array}$ & $\begin{array}{l}25,47 \\
32,45 \\
50,70 \\
13,56\end{array}$ & $\begin{array}{l}* * \\
* * \\
* * \\
* *\end{array}$ & $\begin{array}{l}97,9 \\
98,7 \\
99,5 \\
93,2\end{array}$ \\
\hline
\end{tabular}




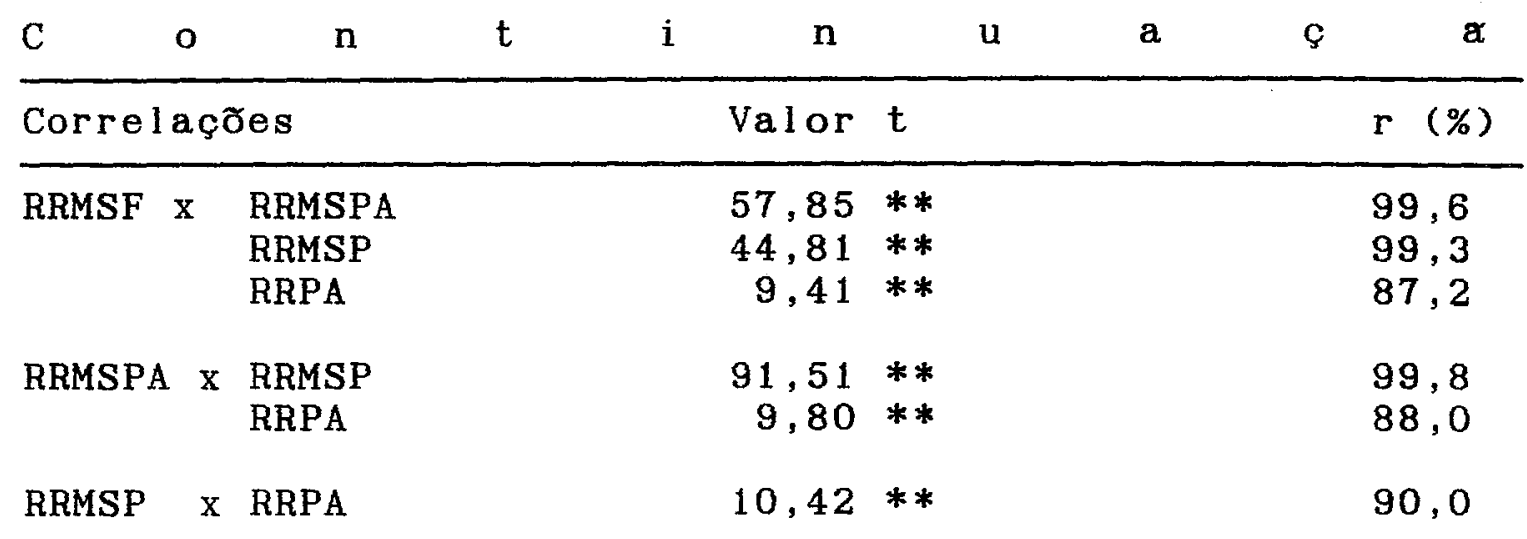

** Significativo pelo teste $t$ ao nivel de $1 \%$ de significância; ns = não significativo.

4.7. Efeito de niveis de aluminio na soluça nutritiva sobre o teor e a extraça de aluminio e alguns macronutrientes pela aveia.

4.7.1. Rendimento de matéria seca

A análise de variância dos resultados do rendimento de matéria seca da planta de aveia (RMSP), submetida a quatro níveis de $A l$, revelou não ser significativa a interação genótipos $x$ níveis de alumínio pelo teste $F$, ao nível de $5 \%$ de significância (Tabela D9). As diferenças entre os genótipos e os niveis de alumínio, foram altamente significativas ( $P<0,01)$. Também foram detectadas, diferenças altamente significativas entre a matéria seca de raízes e da parte aérea, genótipos e níveis de Al e a interação partes $x$ níveis de Al. A interação partes $x$ genótipos foi significativa ao nivel de $5 \%$, não sendo significativa a interação genótipos $x$ níveis de $A l$ e a imteraça tripla, entre partes $x$ genótipos $x$ níveis de alumínio (Tabela D10).

o rendimento médio de MS das plantas do genótipo UPF 86A1169-2b, foi superior ao do cultivar UPF7, pelo teste de 
Tukey, ao nível de $5 \%$ de significância (Tabela 42). Quanto ao efeito dos níveis de alumínio observa-se, uma redução significativa no rendimento de matéria seca entre os níveis 0 e 10 $\mathrm{mg} A l / l$ e entre 10 e $20 \mathrm{mg} A l / 1$, sem que este último nivel diferisse do nível de $30 \mathrm{mg} \mathrm{Al/l}$. Em termos percentuais, o maior nível de alumínio promoveu, uma redução de $65 \%$ no rendimento médio de matéria seca dos dois genótipos (Tabela 42).

Tabela 42. Efeito dos niveis de aluminio na solução nutri- tiva, sobre o rendimento de matéria seca de plantas de dois genótipos de aveia.

\begin{tabular}{lccc}
\hline Niveis de & \multicolumn{4}{c}{ Genótipos } \\
Al (mg/l) & UPF86Al 169-2b & UPF & Media \\
\hline & $-m / v a s o$ & $4267(100)$ & $4413(100) \mathrm{a}$ \\
0 & $4560(100)$ & $2163(51)$ & $2300(52) \mathrm{b}$ \\
10 & $2437(53)$ & $1587(37)$ & $1735(39) \mathrm{c}$ \\
20 & $1883(41)$ & $1487(35)$ & $1547(35) \mathrm{c}$ \\
30 & $1607(35)$ & $2376(91) \mathrm{B}$ & 2499 \\
Média & $2622(100) \mathrm{A}$ & & \\
C.V.(\%) & 5,8 & & \\
\hline
\end{tabular}

- Médias seguidas da mesma letra minúscula na vertical e maiúscula na horizontal, não diferem pelo teste de Tukey nível de $5 \%$ de significância.

- Números entre parênteses indicam o rendimento relativo (\%)

a.o

Com relação ao fracionamento da planta, o rendimento médio de matéria seca da parte aérea do genótipo UPF 86Al169-2b foi superior ao cultivar UPF7, sem diferir entretanto, quanto ao rendimento de MS da raiz (Tabela 43).

O rendimento de MS da parte aérea foi superior ao rendimento do MS da raiz nos dois genótipos. 
Quanto ao efeito dos níveis de alumínio, sobre o rendimento médio de MS dos genótipos (Tabela 44), verifica-se que, tanto para parte aérea como para as raizes, a redução foi significativa entre os niveis 0 e $10 \mathrm{mg} A l / l$ e entre os niveis 10 e $20 \mathrm{mg} \mathrm{Al/l}$, sem que os níveis 20 e 30 diferissem entre si ( $P$ ) 0,05). Entretanto, of eito inibitório foi mais pronunciado nas raízes do que na parte aérea onde, a reduça no rendimento de MS no maior nível de alumínio foi de $60 \%$, enquanto que para as raízes a redução foi de $78 \%$. Estes resultados confirmam os relatados por de ALAM \& ADAMS (1979a), BILSKI (1987) e KARATAGLIS (1987), comprovando que o efeito da toxicidade do Al é mais pronunciada nas raízes do que na parte aérea.

Tabela 43. Rendimento de matéria seca da parte aérea e das raizes, de dois genótipos de aveia.

\begin{tabular}{lccc}
\hline $\begin{array}{l}\text { Partes } \\
\text { da planta }\end{array}$ & $\begin{array}{c}\text { UPF86Al169-2b } \\
\text { (A) }\end{array}$ & $\begin{array}{l}\text { UPF7 } \\
\text { (B) }\end{array}$ & $\begin{array}{c}\text { Relativo } \\
\text { (B/A) }\end{array}$ \\
\hline & $-0-0$ & $(\%)$ \\
Parte aérea & $2009 \mathrm{a}$ A & $1817 \mathrm{a} \mathrm{B}$ & 90 \\
Raízes & $613 \mathrm{~b}$ A & $558 \mathrm{~b} \mathrm{~A}$ & 91
\end{tabular}

Médias seguidas da mesma letra minúscula na vertical e maiúscula na horizontal, não diferem pelo teste de Tukey, ao nível de $5 \%$ de significância. 
Tabela 44. Efeito dos niveis de aluminio na soluça nutri- tiva, sobre o rendimento médio de matéria seca da parte aérea e das raizes de plantas de aveia.

\begin{tabular}{lccc}
\hline Niveis de & \multicolumn{2}{c}{ Parte da planta } & Relativo \\
Al (mg/l) & Parte aérea (A) & Raízes (B) & B/A \\
\hline & $3181(100) \mathrm{aA}$ & $1231(100) \mathrm{aB}$ & 39 \\
0 & $1817(57) \mathrm{bA}$ & $481(39) \mathrm{bB}$ & 26 \\
10 & $1380(43) \mathrm{cA}$ & $355(29) \mathrm{cB}$ & 26 \\
20 & $1275(40) \mathrm{cA}$ & $272(22) \mathrm{cB}$ & 21 \\
30 & $1913 \mathrm{~A}$ & $585,4 \mathrm{~B}$ & \\
Média & 7,0 & & \\
C.V. (\%) & & &
\end{tabular}

- Médias seguidas da mesma letra minúscula na vertical e maiúscula na horizontal, não diferem pelo teste de Tukey nível de $5 \%$ de significância.

- Números entre parênteses indicam o rendimento relativo.

\subsubsection{Alumínio}

A análise de variância dos teores de alumí- nio na planta (TAlP) não foi significativa para a intera- ção genótipo $x$ niveis de alumínio e para a diferença entre os genótipos, ao nível de $5 \%$ de significância (Tabela D9). O efeito de níveis de alumínio, entretanto, foi significativo $(P<0,05)$.

Em relação às partes da planta, a análise de variância não revelou variação significativa para as interações genótipos $x$ partes $x$ níveis de alumínio e genótipos $x$ níveis de alumínio, bem como em relação aos genótipos. Mas, foram altamente significativas as diferenças entre partes, niveis de alumínio e as interaçós entre partes $x$ genótipos e partes $x$ niveis de alumínio, ao nivel de $1 \%$ de significância (Tabela D10). 
Tabela 45. Efeito dos niveis de aluminio na soluçá nutritiva sobre o teor e a extração de alumínio por plantas de dois genótipos de aveia.

\begin{tabular}{|c|c|c|c|}
\hline \multirow{2}{*}{ Níveis de } & \multicolumn{2}{|c|}{ Genótipos } & \multirow{2}{*}{ Méd i a } \\
\hline & UPF $86 A 1169-2 b$ & UPF 7 & \\
\hline \multicolumn{4}{|c|}{ Teor (ppm) } \\
\hline 0 & 126,0 & 97,8 & $111,9(100) d$ \\
\hline 10 & 387,8 & 424,1 & $405,9(363) c$ \\
\hline 20 & 683,8 & 700,7 & $692,2(619) b$ \\
\hline 30 & 959,6 & 867,2 & $913,4(816) a$ \\
\hline Méd i a & $529,3 \mathrm{~A}$ & 522,4 A & \\
\hline C.V. (\%) & 15,3 & & \\
\hline \multicolumn{4}{|c|}{ Extração (mg/vaso) } \\
\hline 0 & 513,8 & 417,0 & $465,4(100) c$ \\
\hline 10 & 942,7 & 918,2 & $930,5(200) b$ \\
\hline 20 & 1287,0 & 1103,8 & $1195,4(257) \mathrm{ab}$ \\
\hline 30 & 1557,5 & 1288,3 & $1422,9(306) \mathrm{a}$ \\
\hline Média & $1075,3 \mathrm{~A}$ & $931,8 \mathrm{~A}$ & \\
\hline C.V. (\%) & 16,4 & & \\
\hline
\end{tabular}

- Médias seguidas da mesma letra minúscula na vertical e maiúscula na horizontal, não diferem pelo teste de Tukey ao nível de $5 \%$ de significância.

- Números entre parênteses indicam o rendimento relativo (\%)

A comparação entre (Tabela 45), revelou que o teor de aluminio diferiu significativamente entre os niveis, aumentando 263,519 e $716 \%$, respectivamente, nos niveis 10 , 20 e $30 \mathrm{mg} \mathrm{Al/l}$, em relação ao tratamento com ausência de Al. $O$ aumento do teor de $\mathrm{Al}$, com o aumento da acidez também foi verificado por ALAM (1985). 
A raizes apresentaram teor de Al significativamente superior ao da parte aérea, nos dois genótipos avaliados (Tabela 46). O genótipo UPF86A1169-2b apresentou teor de Al nas raizes significativamente superior ao cultivar sensível UPF7, enquanto na parte aérea esse teor foi menor, não diferindo significativamente.

Esse teor maior de Al na raíz do genótipo tolerante, sugere que a sua tolerância seja devida à imobilização do elemento nas raizes (FOY et al., 1978) ou pela sua exclusão da plasmalema, impedindo seu transporte para a parte aérea, o que concorda com resultados relatados por FOY, (1971); MUGWIRA et a.1., (1981) e WAGATSUMA \& YAMASAKU, (1985).

Tabela 46. Teor médio de alumínio na parte aérea e nas rafzes de dois genótipos de aveia.

\begin{tabular}{lccc}
\hline Partes da & UPF86Al169-2b & UPF 7 & Relativo \\
planta & (A) & (B) & (B/A)
\end{tabular}

$\%$

Teor (ppm)

$\begin{array}{lrrr}\text { Parte aérea } & 359 \mathrm{~b} \text { A } & 424 \mathrm{~b} \text { A } & 118 \\ \text { Raízes } & 1106 \mathrm{a} \text { A } & 947 \mathrm{a} \text { B } & 86\end{array}$

- Medias seguidas da mesma letra minúscula na vertical e maiúscula na horizontal, não diferem pelo teste de Tukey ao nível de $5 \%$ de significância.

Pela análise de regressão verificou-se que na raíz o teor de alumínio variou de forma quadrática, com um coeficiente de determinação $\left(R^{2}\right)$ de $99,3 \%$, enquanto na parte 


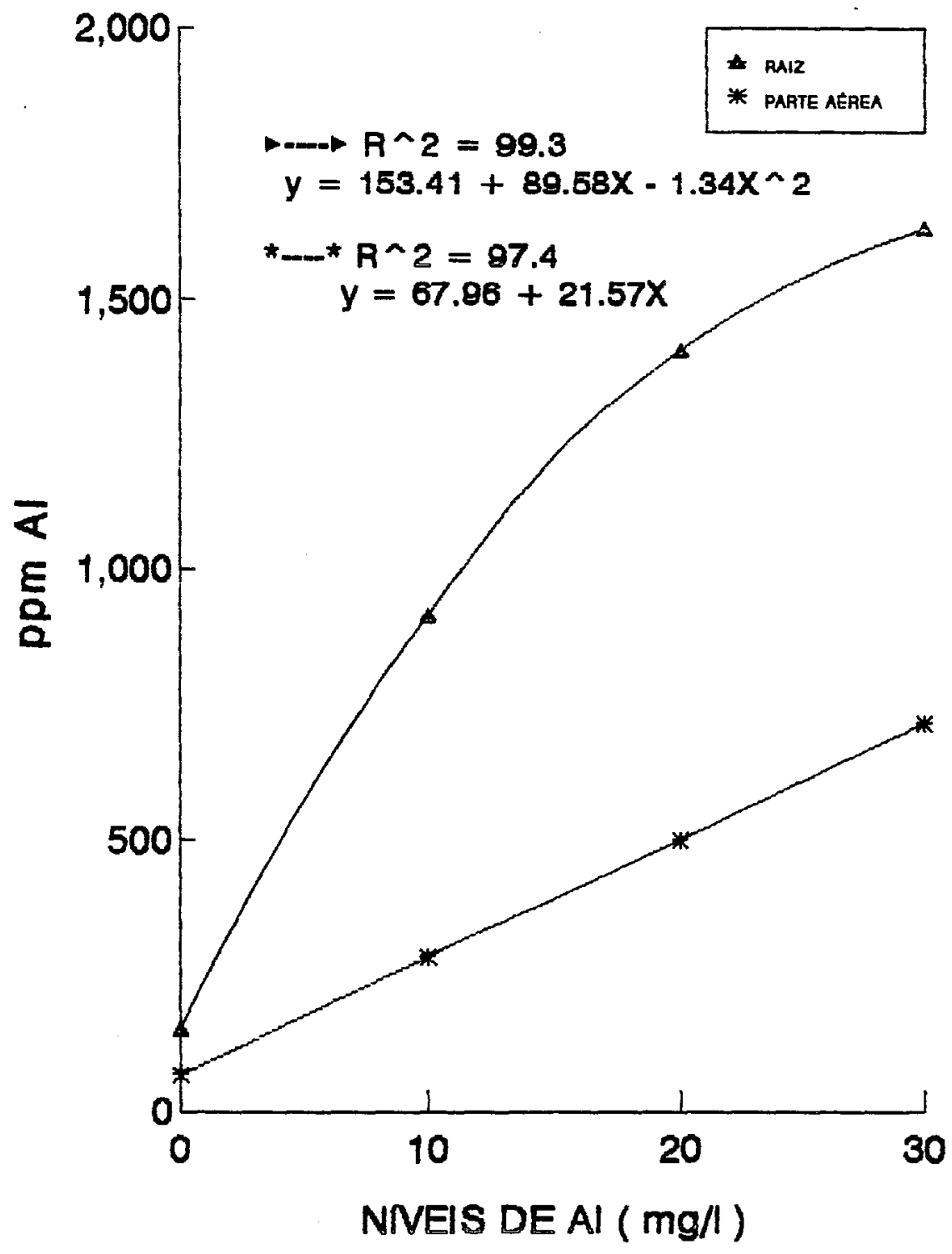

Figura 20. Efeito dos niveis de alumínio na soluçao nutritiva sobre o teor de alumínio na parte aérea e nas raizes de aveia. 
aérea, o aumento foi linear $\left(R^{2}=97,4 \%\right)$, em relaça aos niveis de Al (Figura 20),

Em relação à extração de alumínio (EAlP) pelas plantas, a análise de variância para a interação genótipos $x$ níveis de Al não foi significativa, enquanto as causas individualmente, apresentaram diferenças significativas, pelo teste $F$, ao nível de $5 \%$ de significância, para genótipos e à 1\% para níveis de Al (Tabela D9). Em relaça às partes, as interações genótipos $x$ partes $x$ niveis de $A 1$, partes $x$ genótipos e genótipos $x$ níveis, nao foram significativas. A interaça partes $x$ niveis de Al foi altamente significativa $(P<0,01)$, bem como as diferenças entre as médias para as partes, genótipos e níveis de Al (Tabela D10).

Para a média das extraçóes dos dois genótipos observa-se na Tabela 45, que houve diferenças significativas pelo teste de Tukey, entre os niveis 0 e $10 \mathrm{mg}$ Al/1, mas entre os níveis 10 e 20 , e 20 e $30 \mathrm{mg} \mathrm{Al/l}$ não houve diferenças ( $P$ > 0,05). No nivel de $30 \mathrm{mg} \mathrm{Al/l,} \mathrm{a}$ extração média de aluminio foi significativamente superior aos niveis 0 e $10 \mathrm{mg} \mathrm{Al/l}$.

\subsubsection{Nitrogênio}

A análise de variância dos resultados de teor de nitrogênio na planta (TNP) revelou diferenças significativas para a interação genótipo $x$ niveis de alumínio a $5 \%$ de signifiância e para genótipos a $1 \%$, enquanto as diferenças entre os níveis de Al não foram significativas ao nível de $5 \%$ de significância (Tabela D9).

Pela comparação entre as médias dos genótipos (Tabela 47), através do teste de Tukey, observa-se que os teores de nitrogênio no genótipo tolerante foram superiores 
aos teores do genótipo sensível, nos niveis 0,10 e $20 \mathrm{mg}$ Al/l, não diferindo no nível $30 \mathrm{mg} A l / 1$. Quanto ao comportamento de cada genótipo nos niveis de alumínio (Tabela 47), não se observou diferenças significativas entre as médias do cultivar UPF7, enquanto que para o genótipo UPF86Al169-2b, o teor de $N$ na ausência de alumínio foi

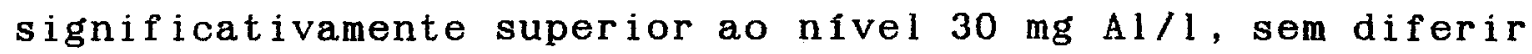
dos níveis 10 e $20 \mathrm{mg} A l / 1$, que por sua vez não diferiram entresi.

A análise de regressão do efeito de niveis de alumínio sobre o teor de nitrogênio na planta, mostrou que a variação se manifesta na forma quadrática para o cultivar UPF $7\left(\mathrm{R}^{2}=99,3 \% * *\right)$ e linear $\left(\mathrm{R}^{2}=57,3 \% * *\right)$ para o genótipo UPF86A1169-2b (Figura 21).

Quanto à extração de nitrogênio pelas plantas (ENP), a análise de variância revelou que foi significativa a interação genótipo $x$ níveis de $A l(P<0,05)$, bem como para os componentes individuais da interação (Tabela D9).

A comparação entre as médias dos genótipos (teste de Tukey), mostrou que a exemplo do teor, a extração de $N$ pelo genótipo tolerante foi superior ao sensivel, nos níveis 0,10 e $20 \mathrm{mg} A l / 1$, mas não diferindo no nivel $30 \mathrm{mg}$ Al/l (Tabela 47). Com relação ao comportamento de cada genótipo nos níveis de Al, verifica-se que as mesmas apresentaram uma redução significativa entre os niveis 0 e 10 mg Al/l e entre 10 e $20 \mathrm{mg} A l / l$, sem diferirem entre os níveis 20 e $30 \mathrm{mg} \mathrm{Al/1}$.

A anál ise de regressão do efeito dos niveis de Al mostrou que a variação na extração de $N$ ocorreu de forma quadrática para dois genótipos (Figura 21). 


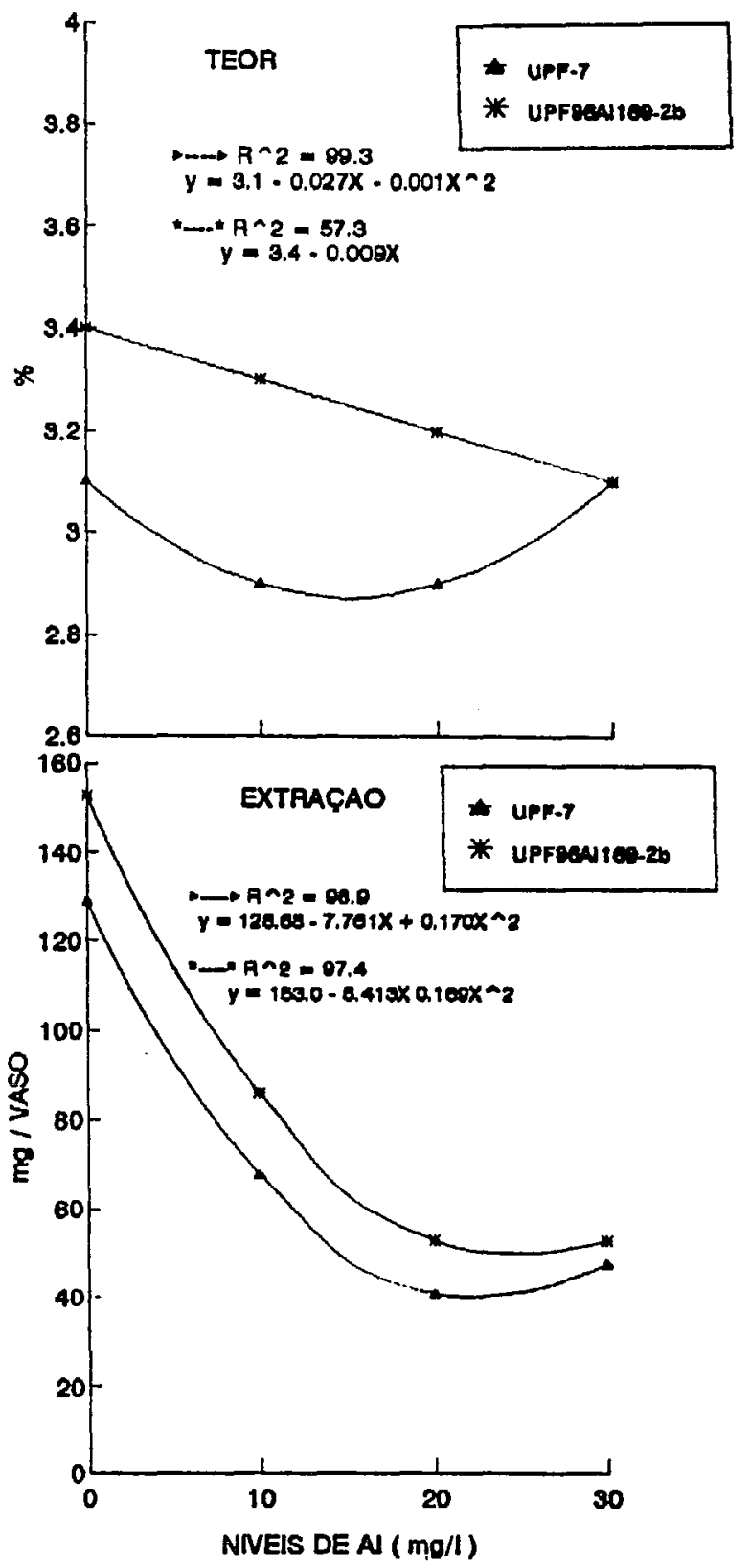

Figura 21. Efeito dos niveis de aluminio na soluço nutritiva sobre o teor e a extração de nitrogênio por plantas de dois genótipos de aveia. 
Tabela 47. Efeito dos niveis de aluminio na soluçao nutritiva, sobre o teor e extração de nitrogênio por plantas de dois genotipos de aveia.

\begin{tabular}{|c|c|c|}
\hline Níveis de & Genótil & \\
\hline Al (mg/l) & UPF $86 A 1169-2 b$ & UPF 7 \\
\hline & Teor (\%) & \\
\hline 0 & $3,4 \mathrm{a} A$ & $3,1 \mathrm{a} B$ \\
\hline 10 & $3,2 \mathrm{abA}$ & $2,9 a \quad B$ \\
\hline 20 & $3,3 \mathrm{abA}$ & $2,9 a \quad B$ \\
\hline 30 & $3,1 \mathrm{~b} \quad \mathrm{~A}$ & $3,1 \mathrm{a} A$ \\
\hline Média & $3,3 \quad A$ & $3,0 \mathrm{~B}$ \\
\hline C.V. (\%) & 4,0 & \\
\hline & Extração (mg/vaso) & \\
\hline 0 & $156,0 \mathrm{a} A$ & $130,3 \mathrm{aB}$ \\
\hline 10 & $77, \mathrm{Ob} \mathrm{A}$ & $63,2 \mathrm{bB}$ \\
\hline 20 & $61,5 \mathrm{c} \quad \mathrm{A}$ & $46,9 \mathrm{cB}$ \\
\hline 30 & $50,2 \mathrm{c} A$ & $46,2 \mathrm{cA}$ \\
\hline Média & $86,2 \quad A$ & $71,6 \mathrm{~B}$ \\
\hline C.V. (\%) & 7,6 & \\
\hline
\end{tabular}

- Médias seguidas da mesma letra minúscula na vertical e maiúscula na horizontal, não diferem pelo teste de Tukey ao nível de $5 \%$ de significância.

Em relação às partes da planta, a análise de variância dos resultados de teor e extração de $N$ mostrou que $a$ interação genótipo $x$ partes $x$ níveis de Al foi significativa, através do teste $F$, ao nivel de $5 \%$ de significância (Tabela D10). Nessa mesma tabela, verifica-se que também foram altamente significativas as interaços genótipos $x$ níveis de Al, partes $x$ níveis de Al, partes $x$ 
genótipos e os fatores componentes genótipos, níveis de Al e partes $(P<0,01)$.

A comparação entre as médias, pelo teste de Tukey, do desdobramento da interação entre genótipos quanto ao teor de $N$ nas raizes, pode ser observada na Tabela 48 , que não houve diferença significativa na ausência de Al. Com o

Tabela 48. Efeito dos niveis de alumínio na soluça nutritiva sobre o teor e extração de nitrogênio pela parte aérea e as ráizes de dois genótipos de aveia.

\begin{tabular}{|c|c|c|c|c|}
\hline \multirow{2}{*}{$\begin{array}{l}\text { Niveis de } \\
\text { Al (mg/l) }\end{array}$} & \multicolumn{2}{|c|}{ Raizes } & \multicolumn{2}{|c|}{ Parte aérea } \\
\hline & UPF $86 A \perp 169-2 b$ & UPF 7 & UPF 86Al169-2b & UPF 7 \\
\hline \multicolumn{5}{|c|}{ Teor (\%) } \\
\hline 0 & $1,8 \mathrm{cA}$ & $1,8 \mathrm{bA}$ & $4,0 \mathrm{aA}$ & $3,5 \mathrm{aB}$ \\
\hline 10 & $2,1 \mathrm{abA}$ & $1,8 \mathrm{bB}$ & $3,4 \mathrm{bA}$ & $3,2 \mathrm{bB}$ \\
\hline 20 & $2,0 \mathrm{bcB}$ & $2,2 \mathrm{aA}$ & $3,6 \mathrm{bA}$ & $3,1 \mathrm{cB}$ \\
\hline 30 & $2,8 \mathrm{aA}$ & $2,1 \mathrm{aB}$ & $3,3 \mathrm{bA}$ & $3,3 a b A$ \\
\hline Méd ia & $2,1 \mathrm{~A}$ & $2,0 \mathrm{~A}$ & $3,6 \mathrm{~A}$ & $3,3 \mathrm{~B}$ \\
\hline C.V. (\%) & 4,0 & & & \\
\hline \multicolumn{5}{|c|}{ Extração (mg/vaso) } \\
\hline 0 & $22,3 a A$ & $22,4 \mathrm{aA}$ & $133,7 \mathrm{aA}$ & $107,9 a B$ \\
\hline 10 & $10,6 \mathrm{bA}$ & $8,2 \mathrm{bA}$ & $66,4 \mathrm{bA}$ & $54,9 \mathrm{bB}$ \\
\hline 20 & $7,6 \mathrm{bA}$ & $7,5 \mathrm{bA}$ & $53,9 \mathrm{cA}$ & $38,7 \mathrm{cB}$ \\
\hline 30 & $7,3 \mathrm{bA}$ & $4,8 \mathrm{bA}$ & $42,9 \mathrm{dA}$ & $42,1 \mathrm{cA}$ \\
\hline Média & $11,9 \mathrm{~A}$ & $10,7 \mathrm{~B}$ & $74,2 \mathrm{~A}$ & $60,9 \mathrm{~B}$ \\
\hline C.V. (\%) & 9,4 & & & \\
\hline
\end{tabular}

- Médias seguidas da mesma letra, minúscula na vertical e maiúscula na horizontal, dentro de cada parte, não diferem pelo teste de Tukey ao nível de 5\% de significância. 
aumento da concentração de Al, o teor de $\mathrm{N}$ nas raízes do genotipo UPF86Al169-2b, foi superior ao cultivar UPF7

$(P<0,05)$ nos níveis 10 e $30 \mathrm{mg} \mathrm{Al/l}$ e inferior no nível de $20 \mathrm{mg} \mathrm{Al/l}$. Na parte aérea, o teor de $\mathrm{N}$ do genótipo UPF86Al169-2b foi superior ao sensivel nos niveis 0,10 e 20 mg $A l / 1$, não diferindo no nível de $30 \mathrm{mg} \mathrm{Al/l}$.

A análise de regressão do efeito de níveis de Al sobre o teor de $N$ nas partes da planta, revelou que na parte aérea, a variação se manifesta através de uma equação quadrática nos dois genótipos, enquanto nas rafizes é linear (Figura 22), com o aumento da concentração de alumínio na solução.

A comparação entre as médias da parte aérea e das ráizes (Tabela 49), mostra que nos dois genótipos, o teor de $\mathrm{N}$ da parte aérea é superior ao das raizes $(\mathrm{P}<0,05)$, em todos os níveis de alumínio. No genótipo tolerante, o teor de $N$ da parte aérea na ausência de $A l$, é superior $(P<0,05)$ em relação aos níveis com Al, que não diferiram entre si. No cultivar sensivel, o teor de $\mathrm{N}$ do nível 0 de $\mathrm{Al}$ somente diferiu dos níveis 10 e $20 \mathrm{mg}$ Al, mas não diferiu do nível 30 mg Al/l. Esse resultado pode ser explicado pelo efeito de concentração do nutriente nos tecidos, provocado pela redução no rendimento de MS.

Nas raízes, o efeito de acumulação do $N$, em função do aumento do teor de Al na solução, é mais marcante no cultivar UPF7 que no genótipo tolerante (Tabela 49).

Quanto à extração de $N$ pelas raízes, verificou-se que, o genótipo UPF86Al169-2b foi superior ao sensível apenas para a média dos quatro níveis de Al (Tabela 48). Na parte aérea, a extraçao de $N$ pelo genótipo UPF86A1169-2b foi superior ao do cultivar UPF7, nos níveis 0 , 10 e $20 \mathrm{mg} \mathrm{Al/1}$, não diferindo no nível de $30 \mathrm{mg} \mathrm{Al/l}$. Já em 


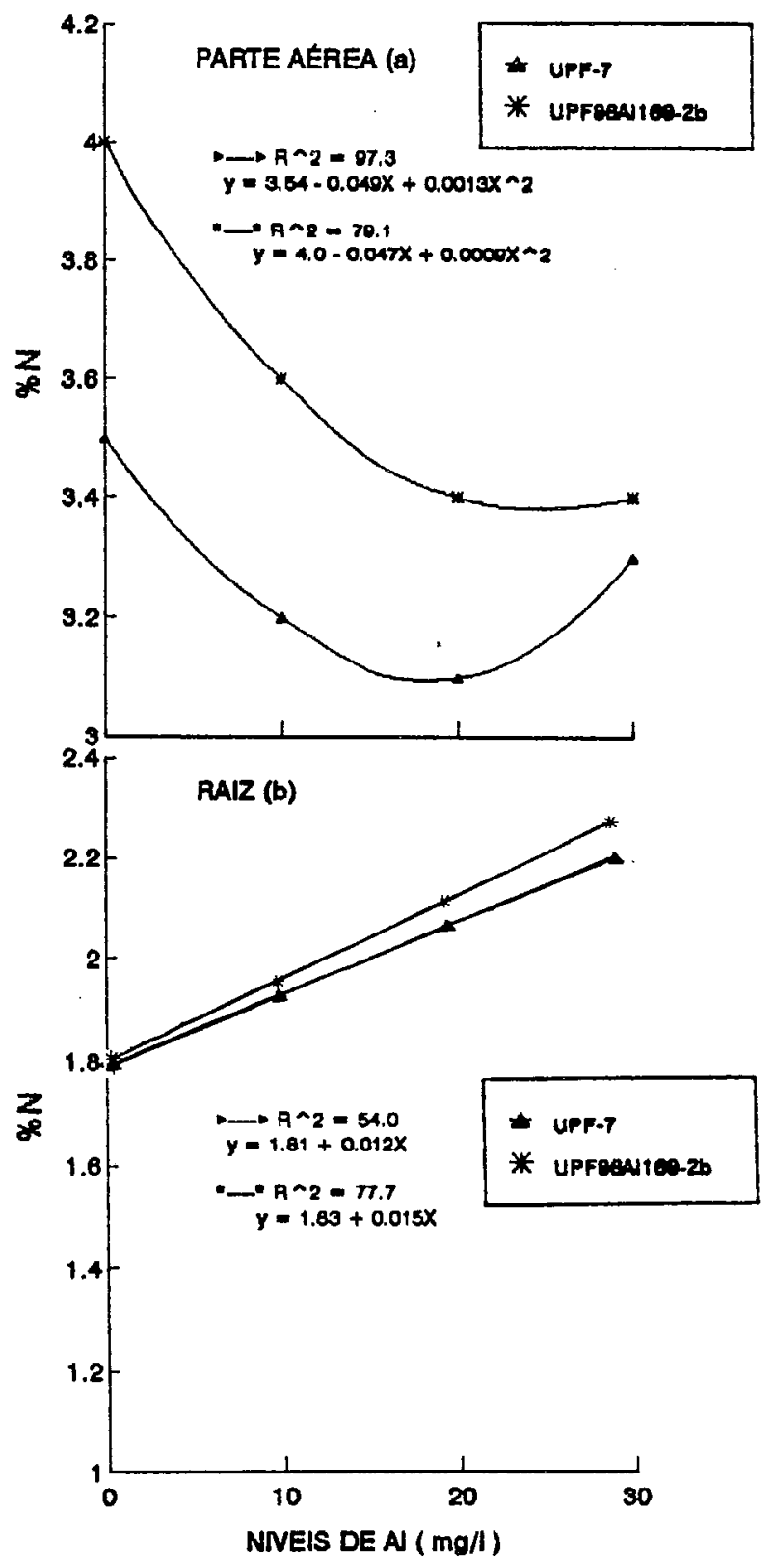

Figura 22. Efeito dos níveis de alumínio na soluça nutritiva sobre o teor de nitrogênio na parte aérea (a) e nas raizes (b), de dois genótipos de aveia. 


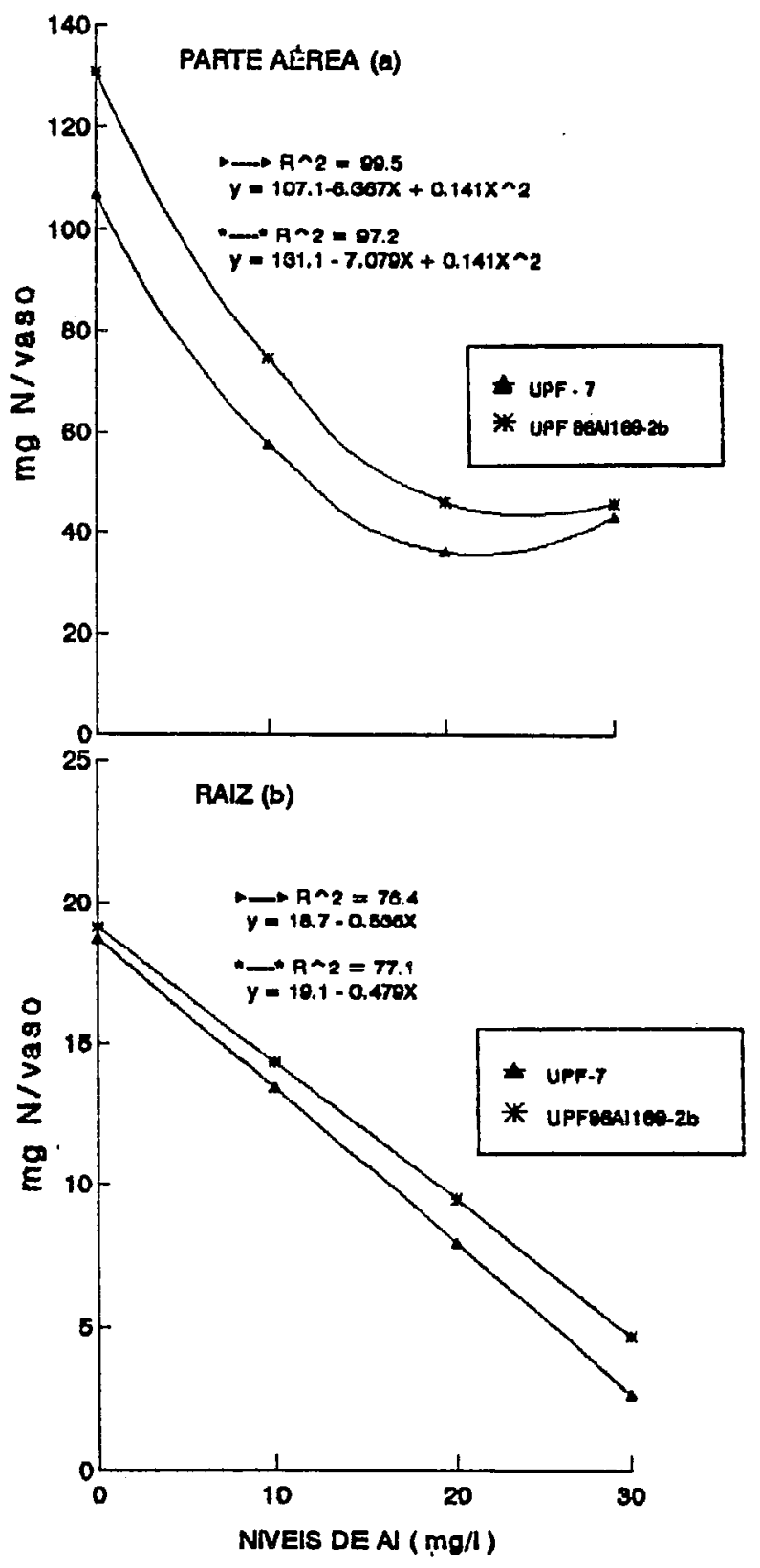

Figura 23. Efeito de niveis de alumínio na soluçao nutritiva sobre a extração de nitrogênio da parte aérea (a) e das raízes (b), de dois genótipos de aveia. 
relaça às partes, verifica-se que nos dois genótipos, a extraça pela parte aérea foi superior à das raízes $(P<0,05)$.

Tabela 49. Efeito dos níveis de alumínio na solução nutritiva, sobre o teor e a extraça de nitrogênio pela parte aérea e raizes de dois genótipos de aveia.

\begin{tabular}{lcccc}
\hline Níveis de & \multicolumn{2}{c}{ UPF86Al169-2b } & UPF \\
Al (mg/l) & $\begin{array}{c}\text { Parte aérea } \\
\text { Raizes }\end{array}$ & $\begin{array}{c}\text { Parte aérea } \\
\text { Raízes }\end{array}$ \\
\hline 0 & $4,0 \mathrm{aA}$ & $1,8 \mathrm{cB}$ & $3,5 \mathrm{aA}$ & $1,8 \mathrm{bB}$ \\
10 & $3,4 \mathrm{bA}$ & $2,1 \mathrm{abB}$ & $3,2 \mathrm{bcA}$ & $1,8 \mathrm{bB}$ \\
20 & $3,6 \mathrm{bA}$ & $2,0 \mathrm{bcB}$ & $3,1 \mathrm{cA}$ & $2,2 \mathrm{aB}$ \\
30 & $3,3 \mathrm{bA}$ & $2,8 \mathrm{aB}$ & $3,3 \mathrm{abA}$ & $2,1 \mathrm{aB}$ \\
Média & $3,6 \mathrm{~A}$ & $2,1 \mathrm{~B}$ & $3,3 \mathrm{~A}$ & $2,0 \mathrm{~B}$ \\
C.V.(\%) & 4,0 & & &
\end{tabular}

Extraçao (mg/vaso)

$\begin{array}{lrrrr}0 & 133,7 \mathrm{aA} & 22,3 \mathrm{aB} & 107,9 \mathrm{aA} & 22,4 \mathrm{aB} \\ 10 & 66,4 \mathrm{bA} & 10,6 \mathrm{bB} & 54,9 \mathrm{bA} & 8,2 \mathrm{bB} \\ 20 & 53,9 \mathrm{cA} & 7,6 \mathrm{bB} & 38,7 \mathrm{cA} & 7,5 \mathrm{bB} \\ 30 & 42,9 \mathrm{dA} & 7,3 \mathrm{bB} & 42,1 \mathrm{cA} & 4,8 \mathrm{bB} \\ \text { Média } & 74,2 \mathrm{~A} & 11,9 \mathrm{~B} & 60,9 \mathrm{~A} & 10,7 \mathrm{~B} \\ \text { C.V.(\%) } & 5,5 & & & \end{array}$

- Médias seguidas da mesma letra minúscula na vertical e maiúscula na horizontal, dentro de cada genótipo não diferem pelo teste de Tukey ao nível de $5 \%$ de significância. 
A análise de regressao do efeito de alumínio sobre a extração de $\mathrm{N}$ pela parte aérea revelou que ocorreu uma variação expressa na forma de uma equação quadrática, para os dois genótipos, enquanto para as raízes, ocorreu uma uma redução de forma 1 inear (Figura 23).

\subsubsection{Fósforo}

A análise de variancia dos teores de fósforo da planta (TPP) revelou que a interaça genótipo $x$ níveis de alumínio foi altamente significativa $(P<0,01)$, enquanto que para extração (EPP) a interação não foi significativa, ao nível de $5 \%$ de significância (Tabela D9). Tanto para o teor quanto para a extração, as diferenças foram significativas para os genótipos e os niveis de Al $(\mathrm{P}<0,05)$.

Na Tabela 50, observa-se que o teor de $\mathrm{P}$ da planta do genótipo UPF86Al169-2b foi superior ao do cultivar UPF 7 , na média dos niveis e nos níveis 0 e $20 \mathrm{mg} \mathrm{Al/l}$, não diferindo nos demais níveis. Com o aumento da concentração de aluminio na solução, verificou-se um aumento do teor de fósforo na planta, que foi mais elevado no nível de $20 \mathrm{mg}$ Al/l para o genótipo UPF86Al169-2b, sendo que no genótipo UPF 7 , seu teor no nivel de $10 \mathrm{mg} A l / l$ foi significativamente superior ao nivel 0 , não diferindo nos demais níveis de Al. Estes resultados discordam daqueles encontrados em aveia por ALAM (1985), que observou menores concentraçóes de $P$ na planta nos solos ácidos em ausência de calagem em relação aos tratamentos com calagem. Esse resultado poderia ser explicado pela maior disponibilidade de Fe no solo não corrigido, que estaria diminuindo a disponibilidade de fósforo.

Pela análise de regressão do efeito dos niveis de Al sobre o teor de $P$ verifica-se que nos dois genótipos, 
ocorreu uma variação expressa na forma de uma equação quadrática, com um $R^{2}$ de $95,7 \%$ para UPF7 e 99,3\% para UPF86A1169-2b (Figura 24).

Tabela 50. Efeito dos niveis de alumínio na solução nutritiva sobre o teor e extração de fósforo pela planta, de dois genótipos de aveia.

\begin{tabular}{|c|c|c|c|}
\hline \multirow{2}{*}{$\begin{array}{l}\text { Níveis de } \\
\text { Al (mg/l) }\end{array}$} & \multicolumn{2}{|c|}{ Genót ipo } & \multirow{2}{*}{ Média } \\
\hline & UPF $86 \mathrm{~A} 1169-2 \mathrm{~b}$ & UPF 7 & \\
\hline \multicolumn{4}{|c|}{ Teor (\%) } \\
\hline 0 & $0,21 \mathrm{cA}$ & $0,18 \mathrm{bB}$ & 0,19 \\
\hline 10 & $0,35 \mathrm{bA}$ & $0,35 \mathrm{aA}$ & 0,35 \\
\hline 20 & $0,41 \mathrm{aA}$ & $0,36 \mathrm{aB}$ & $0,38 \mathrm{a}$ \\
\hline 30 & $0,33 \mathrm{cA}$ & $0,35 \mathrm{aA}$ & $0,34 \quad b$ \\
\hline Méd ia & $0,32 \mathrm{~A}$ & $0,31 \mathrm{~B}$ & \\
\hline C.V. (\%) & 5,3 & & \\
\hline \multicolumn{4}{|c|}{ Extração (mg/vaso) } \\
\hline 0 & 9,3 & 7,6 & $8,5 a$ \\
\hline 10 & 8,4 & 7,5 & $8,0 \mathrm{a}$ \\
\hline 20 & 7,7 & 5,6 & $6,7 b$ \\
\hline 30 & 5,3 & 5,1 & $5,2 \mathrm{c}$ \\
\hline Média & $7,7 \mathrm{~A}$ & $6,5 \mathrm{~A}$ & 7,1 \\
\hline C.V. (\%) & 8,7 & & \\
\hline
\end{tabular}

- Médias seguidas da mesma letra minúscula na vertical e maiúscula na horizontal, não diferem pelo teste de Tukey ao nível de $5 \%$ de significância.

Com relação à extração de $\mathrm{P}$ na média dos níveis de Al, o genótipo UPF86Al169-2b apresentou valor maior que o genótipo UPF7 (Tabela 50). Quanto ao efeito de 
níveis, na média dos dois genótipos, a extraça não diferiu nos niveis 0 e $10 \mathrm{mg} A l / 1$, que superaram o nivel 20, que por sua vez, foi superior ao nível $30 \mathrm{mg} \mathrm{Al/l}(\mathrm{P}<0,05)$.

A análise dos resultados do fracionamento da planta verificou que a interaça genótipos $x$ partes $x$ niveis de alumínio não foi significativa em relação ao teor de $P$, bem como a diferença entre os genótipos $(P>0,05)$ (Tabela D10). As interaçoes genótipo $x$ niveis de Al e partes $x$ níveis de Al e os niveis de Al e as partes, diferiram significativamente pelo teste $F$, ao nivel de $1 \%$ de significância, enquanto a interação entre partes $x$ genótipos foi significativa ao nível de $5 \%$.

Na Tabela 51, verifica-se que o teor de fósforo da parte aérea foi superior ao das raízes, na média dos dois genótipos, e nos níveis 0,10 e $20 \mathrm{mg} \mathrm{Al} / \mathrm{l}$ e que os teores não diferiram no nível $30 \mathrm{mg} \mathrm{Al/l}$. Na comparação entre genótipos (Tabela 52), observa-se que não houve diferenças significativas quanto ao teor de $P$ nas raizes, mas que na parte aérea, o teor de $P$ do genótipo tolerante foi superior ao sensivel $(\mathrm{P}<0,05)$. O genótipo tolerante também apresentou teor de fósforo na parte aérea significativamente superior ao das raizes, enquanto no cultivar sensivel essa diferença não foi significativa (Tabela 52). A variação do teor de fósforo da parte aérea e das raizes, manifestou-se na forma de uma equação quadrática (Figura 25).

Esses resultados sugerem que no genótipo sensivel, haveria uma maior imobilização do fósforo nas células das raizes, o que poderia ser provocado pelo alumínio, conforme CAMBRAIA (1989). O teor de fósforo maior das raízes de aveia estressadas por alumínio, também foi encontrado por ALAM \& ADAMS (1979b) e OTSUKA (1968), em aveia e por MUGWIRA et al. (1981), em triticale. 
A media de extraca de fostoro pela parte asma foi superior a das räzes en todos os niveis de al na soluga (Tabel 52). Na Tabela 53 observase glue o genotipo UFF 8691169 2b acumulou ma is p na parte asea que o outivar

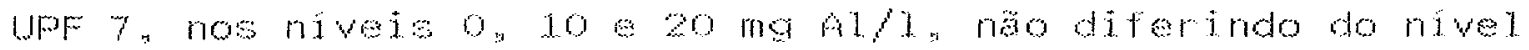
de 30 ma Aly. Ia nas raizes, näo houve difarengas sinifioatusentre os dois genotipos.

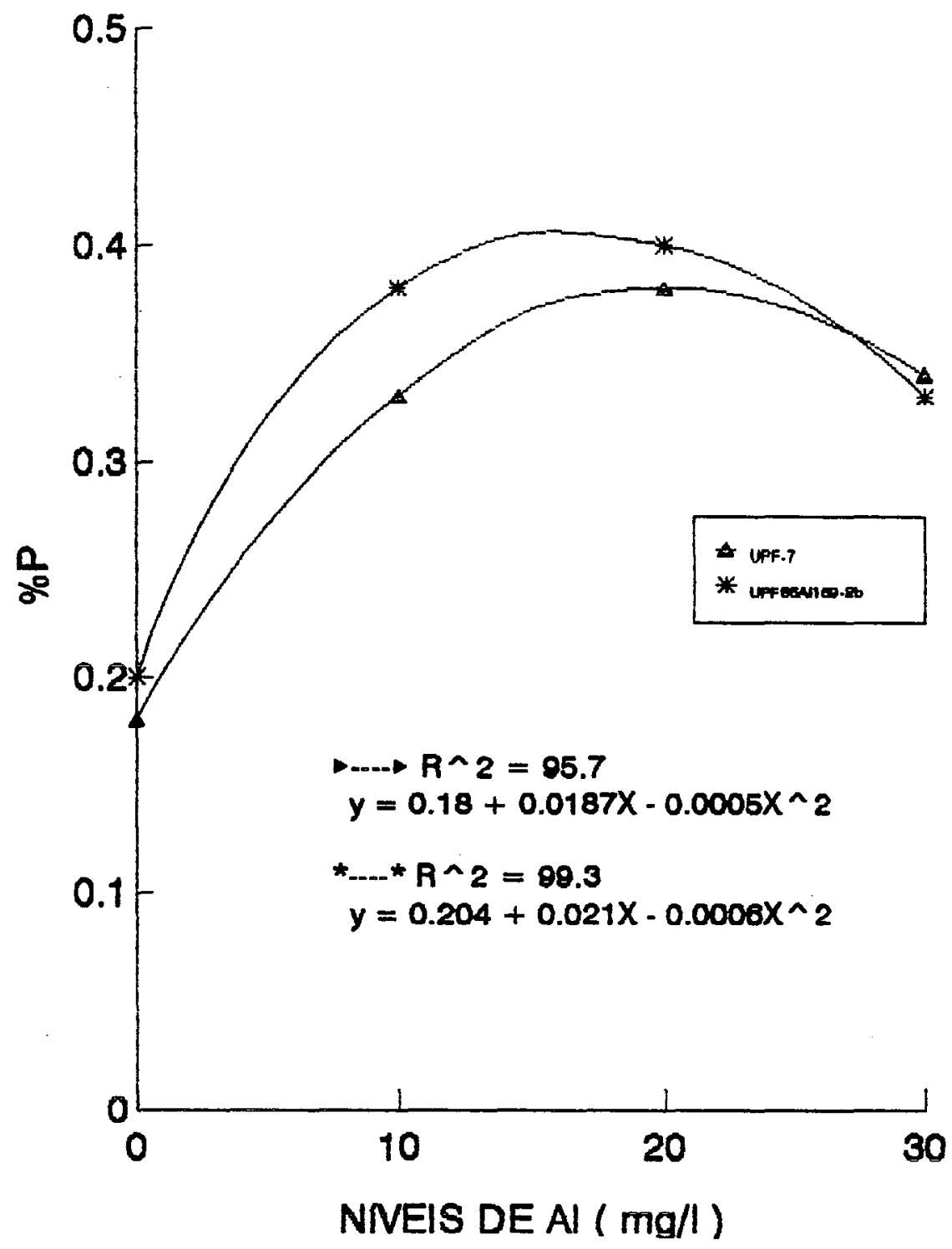

Figura 24. Efeito dos níveis de aluminio na solução nutritiva, sobre o teor de fósforo nas plantas de dois genótipos de aveia. 
Tabela 51. Efeito dos niveis de alumínio na soluça nutritiva sobre o teor e a extraça média de fósforo pela parte aérea e pelas rázes, de dois genótipos de aveia.

Níveis de

Parte da planta

Al (mg/l)

Parte aérea

Raízes

\begin{tabular}{lll}
\hline & Teor (\%) & \\
0 & $0,20 \mathrm{cA}$ & $0,18 \mathrm{bB}$ \\
10 & $0,35 \mathrm{bA}$ & $0,32 \mathrm{aB}$ \\
20 & $0,38 \mathrm{aA}$ & $0,33 \mathrm{aB}$ \\
30 & $0,34 \mathrm{bA}$ & $0,34 \mathrm{aA}$ \\
Média & $0,32 \mathrm{~A}$ & $0,24 \mathrm{~B}$ \\
C.V.(\%) & 5,5 & \\
& Extração $(\mathrm{mg} / \mathrm{vaso})$ & $2,2 \mathrm{aB}$ \\
0 & $6,3 \mathrm{aA}$ & $1,6 \mathrm{bB}$ \\
10 & $6,4 \mathrm{aA}$ & $1,2 \mathrm{bcB}$ \\
20 & $5,3 \mathrm{bA}$ & $1,0 \mathrm{cB}$ \\
Média & $4,3 \mathrm{cA}$ & $1,46 \mathrm{~B}$ \\
$\mathrm{C} . \mathrm{V} .(\%)$ & $5,58 \mathrm{~A}$ & \\
\hline
\end{tabular}

- Médias seguidas da mesma letra minúscula na vertical e maiúscula na horizontal, não diferem pelo teste de Tukey ao nivel de $5 \%$ de significância.

No entanto, o aumento dos teores de $\mathrm{P}$ da parte aérea, verificado neste trabalho, contraria os resultados encontrados por ALAM \& ADAMS (1979b) e ALAM (1985). Este fato poderia ser atribuído ao teor de $\mathrm{P}$ de $1 \mathrm{mg} / \mathrm{l}$ utilizado na solução nutritiva, considerado relativamente alto. A alta concentração de $P$ na raíz com a presença de Al e o inverso na parte aérea é atribuida à precipitação Al-P que ocorre na 
raiz e impede a translocação do $P$ para a parte aérea (ALAM, 1985).

Quanto à extração de fósforo, a análise de variância revelou pelo teste $F$, diferenças significativas, para a interação tripla genótipos $x$ partes $x$ niveis de Al e para as demais causas de variaçăo e interaçôs analisadas.

A média de extração de fósforo pela parte aérea foi superior à das raizes, em todos os níveis de Al na solução (Tabela 51). Na Tabela 53, observa-se que o genótipo UPF86Al169-2b acumulou mais $P$ na parte aérea que o cultivar UPF 7 , nos níveis 0,10 e $20 \mathrm{mg} \mathrm{Al/1}$, não diferindo do nível de $30 \mathrm{mg} \mathrm{Al/l}$. Já nas raízes, não houve diferenças significativas entre os dois genótipos.

Tabela 52. Teor médio de fósforo da parte aérea e das raízes, de dois genótipos de aveia.

Partes

da planta

UPF 86A1 169-2b

UPF 7

Genotipos

$\begin{array}{lcc} & & \\ \text { Raízes } & 0,29 \mathrm{bA} & 0,29 \mathrm{aA} \\ \text { Parte aérea } & 0,33 \mathrm{aA} & 0,31 \mathrm{aB}\end{array}$

- Médias seguidas da mesma letra minúscula na vertical e maíscula na horizontal, não diferem pelo teste de Tukey ao nível de 5\% de significância.

Os genótipos UPF86Al169-2b e UPF 7 apresentaram comportamentos idênticos, na comparação das extrações de $P$, quanto às partes, sendo que o acúmulo da parte aérea foi superior ao das raízes (Tabela 54). 


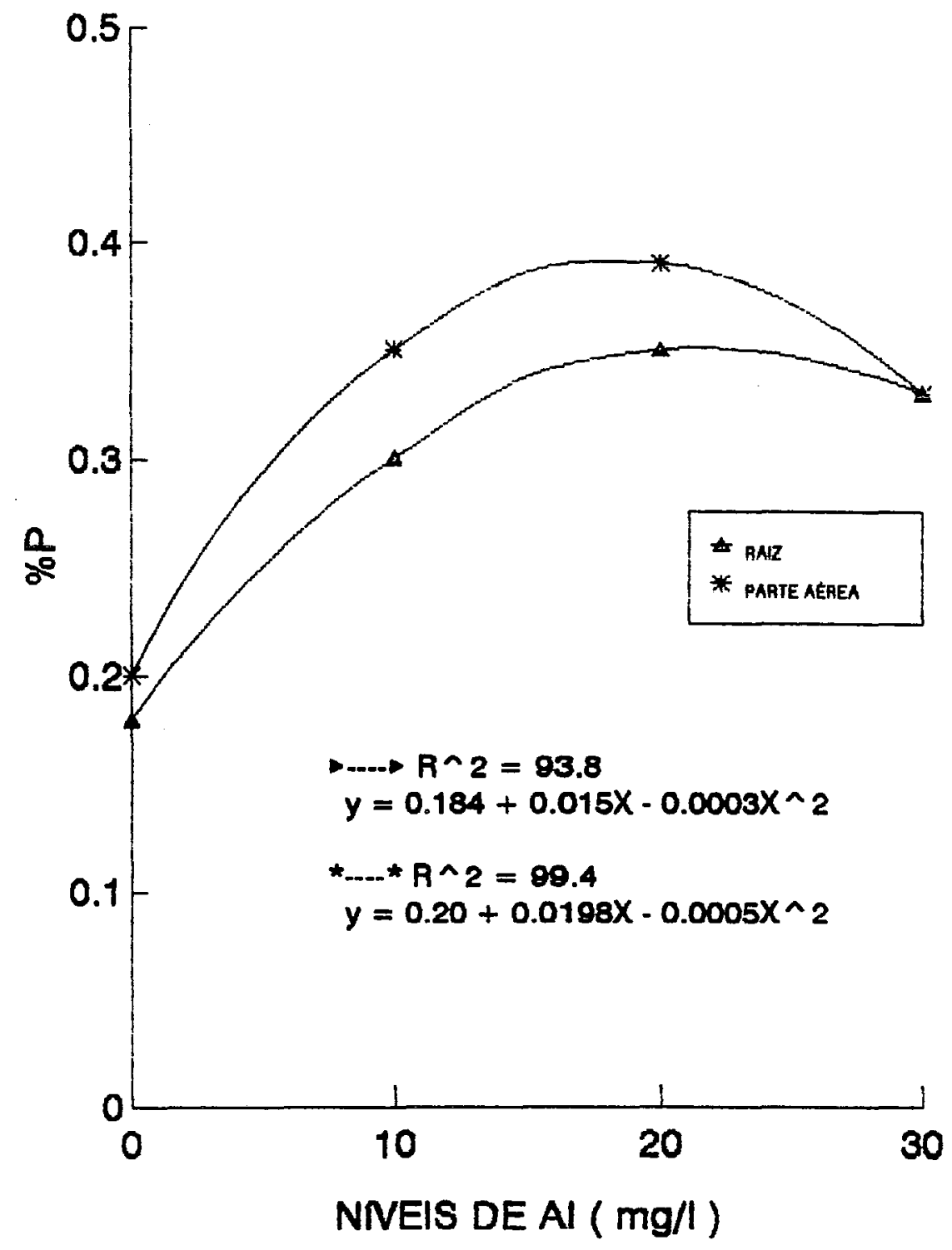

Figura 25. Efeito dos níveis de alumínio na soluçao nutritiva sobre o teor de fósforo da parte aérea e das raizes, de dois genótipos de aveia. 
Tabela 53. Efeito dos niveis de alumínio na soluça nutritiva sobre a extração de fósforo pela parte aérea e pelas raizes, de dois genótipos de aveia.

\begin{tabular}{lcccc}
\hline $\begin{array}{l}\text { Niveis de } \\
\text { Al (mg/l) }\end{array}$ & UPF86Al169-2b & UPF7 & RPF86Al169-2b & UPF7 \\
\hline & UPAizes \\
0 & $6,83 \mathrm{aA}$ & $5,73 \mathrm{aB}$ & $2,47 \mathrm{aA}$ & $1,87 \mathrm{aA}$ \\
10 & $6,90 \mathrm{aA}$ & $5,93 \mathrm{aB}$ & $1,53 \mathrm{bA}$ & $1,60 \mathrm{abA}$ \\
20 & $6,13 \mathrm{aA}$ & $4,53 \mathrm{bB}$ & $1,23 \mathrm{bA}$ & $1,10 \mathrm{bbA}$ \\
30 & $4,27 \mathrm{bA}$ & $4,30 \mathrm{bA}$ & $1,10 \mathrm{bA}$ & $0,83 \mathrm{bA}$ \\
Média & $6,03 \mathrm{~A}$ & $5,13 \mathrm{~B}$ & $1,58 \mathrm{~A}$ & $1,35 \mathrm{~A}$ \\
\hline
\end{tabular}

- Médias seguidas da mesma letra minúscula na vertical e maíscula na horizontal, dentro da mesma parte, nao diferem pelo teste de Tukey ao nivel de $5 \%$ de significância.

$\mathrm{Na}$ Figura 26, verifica-se que a redução da extração de fósforo pelas raizes, ocorreu de forma linear nos dois genótipos, enquanto que na parte aérea a redução foi linear no genótipo sensível e se manifestou na forma de uma equação quadrática no tolerante.

o aumento no teor de fósforo nos genótipos e sensivel de aveia, demonstra que a concentraça do nutriente utilizada na solução nutritiva ( $1 \mathrm{ppm}$ ) nå foi restritiva ao crescimento das plantas, uma vez que a extração diminuiu em função da toxicidade do alumínio e não pela indisponibilidade desse macronutriente. 
Tabela 54. Efeito dos níveis de alumínio na soluça nutritiva sobre a extração de fósforo pela parte aérea e pelas raizes, de dois genótipos de aveia.

\begin{tabular}{lcccc}
\hline $\begin{array}{l}\text { Niveis de } \\
\text { Al (mg/1) }\end{array}$ & UPF86Al 169-2b & \multicolumn{2}{c}{ UPF } \\
\hline & Parte aérea & Raizes & Parte aérea & Rafzes \\
\hline 0 & $6,93 \mathrm{~A}$ & $2,47 \mathrm{~B}$ & $5,73 \mathrm{~A}$ & $1,87 \mathrm{~B}$ \\
10 & $6,90 \mathrm{~A}$ & $1,53 \mathrm{~B}$ & $5,93 \mathrm{~A}$ & $1,60 \mathrm{~B}$ \\
20 & $6,13 \mathrm{~A}$ & $1,23 \mathrm{~B}$ & $4,53 \mathrm{~A}$ & $1,10 \mathrm{~B}$ \\
30 & $4,27 \mathrm{~A}$ & $1,07 \mathrm{~B}$ & $4,30 \mathrm{~A}$ & $0,83 \mathrm{~B}$ \\
Média & $6,03 \mathrm{~A}$ & $1,58 \mathrm{~B}$ & $5,13 \mathrm{~A}$ & $1,35 \mathrm{~B}$ \\
C.V.(\%) & 10,3 & & & \\
\hline
\end{tabular}

- Médias seguidas da mesma letra minúscula na vertical e maíscula na horizontal, dentro do mesmo genótipo, não diferem pelo teste de Tukey ao nível de $5 \%$ de significância.

\subsubsection{Potássio}

A análise de variância dos resultados dos teores e da extração de potássio da planta (TKP e EKP, respectivamente), revelou que a interação genótipo $x$ niveis de aluminio não foi significativa, ao nivel de $5 \%$ de significância (tabela D9) .

Quanto aos genótipos, a diferença não foi significativa para os teores, enquanto que para a extraço as diferenças foram significativas ao nível de 5\%. Para os níveis de aluminio, as diferenças foram altamente significativas para extração $(P<0,01)$ (Tabela D9).

Pela comparaça dos genótipos na média de todos os niveis de Al, pelo teste de Tukey, verifica-se que 


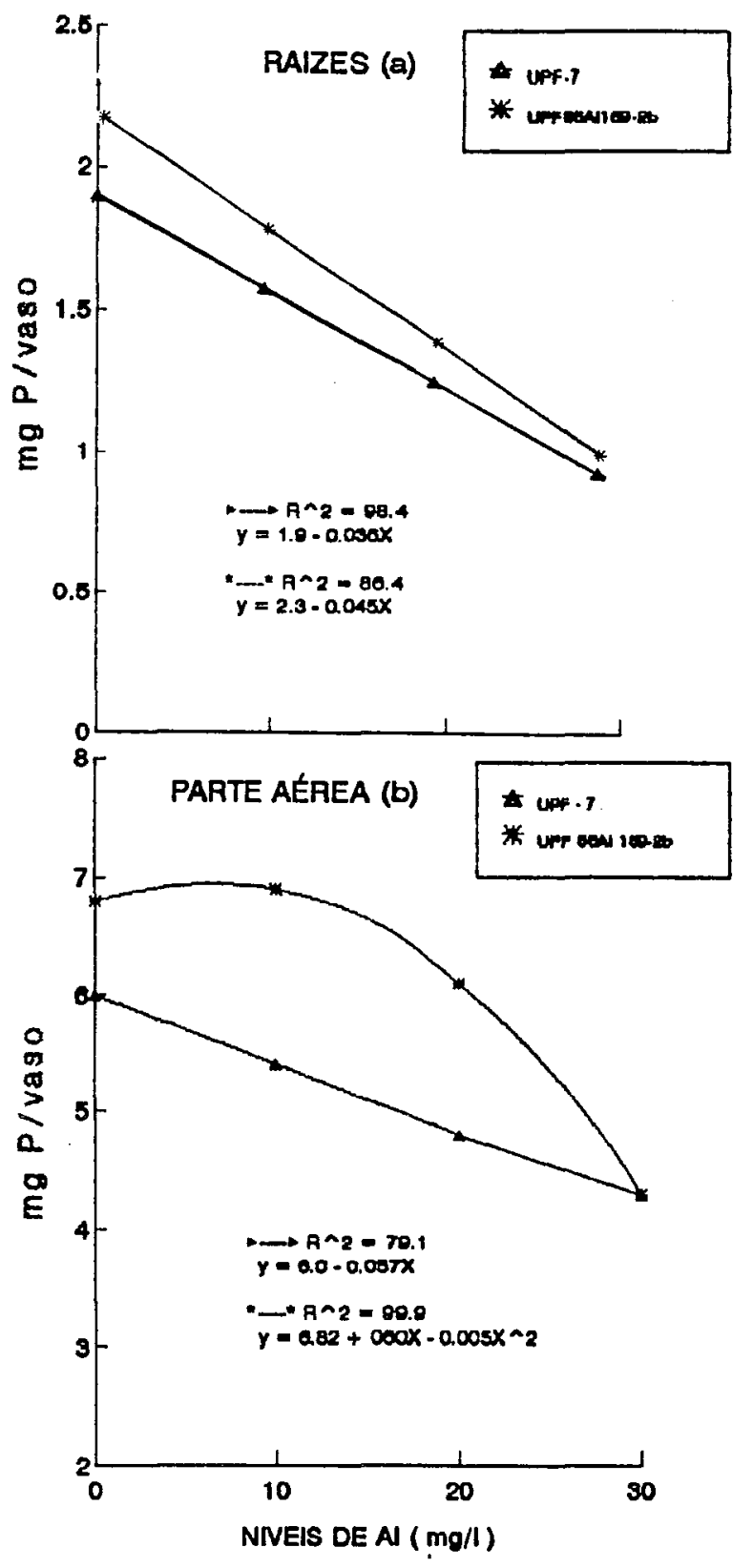

Figura 26. Efeito dos niveis de alumínio na soluça nutritiva sobre a extração de fósforo pelas raízes (a) e pela parte aérea (b), de dois genótipos de aveia. 
o teor de $5,3 \%$ do genótipo tolerante nao diferiu significativamente do teor de $5,0 \%$ do sensivel, conforme a Tabela 55. Quanto à extração, o genótipo UPF86Al169-2b acumulou significativamente mais potássio do que o sensivel. Quanto às partes da planta (Tabela D10), verificou-se pela análise de variância dos teores de potássio (TK), que as interaçôs genótipos $x$ partes $x$ níveis de

Tabela 55. Efeito dos níveis de aluminio na solução nutritiva sobre o teor e a extração de potássio, pelas plantas de dois genótipos de aveia.

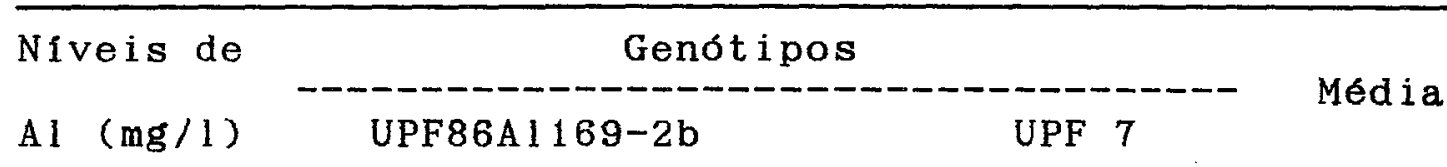

Teor $(\%)$

\begin{tabular}{lccc}
0 & 5,1 & 5,1 & $5,1 \mathrm{ab}$ \\
10 & 5,7 & 6,0 & $5,9 \mathrm{a}$ \\
20 & 5,1 & 4,7 & $4,9 \mathrm{~b}$ \\
30 & 5,2 & 4,4 & $4,8 \mathrm{~b}$ \\
Média & $5,3 \mathrm{~A}$ & $5,0 \mathrm{~A}$ & 5,2 \\
C.V. (\%) & 8,8 & & \\
\multicolumn{4}{c}{} \\
0 & \multicolumn{3}{c}{ Extraça (mg/vaso) } \\
10 & 233,1 & 218,1 & $225,6 \mathrm{a}$ \\
20 & 139,8 & 129,0 & $134,4 \mathrm{~b}$ \\
30 & 96,3 & 74,3 & $85,3 \mathrm{c}$ \\
Média & 83,1 & 65,1 & $74,1 \mathrm{c}$ \\
C.V. (\%) & $138,1 \mathrm{~A}$ & $121,6 \mathrm{~B}$ & 129,8 \\
\hline
\end{tabular}

- Médias seguidas da mesma letra minúscula na vertical e maiúscula na horizontal, não diferem pelo teste de Tukey ao nível de $5 \%$ de significância. 
alumínio, partes $x$ níveis de $A l$ e partes $x$ genotipos foram significativas, bem como as diferenças entre os genótipos, partes e niveis de Al. Quanto à extraça de potássio, as interações genótipo $x$ partes $x$ níveis de alumínio, genótipos $x$ níveis, e partes $x$ genótipos, nå foram significativas. A interaça partes $x$ niveis de $A l$ as demais causas apresentaram diferenças altamente significativas $(P<0,01)$.

Na comparacão pelo teste de Tukey entre as médias dos genótipos, apresentadas na Tabela 56, verifica-se que para o genótipo tolerante, o teor de $\mathrm{K}$ na parte aérea foi superior ao das raizes no nivel de $10 \mathrm{mg} A / / 1(P<0,05)$, não diferindo nos demais niveis $(P>0,05)$. Já para o cultivar UPF 7 (sensível), isso ocorreu nos níveis 0 e $10 \mathrm{mg}$ Al/1, não havendo diferença entre as partes, nos níveis de 20 e $30 \mathrm{mg} \mathrm{Al} / \mathrm{l}$.

$\mathrm{Na}$ parte aérea e nas raízes do genótipo UPF86Al169-2b e nas ráizes do genótipo UPF 7 , observa-se que não houve diferença nos teores de $K$, com o aumento do teor de Al na solução (Tabela 56), mas na parte aérea do genótipo sensivel, os teores de $K$ nos níveis 0 e $10 \mathrm{mg} A l / 1$, que sem diferir entre si, foram significativamente superiores aos dos

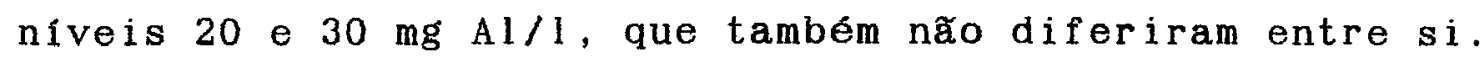

$\mathrm{Na}$ Tabela 57 , observa-se que o teor de $K$ da parte aérea do genótipo tolerante foi superior ao do sensível, no nível de $30 \mathrm{mg} \mathrm{Al/l}$, não diferindo nos demais níveis de $A l$. Nas raizes o teor de $K$ do genótipo tolerante também foi superior ao sensivel nos níveis 0 e $30 \mathrm{mg} \mathrm{Al/1}$, não diferindo nos demais niveis.

Os resultados encontrados são discordantes em relação ao relatado por ALAM \& ADAMS (1979b) e ALAM (1985), que verificaram uma diminuição na concentração de potássio da parte aérea de aveia, com o aumento do nível do Al na 
solução. Possivelmente o resultado encontrado neste trabal ho seja explicado pelo aumento da concentraça de $K$ na solução, com o aumento do nível de alumínio, pois foi utilizado o sulfato de potássio e alumínio $\left(\mathrm{AlK}\left(\mathrm{SO}_{4}\right)_{2} \cdot 12 \mathrm{H}_{2} \mathrm{O}\right)$ como fonte de Al.

Em relação às raízes, a diminuição do teor de K somente foi observada no genótipo sensível, o que está de acordo com os resultados obtidos por WAGATSUMA \& EZOE (1985). Essa menor absorção de potássio poderia ser explicada como sendo devida à competição entre o $K$ e Al pelos mesmos sitios de absorção das raízes, verificada por ALAM (1983) na cultura do arroz.

Tabela 56. Efeito dos níveis de alumínio na solução nutritiva, sobre o teor de potássio, na parte aérea e raízes de plantas de dois genótipos de aveia.

\begin{tabular}{lcccc}
\hline Níveis de & \multicolumn{2}{c}{ UPF86Al164-2b } & \multicolumn{2}{c}{ UPF } \\
Al (mg/1) & $\begin{array}{c}\text { Parte aérea } \\
\text { Raízes }\end{array}$ & Parte aérea & Raízes \\
\hline 0 & $5,4 \mathrm{aA}$ & $5,1 \mathrm{aA}$ & $5,6 \mathrm{aA}$ & $3,9 \mathrm{aB}$ \\
10 & $5,9 \mathrm{aA}$ & $5,1 \mathrm{aB}$ & $6,4 \mathrm{aA}$ & $4,5 \mathrm{aB}$ \\
20 & $5,2 \mathrm{aA}$ & $4,6 \mathrm{aA}$ & $4,7 \mathrm{bA}$ & $4,5 \mathrm{aA}$ \\
30 & $5,1 \mathrm{aA}$ & $5,4 \mathrm{aA}$ & $4,4 \mathrm{bA}$ & $4,4 \mathrm{aA}$ \\
Média & $5,4 \mathrm{~A}$ & $5,1 \mathrm{~B}$ & $5,3 \mathrm{~A}$ & $4,3 \mathrm{~B}$ \\
C.V.(\%) & 7,5 & & &
\end{tabular}

- Médias seguidas da mesma letra minúscula na vertical e maiúscula na horizontal, dentro de cada genótipo não diferem pelo teste de Tukey ao nível de $5 \%$ de significância. 
Tabela 57. Efeito dos níveis de alumínio na soluçao nutritiva, sobre o teor de potássio na parte aérea e nas raízes, de dois genótipos de aveia.

\begin{tabular}{lcrrr}
\hline Níveis de & \multicolumn{2}{c}{ Parte aérea } & \multicolumn{2}{c}{ Raízes } \\
Al (mg/l) & UPF86Al164-2b & UPF 7 & UPF86Al164-2b & UPF7 \\
\hline & & Teor $(\%)$ & \\
0 & $5,4 \mathrm{aA}$ & $5,6 \mathrm{aA}$ & $5,1 \mathrm{aA}$ & $3,9 \mathrm{aB}$ \\
10 & $5,9 \mathrm{aA}$ & $6,4 \mathrm{aA}$ & $5,1 \mathrm{aA}$ & $4,5 \mathrm{aA}$ \\
20 & $5,2 \mathrm{aA}$ & $4,7 \mathrm{bA}$ & $4,6 \mathrm{aA}$ & $4,5 \mathrm{aA}$ \\
30 & $5,1 \mathrm{aA}$ & $4,4 \mathrm{bB}$ & $5,4 \mathrm{aA}$ & $4,4 \mathrm{aB}$ \\
Média & $5,4 \mathrm{~A}$ & $5,3 \mathrm{~A}$ & $5,1 \mathrm{~A}$ & $4,3 \mathrm{~B}$ \\
C.V.(\%) & 7,5 & & & \\
\end{tabular}

- Médias seguidas da mesma letra minúscula na vertical e maiúscula na horizontal, dentro de cada parte não diferem pelo teste de Tukey ao nível de $5 \%$ de significância.

\subsubsection{Cál cio}

A análise de variância dos teores de cálcio da planta (TCaP) revelou que a interação genótipos $x$ níveis foi significativa pelo teste $F$, ao nivel de $1 \%$ de significância. Também foi significativa $(P<0,05)$ a diferença entre niveis de Al e não foi significativa para os genótipos (Tabela D9).

Pela Tabela 58, verifica-se que o teor de cálcio no genótipo tolerante, foi superior ao sensivel, somente no nivel de $20 \mathrm{mg} \mathrm{Al} / \mathrm{l}$. 
Tabela 58. Efeito dos niveis de aluminio na soluçao nutritiva, sobre o teor e extraça de cálcio, pelas plantas de dois genótipos de aveia.

\begin{tabular}{lccc}
\hline Niveis de & & Genótipos & \\
& & & \\
Al (mg/l) & UPF86Al169-2b & UPF 7 & Média \\
\hline
\end{tabular}

Teor (\%)

$\begin{array}{llll}0 & 0,55 \mathrm{bA} & 0,55 \mathrm{bA} & 0,55 \mathrm{~b} \\ 10 & 0,61 \mathrm{aA} & 0,64 \mathrm{aA} & 0,63 \mathrm{a} \\ 20 & 0,61 \mathrm{aA} & 0,53 \mathrm{bB} & 0,57 \mathrm{~b} \\ 30 & 0,49 \mathrm{cA} & 0,48 \mathrm{cA} & 0,49 \mathrm{c} \\ \text { Média } & 0,57 \mathrm{~A} & 0,55 \mathrm{~A} & \end{array}$

C.V. (\%) 3,5

Extração (mg/vaso)

$\begin{array}{lccr}0 & 25,0 & 23,4 & 24,2 \mathrm{a} \\ 10 & 14,9 & 13,9 & 14,4 \mathrm{~b} \\ 20 & 11,5 & 8,5 & 10,0 \mathrm{c} \\ 30 & 7,9 & 7,1 & 7,5 \mathrm{~d} \\ \text { Média } & 14,8 \mathrm{~A} & 13,2 \mathrm{~B} & \\ \text { C.V. }(\%) & 6,1 & & \end{array}$

- Médias seguidas da mesma letra minúscula na vertical e maiúscula na horizontal, não diferem pelo teste de Tukey ao nivel de $5 \%$ de significância.

A análise de regressão do efeito dos niveis de aluminio sobre os teores de cálcio, mostrou que tanto no genótipo sensivel, $\left(R^{2}=75,8 \% * *\right)$ como no genótipo tolerante $\left(\mathrm{R}^{2} 98,8 \% * *\right)$ a variação se manifestou em forma de equação quadrática (Figura 27). 


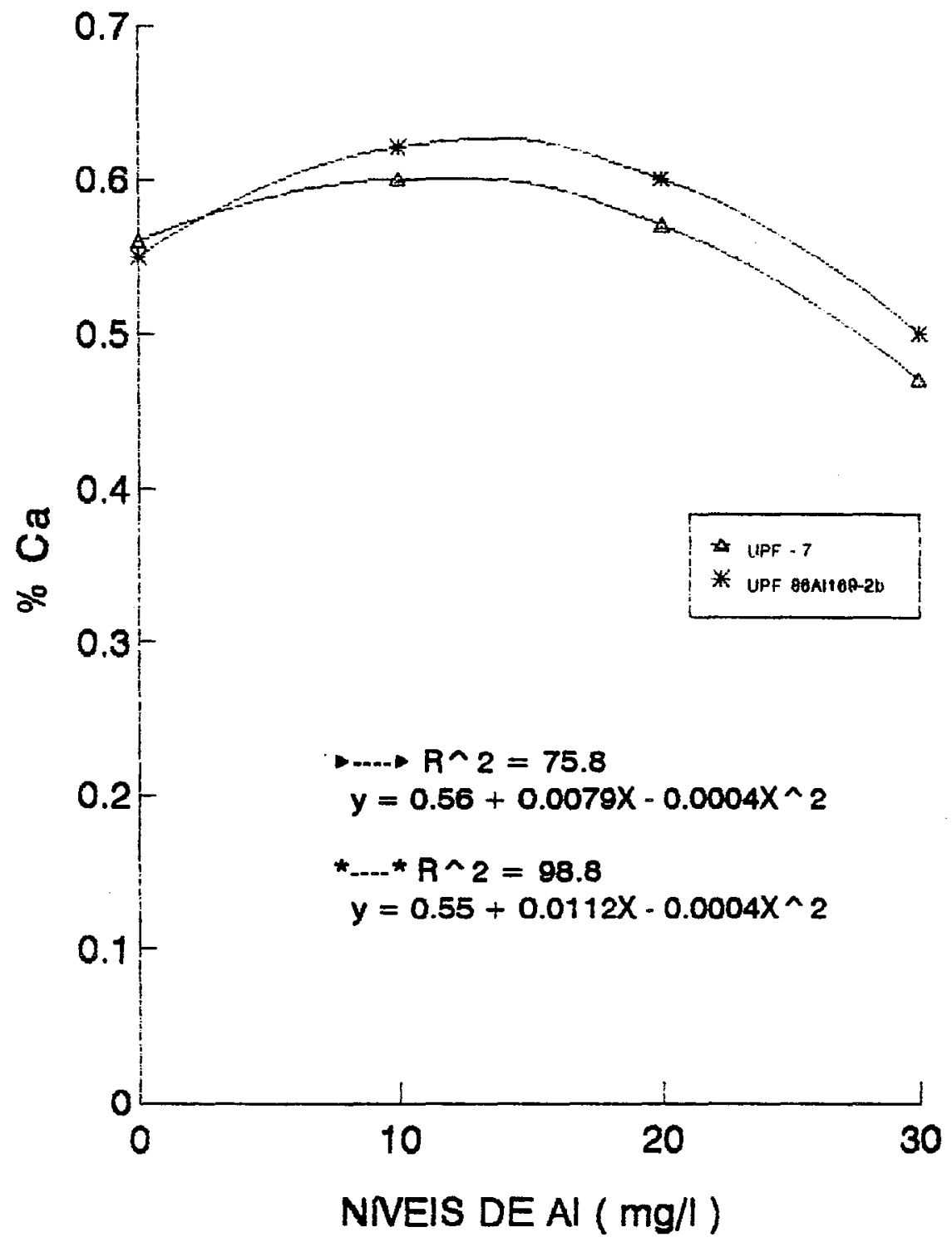

Figura 27. Efeito dos niveis de alumínio na soluçăo nutritiva, sobre a extraça de cálcio pela parte aérea (a) e pelas raízes (b) de dois genótipos de aveia. 
Em relação à extração de cálcio pelas plantas de aveia, a interação genótipos $x$ níveis de $A l$, não foi significativa pelo teste $F$, ao nivel de $5 \%$ de significância. Mas, foram significativas as diferenças entre os genótipos e os níveis de Al $(P<0,05)$, conforme Tabela 9 .

Na média dos quatro níveis de Al, verificou-se que a extração de Ca pelo genótipo UPF86Al169-2b foi superior à do genótipo UPF 7 (Tabela 58). Na médias dos genótipos, verificou-se que a extração no nivel 0 foi superior aos níveis com Al, que diferiram todos entre si, ao nível de $5 \%$ de significância.

A análise de variância dos resultados dos teores de cálcio, nas diferentes partes da planta (Tabela D10), mostrou que a interação genótipo $x$ partes $x$ niveis de Al não foi significativa ao nível de $5 \%$ de significância. Também não foi significativa a interação partes $x$ genótipos e a diferença entre os genótipos ( $P>0,05)$.

Quanto à extração de cálcio pela planta, a análise de variância dos resultados revelou, que foram significativas as interaçðes partes $x$ genótipos $x$ niveis de Al, partes $x$ niveis de aluminio e partes $x$ genótipos $(P<0,05)$ e que não foi significativa a interação genótipos $x$ níveis de Al (Tabela D10).

Pela comparação entre médias, através do teste de Tukey, observou-se que a extração de cálcio pela parte aérea foi superior à das raízes nos dois genótipos (Tabela 59). 
Tabela 59. Efeito dos niveis de alumínio na soluçao nutritiva sobre a extração de cálcio pela parte aérea e pelas raízes, de dois genótipos de aveia.

\begin{tabular}{lcccc}
\hline Níveis de & \multicolumn{2}{c}{ UPF86Al169-2b } & \multicolumn{2}{c}{ UPF } \\
Al (mg/l) & Parte aérea & Raizes & Parte aérea & Raízes \\
\hline & $-5,2 \mathrm{aB}$ & $18,6 \mathrm{aA}$ & $4,8 \mathrm{aB}$ \\
0 & $19,8 \mathrm{aA}$ & $1,8 \mathrm{bB}$ & $12,2 \mathrm{bA}$ & $1,7 \mathrm{bB}$ \\
10 & $13,1 \mathrm{bA}$ & $1,1 \mathrm{bB}$ & $7,5 \mathrm{cA}$ & $1,0 \mathrm{bB}$ \\
20 & $10,4 \mathrm{cA}$ & $1,2 \mathrm{bB}$ & $6,2 \mathrm{dA}$ & $0,9 \mathrm{bB}$ \\
30 & $6,7 \mathrm{dA}$ & $2,3 \mathrm{~B}$ & $11,1 \mathrm{~A}$ & $2,1 \mathrm{~B}$ \\
Média & $12,5 \mathrm{~A}$ & & & \\
C.V.(\%) & 7,3 & & &
\end{tabular}

- Médias seguidas de mesma letra minúscula na vertical e maiúscula na horizontal, dentro de cada genótipo não diferem pelo teste de Tukey ao nível de $5 \%$ de signif icância.

Na comparação dos genótipos dentro de cada parte (Tabela 60), verifica-se que, na parte aérea, a extração de cálcio pelo genótipo tolerante foi superior à do sensível, nos niveis 0,10 e $20 \mathrm{mg} \mathrm{Al/l}$, não diferindo no nível de $30 \mathrm{mg} \mathrm{Al/l}$. Quanto às raízes, não houve diferenças significativas entre os genótipos, em qualquer dos niveis de Al. 
Tabela 60. Efeito dos níveis de alumínio na soluçao nutritiva sobre a extração de cálcio pela parte aérea e pelas raízes de dois genótipos de aveia.

\begin{tabular}{lccccc}
\hline Niveis de & \multicolumn{2}{c}{ Parte aérea } & \multicolumn{2}{c}{ Raizes } \\
Al (mg/1) & UPF86Al $169-2 \mathrm{~b}$ & UPF & 7 & UPF86Al169-2b & UPF 7 \\
\hline & $-18,6 \mathrm{aB}$ & $5,2 \mathrm{aA}$ & $4,8 \mathrm{aA}$ \\
0 & $19,8 \mathrm{aA}$ & $12,2 \mathrm{bB}$ & $1,8 \mathrm{bA}$ & $1,7 \mathrm{bA}$ \\
10 & $13,1 \mathrm{bA}$ & $7,5 \mathrm{cB}$ & $1,1 \mathrm{bA}$ & $1,0 \mathrm{bA}$ \\
20 & $10,4 \mathrm{cA}$ & $6,2 \mathrm{dA}$ & $1,2 \mathrm{bA}$ & $0,9 \mathrm{bA}$ \\
30 & $6,7 \mathrm{dA}$ & $11,1 \mathrm{~B}$ & $2,3 \mathrm{~A}$ & $2,1 \mathrm{~A}$ \\
Média & $12,5 \mathrm{~A}$ & & & \\
C.V.(\%) & 7,3 & & & \\
\hline
\end{tabular}

- Médias seguidas da mesma letra minúscula na vertical e maiúscula na horizontal, dentro de cada genótipo não diferem pelo teste de Tukey ao nível de $5 \%$ de significância.

A análise de regressão do efeito do Al, sobre a extração de cálcio mostrou que a variação se manifestou de forma quadrática na parte aérea e nas raízes, para os dois genótipos (Figura 28).

Os resultados obtidos, quanto ao efeito do nível crescente de aluminio sobre os teores de cálcio, nos dois genótipos de aveia, estaó de acordo com aqueles obtidos, por FOY et al. (1987), cultivando aveia em solos com pH 4,3 e sem calagem.

No entanto, OTSUKA (1968) e ALAM \& ADAMS ( $1979 b)$, encontraram teores de cálcio menores na parte aérea de plantas de aveia, em função do aumento da concentração de Al. 


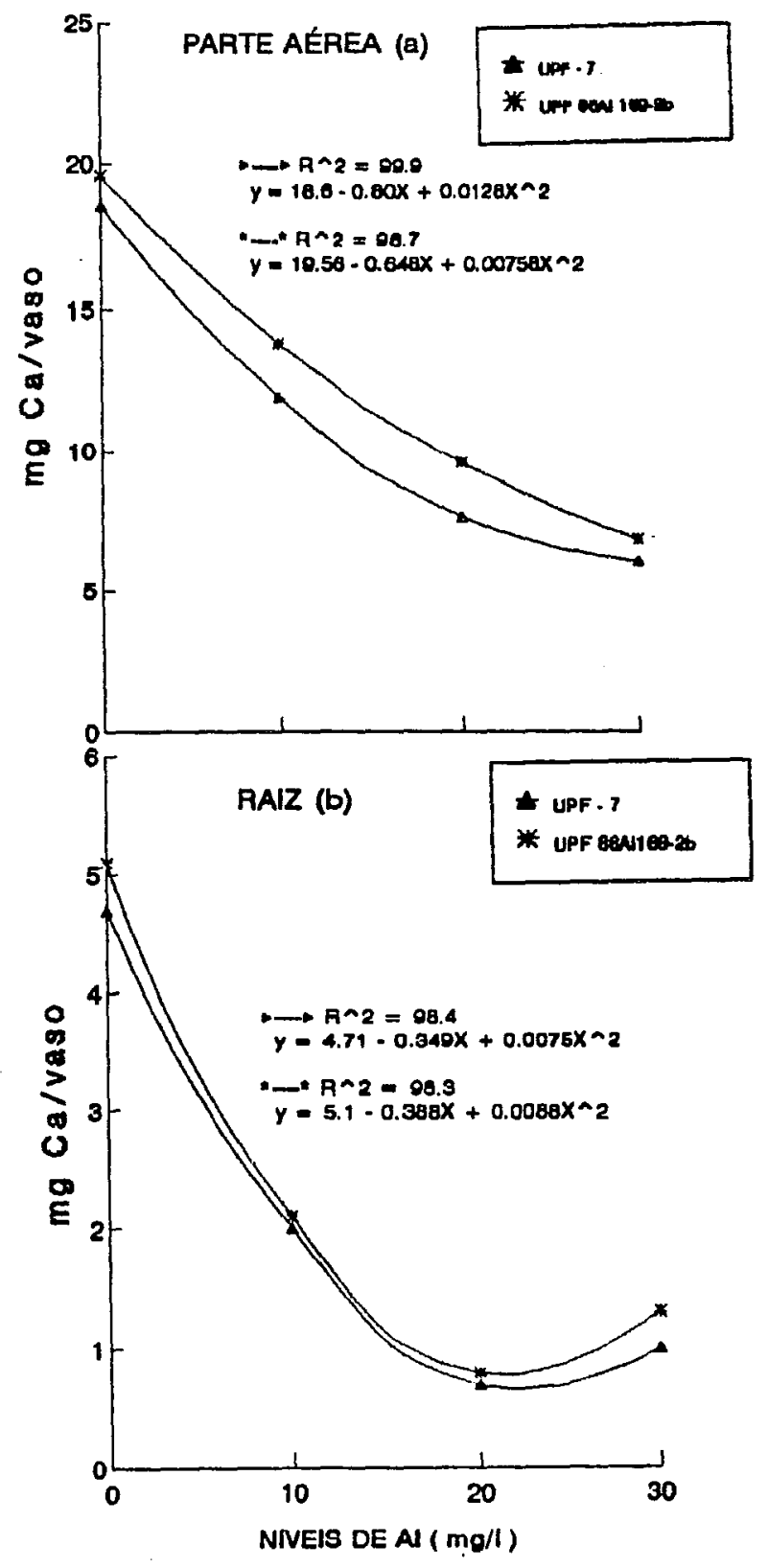

Figura 28. Efeito dos niveis de aluminio, na soluçao nutritiva sobre a extraça de cálcio pela parte aérea (a) e pelas raizes (b) de dois genótipos de aveia. 


\subsubsection{Magnésio}

A análise de variância dos resultados dos teores de magnésio da planta (TMgP) mostrou diferenças altamente significativas $(P<0,01)$ para a interação genótipos $x$ níveis de Al e para os componentes dessa interação (Tabela D9).

Através da Tabela 61 , pela comparaça entre médias, através do teste de Tukey, observa-se que o teor de magnésio do genótipo tolerante foi superior em relaça ao sensivel nos niveis de 20 e $30 \mathrm{mg} \mathrm{Al/l}$, não diferindo nos niveis 0 e $10 \mathrm{mg}$ Al/litro de solução.

Na comparação entre os niveis de Al (Tabela 61), observa-se no genótipo UPF8Al169-2b (tolerante) uma redução significativa no teor de magnésio entre os niveis 0 e $10 \mathrm{mg}$ Al/l, que nå diferiu dos niveis 20 e $30 \mathrm{mg} \mathrm{Al/l}$. No cultivar UPF 7 (sensivel), a redução foi significativa entre os niveis 0 e $10 \mathrm{mg} A 1 / 1$ e entre 10 e $20 \mathrm{mg} \mathrm{Al/l}$, sem que houvesse diferença significativa entre os niveis 20 e $30 \mathrm{mg} \mathrm{Al/1}$. Através da análise de regressão, verificou-se que esta variação manifestou-se de forma de uma equação quadrática nos dois genótipos (Figura 29).

Em relação à extração de magnésio pela planta, a análise de variância não detectou significâncias ao nível de 5\% para a interação genótipo $x$ níveis de Al (Tabela D9). No entanto, foram altamente significativas, os efeitos de genótipos e de níveis de alumínio, ao nivel de $1 \%$ de significância. 
Tabela 61. Efeito dos niveis de alumínio na soluçao nutritiva sobre o teor e a extração de magnésio pelas plantas de dois genótipos de aveia.

\begin{tabular}{lcc}
\hline Niveis de & Genótipos & \\
& & Média \\
Al $(\mathrm{mg} / \mathrm{l})$ & UPF86A1 164-2b & UPF 7
\end{tabular}

Teor (\%)

$\begin{array}{lllll}0 & 0,20(100) \mathrm{aA} & 0,20(100) \mathrm{aA} & 0,198 \mathrm{a} \\ 10 & 0,09(45) \mathrm{bA} & 0,08(45) \mathrm{bA} & 0,087 & \mathrm{~b} \\ 20 & 0,08(40) \mathrm{bA} & 0,07(35) \mathrm{cB} & 0,078 & \mathrm{bc} \\ 30 & 0,08(40) \mathrm{bA} & 0,07(35) \mathrm{cB} & 0,075 & \mathrm{c} \\ \text { Média } & 0,11 \mathrm{~A} & 0,10 \mathrm{~B} & & \end{array}$

C.V. (\%) 5,3

Extração (mg/vaso)

$\begin{array}{llll}0 & 8,9 & 8,4 & 8,7 \mathrm{a} \\ 10 & 2,0 & 2,0 & 2,0 \mathrm{~b} \\ 20 & 1,6 & 1,0 & 1,3 \mathrm{c} \\ 30 & 1,3 & 1,0 & 1,2 \mathrm{c} \\ \text { Média } & 3,5 \mathrm{~A} & 3,1 \mathrm{~B} & \end{array}$

C.V. (\%) 8,0

- Médias seguidas da mesma letra minúscula na vertical e maiúscula na horizontal, não diferem pelo teste de Tukey ao nível de $5 \%$ de significância.

A extração de magnésio médio do genótipo tolerante foi significativamente superior à média do sensível (Tabela 61).

A análise da variância dos resultados de teores de magnésio nas diferentes partes, revelou serem altamente significativas $(P<0,01)$ as interaç⿸es genótipos $x$ partes $x$ níveis de $A l$, genótipos $x$ níveis de Al e partes $x$ 


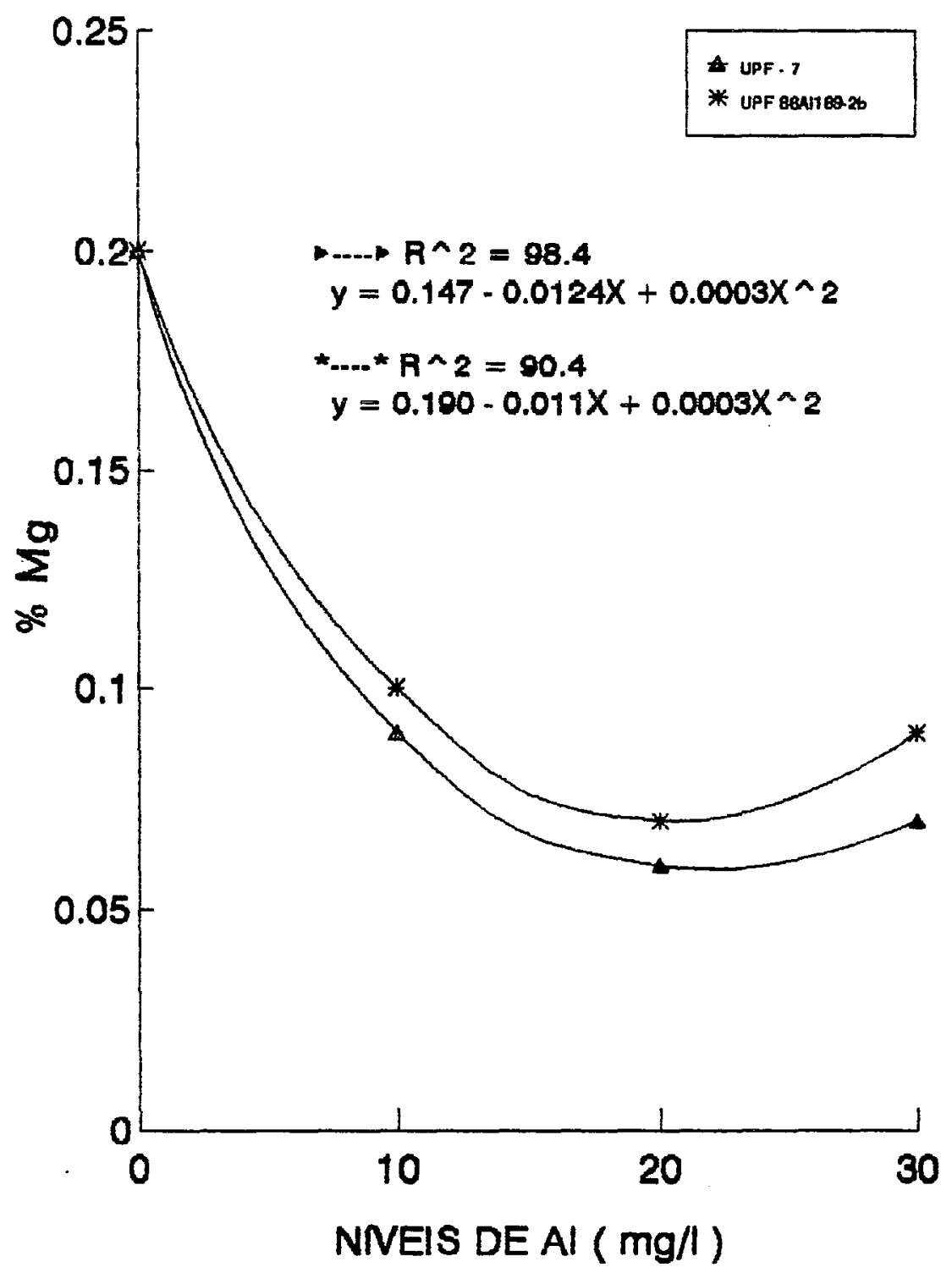

Figura 29: Efeito dos niveis de alumínio sobre o teor de magnésio em plantas de dois genótipos de aveia. 
níveis de Al, bem como as diferenças entre as partes e os niveis de Al. Revelou também que a diferença entre genótipos e a interação genótipos $x$ partes não foram significativas ao nível de $5 \%$ de significância (Tabela D10).

Pela comparaça entre as médias, através do desdobramento da interação, verificou-se pela Tabela 62 que na ausência de alumínio na solução, o teor de magnésio nas raízes do cultivar UPF 7 foi superior $(P<0,05)$ ao tolerante. Nos níveis 10 e $20 \mathrm{mg} \mathrm{Al/l}$, não houve diferença significativa na média dos dois genótipos. No maior nível de Al ( $30 \mathrm{mg} A l / 1$ ), o teor de magnésio na raíz do genótipo tolerante foi superior ao sensível.

Em relação à parte aérea, os genótipos não diferiram quanto ao teor de magnésio nos niveis 0,10 e $30 \mathrm{mg}$

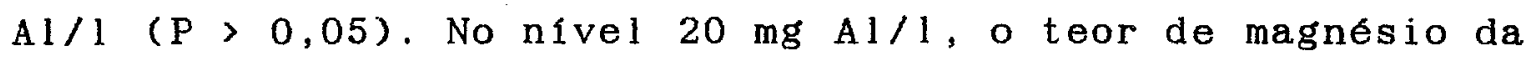
parte aérea no genótipo tolerante foi significativamente superior ao sensivel.

Quanto aos genótipos, verificou-se através da Tabela 63 que no nível 0 de Al, para os dois genótipos, o teor de magnésio é maior nas raizes que na parte aérea, enquanto no nivel $10 \mathrm{mg} A l / l$ esta situação se inverte. No nível $20 \mathrm{mg} \mathrm{Al/l}$, para o genótipo tolerante, observa-se um teor na parte aérea maior que nas raizes, não havendo diferenças no genótipo sensível. No maior nível de Al na solução $(30 \mathrm{mg} / \mathrm{l})$, não se observou diferenças significativas dos teores de magnésio entre a parte aérea e as raízes, nos dois genótipos.

A análise de regressão do efeito de níveis de Al sobre os teores de magnésio na parte aérea e raiz, mostrou que a variação em todas partes e nos dois genótipos ocorreu de forma quadrática (Figura 30). 
Tabela 62. Efeito dos niveis de alumínio na soluçao nutritiva sobre o teor e a extração de magnésio, pela parte aérea e pelas raízes de dois genótipos de aveia.

\begin{tabular}{lccc}
\hline Níveis de & \multicolumn{2}{c}{ Parte aérea } & \multicolumn{2}{c}{ Raízes } \\
Al (mg/l) & UPF86Al169-2b UPF 7 & UPF86Al169-2b & UPF 7
\end{tabular}

Teores (\%)

$\begin{array}{lllll}0 & 0,17 \mathrm{aA} & 0,16 \mathrm{aA} & 0,28 \mathrm{aB} & 0,30 \mathrm{aA} \\ 10 & 0,09 \mathrm{bA} & 0,10 \mathrm{bA} & 0,06 \mathrm{bA} & 0,07 \mathrm{bA} \\ 20 & 0,10 \mathrm{bA} & 0,07 \mathrm{cB} & 0,05 \mathrm{cA} & 0,05 \mathrm{bA} \\ 30 & 0,08 \mathrm{bA} & 0,07 \mathrm{cA} & 0,08 \mathrm{cA} & 0,06 \mathrm{bB} \\ \text { Media } & 0,11 & 0,10 & 0,12 & 0,12 \\ \text { C.V.(\%) } & 9,2 & & & \end{array}$

Extração (mg/vaso)

$\begin{array}{lllll}0 & 5,50 \mathrm{aA} & 4,97 \mathrm{aB} & 3,43 \mathrm{aA} & 3,67 \mathrm{aA} \\ 10 & 1,73 \mathrm{bA} & 1,63 \mathrm{bA} & 0,30 \mathrm{bA} & 0,33 \mathrm{bA} \\ 20 & 1,47 \mathrm{bA} & 0,87 \mathrm{cB} & 0,17 \mathrm{bA} & 0,17 \mathrm{bA} \\ 30 & 1,03 \mathrm{cA} & 0,87 \mathrm{cA} & 0,30 \mathrm{bA} & 0,13 \mathrm{bA} \\ \text { Média } & 2,43 \mathrm{~A} & 2,03 \mathrm{~B} & 1,05 \mathrm{~A} & 1,08 \mathrm{~A} \\ \text { C.V.(\%) } & 10,5 & & & \end{array}$

- Médias seguidas da mesma letra minúscula na vertical e maiúscula na horizontal, dentro de cada parte não diferem pelo teste de Tukey ao nível de $5 \%$ de significância.

Quanto à extração de magnésio pelas diferentes partes da planta, a análise de variancia revelou diferenças significativas para as interaçóes genótipos $x$ plantas $x$ níveis de $A 1$, partes $x$ níveis de Al e partes $x$ genótipos, ao 
Tabela 63. Efeito dos níveis de alumínio na soluça nutritiva sobre o teor e a extração de magnésio, pela parte aérea e pelas raízes de dois genótipos de aveia.

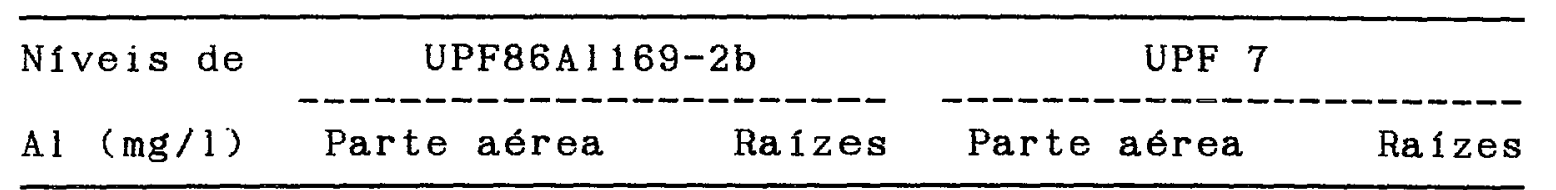

\begin{tabular}{lllll}
\hline \multicolumn{5}{c}{ Teor (\%) } \\
0 & $0,17 \mathrm{aB}$ & $0,28 \mathrm{aA}$ & $0,16 \mathrm{aB}$ & $0,30 \mathrm{aA}$ \\
10 & $0,09 \mathrm{bA}$ & $0,06 \mathrm{bB}$ & $0,10 \mathrm{bA}$ & $0,07 \mathrm{bB}$ \\
20 & $0,10 \mathrm{bA}$ & $0,05 \mathrm{cB}$ & $0,07 \mathrm{cA}$ & $0,05 \mathrm{bA}$ \\
30 & $0,08 \mathrm{bA}$ & $0,08 \mathrm{cA}$ & $0,07 \mathrm{cA}$ & $0,06 \mathrm{bA}$ \\
Média & 0,11 & 0,12 & 0,10 & 0,12 \\
C.V.(\%) & 9,2 & & & \\
& & Extração (mg/vaso) & \\
0 & $5,50 \mathrm{aA}$ & $3,43 \mathrm{aB}$ & $4,77 \mathrm{aA}$ & $3,67 \mathrm{aB}$ \\
10 & $1,73 \mathrm{bA}$ & $0,30 \mathrm{bB}$ & $1,63 \mathrm{bA}$ & $0,33 \mathrm{bB}$ \\
20 & $1,47 \mathrm{bA}$ & $0,17 \mathrm{bB}$ & $0,87 \mathrm{cA}$ & $0,17 \mathrm{bB}$ \\
30 & $1,03 \mathrm{cA}$ & $0,30 \mathrm{bB}$ & $0,87 \mathrm{cA}$ & $0,13 \mathrm{bB}$ \\
Média & $2,43 \mathrm{~A}$ & $1,05 \mathrm{~B}$ & $2,03 \mathrm{~A}$ & $1,08 \mathrm{~B}$ \\
C.V.(\%) & 10,5 & & &
\end{tabular}

- Médias seguidas da mesma letra minúscula na vertical e maiúscula na horizontal, dentro de cada genótipo não diferem pelo teste de Tukey ao nível de $5 \%$ de signnif icância.

nivel de $1 \%$ de significância (Tabela D10). A interação genótipos $x$ níveis de Al não foi significativa $(P>0,05)$, enquanto as diferenças entre os genótipos, as partes e os niveis de aluminio foram altamente significativos, ao nivel de $1 \%$ de significância. 


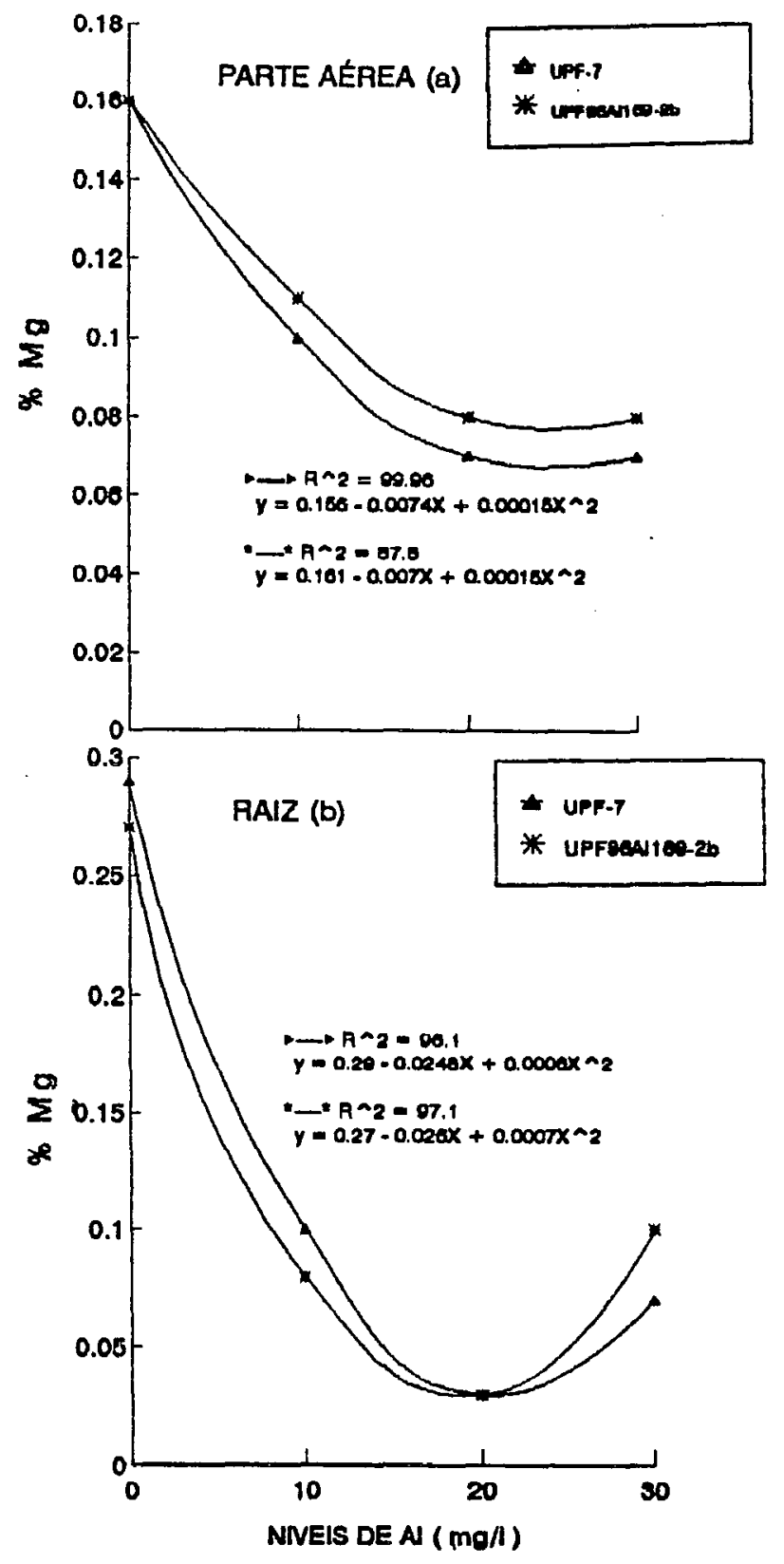

Figura 30. Efeito dos níveis de alumínio na solução nutritiva sobre o teor de magnésio da parte aérea (a) e pelas raízes (b), de plantas de dois genótipos de aveia. 
Na comparação entre as médias, pelo teste de Tukey, observou-se que os genótipos não diferiram quanto à extração de magnésio pelas raízes (Tabela 62). Já na parte aérea, a extração de magnésio pelo genótipo tolerante foi maior que no sensivel nos niveis 0 e $20 \mathrm{mg} \mathrm{Al/1,} \mathrm{sem}$ diferirem nos demais níveis, ao nível de $5 \%$ de significância.

Na comparação entre as médias das partes de cada genótipo, observa-se que nos dois genótipos a extração de magnésio pela parte aérea foi superior à extraça pelas raízes (Tabela 63).

A análise de regressão do efeito de alumínio sobre a extração de magnésio pela parte aérea e pelas raízes, mostrou que nos dois genótipos ocorreu uma variaça de forma quadrática (Figura 31 ).

As reduçós observadas nos teores de magnésio nas raizes e na parte aérea de aveia, com o aumento da concentração de alumínio da solução, estão de acordo com resultados encontrados para arroz (ALAM, 1983), aveia (GRIMME, 1982) e sorgo (CALBO \& CAMBRAIA, 1980; e LEMOS FILHO, 1981). No entanto, ALAM \& ADAMS (1979b), encontraram teores maiores de Mg na parte aérea de aveia com o aumento da concentração de Al.

\subsubsection{Correlaçós entre o teor de alumínio, o rendimento de matéria seca e os teores de alguns macronutrientes}

A análise de correlação linear simples entre o teor de Al (TAl) e os teores de macronutrientes nas raízes dos dois genótipos de aveia revelou que para o cultivar de aveia UPF 7 (sensivel) ocorreram correlaços altamente significativas com o teor de $\mathrm{P}(\mathrm{r}=92,5 * *)$ e com o teor de 


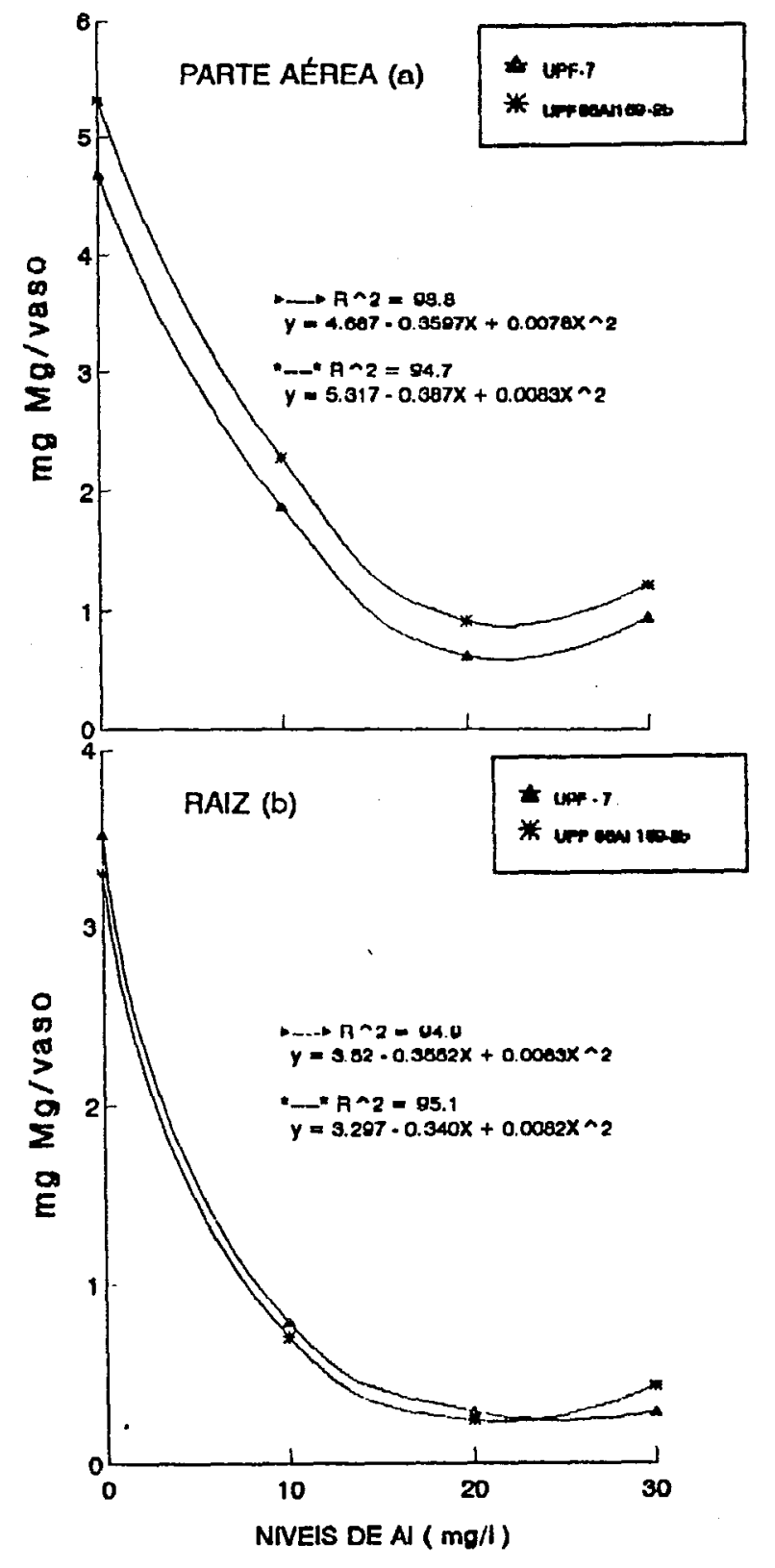

197.

Figura 31. Efeito dos níveis de alumínio na solução nutritiva sobre a extraça de magnésio pela parte aérea (a) e pelas raízes (b), de plantas de aveia. 
magnésio $(r=-93,5 * *)$. Para o genótipo UPF86Al169-2b (tolerante), as correlações foram altamente significativas para o teor de $N(r=76,1 * *), P(r=89,2 * *)$ e $M g(r=-$ $77,9 * *)$. Os teores de $K$ e $\mathrm{Ca}$, não se correlacionaram significativamente com o teor de Al nos tecidos das ráizes.

os resultados obtidos, indicam que o aumento do teor de alumínio nas raizes promoveu um aumento no teor de fósforo desse órgão nos dois genótipos, e de nitrogênio no genótipo UPF86Al169-2b. Em relação ao magnésio, seu teor nas raizes diminuiu significativamente com o aumento do teor de alumínio (Tabela 64).

Na parte aérea do cultivar UPF 7 o teor de Al correlacionou-se significativamente e de forma negativa, com os teores de fósforo $(r=-68,1 *)$, potássio $(r=-72,7 * *)$, cálcio $(r=-64,3 *)$ e magnésio $(r=-84,3 * *)$. No genótipo UPF86Al169-2b, a correlaçăo negativa foi significativa para o nitrogênio $(r=-62,1 *)$, cálcio $(r=-59,6 *)$ e magnésio $\left(r=-62,5^{*}\right)$.

Quanto à correlação entre o teor de Al e o rendimento de matéria seca, observa-se pela Tabela 65 , que a correlação foi negativa e altamente significativa para as raízes e a parte aérea, nos dois genótipos. No entanto, o valor do coeficiente de correlação foi menor no genótipo tolerante em relação ao sensivel, nas raízes $(-91,1$ e $-97,7$ respectivamente), e, na parte aérea $(-69,0$ e $-83,7$ (respectivamente).

o rendimento de matéria seca da raiz do cultivar UPF7 correlacionou-se significativamente com o teor de fósforo $(r=96,0 * *)$ e com o teor de magnésio ( $r=$ $98,2 * *)$, enquanto para o genótipo UPF86A1169-2b a correlação foi significativa para o teor de nitrogênio ( $r=79,6 * *)$, 
Tabela 64. Valores de $t$ e coeficientes de correlaça ( $r$ ) entre o teor de Al na raiz e parte aérea sobre o teor de macronutrientes em dois genótipos de aveia submetidos a quatro níveis de Al.

\begin{tabular}{|c|c|c|c|c|}
\hline \multirow{2}{*}{ Correlações } & \multicolumn{2}{|c|}{ Valor $t$} & \multicolumn{2}{|r|}{$r \quad(\%)$} \\
\hline & UPF7 & UPF $86 A 1169-2 b$ & UPF7 & UPF86A116S \\
\hline & & Raiz & & \\
\hline TAIRXTNR & $2,13 \mathrm{~ns}$ & $3,71 * *$ & 55,9 & 76,1 \\
\hline $\mathrm{xTPR}$ & $7,70 * *$ & $6,24 * *$ & 92,5 & 89,2 \\
\hline $\mathrm{xTKR}$ & $1,78 \mathrm{~ns}$ & $0,22 \mathrm{~ns}$ & 48,9 & $-7,1$ \\
\hline xTCaR & $0,78 \mathrm{~ns}$ & $1,49 \mathrm{~ns}$ & $-24,0$ & $-42,5$ \\
\hline xTMgR & $8,34 * *$ & $3,93 * *$ & $-93,5$ & $-77,9$ \\
\hline
\end{tabular}

Parte aérea

$\begin{array}{rlllr}\text { TA1PAxTNPA } & 1,80 \mathrm{~ns} & 2,51 * & -49,4 & -62,1 \\ \text { xTPPA } & 2,45 * & 1,04 \mathrm{~ns} & -68,1 & 31,1 \\ \text { xTKPA } & 3,34 * * & 1,40 \mathrm{~ns} & -72,7 & -40,4 \\ \text { xTCaPA } & 2,66 * & 2,35 * & -64,3 & -59,6 \\ \text { xTMgPA } & 4,95 * & 2,53 * & -84,3 & -62,5\end{array}$

e ** Significativo, respectivamente nos niveis 5 e $1 \%$ de significância. ns = não significativo.

fósforo $(r=95,2 * *)$ e magnésio $(93,7 * *)$. Este fato 'pode ser atribuido ao efeito do $A 1$, pois o rendimento de matéria seca em relação aos referidos macronutrientes depende da mesma correlação com o teor do Al.

Quanto ao rendimento de matéria seca pela parte aérea, os dois genotipos apresentaram de forma semelhante, correlaçós significativas com os teores de nitrogênio, 
fósforo e magnésio e não significativa para os teores de potássio e cálcio (Tabela 65).

Tabela 65. Valores de $t$ e coeficientes de correlação ( $r$ ) entre a matéria seca das raízes e da parte aérea e o teor de macronutrientes nos dois genótipos de aveia, submetidos a quatro niveis de Al.

\begin{tabular}{|c|c|c|c|c|}
\hline \multirow{2}{*}{ Correl ação } & \multicolumn{2}{|r|}{ Valor $\mathrm{t}$} & \multicolumn{2}{|r|}{$r(\%)$} \\
\hline & UPF7 & UPF $86 \mathrm{~A}$ I $169-2 \mathrm{~b}$ & UPF7 & UPF 86 A $169-2 b$ \\
\hline
\end{tabular}

Raiz

$\begin{array}{lrcrr}\text { MSR xTNR } & 1,96 \mathrm{~ns} & 4,16 * * & 52,8 & 79,6 \\ \text { xTPR } & 10,79 * * & 9,81 * * & 96,0 & 95,2 \\ \text { xTKR } & 2,01 \mathrm{~ns} & 0,32 \mathrm{~ns} & 53,6 & 10,2 \\ \text { xTCaR } & 1,20 \mathrm{~ns} & 1,92 \mathrm{~ns} & 35,4 & 51,4 \\ \text { xTMgR } & 16,22 * * & 8,50 * * & 98,2 & 93,7 \\ \text { xTAlR } & 14,64 * * & 7,01 * * & -97,7 & -91,1 \\ & & \text { Parte aérea } & \\ \text { MSPA } \text { xTNPA } & 4,26 * * & 4,81 * * & 80,3 & 83,6 \\ \text { xTPPA } & 8,56 * * & 4,95 * * & 93,8 & 84,3 \\ \text { xTKPA } & 1,58 \mathrm{~ns} & 0,46 \mathrm{~ns} & 44,8 & 14,3 \\ \text { xTCaPA } & 0,75 \mathrm{~ns} & 0,03 \mathrm{~ns} & 22,9 & 9,4 \\ \text { xTMgPA } & 11,99 * * & 8,11 * * & 96,7 & 93,2 \\ \text { xTA1PA } & 4,85 * * & 3,02 * & -83,7 & -69,0\end{array}$

Significativo ao nivel de $5 \%$ de significância; ns = não significativo. 
4.8. Efeito dos niveis de aluminio na soluço nutritiva sobre o teor e a extração de alguns micronutrientes pela aveia.

\subsubsection{Cobre}

A análise de variância dos resultados dos teores de cobre (TCuP) nas plantas de aveia revelou que não foi significativa a interação genótipos $x$ niveis de Al, nem a diferença entre os genótipos, pelo teste $F$ ao nível de $5 \%$ de significância (Tabela D11). Já a diferença entre os níveis de Al foi altamente significativa ( $P<0,01)$.

Pela comparação entre as médias dos níveis de aluminio observa-se que os teores de cobre nao diferiram entre os niveis 0 e $10 \mathrm{mg} \mathrm{Al/l}$, que foram superiores $(P<0,05)$ às médias nos níveis 20 e $30 \mathrm{mg} A l / 1$, que não diferiram entre si (Tabela 66). Resultados semelhantes foram encontrados em aveia por ALAM (1985).

Quanto à extração de cobre pela planta, a interação genótipo $x$ niveis também não foi significativa, enquanto a diferença entre os genótipos foi significativa ao nível de $5 \%$ de significância e a diferença entre os níveis de Al foi altamente significativa $(P<0,01)$, conforme Tabela D11.

Na Tabela 66, verifica-se que a extração média de cobre pelo genótipo UPF86A1169-2b foi superior ao genótipo UPF 7 ( $P<0,05)$. Quanto ao efeito dos níveis, a extração de cobre na ausência de Al na solução foi superior ao nível de $10 \mathrm{mg} \mathrm{Al} / 1$, que diferiu dos níveis 20 e $30 \mathrm{mg} \mathrm{Al/l,} \mathrm{que} \mathrm{nao}$ diferiram entre si.

Quanto ao fracionamento da aveia em partes, a análise de variância dos resultados de teores de cobre, 
mostrou serem significativas as interaçбes partes $x$ genótipos $x$ níveis de Al, genótipos $x$ niveis de $A l$ e partes $x$ níveis e para as partes, ao nivel de $1 \%$ de significância. Já a interação partes $x$ genótipos não foi significativa, bem como as diferenças entre os genótipos e os níveis de Al (Tabela D12), ao nível de $5 \%$ de significância.

Tabela 66. Efeito dos niveis de aluminio na solução nutritiva sobre o teor e extraça de cobre pelas plantas de dois genótipos de aveia.

Niveis de Al ( $\mathrm{mg} / \mathrm{l})$
Genótipos

UPF 86A1 164-2b

Média

UPF 7

Teor ( $\mathrm{ppm}$ )

$\begin{array}{llrr}0 & 9,8 & 9,6 & 9,7 \mathrm{a} \\ 10 & 9,8 & 10,4 & 10,1 \mathrm{a} \\ 20 & 9,0 & 8,4 & 8,7 \mathrm{~b} \\ 30 & 8,5 & 8,5 & 8,5 \mathrm{~b} \\ \text { Média } & 9,3 \mathrm{~A} & 9,2 \mathrm{~A} & \\ \text { C.V. (\%) } & 5,5 & & \end{array}$

Extração (mg/vaso)

$\begin{array}{lrll}0 & 44,6 & 40,9 & 42,7 \mathrm{a} \\ 10 & 23,9 & 22,6 & 23,3 \mathrm{~b} \\ 20 & 16,9 & 13,4 & 15,1 \mathrm{c} \\ 30 & 13,7 & 12,7 & 13,2 \mathrm{c} \\ \text { Média } & 24,8 \mathrm{~A} & 22,4 \mathrm{~B} & 23,6 \\ \text { C.V. (\%) } & 8,7 & & \end{array}$

- Médias seguidas da mesma letra minúscula na vertical e maíscula na horizontal, não diferem pelo teste de Tukey ao nivel de $5 \%$ de significância. 
Da comparaça entre as médias, pelo teste de Tukey (Tabela 67), verifica-se que no cultivar UPF7, o teor de cobre nas raizes foi significativamente superior em relação a parte aérea, em todos os niveis de Al. No genótipo UPF86Al169-2b, o teor de cobre nas raízes foi superior ao teor da parte aérea nos níveis 0,20 e $30 \mathrm{mg} A 1 / 1$, ño diferindo no nível de $10 \mathrm{mg} \mathrm{Al/l}$.

Tabela 67. Efeito dos niveis de alumínio na solução nutritiva sobre o teor de cobre na parte área e nas raízes de dois genótipos de aveia.

\begin{tabular}{lcccc}
\hline Níeis de & \multicolumn{2}{c}{ UPF86Al164-2b } & \multicolumn{2}{c}{ UPF } \\
Al (mg/1) & $\begin{array}{c}\text { Parte aérea } \\
\text { Raizes }\end{array}$ & $\begin{array}{c}\text { Parte aérea } \\
\text { Raíles }\end{array}$ \\
\hline 0 & $8,7 \mathrm{aB}$ & $12,7 \mathrm{aA}$ & $9,0 \mathrm{abB}$ & $11,0 \mathrm{bcA}$ \\
10 & $9,7 \mathrm{aA}$ & $10,3 \mathrm{bA}$ & $10,0 \mathrm{aB}$ & $12,0 \mathrm{abA}$ \\
20 & $8,0 \mathrm{aB}$ & $12,7 \mathrm{aA}$ & $8,0 \mathrm{bB}$ & $10,0 \mathrm{cA}$ \\
30 & $8,0 \mathrm{aB}$ & $10,7 \mathrm{bA}$ & $7,7 \mathrm{bB}$ & $13,7 \mathrm{aA}$ \\
Média & 11,6 & 8,6 & 8,7 & 11,7 \\
C.V.(\%) & 8,0 & & &
\end{tabular}

* Médias seguidas da mesma letra, minúscula na vertical e maiúscula na horizontal, dentro de cada genótipo, não diferem pelo teste de Tukey ao nivel de $5 \%$ de signif icância.

Na Tabela 68, pela comparação entre os genótipos em cada parte da planta, observa-se que os genótipos não diferiram em relação ao teor de cobre na parte aérea $(P>0,05)$. Nas raizes, o teor de cobre do genótipo UPF86Al169-2b foi superior ao cultivar UPF 7 nos niveis 0 e 
$20 \mathrm{mg} \mathrm{Al/l,} \mathrm{invertendo-se} \mathrm{a} \mathrm{situação} \mathrm{nos} \mathrm{níveis} \mathrm{de} 10$ e $30 \mathrm{mg}$ Al/1.

Tabela 68. Efeito dos níveis de aluminio na solução nutritiva sobre o teor de cobre na parte aérea e nas raizes de dois genotipos de aveia.

\begin{tabular}{|c|c|c|c|}
\hline Niveis de & Parte aére & & Raizes \\
\hline Al (mg/l) & UPF $86 \mathrm{~A} 1169-2 \mathrm{~b}$ & UPF7 & UPF $86 \mathrm{~A} / 169-2 \mathrm{~b}$ \\
\hline
\end{tabular}

Teor (ppm)

$\begin{array}{llcll}0 & 8,7 \mathrm{aA} & 9,0 \mathrm{abA} & 12,7 \mathrm{aA} & 11,0 \mathrm{bcB} \\ 10 & 9,7 \mathrm{aA} & 10,0 \mathrm{aA} & 10,3 \mathrm{bB} & 12,0 \mathrm{abA} \\ 20 & 8,0 \mathrm{aA} & 8,0 \mathrm{bA} & 12,7 \mathrm{aA} & 10,0 \mathrm{cB} \\ 30 & 8,0 \mathrm{aA} & 7,7 \mathrm{bA} & 10,7 \mathrm{bB} & 13,7 \mathrm{aA} \\ \text { Média } & 8,6 & 8,7 & 11,6 & 11,7 \\ \text { C.V. }(\%) & 8,0 & & & \end{array}$

- Médias seguidas da mesma letra minúscula na vertical e maiúscula na horizontal, dentro de cada parte, não diferem pelo teste de Tukey ao nível de $5 \%$ de significância.

A análise de variância dos resultados de extração de cobre pelas plantas, revelou não serem significativas as interaçőes entre partes $x$ genótipos $x$ niveis de alumínio, genótipos $x$ níveis e partes $x$ genótipos $(P>0,05)$. As diferenças entre as médias dos genótipos, das partes, dos niveis de alumínio e a interaça partes $x$ níveis de Al foram altamente significativas, ao nivel de $1 \%$ de significância (Tabela D12).

A redução no teor de cobre da parte aérea e raízes devido ao aumento da concentração de alumínio também foi encontrado no sorgo (LEMOS FILHO, 1981; CAMBRAIA et al., 
1983b). No entanto, LEMOS FILHO (1981) encontrou diferenças entre cultivares tolerante e sensível de sorgo em relaçao ao teor de cobre no sistema radicular, fato nao observado neste trabal ho.

\subsubsection{Ferro}

A análise de variância dos resultados do teor de ferro nas plantas (TFeP) de aveia, revelou nao ser significativa a interação genótipo $x$ niveis de $A l(P>0,05)$, mas que foi altamente significativa a diferença entre genótipos e niveis de Al, ao nível de $1 \%$ de significância (Tabela D11).

Em relação à extração de ferro, a análise de variância revelou diferenças altamente significativas para a interação genótipos $x$ níveis de alumínio, para os genótipos e para os níveis de Al, ao nivel de $1 \%$ de significância (Tabela D11).

A comparação entre as médias, pelo teste de Tukey, apresentada na Tabela 69, mostrou que o teor médio de ferro no genótipo tolerante foi superior ao sensivel ao nivel de $5 \%$ de significância. O alumínio na solução promoveu uma redução significativa, na média dos dois genótipos, do teor de ferro das plantas de aveia. O genótipo tolerante também apresentou extração de ferro superior ao sensível nos níveis 0 e $10 \mathrm{mg} \mathrm{Al/l}$, não diferindo nos dois niveis maiores de Al. Já na média dos dois genótipos, a reduçáo foi significativa entre os níveis $0,10 \mathrm{mg} A l / l$, sem que nos demaís níveis eles não diferiram entre si.

A análise de regressão do efeito do alumínio sobre a extração de ferro revelou que tanto no genótipo 
sensivel quanto no tolerante a variação ocorreu de forma quadrática (Figura 32).

Tabela 69. Efeito dos níveis de alumínio na solução nutritiva sobre o teor e a extração de ferro pelas plantas de dois genótipos de aveia.

\begin{tabular}{lccc}
\hline Niveis de & \multicolumn{3}{c}{ Genótipos } \\
Al (mg/l) & UPF86Al169-2b & Média \\
\hline \multicolumn{4}{c}{ Teor (ppm) } \\
0 & 271,6 & 152,8 & $212,2 \mathrm{a}$ \\
10 & 184,4 & 132,3 & $158,4 \mathrm{~b}$ \\
20 & 161,6 & 120,1 & $140,9 \mathrm{~b}$ \\
30 & 170,2 & 119,8 & $145,0 \mathrm{~b}$ \\
Média & $197,0 \mathrm{~A}$ & $131,2 \mathrm{~B}$ & 164,1 \\
C.V. (\%) & 15,7 & & \\
& Extraça (mg/vaso) & $941,5 \mathrm{a}$ \\
0 & $1234,5 \mathrm{aA}$ & $648,6 \mathrm{aB}$ & $369,8 \mathrm{~b}$ \\
10 & $452,5 \mathrm{bA}$ & $287,1 \mathrm{bB}$ & $247,0 \mathrm{~b}$ \\
20 & $303,8 \mathrm{bA}$ & $190,2 \mathrm{bA}$ & $224,6 \mathrm{~b}$ \\
30 & $272,9 \mathrm{bA}$ & $176,3 \mathrm{bA}$ & \\
Média & $565,9 \mathrm{~A}$ & $325,5 \mathrm{~B}$ & \\
C.V. (\%) & 20,6 & & \\
\hline
\end{tabular}

Médias seguidas da mesma letra minúscula na vertical e maiúscula na horizontal, não diferem pelo teste de Tukey ao nivel de $5 \%$ de significância.

A análise dos resultados de teor de ferro nas partes da aveia mostrou que foram altamente significativas as interaçoes partes $x$ genótipos $x$ níveis de $A l$, genótipos $x$ niveis de Al e partes $x$ níveis, bem como a diferença entre os genótipos, as partes e os níveis de Al, ao nível de $1 \%$ de 


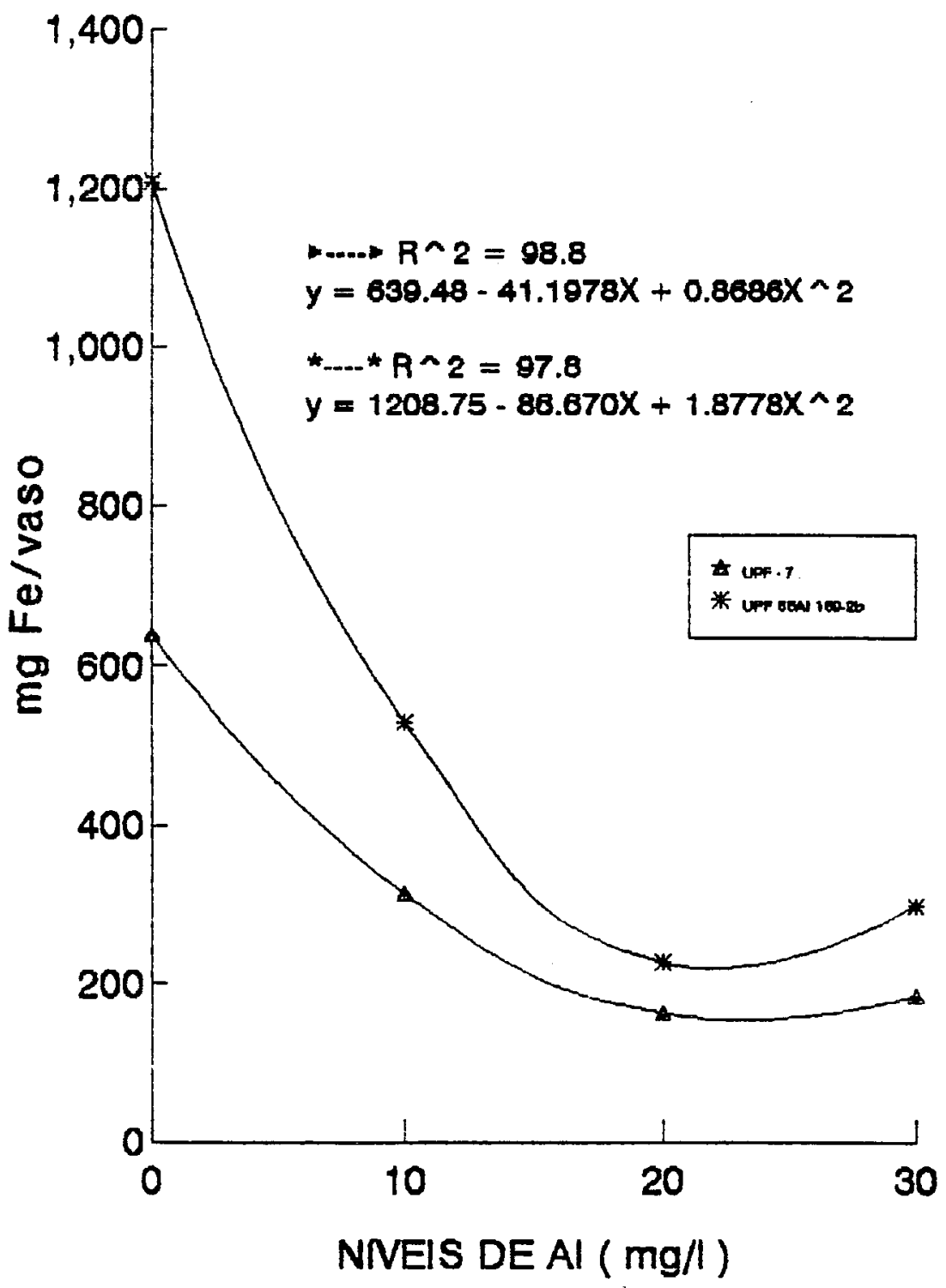

Figura 32. Efeito dos niveis de aluminio na soluçao nutritiva sobre a extraça de ferro pelas plantas de dois genótipos de aveia. 
significância (Tabela D12). No entanto, a interaça parte $x$ genótipos não foi significativa $(P>0,05)$.

Na Tabela 70 , observa-se que o teor de ferro nas raízes foi significativamente superior ao da parte aérea, sem diferenças entre os genótipos. Os genótipos não diferiram significativamente quanto ao teor de ferro na parte aérea, sendo que nas raizes, o teor de ferro no genótipo tolerante (UPF86A1169-2b) foi superior ao sensivel na ausência de Al, enquanto na presença desse elemento não diferiram entre si (Tabela 71 ).

Em relação a extração de ferro pelas partes da planta, verificou-se através da análise de variância, diferenças altamente significativas para todas as causas de variação (Tabela D12).

Pela comparação entre as médias das partes, dentro de cada genótipo, através da Tabela 70 , observa-se que a extração de ferro pelas rázes foi superior à da parte aérea, na ausência de Al na solução nos dois genótipos. Na presença de alumínio os genótipos diferiram, pois no tolerante (UPF86Al169-2b) a extração de ferro pelas raizes foi inferior ao da parte aérea nos niveis 10 e $20 \mathrm{mg} A / / 1$, sem diferir no nível de $30 \mathrm{mg} \mathrm{Al/l}$ e no genótipo sensivel, as quantidades extraidas de ferro pela parte aérea e pelas raízes nao diferiram entre si quanto aos niveis de Al.

Na Tabela 71 é apresentada a comparação entre as médias de extração de ferro entre genótipos em cada parte da planta. Observa-se, em relação à extração de ferro pela parte aérea, que os genótipos não diferiram nos niveis 0 e 30 $\mathrm{mg} A \mathrm{l} / 1$, enquanto nos níveis de 10 e $20 \mathrm{mg} A l / 1$, a extraça de ferro pelo genotipo de aveia tolerante foi superior ao sensível. 
Tabela 70. Efeito dos niveis de alumínio na soluça nutritiva sobre o teor e a extração de ferro pela parte aérea e pelas raízes, de dois genótipos de aveia.

\begin{tabular}{|c|c|c|c|c|}
\hline \multirow{2}{*}{$\begin{array}{l}\text { Niveis de } \\
\text { Al (mg/l) }\end{array}$} & \multicolumn{2}{|c|}{ UPF $86 A 1169-2 b$} & \multicolumn{2}{|c|}{ UPF 7} \\
\hline & Parte aérea & Raízes & Parte aérea & Raízes \\
\hline \multicolumn{5}{|c|}{ Teor (ppm) } \\
\hline 0 & $60,7 \mathrm{aB}$ & $825,0 \mathrm{aA}$ & $82,7 \mathrm{aB}$ & $330,0 \mathrm{aA}$ \\
\hline 10 & $154,0 \mathrm{aB}$ & $302,7 \mathrm{bA}$ & $82,7 \mathrm{aB}$ & $324,3 \mathrm{aA}$ \\
\hline 20 & $136,3 \mathrm{aB}$ & $264, \mathrm{ObA}$ & $93,7 \mathrm{aB}$ & $220,0 \mathrm{aA}$ \\
\hline 30 & $132,0 a B$ & $259, \mathrm{ObA}$ & $82,7 \mathrm{aB}$ & $330,0 \mathrm{aA}$ \\
\hline Média & 120,8 & 412,7 & 85,4 & 301,1 \\
\hline C.V. (\%) & 30,4 & & & \\
\hline \multicolumn{5}{|c|}{ Extração (mg/vaso) } \\
\hline 0 & $200,1 \mathrm{abB}$ & $1034,4 \mathrm{aA}$ & $221,0 \mathrm{aB}$ & $397,5 \mathrm{aA}$ \\
\hline 10 & $298,7 \mathrm{aA}$ & $153,8 \mathrm{bB}$ & $140,3 \mathrm{abA}$ & $146,9 \mathrm{bA}$ \\
\hline 20 & $204,4 \mathrm{abA}$ & $99,4 \mathrm{bB}$ & $116,9 a b A$ & $73,3 \mathrm{bA}$ \\
\hline 30 & $170,0 \mathrm{bA}$ & $102,9 \mathrm{bA}$ & $103,2 \mathrm{bA}$ & $73, \mathrm{ObA}$ \\
\hline Media & $218,3 \mathrm{~B}$ & $347,6 \mathrm{~A}$ & $145,4 \mathrm{~A}$ & $172,7 \mathrm{~A}$ \\
\hline C.V. $(\%)$ & 23,2 & & & \\
\hline
\end{tabular}

- Médias seguidas da mesma letra minúscula na vertical e maiúscula na horizontal, dentro de cada genótipo não diferem pelo teste de Tukey ao nivel de $5 \%$ de significância.

Quanto às raizes, observa-se que no nivel 0 de aluminio, a extração de ferro pelo genótipo tolerante foi superior ao sensivel ( $\mathrm{P}<0,05)$, nđo diferindo nos demais nịveis . 
A análise de regressão do efeito dos niveis de Al sobre a extração de $\mathrm{Fe}$ pelas partes da planta mostrou que na parte aérea a redução no cultivar sensível ocorreu de forma linear, enquanto no genótipo tolerante, a variação ocorre de forma quadrática (Figura 33). Para as raizes, a regressão revelou que a variação da extração de ferro ocorreu de forma quadrática nos dois genótipos.

Tabela 71. Efeito dos niveis de alumínio na soluça nutritiva, sobre o teor e extração de ferro pela parte aérea e pelas raizes, de dois genótipos de aveia.

\begin{tabular}{lllll}
\hline Niveis de & \multicolumn{2}{c}{ Parte aérea } & \multicolumn{3}{c}{ Raízes } \\
Al (mg/1) & UPF86Al169-2b & UPF 7 & UPF86Al169-2b & UPF 7 \\
\hline
\end{tabular}

\section{Teor (ppm)}

\begin{tabular}{lcccc}
0 & $60,7 \mathrm{aA}$ & $82,7 \mathrm{aA}$ & $825,0 \mathrm{aA}$ & $330,0 \mathrm{aB}$ \\
10 & $154,0 \mathrm{aA}$ & $82,7 \mathrm{aA}$ & $302,7 \mathrm{bA}$ & $324,3 \mathrm{aA}$ \\
20 & $136,3 \mathrm{aA}$ & $93,7 \mathrm{aA}$ & $264,0 \mathrm{bA}$ & $220,0 \mathrm{aA}$ \\
30 & $132,0 \mathrm{aA}$ & $82,7 \mathrm{aA}$ & $259,0 \mathrm{bA}$ & $330,0 \mathrm{aA}$ \\
Média & 120,8 & 85,4 & 412,7 & 301,1 \\
C.V. $\%$ ) & 30,4 & \multicolumn{4}{c}{} \\
\multicolumn{5}{c}{ Extraça (mg/vaso) } \\
0 & $200,1 \mathrm{abA}$ & $221,0 \mathrm{aA}$ & $1034,4 \mathrm{aA}$ & $397,5 \mathrm{aB}$ \\
10 & $298,7 \mathrm{aA}$ & $140,3 \mathrm{abB}$ & $153,8 \mathrm{bA}$ & $146,9 \mathrm{bA}$ \\
20 & $204,4 \mathrm{abA}$ & $116,9 \mathrm{abB}$ & $99,4 \mathrm{bA}$ & $73,3 \mathrm{bA}$ \\
30 & $170,0 \mathrm{bA}$ & $103,2 \mathrm{bA}$ & $102,9 \mathrm{bA}$ & $73,0 \mathrm{bA}$ \\
Média & $218,3 \mathrm{~A}$ & $145,4 \mathrm{~B}$ & $347,6 \mathrm{~A}$ & $172,7 \mathrm{~B}$ \\
C.V. (\%) & 23,2 & &
\end{tabular}

- Médias seguidas da mesma letra minúscula na vertical e maiúsculas na horizontal, nåo diferem pelo teste de Tukey, a nivel de $5 \%$ de significância. 


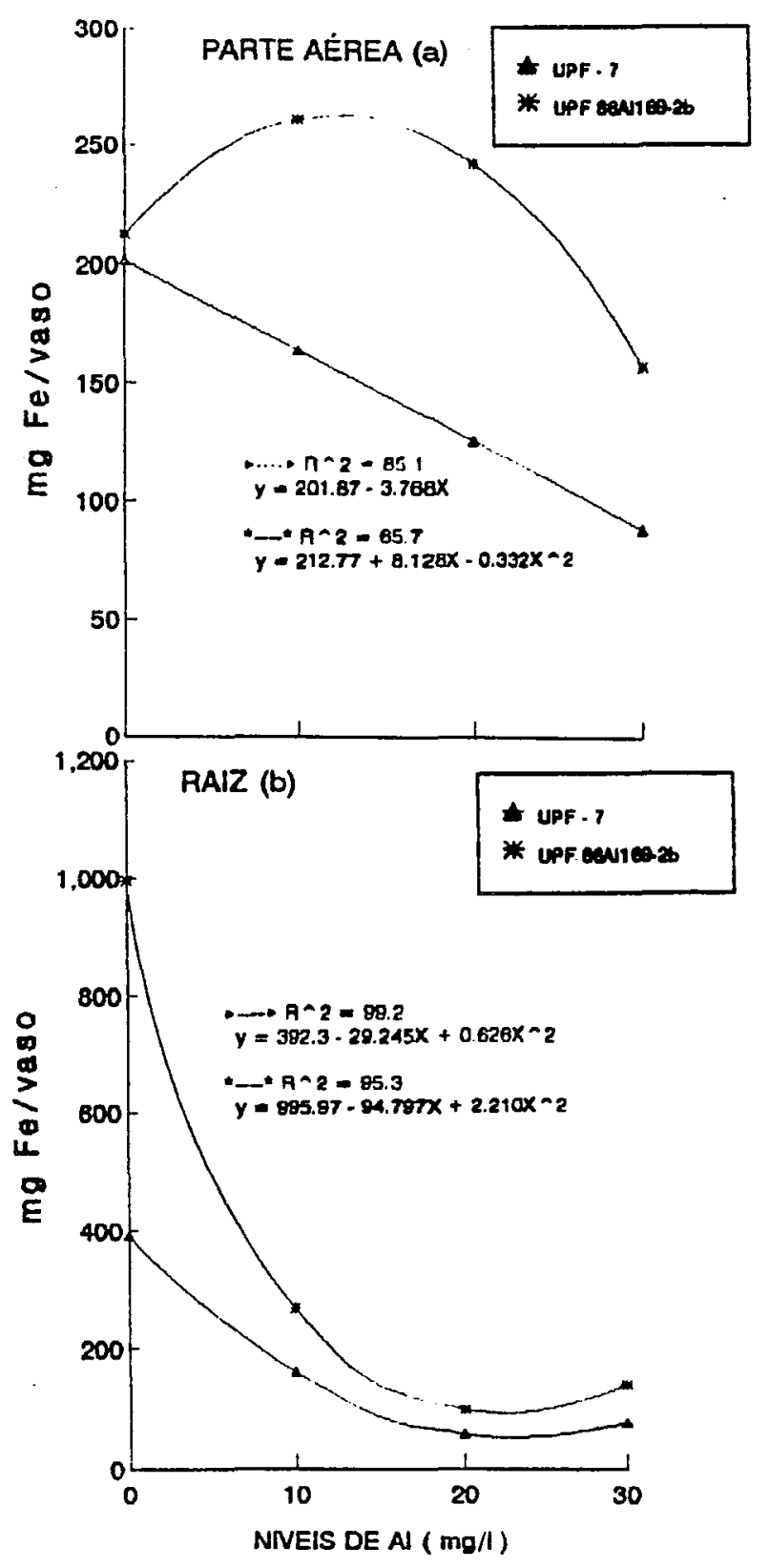

211.

Figura 33. Efeito dos niveis de alumínio na soluça nutritiva sobre a extraçáo de ferro pela parte aérea (a) e raízes (b), de plantas de dois genótipos de aveia. 
Os resultados encontrados sao discordantes dos relatados por ALAM \& ADAMS $(1979 b)$, que encontraram um aumento no teor de ferro nas raízes de aveia. Mas estao de acordo com os obtidos por OTSUKA (1968), que verificou que o Al induziu à uma clorose por deficiência de ferro em cultivares de trigo e cevada sensiveis à acidez do solo.

Em arroz foi observado um acúmulo de $F e$ nas raízes, com aumento da concentração de Al superior a $10 \mathrm{ppm}$ (ALAM, 1983). Também, em sorgo foi observada clorose por deficiência de Fe devido à toxicidade de Al (FURLANI \& CLARK, 1981 ).

\subsubsection{Manganẽs}

A análise de variância dos resultados de teores (TMn) e extração (EMn) de manganês pelas plantas de aveia revelou não ser significativa a interação genótipo $x$ níveis de Al, ao nivel de $5 \%$ de significância, enquanto que as diferenças entre os genótipos e os niveis de Al foram altamente significativos ( $P<0,01)$ (Tabela D11).

Pela comparação entre as médias (Tabela 72) observa-se que o teor e a extraça de Mn pelo genótipo tolerante foram significativamente superiores aos da sensivel, na média dos quatro níveis de Al. Na média dos genótipos, verificou-se que o teor de manganês no nível de $10 \mathrm{mg}$ Al/l foi superior ao teor desse nutriente nos niveis 20 e $30 \mathrm{mg} \mathrm{Al/l}$, sem que eles diferissem no nivel 0 de Al. 
Tabela 72. Efeito dos níveis de aluminio na soluça nutritiva sobre os teores e a extraçao de manganês pelas plantas de aveia.

\begin{tabular}{|c|c|c|c|}
\hline \multirow{2}{*}{$\begin{array}{l}\text { Níveis de } \\
\text { Al (mg/l) }\end{array}$} & \multicolumn{2}{|c|}{ Genót ipos } & \multirow{2}{*}{ Médi a } \\
\hline & UPF $86 \mathrm{Al} 169-2 \mathrm{~b}$ & UPF 7 & \\
\hline \multicolumn{4}{|c|}{ Teor (ppm) } \\
\hline 0 & 23,9 & 21,0 & $22,5 \mathrm{ab}$ \\
\hline 10 & 23,4 & 23,7 & $23,6 \mathrm{a}$ \\
\hline 20 & 22,5 & 16,0 & $19,3 b$ \\
\hline 30 & 21,3 & 17,3 & $19,3 b$ \\
\hline Média & $22,8 \mathrm{~A}$ & $19,5 \mathrm{~B}$ & 21,2 \\
\hline C.V. (\%) & 9,9 & & \\
\hline \multicolumn{4}{|c|}{ Extração (mg/vaso) } \\
\hline 0 & 108,7 & 89,8 & $99,2 a$ \\
\hline 10 & 57,5 & 51,3 & $54,4 b$ \\
\hline 20 & 42,4 & 25,4 & $33,9 \mathrm{c}$ \\
\hline 30 & 34,3 & 25,7 & $30,0 \mathrm{c}$ \\
\hline Média & $60,7 \mathrm{~A}$ & $48,0 \mathrm{~B}$ & 54,4 \\
\hline C.V. (\%) & 12,1 & & \\
\hline
\end{tabular}

* Médias seguidas da mesma letra, minúscula na vertical e maiúsculas na horizontal, não diferem pelo teste de Tukey, a nivel de $5 \%$ de significância.

Quanto à extração de Mn, a redução entre os níveis 0 e $10 \mathrm{mg} A 1 / \mathrm{l}$ e 10 e $20 \mathrm{mg} \mathrm{Al/l}$, foi significativa $(P<0,05)$, embora sem diferirem nos niveis mais elevados de Al (Tabela 72). A análise de variância dos resultados de teores e extração de manganês entre as partes da planta de aveia apresentou resultados semelhantes aos obtidos para o ferro (Tabela D12). 
A comparação entre as médias dos teores de manganês através do teste de Tukey, apresentada na Tabela 73 , mostrou que em relação à parte aérea os dois genótipos não diferiram nos niveis 0 e $10 \mathrm{mg} \mathrm{Al/l}(\mathrm{P}>0,05)$, enquanto nos niveis 20 e $30 \mathrm{mg} \mathrm{Al/1}$, o teor desse nutriente na planta tolerante foi superior ao teor da planta sensivel. Quanto às raízes, o teor desse micronutriente no genótipo tolerante foi maior que o sensivel nos niveis 0 e $20 \mathrm{mg}$ Al/l, não diferindo nos demais niveis.

Na comparação entre as partes da planta em cada genótipo (Tabela 74), observa-se que tanto no genótipo tolerante quanto no sensível, o teor de Mn na parte aérea foi superior ao das raizes $(P<0,05)$, exceto no nível 0 de Al, para o genótipo tolerante. Com o aumento do Al na solução, a redução no teor de Mn das raizes foi mais pronunciada do que na parte aérea, no genótipo tolerante, onde nao houve diferença significativa quanto ao teor de $M n$ na parte aérea, com o aumento do nível de Al. No cultivar sensivel, os teores de Mn na parte aérea nos níveis 20 e $30 \mathrm{mg} A / / 1$, que não diferiram entre si, foram significativamente inferiores em relação aos niveis 0 e $10 \mathrm{mg} \mathrm{Al} / \mathrm{l}$.

Nas raizes, a redução no teor de $M$ n no genótipo tolerante foi significativa entre o tratamento com ausência de Al e os niveis de Al, os quais não diferiram entre si. No cultivar UPF 7 , o teor de $M n$ no nivel 0 de alumínio, foi superior ao nivel $30 \mathrm{mg} \mathrm{Al/l}$, sem diferir dos niveis 10 e $20 \mathrm{mg}$ Al/l. O maior teor de Mn na parte aérea em relação às raizes e a reduçao no teor de $M n$ com o aumento da concentração de Al encontrado neste trabalho, estão de acordo com resultados obtidos em aveia por ALAM \& ADAMS (1979b). 
Tabela 73. Efeito dos niveis de alumínio na soluçao nutritiva, sobre os teores e a extração de manganês pela parte aérea e pelas raizes das plantas de dois genótipos de aveia.

\begin{tabular}{|c|c|c|c|c|}
\hline \multirow{2}{*}{$\begin{array}{l}\text { Niveis de } \\
\text { Al (mg/l) }\end{array}$} & \multicolumn{2}{|c|}{ Parte aérea } & \multicolumn{2}{|c|}{ Raizes } \\
\hline & UPF 86A1 169-2b & UPF 7 & UPF 86AI 169-2b & UPF 7 \\
\hline \multicolumn{5}{|c|}{ Teor (ppm) } \\
\hline 0 & $25,7 \mathrm{aA}$ & $25,0 \mathrm{aA}$ & $22,0 \mathrm{aA}$ & $11,0 \mathrm{aB}$ \\
\hline 10 & $26,7 \mathrm{aA}$ & $28,0 \mathrm{aA}$ & $11,0 \mathrm{bA}$ & $8,3 a b A$ \\
\hline 20 & $25,7 \mathrm{aA}$ & $18,7 \mathrm{bB}$ & $10,0 \mathrm{bA}$ & $6, \mathrm{OabB}$ \\
\hline 30 & $24,7 \mathrm{aA}$ & $19, \mathrm{ObB}$ & $7,7 \mathrm{bA}$ & $7,7 \mathrm{bA}$ \\
\hline Média & 25,7 & 22,7 & 12,7 & 8,3 \\
\hline C.V. (\%) & 12,9 & & & \\
\hline \multicolumn{5}{|c|}{ Extração (mg/vaso) } \\
\hline 0 & $86,2 \mathrm{aA}$ & $76,4 \mathrm{aB}$ & $27,6 \mathrm{aA}$ & $13,3 \mathrm{aB}$ \\
\hline 10 & $51,9 \mathrm{bA}$ & $47,4 \mathrm{bA}$ & $5,6 \mathrm{bA}$ & $3,9 \mathrm{bA}$ \\
\hline 20 & $38,6 \mathrm{cA}$ & $23,4 \mathrm{cB}$ & $3,8 \mathrm{bA}$ & $2, \mathrm{ObA}$ \\
\hline 30 & $31,8 \mathrm{cA}$ & $23,9 \mathrm{cB}$ & $2,4 \mathrm{bA}$ & $1,8 \mathrm{bA}$ \\
\hline Média & $52,2 \mathrm{~A}$ & $42,8 \mathrm{~B}$ & $9,8 \mathrm{~A}$ & $5,3 \mathrm{~B}$ \\
\hline C.V. (\%) & 13,2 & & & \\
\hline
\end{tabular}

* Médias seguidas da mesma letra, minúscula na vertical e maiúsculas na horizontal, dentro de cada parte da planta, não diferem pelo teste de Tukey, ao nível de $5 \%$ de signifi i cância .

Quanto à extração de manganês, pela parte aérea, verifica-se na Tabela 73, que o genótipo tolerante foi superior ao sensível nos níveis 0,20 e $30 \mathrm{mg} \mathrm{Al/l}$, não diferindo em relação ao nível de $10 \mathrm{mg} \mathrm{Al/l}$. Já para as raízes, a extração de manganês pelo genótipo tolerante foi superior apenas no 
Tabela 74. Efeito dos niveis de aluminio na solução nutritiva sobre os teores e extração de manganẽs pela parte aérea e pelas raizes das plantas de dois genótipos de aveia.

\begin{tabular}{|c|c|c|c|c|}
\hline \multirow{2}{*}{$\begin{array}{l}\text { Níveis de } \\
\text { Al (mg/l) }\end{array}$} & \multicolumn{2}{|c|}{ UPF 86Al 169-2b } & \multicolumn{2}{|c|}{ UPF 7} \\
\hline & Parte aérea & Raízes & Parte aérea & Raízes \\
\hline \multicolumn{5}{|c|}{ Teor (ppm) } \\
\hline 0 & $25,7(100) a A$ & $22,0(100) a A$ & $25,0(100) \mathrm{aA}$ & $11,0(100) \mathrm{aB}$ \\
\hline 10 & $26,7(104) \mathrm{aA}$ & $11,0(50) \mathrm{bB}$ & $28,0(112) a A$ & $8,3(75) \mathrm{abB}$ \\
\hline 20 & $25,7(100) a A$ & $10,0(45) \mathrm{bB}$ & $18,7(75) \mathrm{bA}$ & $6,0(55) \mathrm{abB}$ \\
\hline 30 & $24,7(96) \mathrm{aA}$ & $7,7(35) \mathrm{bB}$ & $19,0(76) \mathrm{bA}$ & $7,7(70) \mathrm{bB}$ \\
\hline Média & 25,7 & 12,7 & 22,7 & 8,3 \\
\hline C.V. (\%) & 12,9 & & & \\
\hline
\end{tabular}

Extração (mg/vaso)

$\begin{array}{lllll}0 & 86,2 \mathrm{aA} & 27,6 \mathrm{aB} & 76,4 \mathrm{aA} & 13,3 \mathrm{aB} \\ 10 & 51,9 \mathrm{bA} & 5,6 \mathrm{bB} & 47,4 \mathrm{bA} & 3,9 \mathrm{bB} \\ 20 & 38,6 \mathrm{cA} & 3,8 \mathrm{cB} & 23,4 \mathrm{bA} & 2,0 \mathrm{bB} \\ 30 & 31,8 \mathrm{cA} & 2,4 \mathrm{cB} & 23,9 \mathrm{bA} & 1,8 \mathrm{bB} \\ \text { Média } & 52,2 \mathrm{~A} & 9,8 \mathrm{~B} & 42,8 \mathrm{~A} & 5,3 \mathrm{~B}\end{array}$

C.V. (\%) 13,2

* Médias seguidas da mesma letra minúscula na vertical e maiúsculas na horizontal, dentro de cada genótipo, não diferem pelo teste de Tukey, ao nível de $5 \%$ de significância.

tratamento com ausência de Al, não diferindo nos demais tratamentos. Nos dois genotipos, observou-se que a extraça de manganês pela parte aérea foi superior à das raizes, em todos os niveis de Al (Tabela 74 ). 
A análise de regressao do efeito do Al sobre o teor de manganẽs na parte aérea do cultivar UPF 7 , mostrou que a redução ocorreu de forma linear, enquanto que para o genótipo UPF86Al169-2b, a regressão linear, quadrática ou cúbica foi significativa (Figura 34 ). Já em relação as raízes, observa-se na Figura 34 , que no genótipo sensível a redução do teor ocorreu de forma linear, enquanto no tolerante, a variação se manifestou da forma de equação quadrática.

A análise de regressão do efeito dos niveis de alumínio sobre a extração de manganês, revelou que na parte aérea, a variação nos dois genótipos ocorreu de forma quadrática (Figura 35). Nas raizes, a extração de manganês diminuiu linearmente no genótipo UPF 7 (sensivel), enquanto a variação no genótipo UPF 86Al169-2b (tolerante) se manifestou através de uma equação quadrática. Observa-se na figura 35, que devido ao ajuste das médias pela regressão linear do teor de manganês nas raízes do genótipo UPF 7 apresentou valor negativo no nível de $30 \mathrm{mg} \mathrm{Al/l}$.

Os resultados encontrados também estão de acordo com relatos de LEMOS FILHO (1981) e CAMBRAIA et al. (1983) em sorgo, onde a presença de Al causou reduçós nos teores de $\mathrm{Mn}$ na parte aérea e raíz, não encontrando diferença entre cultivar tolerante e sensível, exceto para as raizes do genótipo sensivel.

Em cevada, ALAM (1981), também verificou que o Al promoveu um decréscimo na concentração de Mn em todas as partes da planta, com exceçao dos colmos. Entretanto, ALAM (1983), verificou que no arroz, o aumento de Al na solução promoveu uma diminuição do teor de Mn na parte aérea, enquanto nas raízes ocorreram aumentos, sugerindo que o Mn pode competir efetivamente com o Al pelos sitios ativos de absorção. 


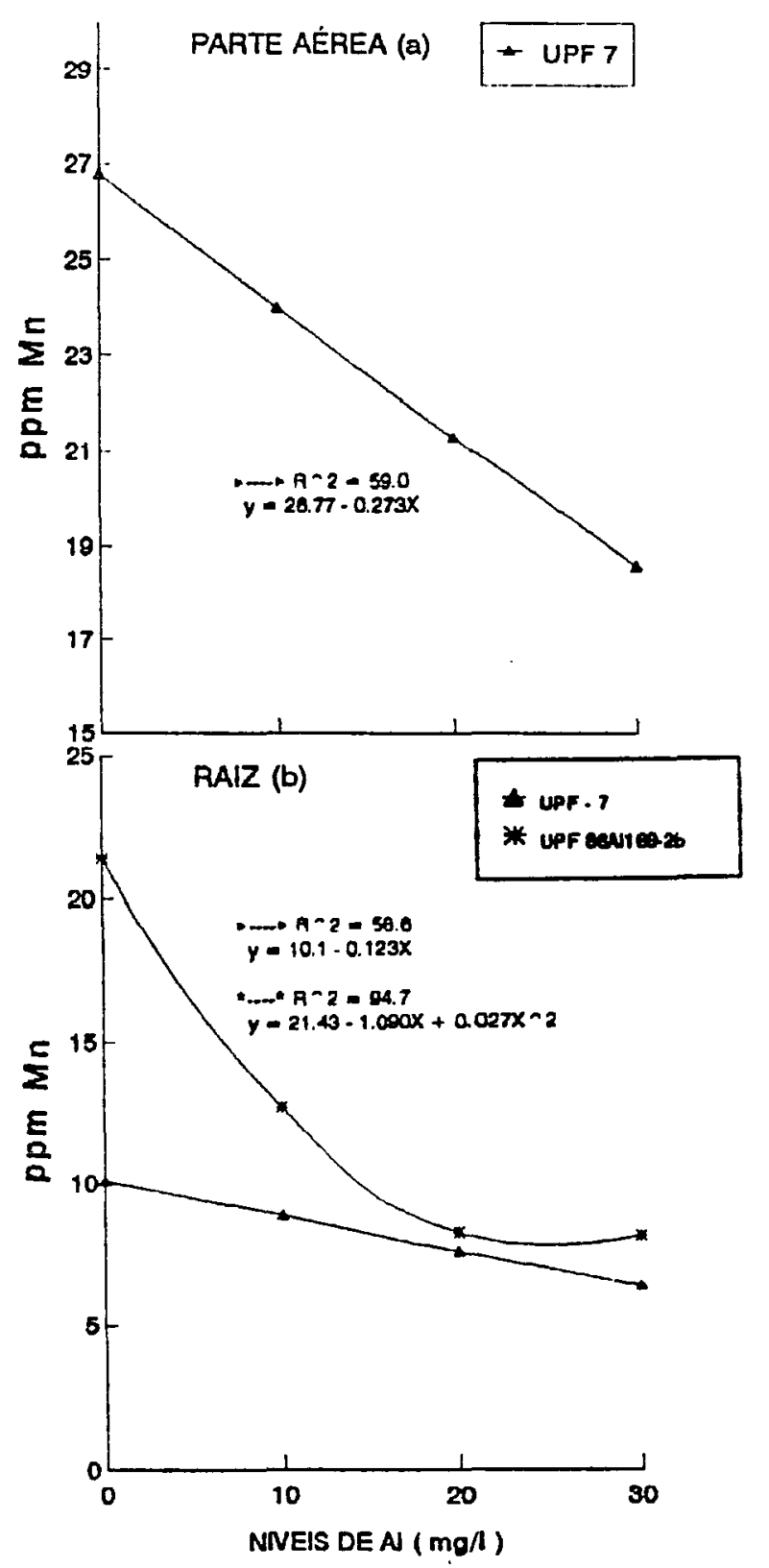

218

Figura 34. Efeito dos níveis de alumínio na soluçå nutritiva sobre o teor de manganês na parte aérea (a) e nas raizes (b), de plantas de dois genótipos de aveia. 


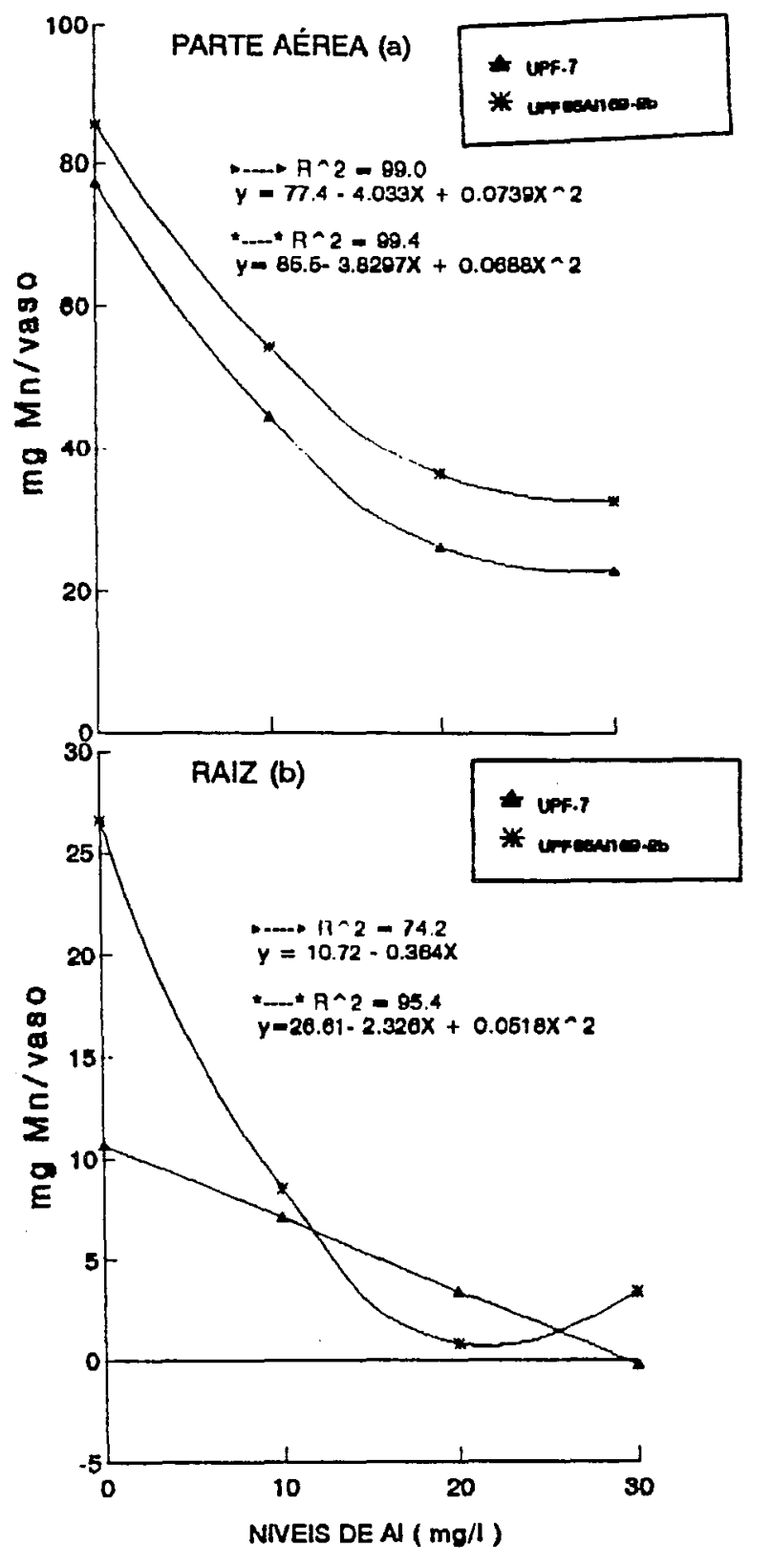

219.

Figura 35. Efeito dos niveis de alumínio na soluçao nutritiva sobre a extração de manganês pela parte aérea (a) e pelas raizes (b) de plantas de dois genotipos de aveia. 


\subsubsection{Zinco}

A análise de variância dos resultados dos teores de zinco das plantas de aveia (TZnP) revelou ser significativa a interação genótipos $x$ níveis de $A l$ e a diferença entre os genótipos, ao nivel de $5 \%$ de significância (Tabela D11). o efeito dos niveis de Al foi altamente significativa $(P>0,01)$.

Em relaçào à extração de zinco, a análise de variância não foi significativa para a interação genótipos $x$ níveis de Al ( $P>0,05$ ), enquanto que as diferenças entre os genótipos $e$ os níveis de Al foram altamente significativas $(P<0,01)$.

Através da comparação entre as médias pelo teste de Tukey (Tabela 75), observa-se que o genótipo tolerante apresentou teor de zinco superior ao sensivel no nível $10 \mathrm{mg}$ Al/l, não diferindo nos demais niveis. Em relação à extração, a média dos niveis do genótipo tolerante foi superior ao sensível.

A anál ise de regressão do efeito de niveis de Al sobre os teores de zinco na planta revelou que tanto no genótipo tolerante quanto no sensível, a redução dos teores desse micronutriente ocorre de forma linear com os níveis de Al (Figura 36).

Em relação às partes da aveia, a análise de variância dos resultados do teor e extração de zinco revelou não serem significativas as interaçőes entre genótipos x partes $x$ níveis de $A l$, genótipos $x$ niveis e partes $x$ niveis, ao nível de 5\% de significância (Tabela D12). Já a interação partes $x$ genótipos e as diferenças de médias entre as partes, os genótipos e os níveis de aluminio foram altamente significativas. 
Pela comparaça entre médias, apresentada na Tabela 76, verifica-se que o teores de zinco na raiz foram significativamente superiores aos da parte aérea, nos dois genótipos avaliados. Na comparação entre as partes, observa-se quanto aos teores na parte aérea os genótipos não diferiram, mas em relação às raizes, o teor no genótipo tolerante foi superior ao do cultivar sensivel.

Tabela 75. Efeito dos níveis de aluminio na solução nutritiva sobre os teores e extração de zinco, em plantas de dois genótipos de aveia.

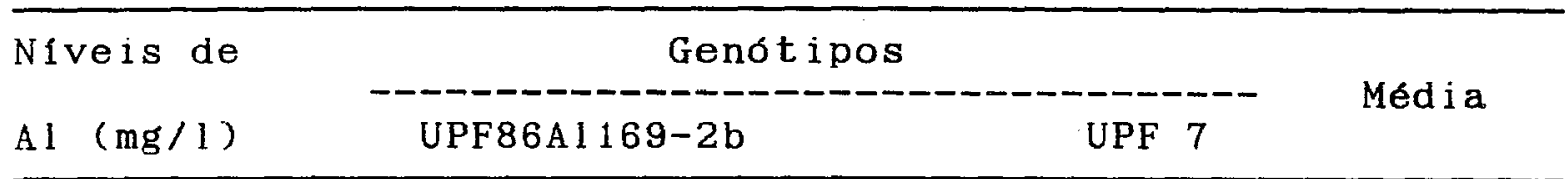

Teor (ppm)

$\begin{array}{lcll}0 & 26,0 \mathrm{aA} & 24,5 \mathrm{aA} & 25,7 \mathrm{a} \\ 10 & 28,3 \mathrm{aA} & 23,0 \mathrm{abB} & 25,7 \mathrm{a} \\ 20 & 20,0 \mathrm{bA} & 20,6 \mathrm{bcA} & 20,3 \mathrm{~b} \\ 30 & 17,9 \mathrm{bA} & 18,6 \mathrm{cA} & 18,3 \mathrm{~b} \\ \text { Média } & 23,1 \mathrm{~A} & 21,7 \mathrm{~B} & \\ \text { C.V. }(\%) & 6,6 & & \end{array}$

Extração (mg/vaso)

$0 \quad 118,7$

$104,9 \quad 111,8 \mathrm{a}$

10

69,5

$49,7 \quad 54,6 \mathrm{~b}$

20

37,6

32,6

$35,1 \mathrm{c}$

30

28,7

27,7

$28,3 \mathrm{c}$

Média

$63,6 \mathrm{~A}$

$53,7 \mathrm{~B}$

58,7

C.V. (\%)

11,6

* Médias seguidas da mesma letra minúscula na e maiúsculas na horizontal, não diferem pelo teste Tukey, a nível de $5 \%$ de significância. 


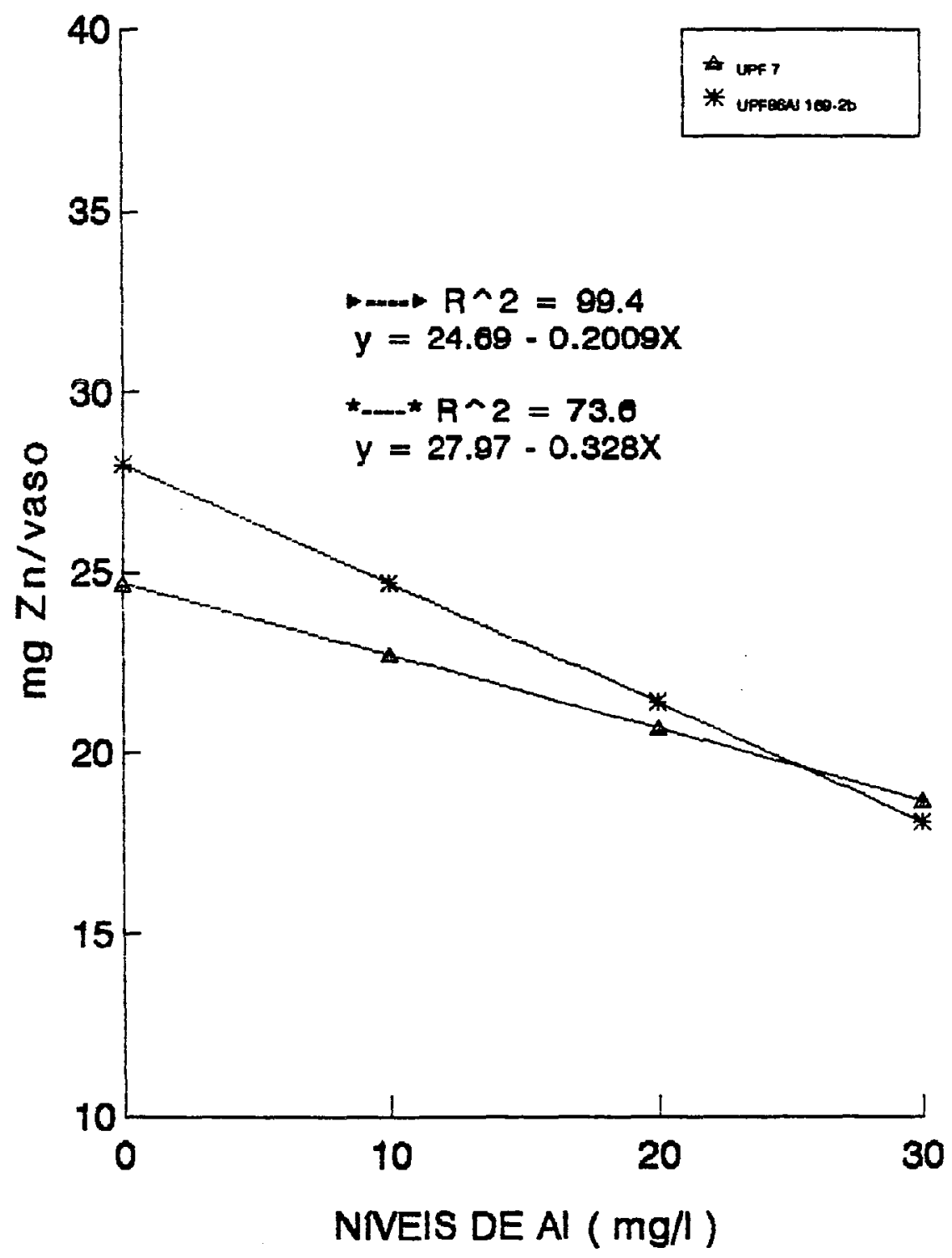

Figura 36. Efeito de níveis de alumínio na soluça nutritiva sobre os teores de zinco nas plantas de dois genótipos de aveia. 
Tabela 76. Teores e extraçao média de zinco pela parte aérea e pelas raízes de plantas dos dois genótipos de aveia.

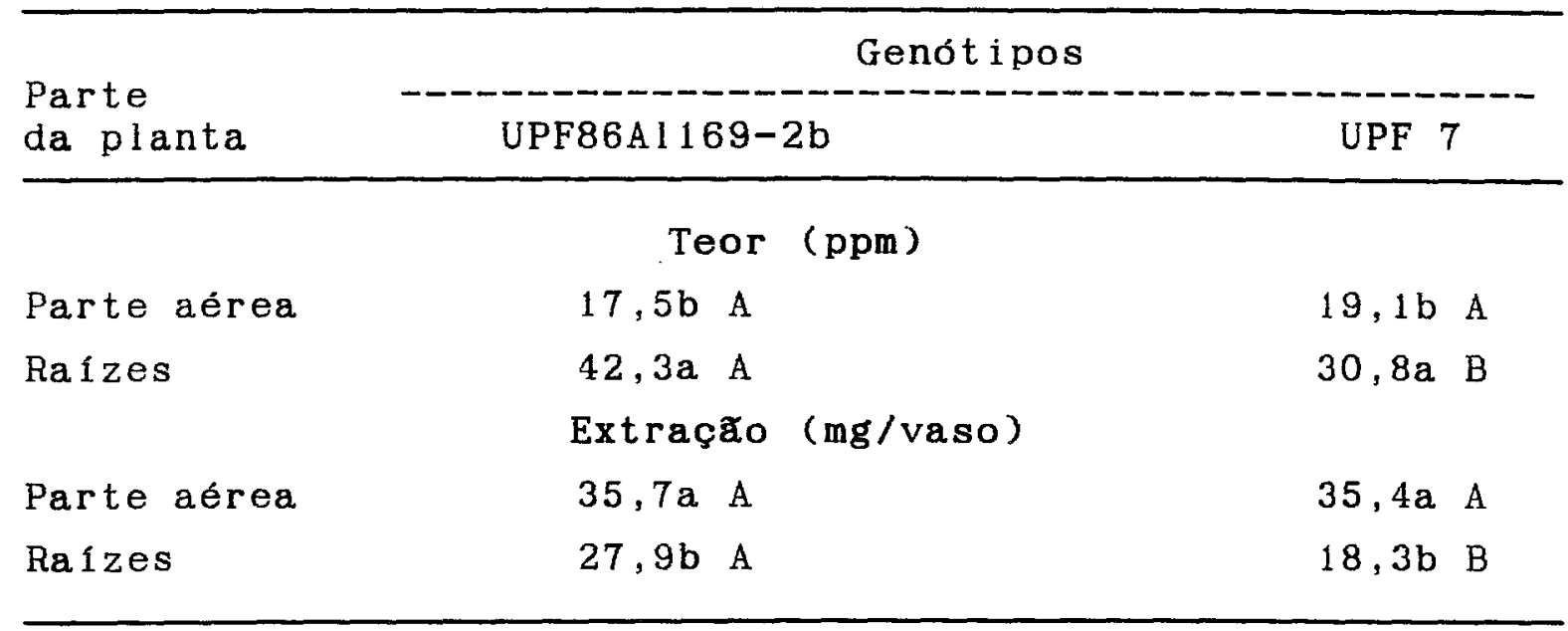

Médias seguidas da mesma letra minúscula na vertical e maiúsculas na horizontal, não diferem pelo teste de Tukey, a nível de 5\% de significância.

Quanto à extração, observa-se que para os dois genótipos, o acúmulo pela parte aérea foi superior ao das raízes $(P<0,05)$. Na comparação entre os genótipos o comportamento foi igual ao observado quanto aos ao teores.

ALAM \& ADAMS (1979b), não encontraram diferenças significativas entre os teores de $\mathrm{Zn}$ na parte aérea e nas raizes de aveia em função do aumento da concentração de aluminio. Entretanto, aqueles autores encontraram teores nas raizes, superiores aos da parte aérea, concordando com os resultados obtidos neste trabalho. 
4.8.5. Correlaçðes entre teor de alumínio, o rendimento de matéria seca e os teores de alguns micronutrientes

A correlação linear simples entre o teor de Al e os teores de alguns micronutrientes nas raizes do cultivar de aveia UPF 7 foi significativa e negativa para os teores de manganês $(r=-71,7 * *)$ e zinco $(r=-62,2 *)$, enquanto para o genótipo UPF86Al169-2b elas foram significativa e negativas para os teores de ferro $(r=-82,2 * *)$ e manganẽs $(r=-$ $83,6 * *)$, conforme Tabela 77 .

Em relação aos teores da parte aérea, observouse que no cultivar sensivel (UPF 7 ), o teor de Al na parte aérea se correlacionou negativamente com o teor de $\mathrm{Cu}(\mathrm{r}=-$ $61,0 *)$, manganês $(r=-72,0 * *)$ e zinco $(r=-78,4 * *)$. Para o genótipo tolerante (UPF $86 \mathrm{~A}(169-2 \mathrm{~b}$ ), o teor de Al na parte aérea não se correlacionou significativamente com os teores de nenhum dos micronutriente analisados.

Com relação ao rendimento de matéria seca das raizes e os teores de micronutrientes (Tabela 78) observou-se que no cultivar UPF 7 a correlação foi significativa e positiva para os teores de manganês $(r=76,5 * *)$ e zinco $(r=67,5 *)$, enquanto que no genótipo UPF86Al169-2b a correlação foi significativa e também positiva para os teores de ferro $(r=94,9 * *)$ e de manganês $(r=91,1 * *)$.

Quanto à parte aérea, o rendimento de matéria seca do genótipo UPF 7 não se correlacionou significativamente com nenhum dos micronutriente analisados. Para o genótipo UPF 86A1169-2b verificou-se uma correlaçăo significativa e negativa entre o rendimento de matéria seca e o teor de ferro $(r=-80,7 * *)$. 
Tabela 77. Valores de $t$ e coeficientes de correlaçao ( $r$ ) entre os teores de alumínio nas raízes e na parte aérea, e os teores de alguns micronutrientes em dois genótipos de aveia.

\begin{tabular}{|c|c|c|c|c|}
\hline \multirow{2}{*}{ Correlações } & \multicolumn{2}{|c|}{ Valor $t$} & \multicolumn{2}{|r|}{$r(\%)$} \\
\hline & UPF 7 & UPF $86 \mathrm{~A} 1169-2 \mathrm{~b}$ & UPF 7 & UPF $86 \mathrm{~A} 1169-2 \mathrm{~b}$ \\
\hline
\end{tabular}

\section{Raízes}

\begin{tabular}{|c|c|c|c|c|c|}
\hline \multirow[t]{5}{*}{ TAl } & $\mathrm{x} T \mathrm{TCu}$ & $1,51 \mathrm{~ns}$ & $0,84 \mathrm{~ns}$ & 40,1 & $-26,4$ \\
\hline & $\mathrm{x} T F e$ & $0,19 \mathrm{~ns}$ & $4,57 * *$ & $-5,9$ & $-82,2$ \\
\hline & $\mathrm{x}$ TMn & $3,26 * *$ & $4,82 * *$ & $-71,7$ & $-83,6$ \\
\hline & $\mathrm{x} T \mathrm{TZn}$ & $2,51 *$ & $1,68 \mathrm{~ns}$ & $-62,2$ & $-47,0$ \\
\hline & & & Parte aérea & & \\
\hline \multirow[t]{4}{*}{ TAl } & $\mathrm{x} T \mathrm{TCu}$ & $2,44 *$ & $1,74 \mathrm{~ns}$ & $-61,0$ & $-48,3$ \\
\hline & $\mathrm{x} T F e$ & $0,64 \mathrm{~ns}$ & $1,30 \mathrm{~ns}$ & 19,4 & 38,0 \\
\hline & $\mathrm{x}$ TMn & $3,28 * *$ & $0,80 \mathrm{~ns}$ & $-72,0$ & $-24,6$ \\
\hline & $\mathrm{x} T Z n$ & $4,00 * *$ & $1,62 \mathrm{~ns}$ & $-78,4$ & $-45,5$ \\
\hline
\end{tabular}

* e ** significativo, respectivamente no niveis 5 e $1 \%$ de significância. ns = não significativo. 
Tabela 78. Valores de $t$ e coeficientes de correlaça $r$ entre o rendimento de matéria seca das raizes e da parte aérea e os teores de alguns micronutrientes em plantas dos dois genótipos de aveia.

\begin{tabular}{|c|c|c|c|c|c|}
\hline \multirow{2}{*}{\multicolumn{2}{|c|}{ Correlações }} & \multicolumn{2}{|c|}{ Valor $\mathrm{t}$} & \multicolumn{2}{|c|}{ r (\%) } \\
\hline & & UPF 7 & UPF $86 A 1169-2 b$ & UPF 7 & UPF 86Al 169-2b \\
\hline \multicolumn{6}{|c|}{ Raízes } \\
\hline \multirow[t]{5}{*}{ RMS } & $\mathrm{x} \mathrm{TCu}$ & $1,03 \mathrm{~ns}$ & $1,42 \mathrm{~ns}$ & $-31,00$ & 40,9 \\
\hline & $\mathrm{x} T \mathrm{TFe}$ & $0,38 \mathrm{~ns}$ & $9,62 * *$ & 0,12 & 94,9 \\
\hline & $\mathrm{x} T \mathrm{Tn}$ & $3,75 * *$ & $6,98 * *$ & 76,50 & 91,1 \\
\hline & $\mathrm{x} T \mathrm{Tn}$ & $2,89 *$ & $1,09 \mathrm{~ns}$ & 67,50 & 32,5 \\
\hline & & & Parte aérea & & \\
\hline \multirow[t]{4}{*}{ RMS } & $\mathrm{x} \mathrm{TCu}$ & $1,35 \mathrm{~ns}$ & $1,03 \mathrm{~ns}$ & 39,30 & 30,9 \\
\hline & $\mathrm{x} T \mathrm{TFe}$ & $0,45 \mathrm{~ns}$ & $4,32 * *$ & $-14,10$ & $-80,7$ \\
\hline & $\mathrm{x} T \mathrm{TMn}$ & $1,79 \mathrm{~ns}$ & $0,29 \mathrm{~ns}$ & 49,20 & 9,0 \\
\hline & $\mathrm{x} T \mathrm{Tn}$ & $1,80 \mathrm{~ns}$ & $0,92 \mathrm{~ns}$ & 49,50 & 27,9 \\
\hline
\end{tabular}

* e ** significativo, respectivamente no niveis 5 e $1 \%$ de significância. ns = não significativo.

4.9. Efeito dos níveis de aluminio sobre o pH na solução nutritiva, no cultivo de aveia.

A análise de variância dos resultados da aval iação do $\mathrm{pH}$ da solução nutritiva, medida durante um periodo de cinco dias, revelou que as interaçóes dias $x$ genótipos $x$ niveis de Al e dias $x$ niveis de Al foram altamente significativas ao nivel de $1 \%$, enquanto a interação dias $x$ genótipos foi significativa ao nivel de $5 \%$ (Tabela D13). Em relaçăo aos efeitos principais, as médias dos genótipos diferem 
significativamente ao nível de $5 \%$ e as médias entre os dias e niveis de Al diferem ao nível de $1 \%$. A interação genótipos $x$ niveis de Al não foi significativamente, ao nível de $5 \%$ de signif icância .

Pela comparação entre as médias dos genótipos, através do teste de Tukey, apresentada na Tabela 79, observou-se que o pH médio da solução do genótipo tolerante foi superior ao sensível, ao nível de $5 \%$ de significância.

Tabela 79. Variação do $\mathrm{pH}$ da solução nutritiva em função dos níveis de aluminio, no cultivo hidropônico de aveia.

Niveis de

UPF 7

UPF86A $1169-2 b$

Al ( $\mathrm{mg} / \mathrm{l}$ )

\begin{tabular}{cccc}
\hline 0 & 4,26 & $\mathrm{~A}$ & $4,32 \mathrm{~A}$ \\
10 & $3,98 \mathrm{~A}$ & $3,98 \mathrm{~A}$ \\
20 & $3,90 \mathrm{~A}$ & $3,93 \mathrm{~A}$ \\
30 & 3,84 & $\mathrm{~A}$ & $3,87 \mathrm{~A}$ \\
40 & 3,76 & $\mathrm{~B}$ & $3,83 \mathrm{~A}$ \\
Média & $3,95 \mathrm{~B}$ & $3,99 \mathrm{~A}$ \\
\hline
\end{tabular}

- Médias seguidas da mesma letra na horizontal, não diferem pelo teste de Tukey ao nível de $5 \%$ de significância.

Em relação aos níveis de alumínio, o pH da solução utilizada com o genótipo UPF86Al169-2b foi superior ao da solução de cultivo do cultivar UPF 7 no nível $40 \mathrm{mg} \mathrm{Al/l,}$ não diferindo ( $P>0,05)$ nos demais níveis.

A análise de regressão do efeito de niveis de aluminio, sobre o $\mathrm{pH}$ da solução nutritiva dos dois genótipos é apresentada na Figura 37 . Verifica-se que a diminuiça no pH, com o aumento dos níveis de alumínio, se manifestou de forma quadrática para os dois genótipos, sendo que o coeficiente de 
228.

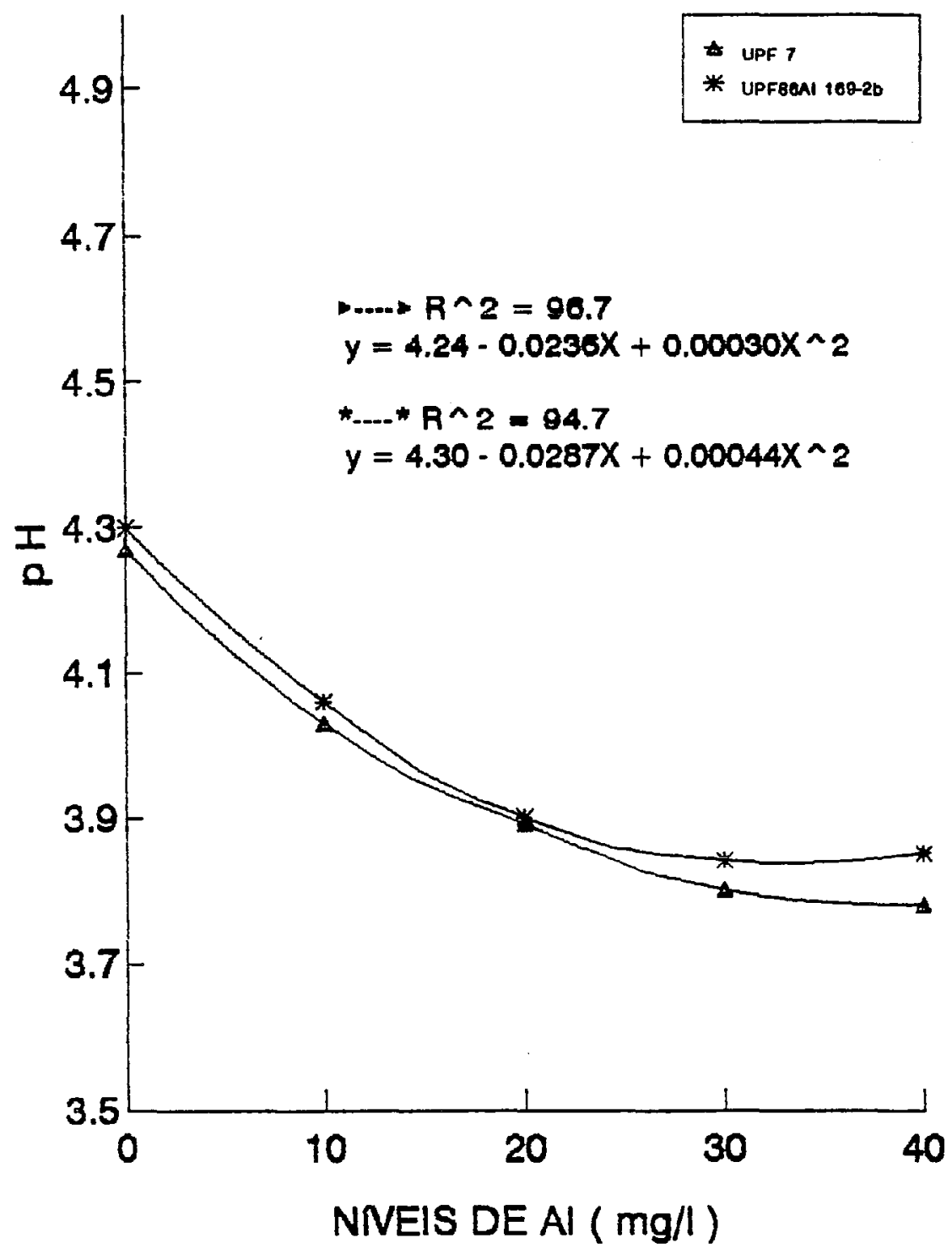

Figura 37. Efeito dos niveis de aluminio sobre o pH na soluçac nutritiva de dois genótipos de aveia. 
determinação igual a $96,7 \%$ e $94,7 \%$, para UPF 7 e UPF86Al169$2 b$, respectivamente.

Em relação à comparação entre as médias de pH durante os dias de avaliação (Tabela 80), observa-se que o $\mathrm{pH}$ na solução nutritiva do genótipo tolerante foi superior ao $\mathrm{pH}$ do genótipo sensível, na média do período e em cada dia de avaliação, partindo-se de $u m p H$ inicial igual.

Tabela 80. Variação do $\mathrm{pH}$ da solução nutritiva na média dos diferentes dias de avaliação em cultivo hidropônico de aveia.

$\begin{array}{lll}\text { Dias UPF } 7 & \text { UPF86A1169-2b }\end{array}$

\begin{tabular}{|c|c|c|}
\hline 0 & $4,16 \mathrm{~A}$ & $4,16 \mathrm{~A}$ \\
\hline 1 & $4,06 \mathrm{~B}$ & $4,11 \mathrm{~A}$ \\
\hline 2 & $3,95 \mathrm{~B}$ & $3,99 \mathrm{~A}$ \\
\hline 3 & $3,82 \mathrm{~B}$ & $3,90 \mathrm{~A}$ \\
\hline 4 & $3,76 \mathrm{~A}$ & 3,80 \\
\hline dia & $3,95 \mathrm{~B}$ & 3,99 \\
\hline
\end{tabular}

- Médias seguidas da mesma letra na horizontal, não diferem pelo teste de Tukey ao nivel de $5 \%$ de significância.

A análise de regressão do efeito do tempo de cultivo (dias) sobre o pH da solução nutritiva, revela que a diminuição do $\mathrm{pH}$ ocorreu de forma linear nos dois genótipos (Figura 38).

Apesar do pequeno valor numérico, a diferença do pH na solução nutritiva entre o genótipo tolerante (UPF86Al1692b) e o sensivel (UPF7), foi significativa. Este resultado 
230.

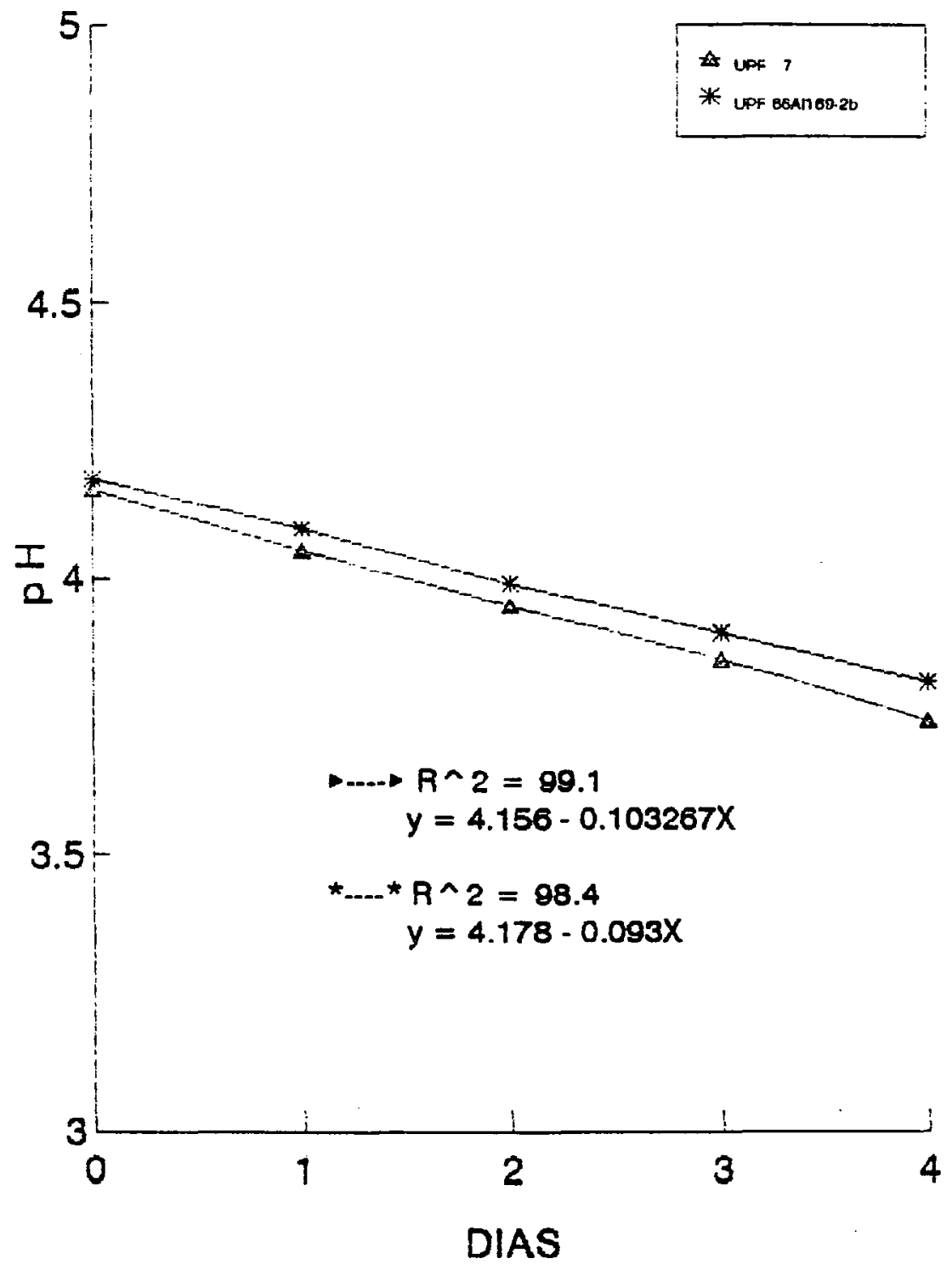

Figura 38. Efeito do tempo de cultivo (dias) sobre o pH na solução nutritiva de dois genótipos de aveia. 
poderia indicar a capacidade dos genótipos de aveia tolerantes ao alumínio, de manterem um $\mathrm{pH}$ mais elevado em relaçao ao sensivel. Este fato seria entao explicado pela maior absorção de nitrato $\left(\mathrm{NO}_{1}{ }^{-}\right)$em relação a amônio $\left(\mathrm{NH}_{4}{ }^{+}\right)$, conforme os resultados obtidos em trigo (FOY et al., 1965; FOY \& FLEMING, 1978; FOY \& FLEMING, 1982). Entretanto, a diminuição do $p H$ na solução, observada neste trabalho, é discordante dos resultados apresentados por McLEAN \& GILBERT (1927) verificaram que o pH na solução de alumínio apresentou um aumento de 4,5 para 6,5 em três dias e meio de cultivo de aveia. Aqueles autores também observaram que a variação no $\mathrm{pH}$ não estava correlacionada com a sensibilidade de genótipos de aveia ao alumínio.

4.10. Efeito de niveis de aluminio sobre a atividade "in vitro" da redutase do nitrato em aveia

A análise de variância dos resultados da atividade "in vitro" da redutase do nitrato (RN) em aveia revelou que não foram significativas as interações genótipos $x$ estádios $\mathrm{x}$ órgãos, genótipos $\mathrm{x}$ órgãos e genótipos $\mathrm{x}$ estádios, ao nivel de $5 \%$ de significância (Tabela D14). A interação estádios $x$ órgãos revelou-se altamente significativa $(P<0,01)$, bem como a diferença entre órgãos. A diferença de atividade nos dois estádios foi significativa ao nível de $5 \%$ de significância e os genótipos UPF 7 e UPF86Al169-2b năo diferiram $(P>0,05)$ em relação à atividade da redutase do nitrato.

Na Tabela 81 é apresentada a comparação entre as médias do desdobramento de órgáos e estádios de desenvolvimento. Verifica-se que nos dois estádios, a atividade "in vitro" da redutase do nitrato na folha foi superior à atividade nas raízes. 
Quanto ao estádio de desenvolvimento, observa-se que a atividade nas folhas aos 14 dias após a emergencia (14DAE) foi superior à atividade aos 21 dias após a emergência (21DAE). A atividade enzimática nas raizes não diferiu nos dois estádios.

Tabela 81. Efeito do estádio de desenvolvimento sobre a atividade "in vitro" da redutase do nitrato, em folhas e raízes de plantas de aveia.

\begin{tabular}{|c|c|c|}
\hline \multirow{2}{*}{ Estádio } & \multicolumn{2}{|c|}{ órgãos } \\
\hline & Folha & Raízes \\
\hline & ---- umo & F-ーーーーーー \\
\hline $14 \mathrm{DAE}$ & $3,06 \mathrm{a} A$ & $0,13 \mathrm{a} B$ \\
\hline 21 DAE & $2,33 \mathrm{~b} \quad \mathrm{~A}$ & $0,19 \mathrm{a} \quad \mathrm{B}$ \\
\hline
\end{tabular}

- Médias seguidas da mesma letra minúscula na vertical e maíscula na horizontal, não diferem pelo teste de Tukey, ao nível de $5 \%$ de significância.

A maior atividade da redutase do nitrato nas folhas em relação as raízes, obtida neste trabalho confirma as informações apresentadas por BEEVERS \& HAGEMAN (1969). Segundo BEN ZIONI et al. (1971), a redução do nitrato na parte aérea estimula a absorção de nitrato pela raíz.

A partir desses resultados, a avaliação do efeito dos níveis de alumínio sobre a atividade "in vitro" da redutase do nitrato (RN) foi realizada utilizando apenas a última folha completamente expandida da planta.

Quanto à relação entre a atividade da enzima RN e o estádio de desenvolvimento da aveia, a maior atividade 
observada foi no estádio de início de afilhamento das plantas de aveia. Segundo SAUVESTY \& GENDRON (1987), em plantas de aveia a atividade da enzima é alta na fase de plântula, máxima na fase de afilhamento, decaindo após a emissão da panícula.

A análise de variância dos resultados do efeito do alumínio sobre a $\mathrm{RN}$, revelou que a interaça genótipos $\mathrm{x}$ niveis de aluminio e a diferença entre os niveis de alumínio não foi significativa, ao nível de $5 \%$ de significância. Entretanto, foram observadas diferenças significativas entre os genótipos UPF 7 e UPF86Al169-2b $(P<0,05)$, conforme Tabela D14).

Através da comparaça entre as médias dos genótipos (Tabela 82), observa-se que a atividade média da redutase do nitrato no genótipo tolerante foi superior à atividade no genótipo sensivel, ao nivel de $5 \%$ de significância.

Apesar da diferença entre os níveis de Al, năo ser significativa, verifica-se uma diminuição da atividade da redutase do nitrato no genótipo sensível UPF 7 , com o aumento da concentração de Al. Para o genótipo tolerante, observa-se um aumento da atividade da enzima com o aumento da concentraça de A1 .

Essa maior atividade da redutase do nitrato em genótipos tolerantes em relação aos sensiveis também foi encontrada para trigo (FOY \& FLEMING, 1982). A maior atividade da enzima em genótipos tolerantes ao aluminio, aumenta a eficiência na utilização do nitrogênio, e poderia ser responsável pelo maior teor de proteina encontrado nos graos de aveia (BILSKI \& FOY, 1987). 
Tabela 82. Atividade "in vitro" da redutase do nitrato em folhas de aveia ( $\mu \mathrm{mol} / \mathrm{NO}^{-2} / \mathrm{h} / \mathrm{gMF}$ ) sob diferentes níveis de alumínio na solução nutritiva em cultivo hid ropônico.

\begin{tabular}{|c|c|c|c|c|}
\hline \multirow{2}{*}{$\begin{array}{l}\text { Niveis de } \\
\text { Al (mg/l) }\end{array}$} & \multicolumn{4}{|c|}{ Genót i pos } \\
\hline & UPF 7 & UPFE & $36 \mathrm{~A} I 169-2 \mathrm{~b}$ & Média \\
\hline & --------- & Hmo 1 & $\mathrm{NO}^{-1} / \mathrm{h} / \mathrm{gMF}$ & -ー-ー-ー-ー-ー \\
\hline 0 & $2,32 \mathrm{~A}$ & & $1,99 \mathrm{~A}$ & 2,15 \\
\hline 10 & $1,64 \mathrm{~A}$ & & $1,94 \mathrm{~A}$ & 1,79 \\
\hline 20 & $1,55 \mathrm{~A}$ & & $1,99 \mathrm{~A}$ & 1,79 \\
\hline 30 & $1,52 \mathrm{~A}$ & & $2,01 \mathrm{~A}$ & 1,77 \\
\hline 40 & $1,30 \mathrm{~A}$ & & $2,27 \mathrm{~A}$ & 1,77 \\
\hline Média & $1,66 \mathrm{~B}$ & & $2,04 \mathrm{~A}$ & 1,85 \\
\hline C.V. (\%) & 21,77 & & & \\
\hline
\end{tabular}

* Médias seguidas pela mesma letra maíscula na horizontal, não diferem pelo teste de Tukey ao nivel de $5 \%$ de significância. 
5. CONCLUSÕES

Os resultados verificados neste trabalho quanto a toxicidade do Al em aveia, permitiram estabelecer as seguintes conclusões :

a) Quanto à classificação de genótipos de aveia branca e aveia preta:

- existe grande variabilidade nas aveias brancas e pretas quanto à toxicidade do alumínio, avaliada através do crescimento da raíz seminal em solução nutritiva;

- as aveias pretas são mais tolerantes e responsivas ao alumínio que as brancas;

- a concentração adequada para classificação de genótipos de aveia branca quanto ao alumínio foi $7,5 \mathrm{mg} / \mathrm{litro}$ de soluça nutritiva;

- os genótipos da aveia branca UPF82079, UPF86A1198-5-46, UPF3, UFRGS6, UPF86068, UFRGS1, UFRGS4, UPF15, UPF86120, UPF84297, UPF84125, UPF87070, UPF84321, UPF87128, CTC1, CTC84B1412-3 e UPF79159-6b foram classificados como tolerantes e responsivos no nível $7,5 \mathrm{mg}$ Al/litro;

- os genótipos de aveia branca UPF82079, UPF77394-1, UFRGS6, UPF86006, UPF81360, UPF86160, UPF86112, UPF81359 e UPF21, foram classificadas como tolerantes no nível $15 \mathrm{mg} \mathrm{Al/litro;}$

- os genótipos de aveias pretas UPF77434, UPF84AP01, UPF77066, UPF77436, Preta Argentina, UPF77352 e UPF85AP01 foram 
classificados como tolerantes e responsivos no nivel $30 \mathrm{mg}$ Al/litro:

b) Quanto aos genótipos tolerante (UPF86Al169-2b) e sensível (UPF 7):

- a toxicidade do Al promoveu maior diminuição no número de afilhos e no comprimento da maior raiz do genótipo sensivel que no tolerante;

- o crescimento da raiz seminal correlacionou-se mais com o rendimento relativo de MS da planta e da parte aérea, do que o rendimento de MS da raíz;

- as plantas do genotipo tolerante apresentaram teores de $\mathrm{N}$, $\mathrm{P}, \mathrm{Mg}, \mathrm{Fe}, \mathrm{Mn}$ e $\mathrm{Zn}$ e extração de $\mathrm{N}, \mathrm{K}, \mathrm{Ca}, \mathrm{Mg}, \mathrm{Cu}, \mathrm{Fe}$, Mn e Zn superiores ao sensivel;

- o genótipo tolerante apresentou teores de $K$ e Zn nas raizes e de $N$ e $P$ na parte aérea, superiores ao sensível;

- o genótipo tolerante apresentou extração de $\mathrm{N}, \mathrm{Fe}$, Mn e Zn nas raízes e de $\mathrm{N}, \mathrm{P}, \mathrm{Ca}, \mathrm{Mg}, \mathrm{Fe}$ e $\mathrm{Mn}$ na parte aérea superiores ao sensível;

- o teor de $P$ nas plantas aumentou enquanto a extração diminuiu com o aumento da concentração de Al na solução;

- o Mg foi o nutriente mais afetado pela toxicidade do alumínio nas plantas; 
- o genótipo tolerante e o sensivel não diferiram quanto ao teor e a extração de Al pelas plantas, mas nas raizes, o teor de Al no genótipo tolerante foi superior ao do sensível;

- o teor de Al nas raízes correlaciono-se de forma positiva com o teor de $\mathrm{P}$ e de forma negativa com os teores de Mg, Mn e Zn no genótipo sensivel e positivamente com os teores de $\mathrm{N}$ e $\mathrm{P}$ e negativamente com $\mathrm{Mg}, \mathrm{Fe}$ e Mn no tolerante.

- o rendimento de matéria seca das raízes do genótipo sensivel correlacionou-se de forma positiva com os teores de $\mathrm{P}, \mathrm{Mg}$, Mn e Zn e com os teores de N, P, Mg, Fe e Mn no genótipo tolerante.

- o teor de Al na parte aérea do genótipo sensivel correlacionou-se de forma negativa com os teores de $P, K$, $\mathrm{Ca}, \mathrm{Mg}, \mathrm{Cu}, \mathrm{Mn}$ e $\mathrm{Zn}$ e no tolerante com os teores de $\mathrm{N}$, Ca e Mg.

- o rendimento de MS da parte aérea do genótipo sensivel correlacionou-se de positiva com os teores de $\mathrm{N}, \mathrm{P}$, Mg e no tolerante com os teores de N, P, Mg e Fe;

- o teor de Al correlacionou-se de forma negativa com a matéria seca das raizes e parte aérea nos dois genótipos;

- a atividade da redutase de nitrato no genótipo tolerante foi superior a no sensivel; 


\section{REFERÊNCIAS BIBLIOGRÁFICAS}

ALAM, S.M. Influence of aluminum on plant growth and mineral nutrition of barley. Communication in soil science and Plant Analysis, New York, 12:121-38, 1981 .

ALAM, S.M. Effect of aluminum on the dry matter and mineral content of rice. Journal of Science and Technology, Peshawar, $7(1 / 2): 1-3,1983$.

ALAM, S.M. Aluminium toxicity in barley and oats in soil and hydroponic culture. Pakistan Journal of Scientific and Industrial Research, Karachi, 37(1/4): 17-30, 1985.

ALAM, S.M. \& ADAMS,W.A. Effect of soil $\mathrm{pH}$ on the growth and mineral content of oats. Pakistan Journal of Scientific and Industrial Research, Karachi, 22(3):147-51, 1979a.

ALAM, S.M. \& ADAMS, W.A. Effects of aluminum on nutrient composition and yield of oats. Journal of Plant Nutrition. New York, 1(4):365-75, $1979 b$. 
ANDREW, C.S.; JOHNSON, A.D.; SANDLAND, R.L. Effect of alu minum on the growth and chemistry composition of some tropical and temperate pasture legumes. Australian Journal of Agricultural Research, East Melbourme, $24: 325-39,1973$.

ANUÁRIO ESTATÍSTICO DO BRASIL - 1989, Rio de Janeiro, 48 : 337,1990 .

ANUÁRIO ESTATÍSTICO DO BRASIL - 1990, Rio de Janeiro, $51: 517,1991$.

BARKER, A.V. Nutritional factors in photosynthesis of higher plants. Journal of Plant Nutrition, New York, 1:309-42, 1979.

BEEVERS, L. \& HAGEMAN, R.H. Nitrate reduction in higher plants. Annual Review of Plant Physiology, Palo Alto, $20: 495-522,1969$.

BEN, J.R. \& ROSA, O. S. Resposta de alguns genótipos de trigo e fósforo no solo. In: REUNIÃO NACIONAL DE PESQUISA DE TRIGo, 14., Lonarina, 1986. Resultados de Pesquisa do Centro Nacional de Pesquisa de Trigo. Passo Fundo, EMBRAPA-CNPT, 1986 p. 189-93. (EMBRAPA-CNPT. Documentos, 8).

BEN ZIONI, A.; VAADIA, Y.; HERMAN LIPS, S. Nitrate uptake by roots as regulated by nitrate reduction products of the shoot. Physiologia Plantarum, Copenhagen; 24:288-90, 1971 . 
BILSKI, J.J. Response of plants to mineral stresses caused by acidification and salination of the medium. 1. Effect of the reaction of the medium and the aluminium and calcium content on the growth and chemical composition of roots systems of barley, wheat and oats in water cultures. Biuletyn Instytutu Hodowli Aklimatyzacji Rosin. Bydgoszcz, 164:89-198, 1987. Apud Field Crops Abstracts. Farnhan Royal, 42(6):519, June 1989a. (Resumo).

BIISKI, J.J. Response of plants to mineral stresses caused by acidification and salination of the medium. II. The effect of aluminium and manganese on seedlings of some plants in a pot experiment. Biuletym Instytutu Hodowli i Aklimatyzacji Roslin, Bydgoszcz, 165:67-73, 1988 Apud Field Crop Abstracts, Farnhan Royal, 42(6):574, $1989 \mathrm{~b}$. (Resumo)

BIISKI, J.J. \& FOY, C.D. Differential tolerances of oat cultivars to aluminum in nutrient solutions and in acid soils of Paland. Journal of Plant Nutrition, New York, $10(2): 129-41,1987$.

BILSKI, J.J. \& FOY, C.D. Differential tolerances of weed species to aluminum, manganese and salinity. Journal of Plant Nutrition, New York, 11(1):93-105, 1988.

BRAUNER, J.L. Tolerância de cultivares de trigo (Triticum aestivum L.) ao alumínio e ao manganês: sua determinaçăo, influência na concentração de nutrientes e absorção de cálcio e fósforo. Piracicaba, 1979. 211p. (DoutoradoEscola Superior de Agricultura "Luiz de Queiroz"/USP). 
CALBO, A.G. \& CAMBRAIA, J. Efeito do alumínio sobre a composição mineral de dois cultivares de sorgo (Sorghum bicolor L. Moench). Revista Ceres, Viçosa, 27:369-78, 1980 .

CAMARGo, C.E.O. Efeito da temperatura da soluçäo nutritiva na tolerância ao aluminio de cultivares de trigo. Bragantia, Campinas, 42(1):51-63, 1983.

CAMARGO, C.E.O.; CAMARGO, O.B.A.; SOUZA, D.M. Diferentes concentrações de alumínio em soluçăo nutritiva na tolerância de cultivares de arroz. Bragantia, Campinas, $43(2): 357-68,1984$.

CAMARgo, O. A. \& FURLANI, P.R. Alumínio no solo: concentraçăo, especiação e efeito no desenvolvimento radicular. In: SIMPósIo AVANÇADO DE SOLOS E NUTRIÇÃO DE PLANTAS, 2., Piracicaba, 1989. Anais. Campinas, Fundaçăo Cargill, 1989. p. 45-69.

CAMBraIA, J. Mecanismos de tolerância à toxidez de alumínio em plantas. In: REUNIÄO BRASILEIRA DE FISIOLOGIA VEGETAL, 2., Piracicaba, 1989. Anais. Piracicaba, SBFV/ESALQ, 1989. p.85-92.

CAMBRAIA, J.; GALVANI, F.R.; ESTEVAO, M.D.M.; SANTANA, R. Effects of aluminum on organic acid, sugar and aminoacid composition of the root system of sorghum (Sorghum bicolor L. Moench). Journal of Plant Nutrition, New York, $6(4): 313-22$, 1983a. 
CAMBRAIA, J., LEMOS FILHO, J.P., ESTEVAO, M.M., OLIVA, M.A Efeito do alumínio sobre os teores de $\mathrm{Mg}, \mathrm{Fe}, \mathrm{Mn}$ e $\mathrm{Cu}$ em sorgo. Revista Ceres, Viçosa, 30 (167):45-54, 1983b

CAMPBEL, L.G. \& LAFEVER, H.N. Correlation of field and nutrient culture techniques of screening wheat for aluminum tolerance. In: WORKSHOP ON PLANT ADAPTATION TO MINERAL STRESS IN PROBLEM SOILS, Beltsville, 1976. Plant adaptation to mineral stress in problem soils; proceedings, edited by M.J. Wright and S.A. Ferrari. Ithaca, Cornell University, 1976. p.277-86.

CLARK, R.B. Characterization of phosphatases of intact mayze roots. Journal of Agricultural and Food Chemistry, Washington, $23: 458-60,1975$.

CLARK, R.B. \& BROWN, J.C. Differential phosphorus uptake by phosphorus-stressed maize imbreds. Crop Science, Madison, $14: 505-8,1974$.

CLARKSON, D.T. Effect of aluminum on the uptake and metabolism of phosphorus by barley seedlings. Plant Physiology, Maryland, 41:165-72, 1966.

CLARKSON, D.T. Metabolic aspects of aluminum toxicity and some possible mecanisms for resistance. In: RORISON, I.H., ed. Ecological aspects of mineral nutrition of plants. Oxford. Blackwell Scientific, 1969. p. 381-97.

DELORIT, R.J.; GREUB, L.J.; AHLGREEN, H.L. Oats. In: Crop production. New Jersey, Prentice-Hall, 1984 . p. 157-68. 
EMPRESA BRASILEIRA DE PESQUISA AGROPECUÁRIA.

Relatório técnico anual - 1976/1977. Brasília, 1978. 183p.

FAGERIA, N.K. Tolerância diferencial de cultivares de arroz ao alumínio em soluçăo nutritiva. Pesquisa Agropecuária Brasileira, Brasilia, 17(1): 1-9, 1982.

FAGERIA, N.K. \& ZIMMERMANN, F.J.P. Seleçăo de cultivares de arroz para tolerância à toxidez do alumínio. Pesquisa Agropecuária Brasileira, Brasília, 14: 141-7, 1979.

FAGERIA, N.K.; BALIGAR, U.C.; WRIGHT, R.J. Aluminum toxicity in crop plants. Journal of Plant Nutrition, New York, $11(3): 303-19,1988$.

FLOSS, E.L.; BAIER, A.C.; MCDANIEL, M.E.; BRINKMAN, M.; SHANDS, H.L. Seleção de cultivares de aveia (Avena sp) tolerantes ao alumínio. In: REUNIÃO DA COMISSAO SULBRASILEIRA DE PESQUISA DA AVEIA, 1., Florianópolis, 1989. Passo Fundo, Universidade de Passo Fundo / Faculdade de Agronomia, 1990. p.146-70.

FLOSS, E.L.; BAIER, A.C.; BRINKMAN, M.A.; MCDANIEL, M.E.; SHANDS, H.L.; CECCON, G. Melhoramento genético de aveia visando a tolerância ao alumínio. In: SOUTH AMERICAN OAT CONGRESS, 1. Buenos Ayres, 1991. Passso Fundo, Universidade de Passo Fundo, 1991. p.1-41

FOY, C.D. Effect of aluminum on the uptake and metabolism of phosphorus by barley seedings. Plant Physiology, Rockyille, 41:165-72, 1966. 
FOY, C.D. Effects of aluminum on plant growth. In: CARSON, E.W., ed. The plant root and its enviroment. Charlottesville, University Press of Virginia, 1971. p. $601-40$.

FOY, C.D. Effect of aluminum on plant growth. In: E.W. Carson (ed.). The plant root and its environment. Charlottesville, University Press of Virgínia, p. 601-42. 1974 .

FOY, C.D. General principles invalued in screening plants for aluminum and manganese. In: WORKSHOP ON PLANT ADAPTATION TO MINERAL STRESS IN PROBLEM SOILS, Beltsville, 1976. Plant adaptation to mineral stress in problem soils; proceedings, edited by M.J. Wright and S.A. Ferrari. Ithaca, Cornell University, 1976. p.255-68.

FOY, C.D. Physiological effects of hydrogen, aluminium and manganese toxicities in acid soil. In: ADAMS, F., ed.. Soil acidity and liming. 2. ed. Madison, Soil Science Society American, 1984. p.57-97.

FOY, C.D. Plant adaptation to acid, aluminum-toxic soils. Communications in Soil science and Plant Analysis, New York, 19: 959-87, 1988.

FOY, C.D. Soil chemical factors limiting plant root growth. In: HATFIELD, J.L. \& STEWART, B.A. Limitations to plant root growth. New York, Springer - Verlag, 1992. p. 97-149.

FOY, C.D. \& FIEMING, A.L. The physiology of plant tolerance to excess available aluminum and manganese in acid soils. 
In: JUNG, G.A., ed. Crop tolerance to suboptimal land conditions. Madison, ASA, 1978, p.301-28.

FOY, C.D. \& FLEMING, A.L. Aluminum tolerance of two wheat genotypes related to nitrate reductase activities. Journai of Plant Nutrition, New York, 5:1313-33, 1982.

FOY, C.D. \& LEE, E.H. Differential aluminum tolerance of two barley cultivars related to organic acids in their roots. Journal of Plant Nutrition, New York, 10(9/16):1089-101, 1987.

FOY, C.D.; CHANEY, R.I.; WHITE, M.C. The physiology of metal toxicity in plants. Annual Review of plant Physiology, Palo Alto, 29:511-66, 1978 .

FOY, C. D.; FLEMING, A. L.; ARMIGER, W. H. Aluminum tolerance of soybean varieties in relation to calcium nutrition. Agronomy Journal, Madison, 61: 505-11, 1969 .

FOY, C.D., SMITH, Jr. D.H.; BRIGLE,L.W. Tolerances of oat cultivars to an acid soil high in exchangeable aluminum. Journal of Plant Nutrition, New York, 10(9/16):1163-74, 1987.

FOY, C.D.; ARMIGER, W.H.; BRIGGLE, L.W.; REID, D.A. Differential aluminum tolerance of two wheat varieties associated with plant induced $\mathrm{pH}$ changes around their roots. Soil Science Society of America Proceedings, Madison, 29:64-7, 1965 . 
FOY, C.D.; FLEMING, A.L.; BURNS, G.R.; ARMINGER, W.H. Characterization of differential aluminum tolerance among varieties of wheat and barley. Soil science Society of America Proceedings, Madison, 31:513-21, 1967.

FRINK, C.R. \& PEECH, M. Hydrolysis and exchange reactions of the aluminum ion in hectarite and montmorillonite suspensions. Soil Science Society of America Proceedings, Madison, 27: 527-30, 1963.

FURLANI, P.R. Efeitos fisiológicos do alumínio em plantas. In: SIMPÓSIO AVANÇADO DE SOLOS E NUTRIÇÃO DE PLANTAS, 2., Piracicaba, 1989. Anais. Campinas, Fundação Cargil1, 1989. p. $73-90$.

FURLANI, P.R. \& CASTRO, J.I. Tolerância a alumínio em aveia e cevada. In: REUNIÃO BRASILEIRA DE FERTILIDADE DO SOLO E NUTRIÇĂO DE PLANTAS, 19., Santa Maria, 1990. Resumos. Santa Maria, Sociedade Brasileira de Ciência do Solo, 1990. p.102.

FURLANI, P.R. \& CLARK, R.B. Screening sorghum for aluminum tolerance in nutrient solutions. Agronomy Journal. Madison, 73: 587-94, 1981 .

FURLANI, P.R. \& HANNA, L.G. Avaliaçăo da tolerância de plantas de arroz e milho ao alumínio em soluçăo nutritiva. Revista Brasileira de Ciência do Solo, Campinas, 8 : 205-8, 1984.

GOMES, F.P. Curso de estatística experimental. 5.ed., Săo Paulo, Nobel, 1972. 530p. 
GOODMAN, P.J.; FOTHERGILL, M.; HUGHES, D.M. Variation in nitrate reductase, nitrite and nitrite reductase in some grasses and cereals. Annals of Botany, Aberystwith, 38:317,1974 .

GRIMME, H. The effect of AI on Mg uptake and yield of oats. In: INTERNATIONAL PLANT NUTRITION COLLOQUIUM, 9., Coventry, 1982. Proceedings. Coventry, Warwick University, p.198203.

GRIMME, H. Aluminum induced magnesium deficiency in oats. Zeitscrift fuer Pflanzenernaehrung Bodenkunde, Weinheim, $146: 666-76,1983$.

HARPER, J.E. \& HAGEMAN, R.H. Canopy and seazonal profiles of nitrate reductase in soybeans (Glycine max (L.) Merril). Plant Physiology, Rockyville, 49: 146-54, 1972.

HECHT-BUCHHOLZ, C. \& SCHUSTER, J. Responses of Al tolerant Dayton and Al-sensitive Kearney barley cultivars to calcium and magnesium during $A l$ stress. In: SYMPOSIUM ON GENETIC ASPECTS OF PLANT MINERAL NUTRITION, 2., Madison, 1985. Genetic aspects of plant nutrition; Proceedings. Dordrecht, Martinus Nijhoff, 1987. p.223-37.

HOWELLER, R.H. \& CADAVID, L.F. Screening of rice cultivars for tolerance to Al-toxicity in nutrient solutions as compared with a field screening method. Agronomy Journal, Madison, 68: 551-5, 1976. 
KAMPRATH, E.J. Exchangeable aluminum as a criterion for liming leached mineral soils. Soil science society of America Proceedings, Madison, 34:252-4, 1970.

KAMPRATH, E.J. Crop response to lime on soils in the tropics. Agronomy Journal, Madison, 12:349-68, 1984 .

KARATAGLIS, S. Aluminum toxicity in Avena sativa cV. Kassandra and a comparison with the toxicity caused by some other metals. Phyton, Horn, 27(1):1-14, 1987.

KELTJENS, W.G. Short-term effects of Al on nutrient uptake, $\mathrm{H}^{+}$efflux, root respiration and nitrate reductase activity of two sorghum genotypes differing in Al-susceptibility. Communication in Soil Science and Plant Analysis, New York, $19(7 / 12): 1155-63,1988$.

KLIMOV, S.V. Interaction of stress factors: intensification of drought action on plants when $\mathrm{Al}^{\prime \prime}$ is present in the medium. Soviet Plant Physiology, New York, 32(3):423-8, 1985.

KLIMOV, S.V.; VLASENKO, N.M.; RYBAKOVA, M. I. Evaluation of the resistance of spring cereals to some soil stresses. Moscou, Nechernozem'ya, p.155-64. 1985. Apud Field Crops Abstracts.,Farnhan Royal, 41(1):93, 1988 (Resumo).

KYLIN, A. \& KAHR, M. The effect of magnesium and calcium ions on adenosine triphosphatases from wheat and oat roots at different pH. Physiologia Plantarum, Copenhagen, $28: 452-7,1973$. 
LAFEVER, H.N.; CAMPBELL, L.C.; FOY, C.D. Differential reponse of wheat cultivars to Al. Agronomy Journal, Madison, 69:563-8, 1977 .

LARKIN, P. J. Calmodulin levels are not responsible for aluminum tolerance in wheat. Australian Journal of Plant Physiology, East Melbourne, 14:377-85, 1987.

LEMOS FILHO, J.P. Efeito do alumínio sobre os teores de alguns elementos minerais, sobre a fotossintese e sobre a atividade de certas oxidases em sorgo (Sorghum bicolor L. Moench). Viçosa, 1981. 46p. (Mestrado-Universidade Federal de Viçosa).

LILLO, C. \& HENDRIKSEN, A. Comparative studies of diurnal variations of nitrate reductase activity in wheat, oat and barley. Physiologia Plantarum, Copenhagen, 62:89-94, 1984 .

LOCKHART, J.A.R. \& WISEMAN, A.J.L. SOIls. In: Crop husbandry. New York, Pergamon Press, 1975. p. 33-90.

LONG, F.L.; LANGDALE, G.W.; MYHRE, D.L. Response of an Altolerant and $A l$-sensitive genotype to lime, $P$ and $K$ on three Atlantic Coast Flatwoods soils. Agronomy Journal, Madison, 65(1):30-4, 1973 .

MALAVOLTA, E. Reação do solo e crescimento das plantas. In: SEMINÁRIO SOBRE CORRETIVOS AGRICOLAS, Piracicaba, 1983. Trabalhos apresentados, coord. por E. Malavolta Campinas, Fundaçăo Cargill, 1985. p. 3-64. 
MARTINI, J.A.; KOCHHANN, R.A.; GOMES, E.P.; LANGER, F. Response of wheat cultivars to liming in some high $A$ oxisols of Rio Grande do Sul, Brazil. Agronomy Journal, Madison, 69:612-6, 1977 .

MARSCHNER, H. Mineral nutrition of higher plants. London, Academic Press, 1986. 674p.

MATSUMOTO, H.; HIRSAWA, F.; MORIMURA, S.; TAKAHASHI. E. LOcalization of aluminum in tea leaves. Plant cell Physiology, Kyoto, $17: 890-5,1976$.

MCLEAN, F.T. \& GILBERT, B.E. The relative aluminum tolerance of crop plants. Soil science, Baltimore, 24:163-75, 1927 .

MESDAG, I.; SLOOTMAKER, I.A.J.; POST Jr, J. Linkage between tolerance to high soil acidity and genetically high protein content in the kernel of wheat (Triticum aestivum L.) and its possible use on breeding. Euphytica, Dordrecht, $19: 163-74,1970$.

MESDAG, J. \& BALKEMA-BOOMSTRA, A.G. Varietal differences for reaction to high soil acidity and to trace elements: a survey of research in the Netherlands. Fertilizer Research, Hague, 5:213-33, 1984 .

METCALFE, D. S。 \& ELKINS, D.M. Avena, cevada e arroz. In: - Produccion de cosechas; fundamentos y practicas. Madrid, Limusa, 1987. p.537-71. 
MINELIA, E. Aluminum tolerance in barley: inheritance, chromosome location, genetic relationship of sources of diverse origins and breeding implications. Ithaca, 1989. 70p. (Ph.D. Cornell University).

MOHR, W.A. A influência da acidez sobre a fertilidade dos solos. In: CONGRESSO NACIONAL DE CONSERVAÇÃO DE SOLOS, 1., Săo Paulo, 1960. Anais Săo Paulo, s.ed., s.d.

MOORE, D.P.; KRONSTAD, W.E.; METZGER,R.J. Screening wheat for aluminum tolerance. In: WORKSHOP ON PLANT ADAPTATION TO MINERAL STRESS IN PROBLEM SOILS, Beltsville, 1976. Plant adaptation to mineral stress in problem soils; proceedings, edited by M.J. Wright and S.A. Ferrari. Ithaca, Cornell University, 1976. p.287-95.

MUGWIRA, L.M. Growth and $\mathrm{Ca}, \mathrm{Mg}, \mathrm{K}$ and $\mathrm{P}$ uptake by triticale, wheat and rye at four Al levels. Journal of plant Nutrition, New York, 2:591-606, 1980.

MUGWIRA, I.M. \& ELGAWHARY, S. M. Aluminium accumulation and tolerance of triticale and wheat in relation to root cation exchange capacity. Soil Science Society of America Journal, Madison, 32: 179-88, 1979.

MUGWIRA, I.M.; ELGAWHARY, S.M.; PATEL, K.I. Differential tolerances of triticale, wheat, rye and barley to aluminum in nutrient solution. Agronomy Journal, Madison, $68: 782-7,1976$. 
MUGWIRA, L.M.; SAPRA, V.T.; PATEL, S.U.; CHOLANDRY, M.A. Aluminum tolerance of triticale and wheat cultivars developed in different regions. Agronomy Journal, Madison, $73: 470-5,1981$.

NUERNBERG, N. J.; BISSANI, C. A.; CAMPBEL, T. A.; FOY, C. D. screening pasture plants for aluminum tolerance. In: SYMPOSIUM ON GENETIC ASPECTS OF PLANT MINERAL NUTRITION, 2., Madison, 1985. Genetic aspects of plant mineral nutrition; proceedings. Dordrecht, Martinus Nijhoff, 1987 p. 345-53.

OJIMA, K. \& OHIRA, K. Aluminium - tolerance and citric acid release from a stress - selected cell lin of carrot. Communication in Soil Science and Plant Analysis, New York, 19: 1229-36, 1988.

OTSUKA, K. Aluminum and manganese toxicities for plants. 2 . Effect of aluminum on growth of barley, wheat, oat and rye seedlings. Journal Science Soil Manure, 39(10):469-74, 1968. Apud Field Crops Abstracts, Farnhan Royal, $23(2): 192$, 1970. (Resumo).

OTSUKA, K. Aluminum induced iron clorosis. IV. Aluminum and manganese toxicities for plants. Soil science and Plant Nutrition, Tokyo, 16:140, 1970 .

PAVAN, M.A. \& BINGHAN, F.T. Toxicity of aluminium to coffee seedlings grown in nutrient solution. Soil Science Society of America Journal, Madison, 46:993-7, 1982. 
PIERRE,.W.H.: MEISINGER,J.: BIRCHETT,J.R. Cation-anion balance in crops as a factor in determining the effect of nitrogen fertilizers on soil acidity. Agronomy Journal, Madison, $62: 106-12,1970$.

PIMENTA, J.A.; CAMBRAIA, J.; SANT'ANA, R.; ESTEVAO, M.M. Efeito do alumínio sobre algumas enzimas ligadas a assimilaçăo do nitrogênio no sorgo. In: REUNIAO BRASILEIRA DE FISIOLOGIA VEGETAL, 1. Londrina, 1987. Resumos. Londrina, SBFV, 1987. p.22.

PIRSON, A. Functional aspects in mineral nutrition in green plants. Annual Review of Plant Physiology, Palo Alto, $6: 71-114,1955$.

QUELLETTE, E.J. \& DESSUREAUX, L. Chemical composition of alfalfa as related to degree of tolerance to manganese and aluminium. Canadian Journal of Soil Science, Ottawa, $38: 206-14,1958$.

RAGLAND, J.L. \& COLEMAN, N.T. The hydrolysis of aluminum salts in clay and soil systems. Soil science society of Ameríca Proceedings, Madison, 24:457-60, 1960.

REID, D.A., Genetic potentials for solving problems of soil mineral stress: aluminum and manganese toxicities in the cereal grains. In: WORKSHOP ON PLANT ADAPTATION TO MINERAL STRESS IN PROBLEM SOILS, Beltsville, 1976. Plant adaptation to mineral. stress in problem soils; proceedings, edited by M.J. Wright and S.A. Ferrari. Ithaca, Cornell University, 1976. p.22-3 
REID, D.A.; FLEMING, A.L.; FOY, C.D. A method for determining aluminum response of barley in nutrient solution in comparison to response in Al-toxic soil. Agronomy Journal, Madison, 63:600-3, 1971 .

RHUE, R.D. Differential aluminum tolerance in crop plants. In: MUSSEL, H. \& STAPLES, R.C. Stress physiology in crop plants. New York, Willey \& Sons, 1979. p.61-80.

RHUE, R.D. \& GROGAN, C.O. Screening corn for Al tolerance using different $\mathrm{Ca}$ and $\mathrm{Mg}$ concentrations.

Agronomy Journal, Madison, 69(5):755-60, 1977.

ROY, K.A.; SHARMA, A.; TALUKDER, G. SOme aspects of aluminum toxicity in plants. The Botanical Review, Bronx, 54(1): $145-78,1988$.

SARRUGE, J.R. \& HAAG, H.P. Análises químicas em plantas. Piracicaba,ESALQ, 1974. 55p.

SARTAIN, J.B. \& KAMPRATH, E.J. Aluminum tolerance of soybean cultivars based on root elongation in solution culture compared with growth in acid soil. Agronomy Journal, Madison, 70:17-20, 1978 .

SCHRADER, L.E. Critique of factors influencing nitrate acquisition by plants: assimilation and fate of reduced nitrogen. In: NIELSEN, D.R. \& MACDONALD, J.G. Nitrogem in the environment. New York, Academic Press, 1978. v.2, p. 101-41. 
SAUVESTRY, A. \& GENDRON, G. Influence de la fertilisation azotée sur Lactivité nitrate réductase et la teneur en protéines de trois varietés davaine. Canadian Journal of Plant Science, Otawa, 67(2):373-83, 1987.

SIQUEIRA, O.J.F., eã. Recomendaçōes de adubaçăo e calagem para os Estados do Rio Grande do Sul e Santa Catarina. Passo Fundo, EMBRAPA-CNPT, 1987. 100p.

TANAKA, A. \& NAVASERO, S.A. Aluminum toxicity of the rice plant under culture conditions. Soil science and plants Nutrition, Tokyo, 12:9-14, 1966.

TANAKA, A.; HITSUDA, K.; TSUCHIHASHI, Y. Tolerance to low pH and low available phosphorus of various field and forage crops. Soil Science and Plant Nutrition, Tokyo, 30(1):3949,1984 .

TAYLOR, G.J. The physiology of aluminum tolerance in higher plants. Communications in Soil Science and Plant Analysis, New York, 19(7/12):1179-94, 1988.

TAYLOR, G.J. \& FOY, C.D. Mechanism of aluminum tolerance in Triticum aestivum L. 2. (Wheat). I. Differential pH induced by winter cultivars in nutrient solutions. American Journal of Botany. Baltimore, 72:695-701. 1985.

THOMAS, G.W. \& HARGROVE, W.L. The chemistryof soil acidity. In : Soil acidity and liming. Madison Soil Science Society of America, 1984. p.3-56. 
THOMPSON, L.M. Soils and soil Eertility. 2.ed. New York, MeGraw Hill, 1957. $136 \mathrm{p}$.

VIDOR, C. Toxidez de alumínio e manganês e suas relaçớes com nodulação e absorção de manganês por Glycine max (L.) Merril. Porto Alegre, 1972. 71p. (Mestrado - Faculdade de Agronomia/UFRGS) .

VOSE, P.B. Screening techniques for plant nutrient efficiency: philosophy and methods. In: In: SYMPOSIUM ON GENETIC ASPECTS OF PLANT MINERAL NUTRITION, 2., Madison, 1985. Genetic aspects of plant mineral nutrition; proceedings. Dordrecht, Martinus Nijhoff, 1987. p.283-9.

WAGATSUMA, T. Characterization of absorpticn sites for aluminum in the roots. Soil science and Plant Nutrition, Tokyo, 29(4):499-515, 1983a.

WAGATSUMA, T. Effect of non-metabolic conaitions on the uptake of aluminum by plant roots. Soil science and plant Nutrition, Tokyo, $29(3): 223-33,1983 b$.

WAGATSUMA, T. \& AKIBA, R. Low surface negativity of root protoplasts from aluminum-tolerant plant species. Soil Science and Plant Nutrition, Tokio, 35(3):443-52, 1989.

WAGATSUMA, T. \& EZOE, $Y$. Effect of $\mathrm{pH}$ on ionic species of aluminum in medium and on aluminum toxicity under solution culture. Soil Science and Plant Nutrition, Tokyo, $31(4): 547-61,1985$.

WAGATSUMA, T. \& KANEKO, M. High toxicity of hidroxy-aluminum polymer ions to plant roots. Soil science and Plant Nutrition, Tokyo, 33(1):57-67, 1987. 
WAGATSUMA, T. \& YAMASAKU, K. Relationship between differential aluminum tolerance and plant-induced $\mathrm{pH}$ change of medium among barley cultivars. Soil science and plant Nutrition, Tokyo, 31(4):521-35, 1985.

WAGATSUMA, T.; KANEKO, M.; HAYASAKA, Y. Destruction process of plant root cells by aluminum. Soil science and Plant Nutrition, Tokyo, 33:161-75,1987.

WAGATSUMA, T.; KAWASHIMA, T.; TAWARAYA, K. Comparative stainability of plant root cells with basic dye (Methylene blue) in association with aluminum tolerance. Communications in Soil Science and Plant Analysis, New York, 19(7/12):1207-15, 1988 .

WRIGHT, K.E. Internal precipitation of phosphorus in relation to aluminum toxicity. Plant physiology, Rockvilie, $18: 708-12,1943$. 


\section{APENDICE A}

Tabela Al. Identificação e genealogia/cruzamento dos genótipos de aveia branca (Avena sativa L.) avaliados quanto a reaçăo ao alumínio, em soluçăo nutritiva.

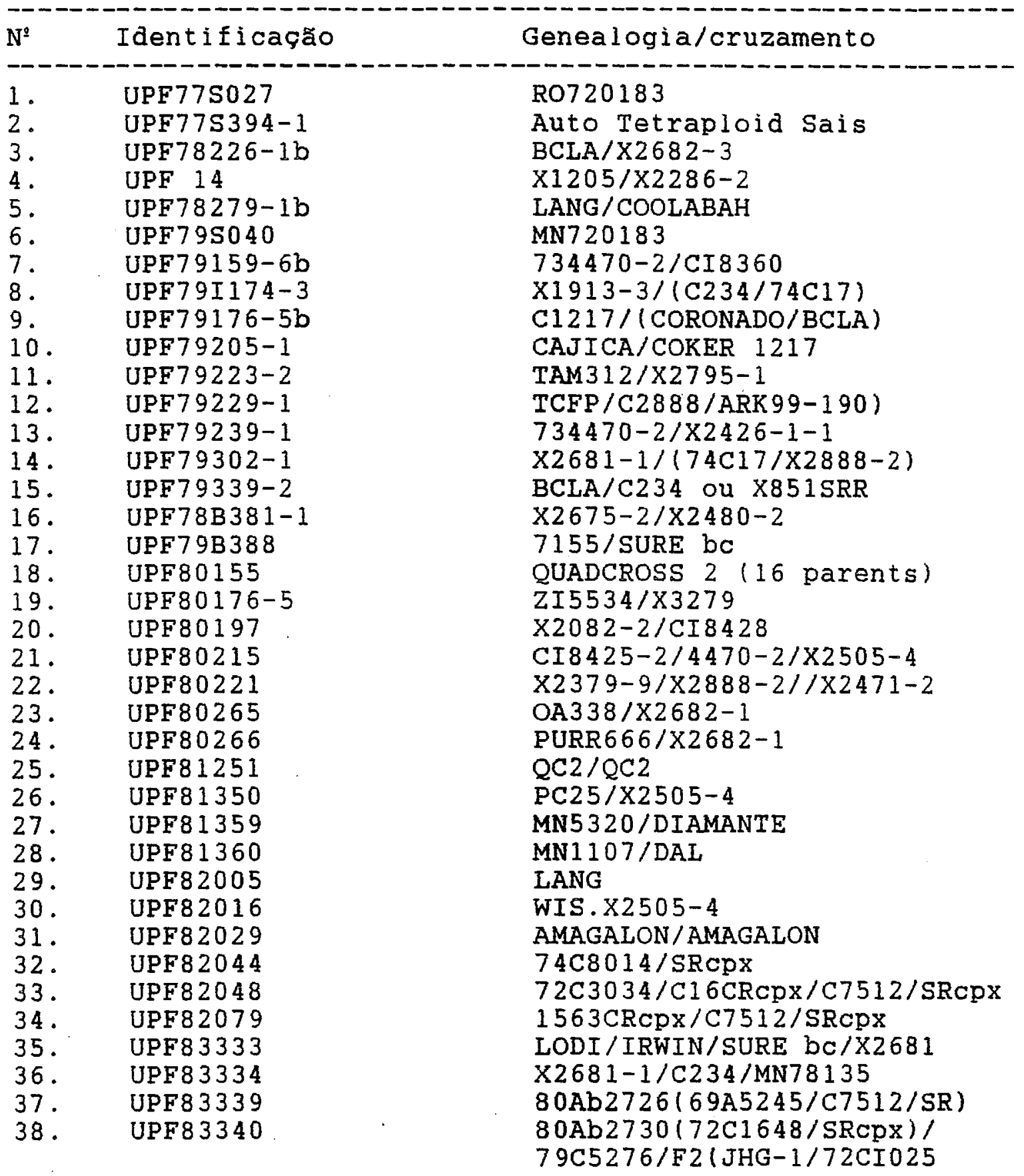


Cont inuaçăo.

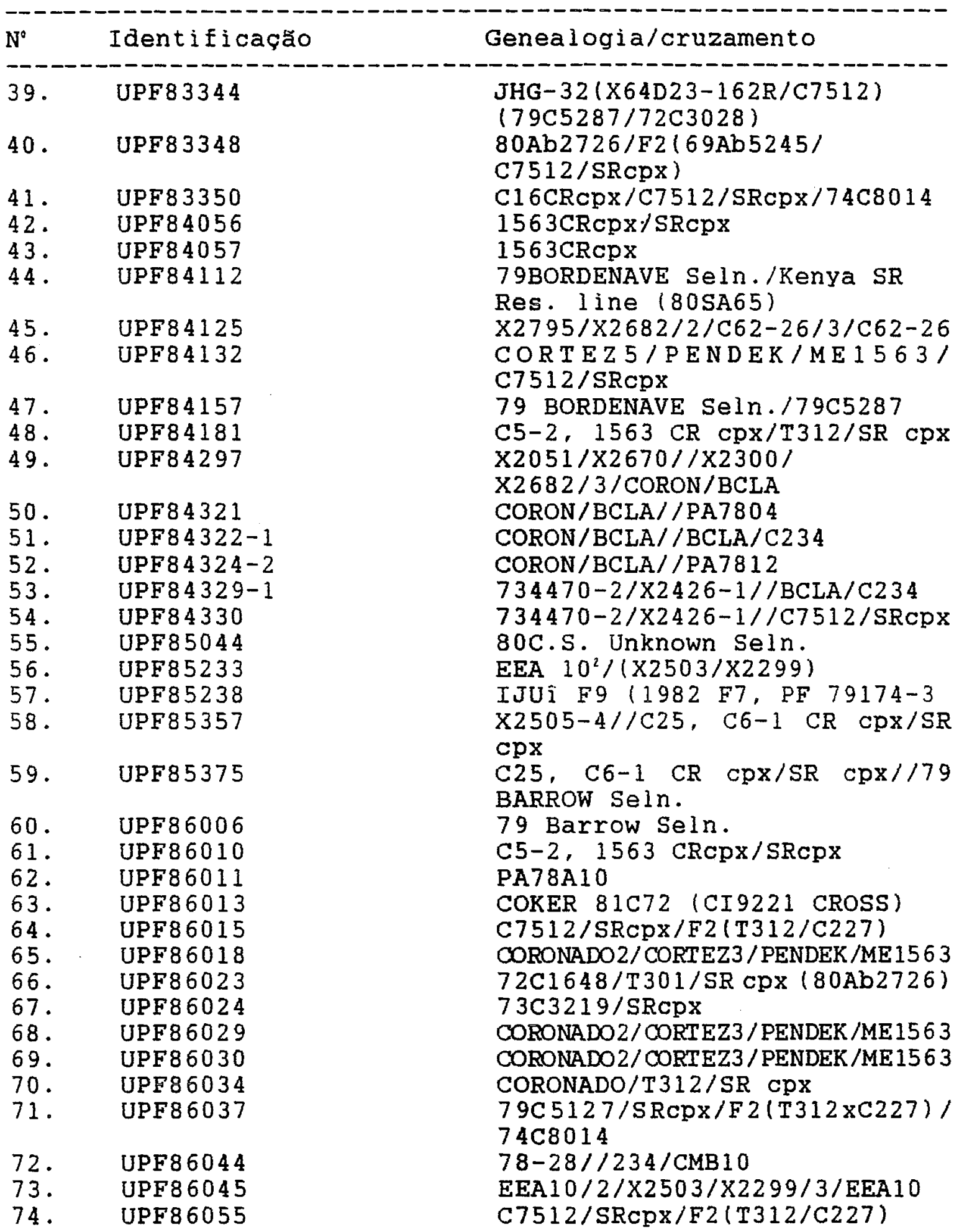


Cont inuação.

\begin{tabular}{|c|c|c|}
\hline $\mathbf{N}^{0}$ & Identificaçăo & Genealogia/cruzamento \\
\hline $\begin{array}{l}75 . \\
76 . \\
77 . \\
78 .\end{array}$ & $\begin{array}{l}\text { UPF } 86066 \\
\text { UPF } 86067 \\
\text { UPF } 86068 \\
\text { UPF } 86081\end{array}$ & $\begin{array}{l}\text { CORONADO2/CORTEZ3/PENDEK/ME1563 } \\
\text { C7512/SRCpX } \\
\text { C5-2, 1563 CR CPX/T312/SRCpx } \\
\text { CORTEZ5/PENDEK/MEI563/ } \\
\text { C7512/SRCpX }\end{array}$ \\
\hline 79. & UPF 86083 & $\begin{array}{l}\text { CORTEZ3/PENDEK/C16CRCpX/C7512/ } \\
\text { SRCpx/74C8014 }\end{array}$ \\
\hline $\begin{array}{l}80 . \\
81 .\end{array}$ & $\begin{array}{l}\text { UPF } 86094 \\
\text { UPF } 86110\end{array}$ & $\begin{array}{l}\text { CORONADO2/CORTEZ3/pendek/me } 1563 \\
\text { DON }\end{array}$ \\
\hline 82. & UPF 86111 & HAZEL \\
\hline 83. & UPF 86112 & STEELE \\
\hline 84 . & UPF 86113 & PORTER \\
\hline 85 . & UPF8 6120 & COKER 85A85 \\
\hline $\begin{array}{l}86 . \\
87 .\end{array}$ & $\begin{array}{l}\text { UPF } 86134 \\
\text { UPF } 86136\end{array}$ & $\begin{array}{l}\text { UFRGS841028 sel. } 2 \\
\text { UPF79331-1 (UPF-10) }\end{array}$ \\
\hline 88. & UPF 86139 & UPF 78227-1 \\
\hline 89. & UPF 86155 & $\begin{array}{l}79 \text { BORDENAVE Selection/Kenya SR } \\
\text { resistance }\end{array}$ \\
\hline $\begin{array}{l}90 . \\
91 .\end{array}$ & $\begin{array}{l}\text { UPF8 } 6160 \\
\text { UPF8 } 6169-2 b\end{array}$ & $\begin{array}{l}\text { COKER } 62-26 / \text { EEA10//X2503/X2299 } \\
\text { QR305=Coker } 82-33 / / \text { C5-2, } 1563 \\
\text { CRCpX/SRcpx }\end{array}$ \\
\hline $\begin{array}{l}92 . \\
93 .\end{array}$ & $\begin{array}{l}\text { UPF } 15 \\
\text { UPF } 8 \text { 6Al } 198-5-1 b\end{array}$ & $\begin{array}{l}\text { QR 306 =COKER82-33//IL3376/OA338 } \\
\text { QR336=X2051-6/X1913-3/3/DC9/ } \\
\text { Coker } 74 \text { C17/OTEE }\end{array}$ \\
\hline 94. & UPF 8 6AI198-5-4b & $\begin{array}{l}\text { QR336=X2051-6/X1913-3/3/DC9// } \\
\text { Coker 74C17/OTEE }\end{array}$ \\
\hline 95. & UPF 86212 & $\begin{array}{l}\text { QR3 } 51=C 7620 / / \mathrm{BCLA} / \mathrm{C} 234 / 3 / \\
\text { CORONADO } 2 / \text { CORTEZ3/PENDEK/ME1563 }\end{array}$ \\
\hline 96 . & UPF 86238 & $\begin{array}{l}\text { QR383=IL5680//X2300/CI2332/3/ } \\
\text { IL5680/4/IL79-1178 }\end{array}$ \\
\hline 97. & UPF 86243-2 & $\begin{array}{l}\text { QR } 389=\text { I N } 73-109 / \text { P C } 25 / \\
\text { CORONADO/XI } 779-2 / \text { Selection } 11 \\
\text { Passo Fundo }\end{array}$ \\
\hline 98. & UPF $86 \mathrm{~A} 1264-1 \mathrm{~b}$ & $\begin{array}{l}\mathrm{QR} 414=\mathrm{C} 234 / 74 \mathrm{C} 70 / \mathrm{C} 234 / \mathrm{CMB} 10 / \\
3 / \mathrm{C} 5-2,1563 \mathrm{CR} \mathrm{Cpx} / \mathrm{SR} \mathrm{Cpx}\end{array}$ \\
\hline 99. & UPF 8 6A1264-10b & $\begin{array}{l}\mathrm{QR} 414=\mathrm{C} 234 / 74 \mathrm{C} 70 / / \mathrm{C} 234 / \mathrm{CMBIO} / \\
3 / \mathrm{C} 5-2,1563 \mathrm{CR} \mathrm{cpx} / \mathrm{SR} \mathrm{cpx}\end{array}$ \\
\hline 100 . & UPF 8 6A1264-7-4b & $\begin{array}{l}\mathrm{QR414}=\mathrm{C} 234 / 74 \mathrm{C} 70 / / \mathrm{C} 234 / \mathrm{CMB} 10 / \\
3 / \mathrm{C} 5-2,1563 \mathrm{CR} \mathrm{Cpx} / \mathrm{SR} \mathrm{Cpx}\end{array}$ \\
\hline 101. & UPF $86 A 1264-1-4 \mathrm{~b}$ & $\begin{array}{l}\text { QR } 414=C 234 / 74 \mathrm{C} 70 / / \mathrm{C} 234 / \\
\mathrm{CMB} 10 / 3 / \mathrm{C} 5-2, \mathrm{CR} 3 \mathrm{CR} \mathrm{cPx} / \mathrm{SR} \mathrm{cPx}\end{array}$ \\
\hline 102. & UPF $86 \mathrm{Al} 264-1-1 \mathrm{~b}$ & $\begin{array}{l}\mathrm{QR} 414=\mathrm{C} 234 / 74 \mathrm{C} 70 / / \mathrm{C} 234 / \mathrm{CMB} 10 / \\
3 / \mathrm{C} 5-2,1563 \mathrm{CR} \mathrm{cpx} / \mathrm{SR} \mathrm{cpx}\end{array}$ \\
\hline
\end{tabular}


Cont inuação.

\begin{tabular}{|c|c|c|}
\hline $\mathrm{N}^{0}$ & Identificação & Genealogia/cruzamento \\
\hline 103. & UPF $86 A 1264-2-7 b$ & $\begin{array}{l}\text { QR } 414=\mathrm{C} 234 / 74 \mathrm{C} 70 / / \mathrm{C} 234 / \mathrm{CMB} 10 / \\
3 / \mathrm{C} 5-2,1563 \mathrm{CR} \mathrm{Cpx} / \mathrm{SR} \mathrm{cpx}\end{array}$ \\
\hline 104. & UPF $86 \mathrm{Al} 264-7-8 \mathrm{~b}$ & $\begin{array}{l}\mathrm{QR} 414=\mathrm{C} 234 / 74 \mathrm{C} 70 / / \mathrm{C} 234 / \mathrm{CMB} 10 / \\
3 / \mathrm{C} 5-2,1563 \mathrm{CR} \mathrm{cpx} / \mathrm{SR} \mathrm{cpx}\end{array}$ \\
\hline 105. & UPF $86 A 1264-10-2 b$ & $\begin{array}{l}\text { QR4 } 14=\mathrm{C} 234 / 74 C 70 / / \mathrm{C} 234 / \mathrm{CMB} 10 / \\
3 / \mathrm{C} 5-2,1563 \mathrm{CR} \mathrm{Cpx} / \mathrm{SR} \mathrm{Cpx}\end{array}$ \\
\hline 106. & UPF8 $6301-1$ & Desconhecido \\
\hline & UPF87069 & OT212/R13064 \\
\hline 108. & UPF 87070 & OT $224 / W 78181$ \\
\hline 109. & UPF87071 & M921/OT 224 \\
\hline 110 . & UPF 87072 & CI $4492 / O T 224$ \\
\hline 111. & UPF8 7097 & ND8 10104 \\
\hline 112 . & UPF8 7107 & 78SA17/C7512/SRcpx \\
\hline 113. & UPF87111 & CORONADO 2/CORTEZ3/PENDEK /ME1563 \\
\hline 114 & UPF87126 & QR106-1=DC9//COKER 84C17/OTEE \\
\hline 115 & UPF87127 & X3 308/CAN $615 /($ CORONADO /X1779) 2 \\
\hline $\begin{array}{l}116 \\
117\end{array}$ & $\begin{array}{l}\text { UPF8 } 7128 \\
\text { UPF8 } 8130\end{array}$ & $\begin{array}{l}\text { X2795-2/X2682-3/COKER } 62-262 \\
\text { X2795-2/X2682-3/Coker } 62-26 \\
\text { 2/Ijuíf8 }\end{array}$ \\
\hline 118. & UPF87133 & QR102-1=Coker $234 /$ Reyes \\
\hline & UPF 87137 & Coker $86-8$ \\
\hline & UPF88109 & $\begin{array}{l}\text { C 7 } 5-12 / \mathrm{SR} \text { C } \mathrm{p} \times / \mathrm{CR} \mathrm{p} \times / \\
\mathrm{F} 2(\mathrm{~T} 312 / \mathrm{C} 234)\end{array}$ \\
\hline 21. & UPF 89085 & $\mathrm{C} 5-2, \quad 1563 \quad \mathrm{CR} \quad \mathrm{Cpx} / \mathrm{SR}$ \\
\hline & & cpx/Unknown \\
\hline 122. & UPF89106 & $\begin{array}{l}\text { 82C1524/80AB2726/8025/8014/ } \\
\mathrm{CRcpx/SRcpx/JHG-8}\end{array}$ \\
\hline 123. & UPF 89130 & $\begin{array}{l}\text { GUAIBA ENT.9 sel./80AB2726/ } \\
\text { CRCpx/SRCpx/8025/8014/Borrow/ } \\
1563 \text { CRCpx }\end{array}$ \\
\hline 124. & СТC82B312 & - \\
\hline 125. & CTC82B 307 & - \\
\hline 126. & CTC82B 47.7 & - \\
\hline 127. & CTC84B1153 & - \\
\hline 128. & CTC84B1412-3 & - \\
\hline 129. & CTC84B1415-3 & - \\
\hline 130. & $\mathrm{UPF}-1$ & $x 63-46(113)$ \\
\hline 131. & UPF -2 & $\times 2505-4$ \\
\hline 132. & $U P F-3$ & Coronado / X1779-2 \\
\hline 133. & $U P F-4$ & $\times 2055-1$ \\
\hline 134 & UPF -5 & X2185-1/IL1514 \\
\hline & UPF -6 & Coker 1214/ Lang \\
\hline 136 & UPF -7 & TCFP/ X2502-1 \\
\hline & UPF-8 & X2505/Otee \\
\hline
\end{tabular}


Cont inuação.

\begin{tabular}{|c|c|c|}
\hline $\mathrm{N}^{\circ}$ & Identificação & Genealogia/cruzamento \\
\hline $\begin{array}{l}138 . \\
139 . \\
140 . \\
141 . \\
142 . \\
143 . \\
144 . \\
145 . \\
146 . \\
147 . \\
148 . \\
149 . \\
150 . \\
151 . \\
152 . \\
153 . \\
154 . \\
155 . \\
156 .\end{array}$ & $\begin{array}{l}\text { UPF-9 } \\
\text { UPF-10 } \\
\text { UPF-11 } \\
\text { UPF-12 } \\
\text { UPF-13 } \\
\text { UFRGS-1 } \\
\text { UFRGS-2 } \\
\text { UFRGS-4 } \\
\text { UFRGS-5 } \\
\text { UFRGS-6 } \\
\text { UFRGS-7 } \\
\text { UFRGS-8 } \\
\text { UFRGS-9 } \\
\text { UFRGS-10 } \\
\text { UFRGS-11 } \\
\text { UFRGS-12 } \\
\text { CORONADO } \\
\text { SUREGRAIN } \\
\text { SÃO CARLOS }\end{array}$ & 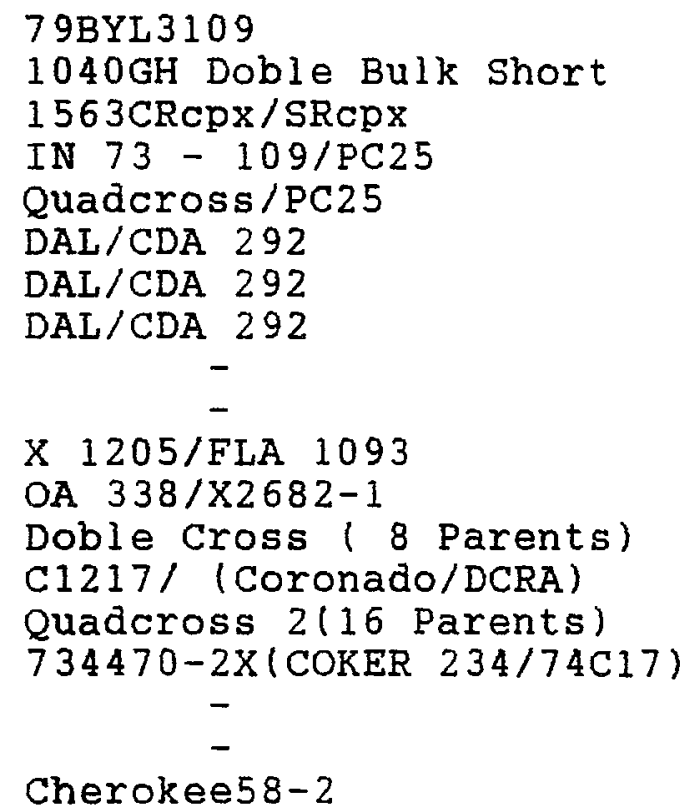 \\
\hline
\end{tabular}


Quadro $A 2$ : Identificaçăo e Genealogia de genótipos de aveias pretas (Avena strigosa Schreb) avaliadas quanto a reação ao aluminio, em soluçăo nutritiva.

No. Identificaçăo

Genealogia/Cruzamento

$1 \quad$ UPF775066

2 UPF775352

3 UPF775434

$4 \quad$ UPF77S436

$5 \quad$ UPF77S456

6 UPF78S101

7 UPF $84 A P 01$

8 UPF845005

9 UPF 85AP0 1

10 UPF87AP01

11 UPF87AP02

PI244471

K2588 / URSS

CD 3820

CD7847(CI9035)

FLA7001153

CI3815

Desconhecida

CI 9020

Desconhecida

Desconhecida

12 Aveia Preta Comum

Desconhecida

13 Aveia Preta Argentina

Desconhecida

14 GR 9

Desconhecida

Desconhecida 


\section{APÊNDICE B}

Tabela Bl: Controle da temperatura e umidade relativa da câmara de crescimento na avaliaçăo da concentraçăo de alumínio para a classificação de aveia branca.

\begin{tabular}{|c|c|c|c|c|c|c|}
\hline & Min. & Máx. & Médi a & Min. & Máx. & Média \\
\hline $\begin{array}{l}23 / 4 \\
24 / 4 \\
25 / 4 \\
26 / 4 \\
27 / 4 \\
28 / 4 \\
29 / 4 \\
30 / 4 \\
01 / 5 \\
02 / 5 \\
03 / 5\end{array}$ & $\begin{array}{l}20,8 \\
20,8 \\
20,6 \\
20,0 \\
20,0 \\
21,0 \\
21,0 \\
20,8 \\
20,8 \\
20,8 \\
20,2\end{array}$ & $\begin{array}{l}31,8 \\
31,2 \\
28,2 \\
29,4 \\
29,4 \\
29,6 \\
29,0 \\
28,0 \\
28,0 \\
27,6 \\
27,8\end{array}$ & $\begin{array}{l}26,3 \\
26,0 \\
24,4 \\
24,7 \\
24,7 \\
25,3 \\
25,0 \\
24,4 \\
24,4 \\
24,2 \\
24,0\end{array}$ & $\begin{array}{l}50 \\
50 \\
51 \\
48 \\
51 \\
48 \\
46 \\
46 \\
49 \\
49 \\
50\end{array}$ & $\begin{array}{l}95 \\
96 \\
98 \\
96 \\
96 \\
96 \\
95 \\
95 \\
98 \\
97 \\
98\end{array}$ & $\begin{array}{l}73 \\
73 \\
73 \\
72 \\
74 \\
72 \\
71 \\
71 \\
74 \\
73 \\
74\end{array}$ \\
\hline $\begin{array}{l}\text { Média } \\
\text { sd } \\
\text { CV }(\text { 망) }\end{array}$ & $\begin{array}{r}20,62 \\
0,36 \\
1,73\end{array}$ & $\begin{array}{r}29,09 \\
1,32 \\
4,55\end{array}$ & $\begin{array}{r}24,85 \\
0,70 \\
2,83\end{array}$ & $\begin{array}{r}48,91 \\
1,68 \\
3,43\end{array}$ & $\begin{array}{r}96,36 \\
1,15 \\
1,19\end{array}$ & $\begin{array}{r}72,73 \\
1,05 \\
1,45\end{array}$ \\
\hline
\end{tabular}


Tabela B2: Variação da temperatura e umidade relativa na câmara de crescimento.

\begin{tabular}{|c|c|c|c|c|c|c|}
\hline \multirow[b]{2}{*}{ Dias } & \multicolumn{3}{|c|}{ Temperatura $\left({ }^{\circ} \mathrm{C}\right)$} & \multicolumn{3}{|c|}{ Umidade relativa (웅 } \\
\hline & Máx. & Mín. & Média & Mín. & Máx & Médìa \\
\hline \multicolumn{7}{|c|}{ Experimento 2} \\
\hline $\begin{array}{l}1 \\
2 \\
3 \\
4 \\
5 \\
6 \\
7 \\
8 \\
9 \\
10 \\
11\end{array}$ & $\begin{array}{l}31,8 \\
32,4 \\
31,8 \\
30,6 \\
30,2 \\
30,0 \\
31,0 \\
30,2 \\
30,0 \\
30,2 \\
32,8\end{array}$ & $\begin{array}{l}21,8 \\
21,8 \\
21,8 \\
21,4 \\
21,4 \\
21,4 \\
21,2 \\
21,9 \\
21,0 \\
21,2 \\
21,0\end{array}$ & $\begin{array}{l}26,8 \\
27,1 \\
26,8 \\
26,0 \\
25,8 \\
25,7 \\
26,1 \\
26,1 \\
26,0 \\
25,7 \\
26,9\end{array}$ & $\begin{array}{l}38 \\
42 \\
45 \\
46 \\
45 \\
46 \\
48 \\
49 \\
48 \\
50 \\
45\end{array}$ & $\begin{array}{l}90 \\
93 \\
93 \\
95 \\
94 \\
95 \\
95 \\
98 \\
97 \\
97 \\
96\end{array}$ & $\begin{array}{l}64 \\
68 \\
69 \\
71 \\
70 \\
71 \\
72 \\
74 \\
73 \\
74 \\
71\end{array}$ \\
\hline $\begin{array}{l}\text { Média } \\
\text { sd } \\
\text { C.V. ( } 8)\end{array}$ & $\begin{array}{r}31,00 \\
0,98 \\
3,16\end{array}$ & $\begin{array}{r}21,45 \\
0,32 \\
1,48\end{array}$ & $\begin{array}{r}26,27 \\
0,50 \\
1,89\end{array}$ & $\begin{array}{r}45,6 \\
3,2 \\
7,0\end{array}$ & $\begin{array}{r}94 \\
2, \\
2\end{array}$ & $\begin{array}{r}70.64 \\
2.77 \\
3.92\end{array}$ \\
\hline
\end{tabular}

Experimento $3-\mathrm{A}$

\begin{tabular}{lcccccc}
1 & 31,9 & 20,8 & 26,4 & 48 & 94 & 71 \\
2 & 32,2 & 20,8 & 26,5 & 48 & 94 & 71 \\
3 & 32,0 & 20,8 & 26,4 & 40 & 89 & 65 \\
4 & 31,2 & 21,2 & 26,2 & 44 & 95 & 70 \\
5 & 31,0 & 21,2 & 26,1 & 44 & 93 & 69 \\
6 & 31,2 & 21,4 & 26,3 & 43 & 90 & 67 \\
7 & 31,2 & 21,4 & 26,3 & 42 & 91 & 67 \\
8 & 31,0 & 21,6 & 26,3 & 48 & 95 & 72 \\
9 & 31,0 & 22,2 & 26,6 & 50 & 97 & 74 \\
10 & 32,2 & 22,0 & 27,1 & 45 & 95 & 70 \\
11 & 31,8 & 21,9 & 26,8 & 45 & 85 & 65 \\
\hline Média & 31,52 & 21,39 & 26,45 & 45,18 & 92,55 & 69,18 \\
sd & 0,48 & 0,47 & 0,27 & 2,89 & 3,31 & 2,76 \\
C.V.(8) & 1,51 & 2,21 & 1,04 & 6,39 & 3,58 & 3,99 \\
\hline$-0-10-0$
\end{tabular}


Cont inuaço

Temperatura $\left({ }^{\circ} \mathrm{C}\right)$

Dias

Máx.

Mín.

Média Mín.

Umidade relativa ( 8$)$

\begin{tabular}{|c|c|c|c|c|c|c|}
\hline \multicolumn{7}{|c|}{ Experimento $3-B$} \\
\hline $\begin{array}{l}1 \\
2 \\
3 \\
4 \\
5 \\
6 \\
7 \\
8 \\
9 \\
10 \\
11\end{array}$ & $\begin{array}{l}32,0 \\
32,2 \\
31,2 \\
31,0 \\
31,2 \\
31,2 \\
31,0 \\
31,0 \\
32,2 \\
31,8 \\
32,0\end{array}$ & $\begin{array}{l}20,8 \\
20,8 \\
21,2 \\
21,2 \\
21,4 \\
21,4 \\
21,6 \\
22,2 \\
22,0 \\
21,9 \\
21,5\end{array}$ & $\begin{array}{l}26,5 \\
26,4 \\
26,2 \\
26,1 \\
26,3 \\
26,3 \\
26,3 \\
26,6 \\
27,1 \\
26,8 \\
26,8\end{array}$ & $\begin{array}{l}48 \\
40 \\
44 \\
44 \\
43 \\
42 \\
48 \\
50 \\
45 \\
45 \\
44\end{array}$ & $\begin{array}{l}94 \\
89 \\
95 \\
93 \\
90 \\
91 \\
95 \\
97 \\
95 \\
85 \\
90\end{array}$ & $\begin{array}{l}71 \\
65 \\
70 \\
69 \\
67 \\
67 \\
72 \\
74 \\
70 \\
65 \\
67\end{array}$ \\
\hline $\begin{array}{l}\text { Média } \\
\text { sd } \\
C V(q)\end{array}$ & $\begin{array}{r}31,53 \\
0,48 \\
1,54\end{array}$ & $\begin{array}{r}21,45 \\
0,43 \\
2,02\end{array}$ & $\begin{array}{r}26,49 \\
0,29 \\
1,10\end{array}$ & $\begin{array}{r}44,82 \\
2,76 \\
6,15\end{array}$ & $\begin{array}{r}92,18 \\
3,35 \\
3,64\end{array}$ & $\begin{array}{r}68,82 \\
2,76 \\
4,01\end{array}$ \\
\hline
\end{tabular}

Experimento $3-\mathrm{C}$

$\begin{array}{lllllll}1 & 32,0 & 20,8 & 26,4 & 40 & 89 & 65 \\ 2 & 31,2 & 21,2 & 26,2 & 44 & 95 & 70 \\ 3 & 31,0 & 21,2 & 26,1 & 44 & 93 & 69 \\ 4 & 31,2 & 21,4 & 26,3 & 43 & 90 & 67 \\ 5 & 31,2 & 21,4 & 26,3 & 42 & 91 & 67 \\ 6 & 31,0 & 21,6 & 26,3 & 48 & 95 & 72 \\ 7 & 31,0 & 22,2 & 26,6 & 50 & 97 & 74 \\ 8 & 32,2 & 22,0 & 27,1 & 45 & 95 & 70 \\ 9 & 31,8 & 21,9 & 26,8 & 45 & 85 & 65 \\ 10 & 32,0 & 21,5 & 26,8 & 44 & 90 & 67 \\ 11 & 32,0 & 21,8 & 26,9 & 46 & 94 & 70\end{array}$

$\begin{array}{lrrrrrr}\text { Média } & 31,51 & 21,55 & 26,53 & 44,64 & 92,18 & 68.73 \\ \text { sd } & 0,46 & 0,38 & 0,31 & 2.60 & 3.35 & 2,70 \\ \text { C.V. }(8) & 1,47 & 1,81 & 1,18 & 5.83 & 3,64 & 3.93\end{array}$




\begin{tabular}{|c|c|c|c|c|c|c|}
\hline Dias & Máx. & Mín. & Média & Mín. & Máx. & Média \\
\hline \multicolumn{7}{|c|}{ Experimento $3-D$} \\
\hline $\begin{array}{l}1 \\
2 \\
3 \\
4 \\
5 \\
6 \\
7 \\
8 \\
9 \\
10 \\
11\end{array}$ & $\begin{array}{l}32,0 \\
32,0 \\
31,8 \\
31,9 \\
32,1 \\
31,8 \\
31,6 \\
31,2 \\
31,4 \\
31,4 \\
32,4\end{array}$ & $\begin{array}{l}21,5 \\
21,8 \\
22,1 \\
22,2 \\
21,9 \\
22,0 \\
21,4 \\
21,0 \\
22,0 \\
21,8 \\
22,0\end{array}$ & $\begin{array}{l}26,8 \\
26,9 \\
27,0 \\
27,0 \\
27,0 \\
26,9 \\
26,5 \\
26,1 \\
26,7 \\
26,6 \\
27,2\end{array}$ & $\begin{array}{l}44 \\
46 \\
42 \\
49 \\
47 \\
48 \\
48 \\
48 \\
49 \\
48 \\
43\end{array}$ & $\begin{array}{l}90 \\
94 \\
90 \\
95 \\
94 \\
94 \\
95 \\
95 \\
95 \\
90 \\
89\end{array}$ & $\begin{array}{l}67 \\
70 \\
66 \\
72 \\
71 \\
71 \\
72 \\
72 \\
72 \\
69 \\
66\end{array}$ \\
\hline $\begin{array}{l}\text { Média } \\
\text { sd } \\
\text { C.V. (o })\end{array}$ & $\begin{array}{r}31,78 \\
0,34 \\
1,06\end{array}$ & $\begin{array}{r}21,79 \\
0,34 \\
1,55\end{array}$ & $\begin{array}{r}26,79 \\
0,29 \\
1,08\end{array}$ & $\begin{array}{r}46,55 \\
2,35 \\
5,05\end{array}$ & $\begin{array}{r}92.82 \\
2,37 \\
2.55\end{array}$ & $\begin{array}{r}69,82 \\
2,33 \\
3,33\end{array}$ \\
\hline
\end{tabular}

Experimento $3-E$

\begin{tabular}{|c|c|c|c|c|c|c|}
\hline $\begin{array}{l}1 \\
2 \\
3 \\
4 \\
5 \\
6 \\
7 \\
8 \\
9 \\
10 \\
11\end{array}$ & $\begin{array}{l}32,0 \\
31,8 \\
31,9 \\
32,1 \\
31,8 \\
31,6 \\
31,2 \\
31,4 \\
31,4 \\
32,4 \\
32,4\end{array}$ & $\begin{array}{l}21,8 \\
22,1 \\
22,2 \\
21,9 \\
22,0 \\
21,4 \\
21,0 \\
22,0 \\
21,8 \\
22,0 \\
21,0\end{array}$ & $\begin{array}{l}26,9 \\
27,0 \\
27,0 \\
27,0 \\
26,9 \\
26,5 \\
26,1 \\
26,7 \\
26,6 \\
27,2 \\
27,2\end{array}$ & $\begin{array}{l}46 \\
42 \\
49 \\
47 \\
48 \\
48 \\
48 \\
49 \\
48 \\
43 \\
40\end{array}$ & $\begin{array}{l}94 \\
90 \\
95 \\
94 \\
94 \\
95 \\
95 \\
95 \\
60 \\
89 \\
90\end{array}$ & $\begin{array}{l}70 \\
66 \\
72 \\
71 \\
71 \\
72 \\
72 \\
72 \\
69 \\
66 \\
65\end{array}$ \\
\hline $\begin{array}{l}\text { Média } \\
\text { sd } \\
\text { C.V. (q })\end{array}$ & $\begin{array}{r}31.82 \\
0.38 \\
1.19\end{array}$ & $\begin{array}{r}21,84 \\
0,33 \\
1,52\end{array}$ & $\begin{array}{r}26,83 \\
0,31 \\
1,17\end{array}$ & $\begin{array}{r}46,18 \\
2,95 \\
6,39\end{array}$ & $\begin{array}{r}92,82 \\
2,37 \\
2,55\end{array}$ & $\begin{array}{r}69,64 \\
2,60 \\
3,74\end{array}$ \\
\hline
\end{tabular}


Cont inuação

Temperatura $\left({ }^{\circ} \mathrm{C}\right)$

Dias

Mín.

Máx.

Média

Umidade relativa $\left(\frac{o}{\gamma}\right)$

Mín.

Máx.

Média

Experimento $3-F$

\begin{tabular}{|c|c|c|c|c|c|c|}
\hline $\begin{array}{l}1 \\
2 \\
3 \\
4 \\
5 \\
6 \\
7 \\
8 \\
9 \\
10 \\
11\end{array}$ & $\begin{array}{l}31,8 \\
31,9 \\
32,1 \\
31,8 \\
31,6 \\
31,2 \\
31,4 \\
31,4 \\
32,4 \\
32,4 \\
31,9\end{array}$ & $\begin{array}{l}22,1 \\
22,2 \\
21,9 \\
22,0 \\
21,4 \\
21,0 \\
22,0 \\
21,8 \\
22,0 \\
22,0 \\
21,9\end{array}$ & $\begin{array}{l}27,0 \\
27,0 \\
27,0 \\
26,9 \\
26,5 \\
26,1 \\
26,7 \\
26,6 \\
27,2 \\
27,2 \\
26,9\end{array}$ & $\begin{array}{l}42 \\
49 \\
47 \\
48 \\
48 \\
48 \\
49 \\
48 \\
43 \\
40 \\
45\end{array}$ & $\begin{array}{l}90 \\
95 \\
94 \\
94 \\
95 \\
95 \\
95 \\
90 \\
89 \\
90 \\
91\end{array}$ & $\begin{array}{l}66 \\
72 \\
71 \\
71 \\
72 \\
72 \\
72 \\
69 \\
66 \\
65 \\
68\end{array}$ \\
\hline $\begin{array}{l}\text { Média } \\
\text { sd } \\
\text { C.V. (8) }\end{array}$ & $\begin{array}{r}31,81 \\
0,38 \\
1,18\end{array}$ & $\begin{array}{r}21,85 \\
0,33 \\
1,52\end{array}$ & $\begin{array}{r}26,83 \\
0,31 \\
1,17\end{array}$ & $\begin{array}{r}46,09 \\
2,97 \\
6,44\end{array}$ & $\begin{array}{r}92,55 \\
2,39 \\
2,58\end{array}$ & $\begin{array}{r}69,45 \\
2,64 \\
3,80\end{array}$ \\
\hline
\end{tabular}

Experimento $3-G$

\begin{tabular}{|c|c|c|c|c|c|c|}
\hline $\begin{array}{l}1 \\
2 \\
3 \\
4 \\
5 \\
6 \\
7 \\
8 \\
9 \\
10 \\
11\end{array}$ & $\begin{array}{l}32,0 \\
31,8 \\
32,4 \\
31,8 \\
30,6 \\
30,2 \\
30,0 \\
31,0 \\
30,2 \\
30,0 \\
30,2\end{array}$ & $\begin{array}{l}21,6 \\
21,8 \\
21,8 \\
21,8 \\
21,4 \\
21,4 \\
21,4 \\
21,2 \\
21,9 \\
21,0 \\
21,2\end{array}$ & $\begin{array}{l}26,8 \\
26,8 \\
27,1 \\
26,8 \\
26,0 \\
25,8 \\
25,7 \\
26,1 \\
26,1 \\
26,0 \\
25,7\end{array}$ & $\begin{array}{l}40 \\
38 \\
42 \\
45 \\
46 \\
45 \\
46 \\
48 \\
49 \\
48 \\
50\end{array}$ & $\begin{array}{l}95 \\
90 \\
93 \\
93 \\
95 \\
94 \\
95 \\
95 \\
98 \\
97 \\
97\end{array}$ & $\begin{array}{l}68 \\
64 \\
68 \\
69 \\
71 \\
70 \\
71 \\
72 \\
74 \\
73 \\
74\end{array}$ \\
\hline $\begin{array}{l}\text { Média } \\
\text { sd } \\
\text { C.V. (q) }\end{array}$ & $\begin{array}{r}30,93 \\
0,87 \\
2,80\end{array}$ & $\begin{array}{r}21,50 \\
0,27 \\
1,33\end{array}$ & $\begin{array}{r}26,26 \\
0,49 \\
1,85\end{array}$ & $\begin{array}{r}45,18 \\
3,61 \\
8,00\end{array}$ & $\begin{array}{r}94,73 \\
2,14 \\
2,25\end{array}$ & $\begin{array}{r}70,36 \\
2.87 \\
3.08\end{array}$ \\
\hline
\end{tabular}


Continuação

\begin{tabular}{|c|c|c|c|c|c|c|}
\hline \multirow[b]{2}{*}{ Dias } & \multicolumn{3}{|c|}{ Temperatura $\left({ }^{\circ} \mathrm{C}\right)$} & \multicolumn{3}{|c|}{ Umidade relativa (웅) } \\
\hline & Máx. & Min. & Média & Min. & Máx. & Média \\
\hline & & & cimento & $3-\mathrm{H}$ & & \\
\hline $\begin{array}{l}1 \\
2 \\
3 \\
4 \\
5 \\
6 \\
7 \\
8 \\
9 \\
10 \\
11\end{array}$ & $\begin{array}{l}31,8 \\
32,4 \\
31,8 \\
30,6 \\
30,2 \\
30,0 \\
31,0 \\
30,2 \\
30,0 \\
30,0 \\
32,8\end{array}$ & $\begin{array}{l}21,8 \\
21,8 \\
21,8 \\
21,4 \\
21,4 \\
21,4 \\
21,2 \\
21,9 \\
21,0 \\
21,2 \\
21,0\end{array}$ & $\begin{array}{l}26,8 \\
27,1 \\
26,8 \\
26,0 \\
25,8 \\
25,7 \\
26,1 \\
26,1 \\
26,0 \\
25,7 \\
26,9\end{array}$ & $\begin{array}{l}38 \\
42 \\
45 \\
46 \\
45 \\
46 \\
48 \\
49 \\
48 \\
50 \\
45\end{array}$ & $\begin{array}{l}90 \\
93 \\
93 \\
95 \\
94 \\
95 \\
95 \\
98 \\
97 \\
97 \\
96\end{array}$ & $\begin{array}{l}64 \\
68 \\
69 \\
71 \\
70 \\
71 \\
72 \\
74 \\
73 \\
74 \\
71\end{array}$ \\
\hline $\begin{array}{l}\text { Média } \\
\text { sd } \\
\text { C.V. (욯) }\end{array}$ & $\begin{array}{r}31,00 \\
0,98 \\
3,16\end{array}$ & $\begin{array}{r}21,45 \\
0,32 \\
1,48\end{array}$ & $\begin{array}{r}26,27 \\
0,50 \\
1,89\end{array}$ & $\begin{array}{r}45,64 \\
3,23 \\
7,07\end{array}$ & $\begin{array}{r}94.82 \\
2.17 \\
2,28\end{array}$ & $\begin{array}{r}70,64 \\
2,77 \\
3,92\end{array}$ \\
\hline
\end{tabular}

Experimento 3-I

\begin{tabular}{lcccccc}
1 & $30,2 I$ & $21,1 I$ & $25,7 I$ & $50 \mathrm{~s}$ & $98 \mathrm{~s}$ & 74 \\
2 & $31,0 I$ & $21,0 I$ & $26,0 I$ & $44 I$ & 95 & 70 \\
3 & 32,0 & 21,4 & 26,7 & $44 I$ & 95 & 70 \\
4 & 31,8 & 21,8 & 26,6 & $44 I$ & 95 & 70 \\
5 & 31,8 & 21,4 & 26,6 & $44 I$ & 95 & 70 \\
6 & 31,8 & 21,4 & 26,6 & 45 & 96 & 71 \\
7 & 32,2 & 21,6 & 26,9 & $51 \mathrm{~s}$ & $98 \mathrm{~s}$ & $75 \mathrm{~s}$ \\
8 & 32,2 & 21,5 & 26,9 & $50 \mathrm{~s}$ & 97 & 74 \\
9 & 31,6 & 21,6 & 26,6 & 49 & $98 \mathrm{~s}$ & 74 \\
10 & 32,2 & 21,4 & 26,8 & 48 & 97 & 73 \\
11 & 31,6 & $21,8 \mathrm{~s}$ & 26,7 & 48 & 96 & 72 \\
\hline Média & 31,69 & 21,50 & 26,58 & 46,80 & 95,90 & 71,90 \\
sd & 0,57 & 0,24 & 0,36 & 2,70 & 1,23 & 1,88 \\
C.V. (8) & 1,80 & 1,12 & 1,35 & 5,77 & 1,28 & 2,61 \\
\hline
\end{tabular}


Tabela B3: Contrôle da temperatura e umidade relativa na câmara de crescimento durante o experimento de seleção de genótipos tolerantes ao nível de 15 $\mathrm{mg} / \mathrm{l}$ de $\mathrm{Al}$.

\begin{tabular}{|c|c|c|c|c|c|c|}
\hline \multirow{2}{*}{ Dias } & \multicolumn{3}{|c|}{ Temperatura $\left({ }^{\circ} \mathrm{C}\right)$} & \multicolumn{2}{|c|}{ Umidade relativa } & $(8)$ \\
\hline & Min. & Máx. & Média & Mín. & Máx. & Média \\
\hline $\begin{array}{l}1 \\
2 \\
3 \\
4 \\
5 \\
6 \\
7 \\
8 \\
9 \\
10 \\
11\end{array}$ & $\begin{array}{l}21,0 \\
21,2 \\
20,1 \\
20,8 \\
20,4 \\
20,2 \\
20,2 \\
20,2 \\
20,4 \\
20,2 \\
20,4\end{array}$ & $\begin{array}{l}28,8 \\
27,8 \\
27,2 \\
29,0 \\
27,8 \\
27,8 \\
27,8 \\
27,4 \\
27,2 \\
27,4 \\
27,8\end{array}$ & $\begin{array}{l}24,9 \\
24,5 \\
23,7 \\
23,9 \\
24,1 \\
24,0 \\
24,0 \\
23,8 \\
23,8 \\
23,8 \\
24,1\end{array}$ & $\begin{array}{l}49 \\
49 \\
50 \\
48 \\
50 \\
50 \\
55 \\
53 \\
54 \\
53 \\
56\end{array}$ & $\begin{array}{l}97 \\
97 \\
98 \\
96 \\
98 \\
98 \\
98 \\
96 \\
98 \\
97 \\
93\end{array}$ & $\begin{array}{l}73 \\
73 \\
74 \\
72 \\
74 \\
74 \\
77 \\
75 \\
76 \\
75 \\
75\end{array}$ \\
\hline $\begin{array}{l}\text { Média } \\
\text { sd } \\
\text { C.V. }(8)\end{array}$ & $\begin{array}{r}20,50 \\
0,35 \\
1,71\end{array}$ & $\begin{array}{r}27,80 \\
0.56 \\
2,01\end{array}$ & $\begin{array}{r}24,10 \\
0,41 \\
1,70\end{array}$ & $\begin{array}{r}51,48 \\
2,61 \\
5,07\end{array}$ & $\begin{array}{r}96,91 \\
1,44 \\
1,49\end{array}$ & $\begin{array}{r}74,36 \\
1.37 \\
1.84\end{array}$ \\
\hline
\end{tabular}


Tabela B4: Contrôle da temperatura e umidade relativa na câmara de crescimento na avaliaçăo da reaçăo de aveias pretas ao aluminio.

Temperatura ( $\left.{ }^{\circ} \mathrm{C}\right)$

Dias
Umidade relativa ( 8 )

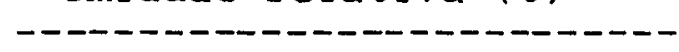

Máx.

Mín.

Média

Mín.

Máx .

Média

\begin{tabular}{|c|c|c|c|c|c|c|}
\hline $\begin{array}{l}1 \\
2 \\
3 \\
4 \\
5 \\
6 \\
7 \\
8 \\
9 \\
10 \\
11\end{array}$ & $\begin{array}{l}31,0 \\
32,0 \\
31,8 \\
31,8 \\
31,8 \\
32,2 \\
32,2 \\
31,6 \\
32,2 \\
31,6 \\
32,0\end{array}$ & $\begin{array}{l}21,0 \\
21,4 \\
21,8 \\
21,4 \\
21,4 \\
21,6 \\
21,5 \\
21,6 \\
21,4 \\
21,8 \\
21,5\end{array}$ & $\begin{array}{l}26,0 \\
26,7 \\
26,6 \\
26,6 \\
26,6 \\
26,9 \\
26,9 \\
26,6 \\
26,8 \\
26,7 \\
26,8\end{array}$ & $\begin{array}{l}44 \\
44 \\
44 \\
44 \\
45 \\
51 \\
50 \\
49 \\
48 \\
48 \\
45\end{array}$ & $\begin{array}{l}95 \\
95 \\
95 \\
95 \\
96 \\
98 \\
97 \\
98 \\
97 \\
96 \\
95\end{array}$ & $\begin{array}{l}70 \\
70 \\
70 \\
70 \\
71 \\
75 \\
74 \\
74 \\
73 \\
72 \\
70\end{array}$ \\
\hline $\begin{array}{l}\text { Média } \\
\operatorname{CV}\left(\frac{\circ}{b}\right)\end{array}$ & $\begin{array}{r}31,84 \\
0,34 \\
1,07\end{array}$ & $\begin{array}{r}21.49 \\
0,21 \\
0,98\end{array}$ & $\begin{array}{r}26.65 \\
0.23 \\
0,88\end{array}$ & $\begin{array}{r}46,55 \\
2,57 \\
5,52\end{array}$ & $\begin{array}{r}96,09 \\
1,16 \\
1,21\end{array}$ & $\begin{array}{r}71.73 \\
1.86 \\
2.60\end{array}$ \\
\hline
\end{tabular}


Tabela B5: Contrôle da temperatura e umidade relativa na casa de vegetaçăo durante a execuçăo dos experimentos de avaliação do efeito do alumínio sobre o crescimento, nutriçăo mineral e outros parâmetros fisiológicos da aveia.

Dias

Mín. Máx. Média Mín. Máx. Média

\begin{tabular}{|c|c|c|c|c|c|c|}
\hline $\begin{array}{l}1 \\
2 \\
3 \\
4 \\
5 \\
6 \\
7 \\
8 \\
9 \\
10 \\
11 \\
12 \\
13 \\
14 \\
15 \\
16 \\
17 \\
18 \\
19 \\
20 \\
21 \\
22 \\
23 \\
24 \\
25 \\
26 \\
27 \\
28 \\
29 \\
30 \\
31 \\
32\end{array}$ & $\begin{array}{l}13,6 \mathrm{I} \\
13,8 \mathrm{I} \\
14,6 \\
15,0 \\
12,8 \mathrm{I} \\
14,2 \mathrm{I} \\
17,8 \\
18,8 \mathrm{~s} \\
19,0 \\
16,1 \\
16,2 \\
15,4 \\
15,6 \\
16,0 \\
16,1 \\
17,8 \\
13,6 \mathrm{I} \\
13,9 \mathrm{I} \\
16,4 \\
20,0 \mathrm{~s} \\
18,8 \mathrm{~s} \\
15,4 \\
15 / 4 \\
15,8 \\
18,2 \\
19,1 \mathrm{~s} \\
18,8 \mathrm{~s} \\
17,8 \\
15,5 \\
16,2 \\
20,6 \mathrm{~s} \\
19,8\end{array}$ & $\begin{array}{l}29,0 \\
30,8 \\
31,8 \\
28,6 \\
29,6 \\
26,2 \\
29,9 \\
31,6 \\
30,2 \\
25,2 \mathrm{I} \\
19,5 \mathrm{I} \\
29,2 \\
27,2 \\
30,5 \\
26,8 \\
25,2 \mathrm{I} \\
26,4 \\
29,8 \\
30,0 \\
29,0 \\
25,2 \mathrm{I} \\
29,2 \\
30,8 \\
30,6 \\
31,4 \\
31,4 \\
31,2 \\
32,4 \\
39,0 \mathrm{~s} \\
41,0 \mathrm{~s} \\
37,8 \mathrm{~s} \\
36,8 \mathrm{~s}\end{array}$ & $\begin{array}{l}21,3 \\
22,3 \\
23,2 \\
21,8 \\
21,3 \\
20,2 \mathrm{I} \\
23,9 \\
25,2 \\
24,6 \\
20,7 \mathrm{I} \\
17,9 \mathrm{I} \\
22,3 \\
21,4 \\
23,3 \\
21,5 \\
21,5 \\
20,0 \mathrm{I} \\
21,9 \\
23,2 \\
24,5 \\
22,0 \\
22,3 \\
23,1 \\
23,2 \\
24,8 \\
25,3 \\
25,0 \\
25,1 \\
27,3 \mathrm{~s} \\
28,6 \mathrm{~s} \\
29,2 \mathrm{~s} \\
28,3 \mathrm{~s}\end{array}$ & $\begin{array}{l}40 \\
47 \\
51 \\
49 \\
50 \\
43 \\
38 \\
35 \\
36 \\
32 \mathrm{I} \\
38 \\
37 \\
48 \\
42 \\
58 \mathrm{~s} \\
67 \mathrm{~s} \\
42 \\
40 \\
58 \mathrm{~s} \\
62, \mathrm{~s} \\
60 \mathrm{~s} \\
48 \\
45 \\
51 \\
49 \\
60, \mathrm{~s} \\
66 \mathrm{~s} \\
31 \mathrm{I} \\
30 \mathrm{I} \\
29 \\
40 \\
33\end{array}$ & $\begin{array}{l}79 \\
83 \\
86 \\
87 \\
75 \\
72 I \\
77 \\
77 \\
81 \\
70 I \\
58 I \\
66 I \\
78 \\
86 \\
79 \\
80 \\
90 \\
945 \\
90 \\
84 \\
90 \\
90 \\
92 \\
935 \\
82 \\
91 \\
93 \\
9 \\
92\end{array}$ & 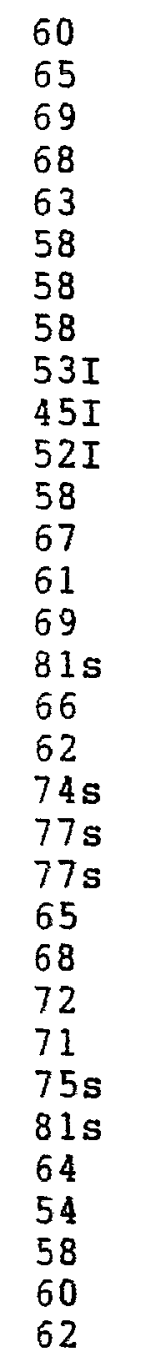 \\
\hline $\begin{array}{l}\text { Média } \\
\text { sd } \\
\text { C.V. }(8)\end{array}$ & $\begin{array}{c}16,5 \\
2,09 \\
12,67\end{array}$ & $\begin{array}{c}30,1 \\
4,17 \\
13,9\end{array}$ & $\begin{array}{c}23,3 \\
2.54 \\
10,9\end{array}$ & $\begin{array}{l}45 \\
10,57 \\
23,5\end{array}$ & $\begin{array}{l}84 \\
8,94 \\
10,6\end{array}$ & $\begin{array}{l}65 \\
8,45 \\
13,0\end{array}$ \\
\hline
\end{tabular}

$s=$ Média acrescida de um desvio padrão; $I=$ média subtraida de um desvio padrão. 
Apêndice C

Tabela Cl: Contrôle do pH inicial e final do experimento 1.

Nível de Al (mg/l)

Dias

0

7,5

15

22,5

30

$\begin{array}{llllll}01 & 5,75 & 3,98 & 3,73 & 3,69 & 3,68 \\ 02 & 5,66 & 3,89 & 3,83 & 3,75 & 3,73 \\ 03 & 5,03 & 3,81 & 3,74 & 3,72 & 3,68 \\ 04 & 4,51 & 3,76 & 3,73 & 3,69 & 3,67 \\ 05 & 3,98 & 3,74 & 3,71 & 3,66 & 3,65 \\ 06 & 3,88 & 3,68 & 3,58 & 3,66 & 3,66 \\ 07 & 3,85 & 3,66 & 3,66 & 3,66 & 3,66 \\ 08 & 3,78 & 3,63 & 3,66 & 3,68 & 3,69 \\ 09 & 3,72 & 3,62 & 3,66 & 3,70 & 3,72 \\ 10 & 3,71 & 3,61 & 3,66 & 3,72 & 3,74\end{array}$

Média $\quad 4,34$

sd

C.V. (뭏) 18,43
3,74

0,12

3,42
3,70

0,07

1,83
3,69

0.82

0,82
3,69

0,85

0,85 
Tabela C2: Contrôle do pH inicial e final do experimento 2 .

Nível

de Al

$(\mathrm{mg} / \mathrm{l})$
$\mathrm{pH}$
Final

Final

$\begin{array}{ll}0 & 5,20 \\ 7,5 & 3,65\end{array}$

Experimento 2-A

$\begin{array}{ll}0 & 5,53 \\ 7,5 & 3,82\end{array}$

0

5,39

7,5

3,83

$\begin{array}{ll}0 & 5,18 \\ 7,5 & 3,66\end{array}$

$0 \quad 5,56$

$\begin{array}{ll}7,5 & 3,78\end{array}$

$0 \quad 5,68$

$7,5 \quad 3,73$

$0 \quad 5,73$

$7,5 \quad 3,84$

$\begin{array}{ll}0 & 5,25 \\ 7,5 & 3,75\end{array}$

Experimento 2-H

4,24

3,82

Experimento 2-B

4,23

3,94

Experimento 2-C

3,92

3,81

Experimento 2-D

4,46

3,94

Experimento 2-E

4,03

3,72

Experimento $2-F$

4,15

3,79

Experimento 2-G

4,29

3,77

5,16

0
7,5

3,78

Experimento 2-I

4,08

3,73

4,15

3,89

Experimento 2-J 
Tabela C3: Contrôle do pH inicial e final do experimento 3.

\section{Nível de Al (mg/l)}

Dias

7,5

15

30

$\begin{array}{lllll}01 & 5,51 & 3,67 & 3,55 & 3,48 \\ 02 & 5,08 & 3,76 & 3,68 & 3,67 \\ 03 & 4,71 & 3,74 & 3,71 & 3,67 \\ 04 & 4,27 & 3,76 & 3,73 & 3,70 \\ 05 & 4,01 & 3,80 & 3,77 & 3,73 \\ 06 & 3,93 & 3,81 & 3,77 & 3,78 \\ 07 & 3,93 & 3,83 & 3,77 & 3,77 \\ 08 & 3,92 & 3,84 & 3,78 & 3,75 \\ 09 & 3,88 & 3,85 & 3,75 & 3,76 \\ 10 & 3,73 & 3,70 & 3,68 & 3,75\end{array}$

Tabela C4: Contrôle do $\mathrm{pH}$ do experimento de seleçăo de genótipos tolerantes a $15 \mathrm{mgAl} / 1$.

Nível de

Al $(\mathrm{mg} / \mathrm{l})$
$\mathrm{pH}$

$\begin{array}{lr}\text { Inicial } & \text { Final } \\ 5,93 & 4,00 \\ 4,00 & 3,74\end{array}$


276.

\section{Apêndice $D$}

Tabela D1: Quadrados médios da análise de variância do efeito de diferentes niveis de aluminio, em solução nutritiva sobre parâmetros de crescimento de genótipos de aveia (Experimento 1 ).

Causas de G.I

Quadrados médios variaçăo

Níveis de

Al (B) $4977,99 * * 33348,83 * * 986,85 * * 18868,73 * * 1,20 \mathrm{~ns}$ Genótipos
(A) 15
$81,91 \star \star$
$7422,64 * \star$
$90,28 * \star$
$4013,76 * \star 4,26 \star *$

Genótipo/

Niveis 60

Resíduo

(A)

$6025,57 \star \star$

$682,65 * \star 24,84 * \star$

$323,98 * \star$

$0,62 \mathrm{~ns}$

Resíduo

(B)

$8 \quad 11,66$

736,70

11.96

301,42

0,95

150

0.97

95,53

1.81

40,17

0,66

C.V. A
(8) $\quad 10,77$
11,71
6.41
6,34
4,32
C.V. B
(8)
12,44
16.86
9,78
$9,34 \quad 14,41$

* Estatisticamente significativo $(P(0,05)$, pelo teste $F$ **Estatísticamente significativo $(P(0,01)$, pelo teste $F$. 
Tabela D2: Quadrados médios da análise de variância do efeito do alumínio $(7,5 \mathrm{mgAl} / 1)$ sobre parâmetros de crescimento de genótipos de aveia, em soluçăo nutritiva.

Causas

de

variação
G. L .
Quadrados médios
RRMSR

RMSPA

\begin{tabular}{lrrrr} 
Niveis de Al (B) & 1 & $132908,7 * *$ & $31937,51 *$ & $728365,04 * *$ \\
Genótipos (A) & 15 & $7501,29 * *$ & $4693,13 *$ & $43899,48 * *$ \\
Genótipos X & & & & \\
Níveis de Al & 15 & $7058,57 * *$ & $4696,13 *$ & $14914,91 * *$ \\
Resíduo (A) & 2 & 615,29 & 522,95 & 1858,04 \\
Resíduo (B) & 60 & 1559,95 & 2283,04 & 4744,69 \\
\hdashline C.V. A(g) & & 6,26 & 6,99 & 2,71 \\
C.V. B (8) & & 39,86 & 58,44 & 17,31 \\
\hline
\end{tabular}

Causas

de

RMSR

variação

Quadrados médios

\begin{tabular}{|c|c|c|c|c|}
\hline \multicolumn{2}{|l|}{ vatiagav } & RRMSPA & RMSP & RRMSP \\
\hline $\begin{array}{l}\text { Niveis de } A l(B) \\
\text { Genótipos }(A) \\
\text { Genótipos } x\end{array}$ & $1 \frac{1}{15}$ & $\begin{array}{r}28050,84 \star \star \\
427,09 \star \star\end{array}$ & $\begin{array}{r}1486032,67^{\star \star \star} \\
78903,54^{\star \star}\end{array}$ & $\begin{array}{r}33600,17 * \star \\
437,97 * \star\end{array}$ \\
\hline $\begin{array}{l}\text { Niveis de Al } \\
\text { Resíduo (A) } \\
\text { Resíduo (B) }\end{array}$ & $\begin{array}{r}15 \\
2 \\
60\end{array}$ & $\begin{array}{c}427,09 \star \star \\
98,84 \\
174,09\end{array}$ & $\begin{array}{r}31303,16 * \star \\
4186,29 \\
7287,60\end{array}$ & $\begin{array}{r}437,97 \star \star \\
141,54 \\
182,34\end{array}$ \\
\hline $\begin{array}{l}\text { C.V. } A\left(\frac{8}{8}\right) \\
\text { C.V. B }(8) 8)\end{array}$ & & $\begin{array}{r}3,00 \\
15,92\end{array}$ & $\begin{array}{r}3,26 \\
17,19\end{array}$ & $\begin{array}{r}3,66 \\
16,61\end{array}$ \\
\hline
\end{tabular}


278 .

Continuação

Causas

de

variação

Quadrados médios

CIRS
CRS

CRRS

\begin{tabular}{|c|c|c|c|c|}
\hline $\begin{array}{l}\text { Níveis de } A 1 \text { (B) } \\
\text { Genótipos }(A)\end{array}$ & $\frac{1}{15}$ & $\begin{array}{l}0,07 \mathrm{~ns} \\
1,56 \star \star\end{array}$ & $\begin{array}{r}798,0 * \star \\
58,3 * \star\end{array}$ & $\begin{array}{r}17136,3 * \star \\
604,1 * \star\end{array}$ \\
\hline $\begin{array}{l}\text { Genótipos } x \\
\text { Niveis de Al } \\
\text { Residuo (A) } \\
\text { Residuo (B) }\end{array}$ & $\begin{array}{r}15 \\
2 \\
60\end{array}$ & $\begin{array}{c}0,12 \mathrm{~ns} \\
0,28 \\
0,17\end{array}$ & $\begin{array}{r}17.3 * * \\
4.34 \\
1.51\end{array}$ & $\begin{array}{r}604,1 * * \\
514,7 \\
48,8\end{array}$ \\
\hline $\begin{array}{ll}\text { C.V.V. } & (8) \\
\text { C.V. } & \text { (8) } \\
\text { B } & \text { B }\end{array}$ & & $\begin{array}{l}1,84 \\
5,73\end{array}$ & $\begin{array}{r}4,99 \\
11,78\end{array}$ & $\begin{array}{l}7,17 \\
8,84\end{array}$ \\
\hline
\end{tabular}

Causas

de

Quadrados médios

variação

G.L. - -

CFRS

CFRRS

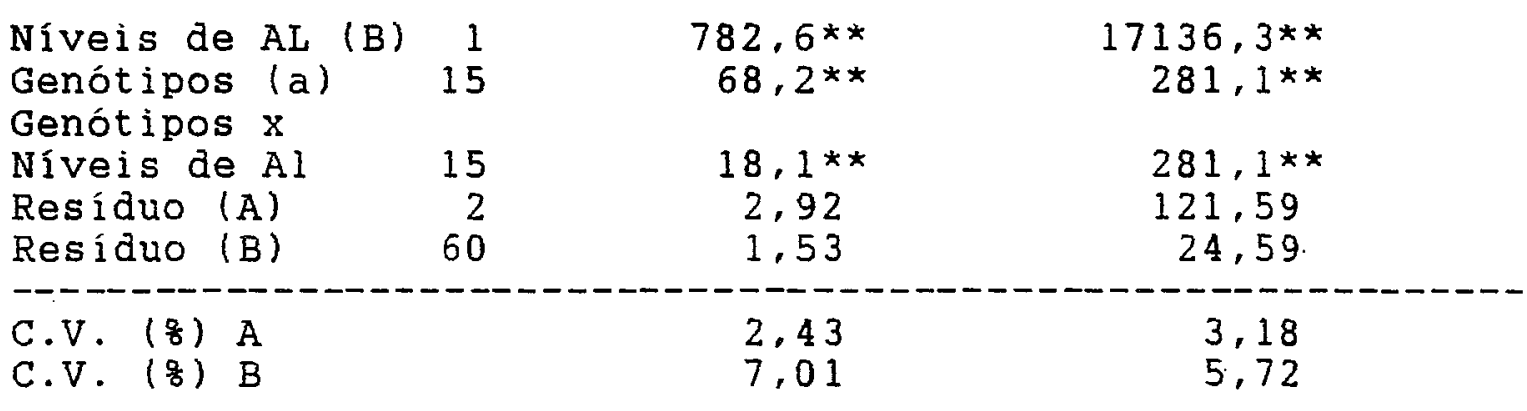

* Significativo pelo teste $F(P<0,05)$

$\star *$ Significativo pelo teste $F(P<0,01)$ 
Tabela D3: Quadrados médios da análise de variância do efeito do alumínio $(7,5 \mathrm{mg} \mathrm{Al/1)}$ sobre o crescimento de raízes de genótipos de aveia, em soluçăo nutritiva

Causas de G.L. variação

Quadrados médios

CIRS CRS CRRS CFRS

CFRRS

Experimento 2

Níveis de

Al (B) $\quad 10,07 \mathrm{~ns} 797,99 * 41826,82 * \star 782,61 * \star 17136,34 \star \star$ Genótipos

(A) $151,56 * \star 58,33 * \star \quad 604,06 * \star \quad 68,15 * * \quad 281,12 \star \star$

Genótipos

$x$ Nivel $150,12 \mathrm{~ns} \quad 17,30 * * \quad 604,06 * \star \quad 18,08 * * \quad 281,12 * *$

Residuo

(A)

20,28

4,34

514.71

2.92

121,59

Resíduo

(B)

$60 \quad 0,17$

1,51

48,80

1,53

24,59

C.V. (A) (8) 1,84

4,99

7,17

8,84

2,43

3,18

C.V. (B)

(용) 5,73

11,78

7,01

5,72

Experimento $3-\mathrm{A}$

Níveis de

Al (B) $10,09 \mathrm{~ns} 2925,38 * \star 94815,51 * \star 3011,01 * \star 48151,04 * \star$ Genótipos

(A) $152,51 * * \quad 46,20 * * \quad 127,09 * * \quad 48,86 * * \quad 95,95 * \star$

Genótipos

$x$ nivel $150,20 \mathrm{~ns} 23,09 * *$

$127,09 * \star \quad 19,61 * \star \quad 95,95 * \star$

Residuo

(A)

20,70

24,85

223,51

19,73

156,95

Resíduo

(B)

$\begin{array}{ll}60 & 0,28\end{array}$

3,93

50,05

3,76

33,46

C.V. (A) (o $) \quad 2,98$

10,97

5,45

10,32

6,02

10,50

4,04

C.V. (B) (8) 7,48

17,44

Continua 
280.

Continuação

Causas de G.I.

Quadrados médios

variação

CIRS

CRS

CRRS

CFRS

CFRRS

EXPERIMENTO 3B

Níveis de

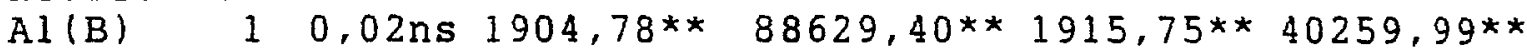
Genótipos

(A) $152,45 * \star \quad 48,70 * \star \quad 384,39 * \star \quad 59,12 \star \star \quad 346,41 * \star$ Genótipos

$x$ nivel $15 \quad 0,13$ ns $38,27 * \star \quad 384,39 * \star \quad 38,99 * \star \quad 346,41 * \star$ Residuo

$\begin{array}{lllllll}\text { (A) } & 2 & 0,07 & 2,23 & 11,85 & 2,02 & 3,03\end{array}$

Resíduo

\begin{tabular}{lcccccr} 
(B) & 60 & 0,29 & 0,97 & 19,15 & 1,10 & 16,80 \\
\hline C.V. (A) $($ (8) & 1,01 & 4,08 & 1,24 & 2,27 & 0,55 \\
C.V. (B) (용) & 8,20 & 10,78 & 6,29 & 6,69 & 5,16
\end{tabular}

Experimento $3-\mathrm{C}$

Níveis de

Al (B) $11,18 \mathrm{~ns} 4199,60 * \star 121266,75 \star \star 4138,71 * \star 55554,58 * \star$ Genótipos

(A) $15 \quad 3,13 * \star \quad 32,72 \star \star \quad 101,99 \star \star \quad 34,97 * \star \quad 51,79 * \star$ Genótipos

$x$ nivel 150,21 s $14,03 * \star \quad 101,99 \star \star \quad 13,83^{\star} \star \quad 51,79 \star \star$ Resíauo

$\begin{array}{lllllll}\text { (A) } & 2 & 0,39 & 17,45 & 329,18 & 14,24 & 158,57\end{array}$

Resíduo

\begin{tabular}{lcccccr} 
(B) & 60 & 0,24 & 2,65 & 19,50 & 2,84 & 18,12 \\
\hline C.V.(A) $(8)$ & 1,85 & 8,84 & 5,87 & 5,27 & 4,15 \\
C.V. (B) $(8)$ & 5,80 & 13,78 & 6,85 & 8,32 & 5,61
\end{tabular}


Continuação

\begin{tabular}{|c|c|c|c|c|c|c|}
\hline \multirow{2}{*}{\multicolumn{2}{|c|}{$\begin{array}{l}\text { Causas de } \\
\text { variação }\end{array}$}} & \multicolumn{5}{|c|}{ Quadrados médios } \\
\hline & & CIRS & CRS & CRRS & CFRS & CFRRS \\
\hline \multicolumn{7}{|c|}{ Experimento $3-D$} \\
\hline $\begin{array}{l}\text { Nivel de } \\
\text { Al (B) }\end{array}$ & 1 & $0,01 \mathrm{~ns}$ & $2115,47^{\star}$ & $80814,90 * \star$ & $2097.11^{\star}$ & $38462.03 \star$ \\
\hline $\begin{array}{l}\text { Genótipos } \\
\text { (A) } \\
\text { Genótipo }\end{array}$ & 15 & $1,75 \star \star$ & $35,74 \star \star$ & $232,39 \star \star$ & $35,12 \star \star$ & $102.09 * *$ \\
\hline $\begin{array}{l}x \text { Nível } \\
\text { Resíduo }\end{array}$ & 15 & $0,17 \mathrm{~ns}$ & $12,50 \star \star$ & $232,39 \star \star$ & $11,46 \star \star$ & $102,09 * *$ \\
\hline $\begin{array}{l}\text { (A) } \\
\text { Residall }\end{array}$ & 2 & 0.58 & 62.77 & 760,45 & 72.60 & 648,06 \\
\hline $\begin{array}{l}\text { Res lduo } \\
\text { (B) }\end{array}$ & 60 & 0,20 & 2,41 & 32,74 & 2,15 & 14,85 \\
\hline $\begin{array}{l}C \cdot V \cdot(A) \\
C \cdot V \cdot(B)\end{array}$ & 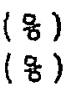 & $\begin{array}{l}2,77 \\
6,48\end{array}$ & $\begin{array}{l}17,83 \\
13,97\end{array}$ & $\begin{array}{l}9.71 \\
8,06\end{array}$ & $\begin{array}{r}11,83 \\
8,14\end{array}$ & $\begin{array}{l}7,96 \\
4,82\end{array}$ \\
\hline
\end{tabular}

Nivei de

Al (B) $10,55 \mathrm{~ns} 2811,47 \star \star \quad 89807,35 \star * 2781,99 \star \star 47121,03 \star \star$ Genót ipo

(A) $153,98 * \pi \quad 71,98 * \star \quad 372,51 * \star 103,19 * \star 264,09 * \star$ Genót ipo $x$ Nivel $150,21 \mathrm{~ns} \quad 37,10 * * \quad 372,51 * * \quad 39,47 * \star 264,09 * *$ Residuo

\begin{tabular}{lcccccc}
$\begin{array}{l}\text { (A) } \\
\text { Residuo }\end{array}$ & 2 & 0,09 & 1,54 & 34,97 & 4,04 & 11,77 \\
(B) & 60 & 0,13 & 1,16 & 16,25 & 1,87 & 13,17 \\
\hline C.V.(A) $\left(\frac{8}{8}\right)$ & 1,13 & 2,68 & 2,13 & 2,76 & 1,10 \\
C.V.(B) (8) & 5,32 & 9,30 & 5,81 & 7,51 & 4,66 \\
\hline
\end{tabular}


Continuação

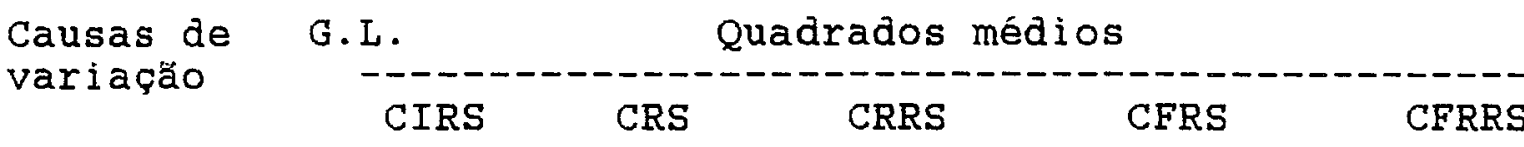

Experimento $3-F$

Nível de

$\mathrm{Al}(\mathrm{B}) \quad 1 \quad 0,43 \mathrm{~ns} \quad 797,18 \star \star \quad 46604,91 \star \star \quad 834,85 * \star 19880,65 \star \star$ Genótipo

(A) $1511,44 * \star \quad 35,29 * \star 1524,69 * \star \quad 65,25 * \star \quad 470,32 \star \star$ Genótipo

$x$ Nivel $15 \quad 0,31 \mathrm{~ns} \quad 13,19 * * \quad 1564,69 * \star \quad 15,67 * \star 470,32 \star *$ Residuo
(A)
20,75
2,34
611,09
0.69
80,91

Residuo

\begin{tabular}{lcccccc} 
(B) & 60 & 0,61 & 1,34 & 129,19 & 1,69 & 35,32 \\
\hline C.V.(A) $(8)$ & 2,84 & 4,46 & 7,93 & 1,28 & 2,63 \\
C.V.(B) $(8)$ & 10,26 & 13,50 & 14,58 & 8,02 & 6,94 \\
\hline
\end{tabular}

Nível de

Experimento $3-G$

Al (B) $10,30 \mathrm{~ns} \quad 755,84 \star \star 68261,33 \star \star \quad 763,54 \star \star \quad 21755,38 \star \star$ Genótipo

(A) $151,59 * * 35,22 * * \quad 372,47 * * \quad 41,47 * * \quad 139,97 * *$ Genót ipo

$x$ Nível $15 \quad 0,14 \mathrm{~ns} \quad 9,38 * * \quad 372,47 * * \quad 8,87 * * \quad 139,97 * *$ Resíduo
(A)
20,93
3,21
91.83
2,99
78,91

Residuo

\begin{tabular}{lcccccr} 
(B) & 60 & 0,21 & 1,18 & 50,83 & 1,37 & 35,32 \\
\hline C.V. (A) $($ (8) & 3,12 & 5,96 & 3,27 & 2,84 & 2,60 \\
C.V. (B) $(8)$ & 5,89 & 14,48 & 9,72 & 7,70 & 6,65 \\
\hline
\end{tabular}


283.

Cont in nuação

Causas de G.L.

Quadrados médios

variaçäo

Experimento $3-\mathrm{H}$

Nível de

Al (B) $\quad 10,73 \mathrm{~ns} \quad 270,88 \mathrm{~ns} \quad 9342,75 \mathrm{~ns} \quad 299,70 \mathrm{~ns} 4407,54 \mathrm{~ns}$ Genótipo

(A) $151,31 * \star \quad 41,26 \star * \quad 857,75 * \star \quad 40,44 * \star \quad 281,01 \star \star$ Genótipo

$x$ Nível 15 0,21ns $19,13 * *$

$857,75 * \star \quad 19,79 \star \star \quad 281,01 \star \star$ Residuo

(A)

20.63

20,15

1023,40

27,78

474,56

Residuo

\begin{tabular}{lcccccc} 
(B) & 60 & 0,37 & 3,42 & 236,72 & 3,61 & 62,22 \\
\hline C.V.(A) $(8)$ & 2,10 & 11,16 & 8,87 & 6,77 & 5,84 \\
C.V.(B) $(8)$ & 6,50 & 18,40 & 17,07 & 9,77 & 8,46
\end{tabular}

Nivel de

Al (B) $10,25 \mathrm{~ns} 1979,53 * 62883,84 * 2023,91 * 31501,26 *$ Genótipo
(A)
$153,14 \star \star 55,02 \star \star$
$684,69 * \star$
$49,94 * \star$
$421,57 * \star$

Genót ì po

$x$ Nivel 15

Res íduo

(A)

$150,11 \mathrm{~ns}$

$41,76 \star \star$

$684,69 * *$

$43,13 * *$

$421,57 * *$

(A)

20,80

80,76

1008,50

69,29

630,76

Residuo

\begin{tabular}{lcccccc} 
(B) & 60 & 0,15 & 3,58 & 81,91 & 3,80 & 42,50 \\
\hline C.V.(A) & (8) & 2,99 & 19,41 & 10,67 & 10,92 & 7,67 \\
C.V.(B) $($ (8) & 5,14 & 16,34 & 12,16 & 10,22 & 7,96
\end{tabular}

C.V.(B)

* Estatisticamente significativo

$(P<0,05)$, pelo teste $F$.

**Estatísticamente significativo $(P<0,01)$, pelo teste $F$. 
284 .

Tabela D4: Quadrados médios da análise de variância do efeito do alumínio sobre parâmetros de crescimento de dois genótipos de aveia, em onze diferentes experimentos em soluçăo nutritiva.

Causas

de

G.I.

Quadrados médios

variação

Experimento 1

Genótipo

Resíduo

C.V. $(8)$

Genótipo

Resíduo

C.V. (8)

Genótipo

Resíduo

C.V. $\left(\frac{8}{8}\right)$

Genótipo

Residuo

C.V. $(8)$

Genót ipo

Resíduo

C.V. $\left(\frac{8}{8}\right)$

Genót ipo

Resíduo

C.V. (용)

Genót ipo

Residuo

C.V. ( $(8)$

$\begin{array}{ll}1 & 0,69 \mathrm{~ns} \\ 4 & 0,07 \\ & 4,69\end{array}$

Exp

Experimento 2

$\begin{array}{ll}1 & 0,10 \mathrm{~ns} \\ 4 & 0,14 \\ & 5,41\end{array}$

60,42 **

4,70

14,85
$25,05 *$

1,18

7,22

Experimento 3-A

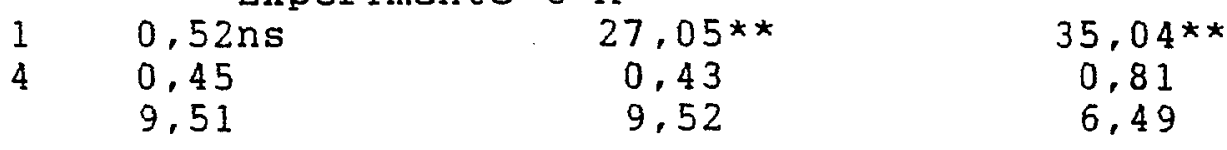

1,37

14,58

37,20

0,61

6,36

Experimento $3-\mathrm{C}$

$\begin{array}{llcr}1 & 0,24 \mathrm{~ns} & 34,56^{\star} & 29,04^{\star} \\ 4 & 0.09 & 2,34 & 3,07 \\ & 3.54 & 15,42 & 11,96\end{array}$

Experimento 3-D

$\begin{array}{llrr}1 & 0,02 \mathrm{~ns} & & \\ 4 & 0.34 & 28,38 * & 27.09 * \\ & 8.29 & 1.43 & 2.28 \\ & & 16.17 & 10.49\end{array}$

Experimento $3-E$

$\begin{array}{lll}1 & 0.01 \mathrm{~ns} & 12,76 * \\ 4 & 0,22 & 1,44 \\ & 6,65 & 16.85\end{array}$

12,24 *

1,34

8,12 
Cont inuaçăo

Causas

de

G.I.

Quadrados médios

variação

\begin{tabular}{|c|c|c|c|}
\hline \multicolumn{4}{|c|}{ Experimento $3-F$} \\
\hline Genót ipo & & $0,002 \mathrm{~ns}$ & $3,39 \mathrm{~ns}$ \\
\hline Resíduo & 4 & 0,11 & $\begin{array}{r}1,08 \\
13.47\end{array}$ \\
\hline
\end{tabular}

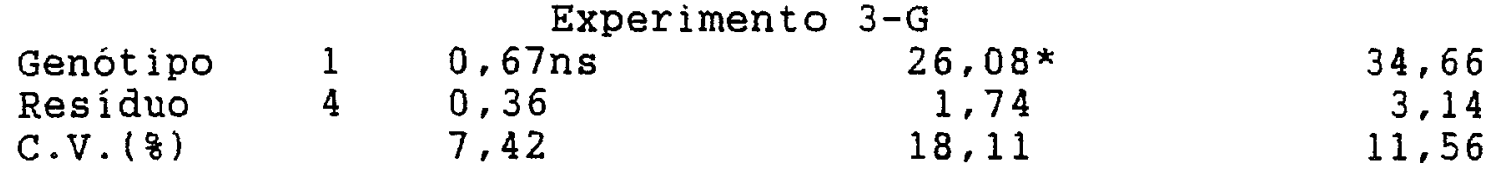

\begin{tabular}{|c|c|c|c|c|}
\hline \multicolumn{5}{|c|}{ Experimento $3-\mathrm{H}$} \\
\hline tipo & & $0,80 \mathrm{~ns}$ & $24,28 *$ & $33,89 * \star$ \\
\hline Res íduo & 4 & $\begin{array}{l}0.19 \\
4.82\end{array}$ & $\begin{array}{r}1,14 \\
10.92\end{array}$ & 1,08 \\
\hline
\end{tabular}

$\begin{array}{lllrc}\text { Genótipo } & 1 & 0,59 \mathrm{~ns} & 55,69 \star \star \\ \text { Resíduo } & 4 & 0,66 & 44,83 & 1.87 \\ \text { C.V. }(8) & & 11,67 & 1.84 & 8,95\end{array}$

\begin{tabular}{|c|c|c|c|c|}
\hline \multirow{3}{*}{$\begin{array}{l}\text { Ensaios } \\
\text { Genót ipo }\end{array}$} & \multicolumn{3}{|c|}{ Análise conjunta } & \multirow{3}{*}{$\begin{array}{r}65,24^{\star \star} \\
320,78^{\star \star}\end{array}$} \\
\hline & 10 & $6.07 \star \star$ & $9,67 * *$ & \\
\hline & 1 & $1,84 * \star$ & $280,04 * *$ & \\
\hline \multicolumn{5}{|l|}{ Ensaios $x$} \\
\hline Genót ipo & 10 & $0,37 \mathrm{~ns}$ & $1.98 \mathrm{~ns}$ & $1,41 \mathrm{~ns}$ \\
\hline Residuo & 44 & 0.24 & 1,65 & 1,93 \\
\hline
\end{tabular}

* Estatísticamente significativo $(P<0,05)$, pelo teste $F$. $\star \star$ Estatisticamente significativo $(P<0,01)$, pelo teste $F$. CIRS: comprimento inicial da raíz seminal, CRS: crescimento da raíz seminal; CFRS: comprimento final da raíz seminal. 
Tabela D5: Quadrados médios da análise de variância do efeito do Alumínio (15mg/l) sobre parâmetros de crescimento de genótipos de aveia, em solução nutritiva.

Causas

de

variação

G.I.

Quadrados médios

CIRS

CIRS

CRS

CFRS

\begin{tabular}{lccc} 
Genótipo 85 & $1,98^{\star *}$ & $18,87^{\star *}$ & $21,32^{\star \star}$ \\
Residuo 170 & 0,17 & 1,29 & 1,52 \\
\hline C.V. $($ o $)$ & 6,83 & 11,69 & 7,80
\end{tabular}

**Estatisticamente significativo $(P<0,01)$, pelo teste F.

Tabela D6: Quadrados médios da análise de variância do crescimento de raizes submetidas aos niveis 0 e $15 \mathrm{mg} / \mathrm{litro}$ de soluçăo.

Causas

de

variação

G.L.

Quadrados médios

CIRS

CRS

CRRS

- -

\begin{tabular}{lcccc} 
Niveis de Al (B) & 1 & $2,600 *$ & $919,15 *$ & $21570,01 *$ \\
Genótipos (A) & 15 & $5,31 * *$ & $81,98 * *$ & $1155,90 * *$ \\
Genótipo $x$ & & & & \\
Niveis & 15 & $0,27 n s$ & 43,35 & $1155,90 * *$ \\
Resíduo (A) & 2 & 0,09 & 15,90 & 295,32 \\
Resíduo (B) & 60 & 0,28 & 1,75 & 87,95 \\
\hline C.V. Genótipos (8) & 1,26 & 7,10 & 5,05 \\
C.V. Niveis Al (8) & 8,91 & 9,43 & 11,03
\end{tabular}


Continuação

Fonte de G.L. Quadrados médios

variaçăo

\section{CFRRS}

Nível de

Al (B)
Genótipos

(A)

CFRS

Genótipos

$x$ Niveis

Resíauo

(A)

(B)

1

$835,74 *$

$11814,84^{\star}$

15

$102.85 * \star$

$895,49 * *$

15

$41,21 \star \star$

$293.47 * *$

2

19,57

263,47

60

2,08

52,98

C.V. Genótipos (g)

C.V. Níveis Al (웅)

5,54

7,22

4,56

8,19

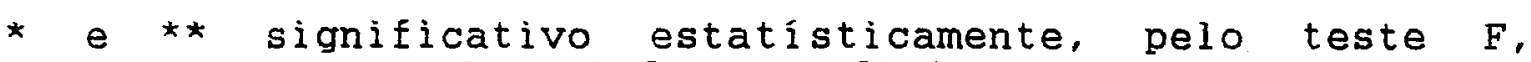
respectivamente a 5 e 18 de significância.

ns = năo significativo. 
Tabela D7: Quadrados médios da análise de variância do efeito do alumínio sobre parâmetros de crescimento de genótipos de aveia preta, em soluçăo nutritiva.

Causas de G.L. Quadrados médios variação

CIRS CRS CRRS CFRS CFFRS

Nível de

Al (B)

3

Genótipos

(A)

Genótipos

$x$ Niveis

Resíduo

\begin{tabular}{|c|c|c|c|c|c|c|}
\hline $\begin{array}{l}\text { (A) } \\
\text { (B) Í duo }\end{array}$ & 120 & 0.23 & 24,59 & 822,70 & 22.81 & 498,16 \\
\hline $\begin{array}{l}C . V .(A) \\
C . V .9 B 0\end{array}$ & $\begin{array}{l}(8) \\
(8)\end{array}$ & $\begin{array}{l}2,01 \\
8,47\end{array}$ & $\begin{array}{r}9,03 \\
10,73\end{array}$ & $\begin{array}{r}8,93 \\
11,56\end{array}$ & $\begin{array}{l}6.10 \\
8.69\end{array}$ & $\begin{array}{l}6.57 \\
8.92\end{array}$ \\
\hline
\end{tabular}

$151,41 * \star \quad 70,93 \star \star 2232,14 * \star \quad 70,78 * 1208,73 * \star$

$45 \quad 0,11$ ns $14,37 * \star \quad 385,80 * * 14,70 * \star 218,43 * \star$

Resíduo

**Estatísticamente significativo $(P<0,01)$, pelo teste $F$. ns=näo significativo.

Tabela D8: Quadrados médios da análise de variância do efeito do aluminio sobre parâmetros de dois genótipos de aveia, em cultivo hidropônico.

Causas

de

varìąão
Quadrados médios

G.L.

\begin{tabular}{|c|c|c|c|c|c|}
\hline & CMR & NAF & RMSR & RMSCB & RMSF \\
\hline Genót ipo & $282,13 * *$ & $0,13 \mathrm{~ns}$ & $0.02 \mathrm{~ns}$ & $0,01 \mathrm{~ns}$ & $0,19 * *$ \\
\hline $\begin{array}{l}\text { Al } \\
\text { Genótipo } x\end{array}$ & $276.75 * *$ & $128,88^{* \star}$ & $1.02 * \star$ & $0.13 * \star$ & $2,68 * \star$ \\
\hline $\begin{array}{l}\text { Nivel de Al } \\
\text { Residuo }\end{array}$ & $\begin{array}{l}47.55^{\star} \\
14.80\end{array}$ & $\begin{array}{l}20,22 * \star \\
2,91\end{array}$ & $\begin{array}{l}0,001 \mathrm{~ns} \\
0,002\end{array}$ & $\begin{array}{l}0,01 \mathrm{~ns} \\
0,002\end{array}$ & $\begin{array}{l}0.01 \mathrm{~ns} \\
0.01\end{array}$ \\
\hline C.V. (8) & 11,32 & 13,20 & 8,81 & 8,53 & 8,50 \\
\hline
\end{tabular}


Cont inuação

Causas

de

variação

Quadrados médios

G.L.

\begin{tabular}{|c|c|c|c|c|c|c|}
\hline 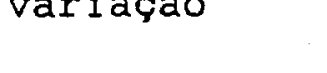 & & RMSPA & RMSP & RPF & RRPA & CRMR \\
\hline $\begin{array}{l}\text { Genótipo } \\
\text { Niveis de } A l \\
\text { Genótipo } x\end{array}$ & $\begin{array}{l}1 \\
4\end{array}$ & $\begin{array}{l}0,26 \star \star \\
3,97 * \star\end{array}$ & $\begin{array}{l}0,42 \star \star \\
9,00 \star \star\end{array}$ & $\begin{array}{c}64,53 \star \\
224,17 \star \star\end{array}$ & $\begin{array}{r}4,80 \mathrm{~ns} \\
372,03 * \star\end{array}$ & $\begin{array}{r}952.03 * * \\
1373.55^{\star *}\end{array}$ \\
\hline $\begin{array}{l}\text { Nivel de Al } \\
\text { Residuo }\end{array}$ & $\begin{array}{r}4 \\
18\end{array}$ & $\begin{array}{l}0.01 \mathrm{~ns} \\
0.01\end{array}$ & $\begin{array}{l}0,01 \mathrm{~ns} \\
0.02\end{array}$ & $\begin{array}{l}8,53 \mathrm{~ns} \\
11,15\end{array}$ & $\begin{array}{c}18,97^{\star} \\
5,14\end{array}$ & $\begin{array}{c}123,62 \mathrm{~ns} \\
81,60\end{array}$ \\
\hline C.V. (8) & & 6,55 & 6,31 & 5,03 & 8,68 & 11.17 \\
\hline
\end{tabular}

Causas

de

variação

G. L .

Quadrados médios

\begin{tabular}{|c|c|c|c|}
\hline & NRAF & RRMSR & RRMSCB \\
\hline $\begin{array}{ll}\text { Genótipo } & 1 \\
\text { Niveis de Al } 4 \\
\text { Genótipo }\end{array}$ & $\begin{array}{l}2448,03 * \star \\
3159,47 * \star\end{array}$ & $\begin{array}{r}67,50 * \star \\
6732,97 * \star\end{array}$ & $\begin{array}{r}433,20 * \star \\
1831,05 * *\end{array}$ \\
\hline $\begin{array}{ll}\text { Niveis de Al } & 4 \\
\text { Residuo } & 18\end{array}$ & $\begin{array}{c}433,20 \star \star \\
58,38\end{array}$ & $\begin{array}{l}8,83 \mathrm{~ns} \\
6.99\end{array}$ & $\begin{array}{l}38,78 \mathrm{~ns} \\
26,60\end{array}$ \\
\hline C.V. (웅) & 11,54 & 6,33 & 7.48 \\
\hline
\end{tabular}

Causas

de

G. L .

Quadrados médios

varíação

RRMSF

$132,30 *$

Genótipo

Níveis de Al 4

Genótipo $x$

Níveis de Al 4

Resíduo

18 $4854,45^{\star \star}$

$22,38 \mathrm{~ns}$

17,03
RRMSPA

$16,13 \mathrm{~ns}$

3914,22 **

$11,38 \mathrm{~ns}$

8,75
RRMSP

28,03 * $4616,72 * \star$

C.V. $(8)$

7,98

5,28

$4,45 \mathrm{~ns}$

5,24

7,98

4,40

* Estatísticamente significativo $(P<0,05)$, pelo teste $F$. **Estatísticamente significativo $(P<0,01)$, pelo teste $F$. ns: não significativo.

CMR= comprimento da maior raíz; NAF= número de afilhos; RMSR= rendimento de matéria seca de raíz; $\mathrm{RMSCB}=$ rendimento de matéria seca de colmos + bainhas; $\mathrm{RMSF}=$ rendimento de 
matéria seca de folhas; RMSPA= rendimento de matéria seca da parte aérea; RMSP= rendimento de matéria seca da planta; RPF= relação de peso foliar; RRPA= relaçăo raíz/parte aérea; $C R M R=$ comprimento relativo da maior raíz; NRAF= no. relativo de afilhos; RRMSR= rendimento relativo da matéria seca da raíz; RRMSCB = rendimento relativo da matéria seca de colmos + bainhas; $R R M S F=$ rendimento relativo de matéria seca da folha; RRMSPA = rendimento relativo da matéria seca da parte aérea; RRMSP = rendimento relativo.

Tabela D9: Quadrados médios da análise de variância do efeito de níveis do alumínio na soluçăo nutritiva sobre o rendimento de matéria seca, teor e extração de macronutrientes e alumínio pela planta de aveia.

Causas

de

variaçăo
Quadrados médios

G. I.
TAIP

EAlP

\section{Genótipos}

Níveis de Al

$1362604,17 * *$

RMSP

$1696,30 \mathrm{~ns}$ $10389815,28 * \star$

727132,57 *

$123410,05 *$ Genótipo $x$ Níveis de $A$ Residuo

$\begin{array}{ll}3 & 10715,28 \mathrm{~ns} \\ 16 & 21242,26\end{array}$

$4896,25 \mathrm{~ns}$ $1015248,39 * \star$ 5,8 6565,22

$16852,62 \mathrm{~ns}$ 27054,83

15,3

16,4

Quadrados médios

\begin{tabular}{|c|c|c|c|c|c|}
\hline TNP & ENP & TPP & EPP & TKP & EKP \\
\hline $\begin{array}{l}0,383 \star \star \\
0,047 \mathrm{~ns} \\
0,060 \star \\
0,015\end{array}$ & $\begin{array}{r}1268,76 * \star \\
11512,77^{*} \star \\
125,26 * \\
35,62\end{array}$ & $\begin{array}{l}0,002 * \\
0,043 * \star \\
0,001 * \star \\
0,0003\end{array}$ & $\begin{array}{r}8,88 * \star \\
12,55 * * \\
1,05 \mathrm{~ns} \\
0,38\end{array}$ & $\begin{array}{l}0,35 \mathrm{~ns} \\
1,36 \star \star \\
0,30 \mathrm{~ns} \\
0,21\end{array}$ & $\begin{array}{c}1621,97 \star \\
28559,5 \star \star \\
33,63 \mathrm{~ns} \\
285,24\end{array}$ \\
\hline 4,0 & 7,6 & 5,3 & 8.7 & 8,8 & 13,0 \\
\hline
\end{tabular}


Cont inuaçăo

\begin{tabular}{|c|c|c|c|}
\hline TCaP & $\mathrm{ECaP}$ & $\mathrm{TMgP}$ & EMgP \\
\hline $\begin{array}{l}0,001 \mathrm{~ns} \\
0,020 \star \star \\
0,003 * \star \\
0,0004\end{array}$ & $\begin{array}{c}15,84^{\star \star} \\
323,76^{\star \star} \\
1,43 \mathrm{~ns} \\
0,740\end{array}$ & $\begin{array}{l}0,0003 * \star \\
0,0211 * \star \\
0,0003 * \star \\
0,00003\end{array}$ & $\begin{array}{c}0,84^{\star \star} \\
78,178 \star \star \\
0,082 \mathrm{~ns} \\
0,069\end{array}$ \\
\hline 3,5 & 6,1 & 5,3 & 8,0 \\
\hline
\end{tabular}

Tabela D10: Quadrados médios da análise de variância do efeito de niveis de alumínio na soluçăo nutritiva sobre o teor e extraçăo de micronutrientes e alumínio pelas raízes e parte aérea de aveia (partes).

Causas de variaçäo
Quadrados médios

G.I.
EAI

\section{RMS}

$21160352,08 * *$ $181302,08 * \star$

Partes (A)

Genótipos Níveis de AI (C)

Partes $x$ Genót ipos Partes $x$ Níveis de Al Genótipos $x$

Niveis de Al 3 Partes $x$ Genótipos $\mathrm{x}$ Niveis de $A l$ Resíduo (B) 1

$$
5194907,64 \text { * }
$$$$
\text { I } 56718,75 *
$$

$3 \quad 584129,86$ *

$$
5357,64 \mathrm{~ns}
$$

TAl

$$
4838636,50 \text { * * }
$$

$27079,75 \mathrm{~ns}$

$608580,46 * *$ 76880,02 *

$5555708,69 * *$

$472580,29 * *$ $150740,88 * \star$ $38714,89 \mathrm{~ns}$ $510011,25 * \star \quad 145520,79 * *$ $10429,26 \mathrm{~ns}$ $7704,64 \mathrm{~ns}$ 
Continuação

Quadrados médios

\begin{tabular}{|c|c|c|c|c|}
\hline TN & $\mathrm{TP}$ & $E N$ & EP & TK \\
\hline $\begin{array}{l}24,325 \star \star \\
0,376 \star \star \\
0,056 \star \star \\
0,174 \star \star \\
0,439 \star \star \\
0,019 \mathrm{~ns} \\
0,165 \star \star \\
0,012\end{array}$ & $\begin{array}{l}0.007 \star \star \\
0,0002 \mathrm{~ns} \\
0,075^{\star \star} \\
0,002^{\star} \\
0,002^{\star \star} \\
0,002^{\star \star} \\
0,0008 \mathrm{~ns} \\
0,0003\end{array}$ & $\begin{array}{r}37974,37^{\star \star} \\
634,38 * \star \\
5756,39 \star \star \\
438,62^{\star \star} \\
2507,44^{\star \star} \\
62,63^{\star \star} \\
99,77^{\star \star} \\
13,83\end{array}$ & $\begin{array}{c}203,36 \star \star \\
3,85 \star \star \\
6,43 \star \star \\
1,40 \star \star \\
1,15 \star \star \\
0,40 \star \\
0,42 \star \\
0,13\end{array}$ & $\begin{array}{l}4,84^{\star \star} \\
2,31 * \star \\
1,24 * \star \\
0,94^{\star} \\
1,24^{\star \star} \\
0,34 \mathrm{~ns} \\
0,48^{\star} \\
0,14\end{array}$ \\
\hline 4,0 & 5,5 & 9,4 & 10,3 & 7,5 \\
\hline
\end{tabular}

Quadrados médios

\begin{tabular}{|c|c|c|c|c|}
\hline EK & $\mathrm{TCa}$ & $\mathrm{ECa}$ & $\mathrm{TMg}$ & EMg \\
\hline $\begin{array}{r}70403,06 * \star \\
1076,36 \star \star \\
15256,03 * \star \\
35,53 \mathrm{~ns} \\
3351,00 * \star \\
28,03 \mathrm{~ns} \\
87,33 \mathrm{~ns} \\
54,60\end{array}$ & $\begin{array}{l}0,728 \star \star \\
0,001 \mathrm{~ns} \\
0,015 \star \star \\
0,001 \mathrm{~ns} \\
0,038 \star \star \\
0,003 \star \\
0,002 \mathrm{~ns} \\
0,0008\end{array}$ & $\begin{array}{r}1101,13^{\star} \star \\
7,92^{\star \star} \\
161,88^{\star \star} \\
3,91 \star \star \\
43,44^{\star \star} \\
0,72 \mathrm{~ns} \\
0,919 \star \\
0,262\end{array}$ & $\begin{array}{l}0,004 \star \star \\
0,0003 \mathrm{~ns} \\
0,069 \star \star \\
0,0004 \mathrm{~ns} \\
0,017 \star \star \\
0,0008 \star \star \\
0,0007 \star \star \\
0,0001\end{array}$ & $\begin{array}{r}16,45 \star \star \\
0,42 \star \star \\
39,09 \star \star \\
0,54 \star \star \\
0,43 \star \star \\
0,04 \mathrm{~ns} \\
0,15 \star \star \\
0,03\end{array}$ \\
\hline 11,3 & 5,9 & 7,3 & 9,2 & 10,5 \\
\hline
\end{tabular}

* e $\star \star$ significativo estatísticamente, pelo teste F, respectivamente a 5 e 1 음 de significância. ns = não significativo. 
Tabela D11: Quadrados médios da análise de variância do efeito de niveis de alumínio na soluçăo nutritiva sobre o teor e extraçăo de micronutrientes pela planta de aveia.

Causas

de

Quadrados médios

variação

\begin{tabular}{|c|c|c|c|c|}
\hline 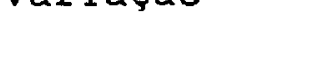 & & TCuP & ECuP & TFeP \\
\hline $\begin{array}{l}\text { Genótipos } \\
\text { Níveis de Al } \\
\text { Genótipo } x\end{array}$ & $\begin{array}{l}1 \\
3\end{array}$ & $\begin{array}{l}0,0028 \mathrm{~ns} \\
3,480 \star \star\end{array}$ & $\begin{array}{c}34,08 \star \\
1092,66^{\star \star}\end{array}$ & $\begin{array}{r}25927,86 \star \star \\
6497,09 \star \star\end{array}$ \\
\hline $\begin{array}{l}\text { Niveis de Al } \\
\text { Residuo }\end{array}$ & 3 & $\begin{array}{l}0,36 \operatorname{lns} \\
0,255\end{array}$ & $\begin{array}{l}3.10 \mathrm{~ns} \\
4.18\end{array}$ & $\begin{array}{c}1910,48 \mathrm{~ns} \\
661,58\end{array}$ \\
\hline C.V. (8) & & 5,5 & 8.7 & 15,7 \\
\hline
\end{tabular}

Quadrados médios

\begin{tabular}{|c|c|c|c|c|}
\hline EFeP & TMnP & EMnP & $\operatorname{TZnP}$ & EZnP \\
\hline $\begin{array}{c}346825,06{ }^{\star \star} \\
680001,03^{\star \star} \\
80878,11^{\star \star} \\
8400,28\end{array}$ & $\begin{array}{l}64,42 \star \star \\
29,25 * \star \\
11,90 \mathrm{~ns} \\
\quad 4,35\end{array}$ & $\begin{array}{r}962,67 \star \star \\
6049,91 \star \star \\
58,13 \mathrm{~ns} \\
43,24\end{array}$ & $\begin{array}{l}11,47^{\star} \\
81,09 \star \star \\
12,24^{\star} \\
2,19\end{array}$ & $\begin{array}{c}589,05 * \star \\
8605,68 * \star \\
109,05 \mathrm{~ns} \\
46,22\end{array}$ \\
\hline 20,6 & 9,9 & 12,1 & 6,6 & 11,6 \\
\hline
\end{tabular}


Tabela D12: Quadrados médios da análise de variância do efeito de níveis de alumínio na soluçăo nutritiva sobre o teor e extração de micronutrientes pela raíz e parte aérea da aveia (partes).

Causas

Quadrados médios

de

G.L.

variaçăo

$\mathrm{TCu}$

$\mathrm{ECu}$

TFe

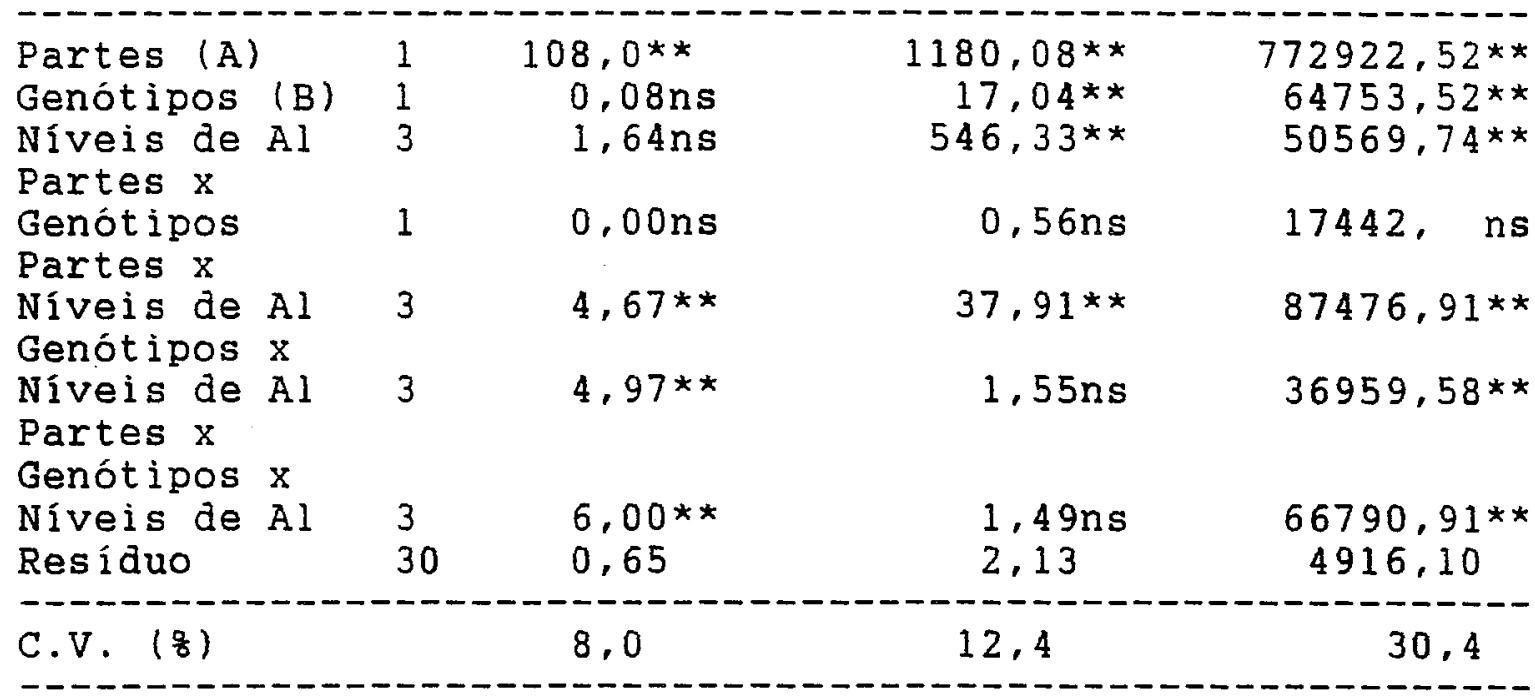

Quadrados médios

\begin{tabular}{|c|c|c|c|c|}
\hline $\mathrm{EFe}$ & TMn & EMn & $\mathrm{TZn}$ & $\mathrm{EZn}$ \\
\hline $\begin{array}{r}73609,84^{\star \star} \\
184400,42^{\star \star} \\
325294,90^{\star \star} \\
31206,90^{\star \star} \\
243543,54^{\star \star} \\
45790,93^{\star \star} \\
104787,13^{\star \star} \\
2625,51\end{array}$ & $\begin{array}{c}2255,02^{\star \star} \\
165,02^{\star \star} \\
103,74^{\star \star} \\
6,02 \mathrm{~ns} \\
39,85^{\star \star} \\
17,74^{\star} \\
38,97^{\star \star} \\
4,96\end{array}$ & $\begin{array}{r}19116,09 \star \star \\
584,51 \star \star \\
3262,68 \star \star \\
68,88 \star \\
804,40 \star \star \\
50,17 \star \\
43,10 \star \\
13,19\end{array}$ & $\begin{array}{c}3996,75^{\star} \star \\
290,08^{\star} \\
241,06^{\star} \\
507,00^{\star} \star \\
71,25 \mathrm{~ns} \\
140,92 \mathrm{~ns} \\
129,83 \mathrm{~ns} \\
56,45\end{array}$ & $\begin{array}{r}1853,81 \star \star \\
294,53 \star \star \\
4302,84^{\star \star} \\
261,80 \star \star \\
49,69 \mathrm{~ns} \\
54,52 \mathrm{~ns} \\
48,79 \mathrm{~ns} \\
23,50\end{array}$ \\
\hline 23,2 & 12.9 & 13,2 & 27,4 & 16.5 \\
\hline
\end{tabular}


Tabela D13: Quadrados médios da análise de variância do efeito de diferentes niveis de aluminio, sobre o pH da solução nutritiva, durante o crescimento de dois genótipos de aveia em cultivo hidropônico.

Causas

de

variaçăo
Quadrados médios

G. L .
Genótipos

Nível de $A l(B)$

Genótipos $x$

Níveis de Al

Dias (A)

Dias $x$ genótipos

Dias $x$ níveis de $A l$

Dias $x$ genótipos $x$

niveis de $A l$

Residuo

Resíduo

(A)

(B)
1
4

$0.07 *$

$1.15^{\star *}$

$4 \quad 0,01 \mathrm{~ns}$

4

4

16

$0,73 * \star$

$0,01 *$

$0,52 \star \star$

16

20

80
$0,01 \star \star$

0,01

0,002

C.V.A. $(8)$

C.V.B. $\left(\frac{8}{8}\right)$

1,12

1,17

* Estatísticamente significativo $(p<0,05)$, pelo teste F.

* Estatísticamente significativo $(P<0,01)$, pelo teste $F$.

ns = não significativo.

Tabela D14: Quadrados médios da avaliaçăo da atividade "in vitro" da redutase do nitrato em folhas e raízes de dois cultivares de aveia, em dois estádios de desenvolvimento.

Causas

Quadrados médios

de

G. L

variação

Genótipos

Estádios

órgãos

Genótipos $x$

estádios

Genótipos $\mathrm{x}$ 
Continuação

Causas

Quadrados médios

de

G.I.

variação

$\begin{array}{lcl}\text { Órgăos } & 1 & 0,0158 \mathrm{~ns} \\ \text { Estádios } \mathrm{x} & 1 & 1,260 * * \\ \text { órgãos } & & \\ \text { Genótipos } \mathrm{x} & 1 & 0,139 \mathrm{~ns} \\ \text { éstádios } \mathrm{x} & 24 & 0,116 \\ \text { Órgăos } & & 23,84 \\ \text { Residuo } & & \\ -\mathrm{C} . \mathrm{V} . & & \end{array}$

* Estatísticamente significativo $(P<0,05)$, pelo teste $F$.

ns = năo significativo.

Tabela D15: Quadrados médios da análise de variância do efeito do alumínio sobre a atividade de redutase do nitrato em folhas de dois genótipos de aveia.

Causas

de

Quadrados médios

variaçäo

Genótipos

Níveis de Al

Genótipos $x$

Niveis de Al

Resíduo
G.I.

Quadrados medios

C.V. ( $(8) \quad 21,77$

* Estatisticamente significativo $(P<0,05)$, pelo teste F. ns = nầo significativo. 